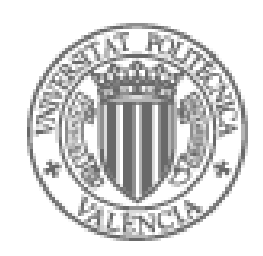

Departamento de Mecanización y Tecnología Agraria Escuela Técnica Superior de Ingenieros Agrónomos. Universidad Politécnica de Valencia, España

\title{
Alteración de las propiedades mecánicas de suelos irrigados con agua con altas concentraciones de sodio.
}

Tesis Doctoral 2012

Doctorando: Ing. Agr. Esteban Miguel MELANI.

Departamento de Ingeniería Agrícola y Forestal, Facultad de Ciencias Agrarias y Forestales, Universidad Nacional de la Plata, Av. 60 y 119, cc 31, 1900, La Plata, Argentina.

Fax: 0054221 4252346. Correo electrónico:

estebanmelani@hotmail.com

Director: Dr. Ing. Agr. Telmo Cecilio PALANCAR.

Departamento de Ingeniería Agrícola y Forestal, Facultad de Ciencias Agrarias y Forestales, Universidad Nacional de la Plata, Av. 60 y 119, cc 31, 1900, La Plata, Argentina.

Fax: 0054221 4252346. Correo electrónico: telmo@agro.unlp.edu.ar

Co Director: Dr. Ing. Paolo SPUGNOLI.

Dipartamento di Economía, Ingegneria, Scienze e Teconologie Agrarie e Forestali. Facoltá di Agraria. Universitá degli Studi di Firenze. Piazzale Delle Cascine 15 (50144). Firenze, Italia.

Tel: 39055367549328 8630. Correo electrónico: paolo.spugnoli@unifi.it 


\section{ÍNDICE TEMÁTICO}

Página

1. TÍTULO Y AUTOR 1

2. RESUMEN 3

3. RESUM 7

4. ABSTRACT 11

5. INTRODUCCION 15

El riego y sus posibles consecuencias 15

6. ANTECEDENTES 19

6.1. Importancia de las propiedades mecánicas de los suelos.

6.2. Efecto de la sodicidad sobre las propiedades físicas de los suelos.

6.3. Efecto de los ciclos de humectación - desecación sobre las propiedades físicas de los suelos.

6.4. Algunos antecedentes de la mecánica del suelo agrícola.

6.5. Teoría del Estado Crítico. 42

6.6. Ley de Coulomb-Mohr 54

6.7. Métodos e instrumentos de medición de las propiedades mecánicas de los suelos.

7. OBJETIVOS 63

8. HIPÓTESIS 65

9. MATERIALES Y MÉTODOS 67 
9.1.1. Suelos utilizados en las pruebas de compresión y corte y resistencia a rotura de agregados individuales.

9.1.2. Procedimiento utilizado en la sodificación de los suelos.

9.1.3. Suelo utilizado en el Brazilian Test.

74

9.2. Pruebas preliminares.

76

9.2.1. Pruebas de estabilidad de agregados en agua.

76

9.2.2. Pruebas de expansión - contracción.

77

9.3. Pruebas de resistencia a rotura de agregados individuales.

9.4. Pruebas de resistencia a rotura mediante Brazilian

Test.

82

9.5. Ensayos de Compresión y Corte.

86

9.5.1. Ensayos con material sometido a ciclo

humectación - desecación.

9.5.2. Ensayos con material no sometido a ciclos

humectación - desecación (material indisturbado).

9.5.3. Descripción de la Caja de Corte. 95

9.5.4. Adquisición y registro de las señales.

100

9.5.5. Cálculo de la Presión de Preconsolidación y

obtención de la Línea Virgen (LV).

9.5.6. Cálculo de la Línea de Estado Crítico.

104

9.6. Tratamiento estadístico de los resultados. 
10.1. Consideraciones previas.

10.2. Pruebas preliminares.

10.2.1. Pruebas de Estabilidad de Agregados en Agua.

10.2.2. Prueba de expansión - contracción.

10.3. Pruebas de resistencia a rotura de agregados individuales.

10.4. Pruebas de resistencia a rotura mediante Brazilian Test.

10.5. Pruebas de Compresión y Corte. 126

10.5.1. Curvas de Compresión. 126

10.5.2. Tensión de Preconsolidación (Pc). 138

10.5.3. Líneas Virgen. 141

10.5.4. Tensión de Corte y parámetros de Coulomb. 158

10.5.5. Líneas de Estado Crítico 175

10.6. Consideraciones Finales. 198

11. CONCLUSIONES 203

12. BIBLIOGRAFÍA 205 


\section{ÍNDICE DE TABLAS}

Página

Tabla 1: Clasificación Taxonómica y origen de ambos suelos (Soil Taxonomy, 1994).

68

Tabla 2: Composición y características químicas de los suelos evaluados.

69

Tabla 3: Mineralogía de las arcillas 70

Tabla 4: Fracciones granulométricas de Cardone y Ozzano según USDA e ISSS.

Tabla 5: Clasificación Textural de ambos suelos.

72

Tabla 6: pH, CE, RAS y PSI de los suelos tratados

73

Tabla 7: Fracciones granulométricas de Cadriano según USDA.

Tabla 8: Composición y características químicas de Cadriano.

Tabla 9: RAS y PSI para ambos tratamientos de Cadriano (COA y COB).

Tabla 10: Composición Granulométrica Porcentual de los tratamientos $\mathrm{COA}$ y $\mathrm{COB}$.

Tabla 11: Humedad, altura y diámetro de la muestra en cada momento de medición y por tratamiento.

Tabla 12: Variación de la densidad en cada momento de medición y por tratamiento. 
Tabla 13: Variación porcentual de volumen de las muestras respecto al volumen inicial.

Tabla 14: Comparación de Tensión de Rotura "Y" (kPa) entre clases de agregados individuales sometidos a 119 tracción para ambos tratamientos (A y B).

Tabla 15: Comparación entre tratamientos $A$ vs. B de Tensión de Rotura " $\mathrm{Y}$ " ( $\mathrm{kPa})$ de agregados individuales 120 de las clases I, II y III.

Tabla 16: Resultados de las pruebas de Brazilian Test.

125

Tabla 17: Volumen Específico Inicial y Final de los tratamientos del suelo Cardone.

Tabla 18: Comparación del Volumen Específico Inicial y Final de OZA vs. OZB al $15 \%$ de $H^{\circ}$ y para ambas clases $\quad 130$ de agregados ensayadas (II y III).

Tabla 19: Comparación de Volumen Específico Inicial y Final de Clase II vs. III para ambos tratamientos de 130 Ozzano al $15 \%$ de humedad.

Tabla 20: Comparación de Vol. Esp. Inicial y Final entre Clases granulométricas (I a IV) para ambos tratamientos 130 de Ozzano al 5\% de humedad.

Tabla 21: Comparación de Volumen Específico Inicial y Final entre tratamientos A vs. B para todas las Clases de 134 agregados de Ozzano al $5 \%$ de humedad. 
Tabla 22: Comparación del parámetro PC entre tratamientos A vs. B para ambos suelos ensayados (CD 140 y OZ).

Tabla 23: Comparación de pendientes de Línea Virgen $(\lambda)$ y término independiente $(\mathrm{N})$ entre A y B para todos 149 los tratamientos.

Tabla 24: Comparación de pendientes de LV entre todas las clases granulométricas (I a IV) para ambos 152 tratamientos (A y B) de OZ al $5 \%$ de humedad.

Tabla 25: Comparación de Términos Independientes de la ecuación de LV entre todas las clases granulométricas (I a IV) para ambos tratamientos de $\mathrm{OZ}$ al $5 \%$ de humedad.

Tabla 26: Comparación de pendientes de LV entre las clases II vs. III para ambos tratamientos (A y B) de OZ al 153 $15 \%$ de humedad.

Tabla 27: Comparación de Términos Independientes de LV entre las clases II vs. III para ambos tratamientos de 154 OZ al $15 \%$ de humedad.

Tabla 28: Humedad al corte promedio por tratamiento $(\% \mathrm{p} / \mathrm{p})$

Tabla 29: Comparación de A vs. B de las Tensiones de Corte $(\mathrm{kPa})$ a diferentes Tensiones Normales ensayadas $(\mathrm{kPa})$, Cohesión $(\mathrm{kPa})$ y Angulo de Rozamiento Interno $(\operatorname{tg} \varphi)$ para todos los tratamientos de ambos suelos. 
Tabla 30: Comparación entre Clases Granulométricas de las Tensiones de Corte $(\mathrm{kPa})$ a diferentes Tensiones Normales ensayadas $(\mathrm{kPa})$, Cohesión $(\mathrm{kPa})$ y Angulo de 168 Rozamiento Interno $(\operatorname{tg} \varphi)$ para los tratamientos OZ 5\% y OZ $15 \%$ de humedad.

Tabla 31: Comparación de A vs. B de la ordenada al origen y pendientes de las rectas de Relación Volumétrica al corte para $\mathrm{CD}$ y $\mathrm{OZ}$ en todos sus tratamientos.

Tabla 32: Tensión Normal (TN)(kPa) a la que se alcanza el Estado Crítico para ambos suelos (CD y OZ) y todos 183 sus tratamientos.

Tabla 33: Términos independientes de la Línea Virgen $(\mathrm{N})$, Línea de Estado Crítico $(Г)$ para todos los 189 tratamientos de ambos suelos (CD y OZ).

Tabla 34: Diferencia entre términos independientes de LV y LEC $(\mathrm{N}-\Gamma)$ para todos los tratamientos de ambos 190 suelos (CD y OZ). 


\section{ÍNDICE DE FIGURAS}

Página

Figura 1: fronteras de Estado en el espacio $\mathrm{p}-\mathrm{q}$-v.

46

Figura 2: Dominio Subcrítico y Supercrítico en el espacio $\mathrm{p}-\mathrm{v}$.

Figura 3: Curva de Compresión donde se ubica la Línea Virgen y Pc.

Figura 4: Expansión: Un suelo representado por el punto "c" ubicado en la región súper crítica alcanza la Línea de Estado Crítico "d" presentando un aumento de su 52 volumen específico. En un gráfico p-q-v (izquierda) y en un gráfico $v-\ln (p)$ (derecha)

Figura 5: Contracción: Un suelo representado por el punto "a" ubicado en la región sub crítica alcanza la Línea de Estado Crítico "b" presentando una disminución 53 de su volumen específico. En un gráfico $p-q-v$ (izquierda) y en un gráfico $v-\ln (p)$ (derecha)

Figura 6: Recta de Coulomb

Figura 7: Diagrama de esfuerzo de corte-deformación en tres condiciones: A: cementado, B: Suelto, C: Denso

Figura 8: Determinación de la resistencia a la tracción de un agregado.

Figura 9: Motor y sistema de empuje del plato inferior 80 
Figura 10: Platos utilizados para determinar la resistencia a la tracción

Figura 11: Vista general de la máquina utilizada para la determinación de la resistencia a tracción de agregados individuales.

Figura 12: Cilindro listo para ser sometido a Brazilian Test.

Figura 13: Cilindro colocado en la máquina (izquierda) y cilindro comprimido exhibiendo rotura (derecha).

Figura 14: Molino utilizado en la molienda de los suelos (vista lateral).

Figura 15: Molino utilizado en la molienda de los suelos (vista de planta).

Figura 16: Tamizado del suelo.

Figura 17: Torta de donde eran extraídas las probetas

Figura 18: Extracción de las probetas con la utilización del cilindro de bronce

Figura 19: Introducción de la probeta en la caja de corte.

Figura 20: Muestra extraída de la caja una vez terminado el corte.

Figura 21: Sección en planta de la caja de corte (arriba) y vertical (abajo).

Figura 22: Sección vertical de la caja de corte.

Figura 23: Vista general de la Caja de Corte Directo construida en el DIAF. 
Figura 24: Motor eléctrico "paso a paso", reductor y eje telescópico de movimiento horizontal encargado de dar el movimiento de traslación a la parte inferior de la caja 99 de corte.

Figura 25: Caja de corte, se observa la parte inferior móvil, la parte superior unida a una celda de carga y 99 tornillo unido al brazo de palanca.

Figura 26: Caja de Corte, se observa el transductor de movimiento vertical utilizado durante la compresión uniaxial, transductor de movimiento horizontal y celda de carga encargada de medir la fuerza de corte.

Figura 27: Colector de Datos Gould TA11 y ordenador portátil utilizados en la adquisición y almacenamiento de 102 las señales

Figura 28: Obtención gráfica de la tensión de preconsolidación (Pc).

104

Figura 29: Regresión Log Tensión Normal - Relación volumétrica para hallar el estado crítico

106

Figura 30: Línea de descarga y de rebote en el ensayo de compresión

Figura 31: Organigrama Resumen de los diferentes ensayos realizados sobre los distintos suelos.

Figura 32: Pruebas de disgregación: arriba izquierda CDB, arriba derecha CDA, abajo izquierda OZB, abajo 112 derecha OZA. 
Figura 33: Prueba de dispersión, OZB (izquierda) y OZA (derecha).

Figura 34: Variación volumétrica en \% durante el ciclo Expansión - Contracción.

Figura 35: Tensión de Rotura de agregados individuales OZA vs. OZB, Clases I, II y III.

Figura 36: Tensión de Rotura de agregados individuales de ambos tratamientos $(A$ y $B$ ) en función de su diámetro 121 efectivo.

Figura 37: Tensión de Compactación de Cilindros de COA vs. COB.

Figura 38: Tensión de Rotura de Cilindros por Brazilian Test de COA vs. COB.

Figura 39: organigrama ilustrativo de las pruebas conducidas con compresión y corte.

Figura 40: Líneas de Compresión CDA vs CDB al 18\% de humedad.

Figura 41: Líneas de Compresión CDA vs. CDB al 8\% de humedad.

Figura 42: Líneas de Compresión OZA vs. OZB Clase II al $15 \%$ de humedad.

Figura 43: Líneas de Compresión OZA vs. OZB Clase III al $15 \%$ de humedad.

Figura 44: Líneas de Compresión de OZA al 5\% de humedad, Todas las Clases Granulométricas. 
Figura 45: Líneas de Compresión de OZB al 5\% de humedad, Todas las Clases Granulométricas.

Figura 46: Líneas de Compresión OZA vs. OZB Clase I al $5 \%$ de humedad.

Figura 47: Líneas de Compresión de OZA vs. OZB Clase Il al $5 \%$ de humedad.

Figura 48: Líneas de Compresión OZA vs. OZB Clase III al $5 \%$ de humedad.

Figura 49: Líneas de Compresión OZA vs. OZB Clase IV al $5 \%$ de humedad.

Figura 50: Líneas Virgen de CDA vs. CDB al 18\% de humedad.

Figura 51: Líneas Virgen de CDA vs. CDB al 8\% de humedad.

Figura 52: Líneas Virgen OZA vs. OZB Clase I al 5\% de humedad.

Figura 53: Líneas Virgen OZA vs. OZB Clase II al 5\% de humedad.

Figura 54: Líneas Virgen de OZA vs. OZB Clase III al 5\% de humedad.

Figura 55: Líneas Virgen OZA vs. OZB Clase IV al 5\% de humedad.

Figura 56: Líneas Virgen de OZA al 5\% de humedad, Todas las Clases Granulométricas. 
Figura 57: Líneas Virgen OZB al 5\% de humedad, Todas las Clases Granulométricas.

Figura 58Líneas Virgen OZA vs. OZB Clase II al 15\% de humedad.

Figura 59: Líneas Virgen OZA vs. OZB Clase III al 15\% de humedad.

Figura 60: Líneas Virgen OZA Clase II vs. Clase III al $15 \%$ de humedad.

Figura 61: Líneas Virgen OZB Clase II vs. Clase III al $15 \%$ de humedad.

Figura 62: Rectas de Coulomb de CDA vs. CDB al 18\% de humedad.

Figura 63: Rectas de Coulomb de CDA vs. CDB al 8\% de humedad.

Figura 64: Rectas de Coulomb de OZB II vs. OZB III al $15 \%$ de humedad.

Figura 65: Rectas de Coulomb de OZA II vs. OZA III al $15 \%$ de humedad.

Figura 66: Rectas de Coulomb de OZA vs. OZB Clase II al $15 \%$ de humedad.

Figura 67: Rectas de Coulomb de OZA vs. OZB Clase III al $15 \%$ de humedad.

Figura 68: Rectas de Coulomb de OZA al 5\% de humedad, Todas las Clases Granulométricas. 
Figura 69: Rectas de Coulomb de OZB al 5\% de humedad, Todas las Clases Granulométricas.

Figura 70: Rectas de Coulomb OZA vs. OZB Clase I al $5 \%$ de humedad.

Figura 71: Rectas de Coulomb OZA vs. OZB Clase II al $5 \%$ de humedad.

Figura 72: Rectas de Coulomb OZA vs. OZB Clase III al $5 \%$ de humedad.

Figura 73: Rectas de Coulomb OZA vs. OZB Clase IV al $5 \%$ de humedad.

Figura 74: Relación de Volumen durante el corte CDA vs. CDB al 8\% de humedad.

Figura 75: Relación de Volumen durante el corte CDA vs. CDB al $18 \%$ de humedad.

Figura 76: Relación de Volumen durante el corte OZA vs.

OZB Clase I al $5 \%$ de humedad.

Figura 77: Relación de Volumen durante el corte OZA vs.

OZB Clase II al $5 \%$ de humedad.

Figura 78: Relación de Volumen durante el corte OZA vs.

OZB Clase III al $5 \%$ de humedad.

Figura 79: Relación de Volumen durante el corte OZA vs.

OZB Clase IV al $5 \%$ de humedad.

Figura 80: Relación de Volumen durante el corte OZA vs.

OZB Clase II al 15\% de humedad. 
Figura 81: Relación de Volumen durante el corte OZA vs.

OZB Clase III al $15 \%$ de humedad.

Figura 82: Líneas Virgen (LV) y de Estado Crítico (EC) de CDA vs. CDB al $8 \%$ de humedad.

Figura 83: Líneas Virgen (LV) y de Estado Crítico (EC) de CDA vs. CDB al $18 \%$ de humedad.

Figura 84: Líneas Virgen (LV) y de Estado Crítico (EC) de OZA vs. OZB Clase I al $5 \%$ de humedad.

Figura 85: Líneas Virgen (LV) y de Estado Crítico (EC) de OZA vs. OZB Clase II al $5 \%$ de humedad.

Figura 86: Líneas Virgen (LV) y de Estado Crítico (EC) de OZA vs. OZB Clase III al $5 \%$ de humedad.

Figura 87: Líneas Virgen (LV) y de Estado Crítico (EC) de OZA vs. OZB Clase IV al $5 \%$ de humedad.

Figura 88: Líneas Virgen (LV) y de Estado Crítico (EC) de OZA vs. OZB Clase II al 15\% de humedad.

Figura 89: Líneas Virgen (LV) y de Estado Crítico (EC) de OZA vs. OZB Clase III al $15 \%$ de humedad.

Figura 90: Líneas de LV y EC para OZ Clase II al 5\% de $H^{\circ}$ (A vs B). A una misma Tensión Normal OZ B tendría 193 la posibilidad de alcanzar Vol.Esp. superiores.

Figura 91: Líneas de LV y EC para OZ Clase III al 5\% de $H^{\circ}$ (A vs B). A una misma Tensión Normal OZ B tendría 194 la posibilidad de alcanzar Vol.Esp. superiores. 
Figura 92: Líneas de LV y EC para OZ Clase II al $5 \%$ de $\mathrm{H}^{\circ}$ (A vs B). Para obtener un mismo valor de Vol. Esp., A 195 soportaría menor Tensión Normal que B.

Figura 93: Líneas de LV y EC para OZ Clase III al 5\% de $\mathrm{H}^{\circ}$ (A vs B). Para obtener un mismo valor de Vol. Esp., A 196 soportaría menor Tensión Normal que B.

Figura 94: Líneas de LV y EC para OZ Clase II al 5\% de $\mathrm{H}^{\circ}$ (A vs B). Tensión Normal al Corte al que se podría esperar un incremento de Vol.Esp. del 10\% aproximadamente.

Figura 95: Líneas de LV y EC para OZ Clase III al 5\% de $\mathrm{H}^{\circ}$ (A vs B). Tensión Normal al Corte al que se podría esperar un incremento de Vol.Esp. del 10\% aproximadamente. 


\section{ABREVIATURAS Y SÍMBOLOS}

Por orden de aparición.

\begin{tabular}{|c|l|}
\hline PSI & Porcentaje de Sodio de Intercambio \\
\hline RAS & Relación de Adsorción de Sodio \\
\hline$Y$ & Resistencia a la Tracción \\
\hline$F^{\prime}$ & Fuerza Polar de Rotura \\
\hline$d$ & Diámetro medio efectivo \\
\hline$d m$ & $\begin{array}{l}\text { diámetro de la clase granulométrica a la que pertenece } \\
\text { el agregado correspondiente }\end{array}$ \\
\hline$m$ & valor individual de masa del agregado \\
\hline$m_{0}$ & $\begin{array}{l}\text { masa media de los agregados de una clase } \\
\text { diámetro de la abertura de la malla del tamiz superior } \\
\text { utilizado en la formación de cada una de las clases } \\
\text { granulométricas de agregados }\end{array}$ \\
\hline$s_{2}$ & $\begin{array}{l}\text { diámetro de la abertura de la malla del tamiz inferior } \\
\text { utilizado en la formación de cada una de las clases } \\
\text { granulométricas de agregados }\end{array}$ \\
\hline$n$ & es el número de agregados \\
\hline MWD & Diámetro medio efectivo, mean wight diameter. \\
\hline MOR & Modulo de Ruptura \\
\hline$p_{a p s}$ & Masa Volumétrica Aparente Seca \\
\hline$v$ & Volumen Específico \\
\hline$p$ & Tensión Normal Media \\
\hline
\end{tabular}




\begin{tabular}{|c|l|}
\hline$q$ & Tensión Desviatórica, Tensión de Corte \\
\hline $\begin{array}{c}\text { L.E.C, } \\
\text { C.S.L. }\end{array}$ & Línea de Estado Crítico, Critical State Line \\
\hline $\begin{array}{c}\text { L.V., } \\
\text { N.C.L }\end{array}$ & $\begin{array}{l}\text { Línea Virgen, Línea de Consolidación Normal, Normal } \\
\text { Consolidation Line }\end{array}$ \\
\hline Pc & Línea de Preconsolidación \\
\hline$\lambda$ & $\begin{array}{l}\text { Pendiente de la Línea Virgen y de la Línea de Estado } \\
\text { Crítico }\end{array}$ \\
\hline N & Término independiente de la Línea Virgen \\
\hline$\Gamma$ & Término independiente de la Línea de Estado Crítico \\
\hline$\varphi$ & Ángulo de rozamiento Interno \\
\hline C & Cohesión \\
\hline$\tau$ & Esfuerzo Cortante \\
\hline$\sigma_{n}$ & Esfuerzo Normal Efectivo \\
\hline CD & Suelo Cardone \\
\hline OZ & Suelo Ozzano \\
\hline CO & Suelo Cadriano \\
\hline A & Tratamiento más sodificado \\
\hline B.I.C. & Tratamiento menos sodificado \\
\hline MO & Materia Orgánica \\
\hline CE & Conductividad Eléctrica \\
\hline$\sigma_{t}$ & Tensión de Rotura del Cilindro, Tensile Strength \\
\hline$F$ & Fuerza de Rotura del Cilindro \\
\hline \hline
\end{tabular}




\begin{tabular}{|c|l|}
\hline$D$ & Diámetro del cilindro \\
\hline$h$ & Altura del cilindro \\
\hline $\mathrm{RV}$ & Relación de Volumen \\
\hline $\mathrm{Vf}$ & Volumen Final \\
\hline $\mathrm{Vi}$ & Volumen Inicial \\
\hline $\mathrm{hf}$ & Altura Final \\
\hline $\mathrm{hi}$ & Altura Inicial \\
\hline $\mathrm{Af}$ & Área Final \\
\hline $\mathrm{Ai}$ & Área Inicial \\
\hline $\mathrm{H}^{\circ}$ & Humedad p/p \\
\hline $\mathrm{h}$ & Altura de la torta \\
\hline $\mathrm{d}$ & Diámetro de la torta \\
\hline$\Delta$ & Variación \\
\hline $\mathrm{TN}$ & Tensión Normal \\
\hline
\end{tabular}




\section{AGRADECIMIENTOS}

Al Doctor Telmo Palancar por la intensa dedicación puesta en la dirección de éste trabajo de Tesis.

Al Doctor Paolo Spugnoli por el atento y cordial trato que me brindó durante mi estadía en Florencia, por facilitar mi estadía allí y por su valioso aporte cognitivo.

Al ingeniero agrónomo Roberto Balbuena, al Doctor Daniel Jorajuría y al Departamento de Mecanización y Tecnología Agraria de la UPV, especialmente, al doctor Carlos Gracia que por intermedio del Programa Alfa permitieron la realización de éste Doctorado.

Al Doctor Luis Val Manterola por su dedicado trabajo de tutoría. 


\title{
1. TÍTULO Y AUTOR
}

\author{
Tesis Doctoral
}

\section{Alteración de las propiedades}

mecánicas de suelos irrigados con agua con altas concentraciones de sodio.

Doctorando: Ing. Agr. Esteban Miguel MELANI.

Departamento de Ingeniería Agrícola y Forestal, Facultad de Ciencias Agrarias y Forestales, Universidad Nacional de la Plata, Av. 60 y 119, cc 31, 1900, La Plata, Argentina.

Fax: 0054221 4252346. Correo electrónico:

estebanmelani@hotmail.com 


\section{RESUMEN}

El riego es una práctica que se utiliza en áreas con déficit de agua para incrementar la producción agrícola y ganadera. Sin embargo un manejo inadecuado del riego puede causar deterioros de la fertilidad química y especialmente física de los suelos. Todas las aguas de riego, superficiales o subterráneas, contienen en mayor o menor medida sales solubles, sodio, cloro y otros elementos. Se espera que los problemas asociados con suelos salinos y sódicos se incrementen en el futuro debido al empobrecimiento de la calidad de las aguas de riego como consecuencia del uso de aquellas de buena calidad para consumo humano. La irrigación con aguas de pobre calidad ejerce alteraciones negativas en las propiedades físicas y químicas y, en consecuencia, reduce el crecimiento de las plantas. Un elevado PSI (Porcentaje de Sodio de Intercambio) conduce a un reordenamiento poroso, aumentando los microporos con sus consecuencias en la circulación del agua y los gases así como impedancias mecánicas derivadas de la pérdida de estructura.

El estudio mecánico del suelo agrícola supone diversos problemas debido esencialmente a su naturaleza de sistema polifásico, insaturado, granular, poroso y generalmente cohesivo. La mecánica del Estado Crítico provee una teoría cuyo principal objetivo es el de relacionar las cargas o tensiones a las que es sometido un suelo con los cambios en el espacio poroso. 
Las máquinas de corte tangencial poseen amplio uso para el estudio de las propiedades de los suelos agrícolas. Las principales ventajas de éste tipo de equipo son que puede ser utilizado tanto para el corte como la compresión de las muestras. Además, la medida del esfuerzo de corte y el desplazamiento horizontal y vertical, lo convierten en un ensayo muy completo cuyo uso es totalmente compatible con la obtención de importantes parámetros de la mecánica del suelo a través de la Teoría del Estado Crítico y Ley de Coulomb.

El objetivo general del presente trabajo fue el de conocer los cambios que ocasiona el agua salino-sódica en las propiedades mecánicas de suelos agrícolas.

Las hipótesis planteadas para lograr dicho objetivo fueron: 1). El sodio disminuye la vulnerabilidad a la compresión de los suelos, 2). El sodio aumenta la resistencia a la rotura de los agregados independientemente de su tamaño y 3). La alteración química del suelo provoca desplazamientos en las líneas de Coulomb y Estado Crítico.

Se utilizaron muestras reconstituidas en laboratorio de tres suelos (Cardone, Ozzano y Cadriano) provenientes de distintas localidades de Italia. Dichos suelos fueron sometidos a tratamientos de sodificación artificial, simulando los efectos de una irrigación con agua con diferentes contenidos de sales de sodio. Producto de éstos procedimientos se obtuvieron 2 tratamientos de cada suelo llamados A y $B$, cuya diferencia fundamental fue el mayor contenido de $\mathrm{Na}^{+}$en el complejo de 
intercambio de A respecto a $\mathrm{B}$. El suelo Cadriano fue evaluado mediante el empleo de Brazilian test, mientras que Cardone y Ozzano fueron sometidos a pruebas de compresión y corte. Además, sobre Ozzano, se realizaron pruebas de resistencia a rotura de agregados individuales. Los resultados obtenidos sobre el suelo Cadriano no presentaron diferencias significativas entre tratamientos en cuanto a la tensión de Compactación ni en Resistencia a Rotura. Respecto a las pruebas llevadas a cabo con agregados individuales de Ozzano, se observó que los agregados de mayores dimensiones tuvieron menor resistencia a rotura que aquellos de dimensiones menores y a su vez que los agregados del tratamiento A presentaron mayor resistencia a rotura que los de B. En las pruebas de compresión y corte se observó que uno de los parámetros más modificados por la presencia de sodio, fue el Volumen Específico o su inversa la Densidad Aparente, presentando el tratamiento $A$ valores inferiores de porosidad y pendiente menos acentuada de la Línea de Compresión, demostrando su menor vulnerabilidad a la compresión. Respecto a los parámetros de Coulomb, el tratamiento A presentó en general valores de resistencia al corte superiores y valores de cohesión más altos, mientras que el ángulo de rozamiento interno no varió significativamente respecto al tratamiento $B$. En términos de operaciones de campo los resultados obtenidos en esta tesis pueden explicar el aumento del requerimiento energético en las operaciones de labranza sobre suelos con alta RAS (Relación de Adsorción de Sodio). En el ámbito de la Teoría del Estado Crítico, 
el tratamiento A presento una región sub-crítica reducida respecto a B lo que le conferiría una mayor tendencia expansiva durante el corte. Sin embargo ésta mayor tendencia a la expansión sería solo en términos relativos ya que difícilmente pueda alcanzar valores de porosidad como las de un suelo menos sodificado a paridad de Tensión Normal. Se concluye que los suelos afectados por el uso de agua de riego con altas concentraciones de sodio poseen agregados más tenaces con mayor resistencia a rotura y menor vulnerabilidad a la compresión. Asimismo los suelos afectados por sodio presentan un incremento de su resistencia al corte, de sus valores de cohesión y un incremento de la región súper-crítica lo que les conferiría una mayor capacidad expansiva relativa durante el corte.

Palabras Claves: agregados, riego, sodio, propiedades mecánicas, Estado Crítico. 


\section{RESUM}

El reg és una pràctica que s'utilitza en àrees amb dèficit d'aigua per a incrementar la producció agrícola i ramadera. No obstant això, un maneig inadequat del reg pot causar deterioracions de la fertilitat química i, especialment, física dels sòls. Totes les aigües de reg, superficials 0 subterrànies, contenen en major o menor mesura sals solubles, sodi, clor i altres elements. S'espera que els problemes associats a sòls salins i sòdics s'incrementen en el futur a causa de l'empobriment de la qualitat de les aigües de reg, com a conseqüència de l'ús de les que són de bona qualitat per al consum humà. La irrigació amb aigües de qualitat pobra origina alteracions negatives en les propietats físiques i químiques i, en conseqüència, redueix el creixement de les plantes. Un elevat PSI (percentatge de sodi d'intercanvi) condueix a un reordenament porós: els microporus augmenten, amb les conseqüències que això té per a la circulació de l'aigua i els gasos, a més de les impedàncies mecàniques derivades de la pèrdua d'estructura.

L'estudi mecànic del sòl agrícola suposa diversos problemes, essencialment a causa de la naturalesa de sistema polifàsic, insaturat, granular, porós i generalment cohesiu que té aquest. La mecànica de l'estat crític proporciona una teoria que té com a objectiu principal relacionar les càrregues o tensions a què se sotmet un sòl amb els canvis en l'espai porós. 
Las màquines de tall tangencial tenen un ús ben ampli per a l'estudi de les propietats dels sòls agrícoles. El principal avantatge d'aquest tipus d'equipament és que es pot utilitzar tant per al tall com per a la compressió de les mostres. A més, el mesurament de l'esforç de tall i el desplaçament horitzontal i vertical en fan un assaig molt complet l'ús del qual és totalment compatible amb l'obtenció d'importants paràmetres de la mecànica del sòl a través de la teoria de l'estat crític i la llei de Coulomb.

L'objectiu general del present treball és contribuir al coneixement del perjudici ocasionat a les propietats mecàniques dels sòls agrícoles pels canvis químics que comporta el reg amb aigües enriquides amb sodi. Les hipòtesis plantejades per a aconseguir aquest objectiu van ser: 1) el sodi disminueix la vulnerabilitat a la compressió dels sòls; 2) el sodi augmenta la resistència al trencament dels agregats independentment de la grandària; i 3) l'alteració química del sòl provoca desplaçaments en les línies de Coulomb i estat crític.

Es van utilitzar mostres reconstituïdes al laboratori de tres sòls (Cardone, Ozzano i Cadriano) provinents de diferents localitats d'Itàlia. Aquests sòls van ser sotmesos a tractaments de sodificació artificial, simulant els efectes d'una irrigació amb aigua amb diferents continguts de sals de sodi. Com a resultat d'aquests procediments es van obtenir 2 tractaments de cada sòl anomenats $A$ i $B$, la diferència fonamental entre els quals va ser el major contingut de $\mathrm{Na}^{+}$en el complex d'intercanvi d'A respecte a $\mathrm{B}$. El 
sòl Cadriano va ser avaluat mitjançant l'ús del Brazilian test, mentre que Cardone i Ozzano van ser sotmesos a proves de compressió i tall. A més, sobre Ozzano es van realitzar proves de resistència al trencament d'agregats individuals. Els resultats obtinguts sobre el sòl Cadriano no van presentar diferències significatives entre tractaments quant a la tensió de compactació, ni tampoc pel que fa a la resistència al trencament. Respecte a les proves dutes a terme amb agregats individuals d'Ozzano, es va observar que els agregats de majors dimensions van tenir menor resistència al trencament que aquells de dimensions menors, $\mathrm{i}$ també que els agregats del tractament $A$ van presentar major resistència al trencament que els de $B$. En les proves de compressió i tall es va observar que un dels paràmetres més modificats per la presència de sodi fou el volum específic (o el paràmetre invers d'aquest, la densitat aparent), i que el tractament A presentava valors inferiors de porositat $\mathrm{i}$ un pendent menys accentuat de la línia de compressió, cosa que demostrava la menor vulnerabilitat d'aquest tractament a la compressió. Respecte als paràmetres de Coulomb, el tractament $A$ va presentar en general valors de resistència al tall superiors i valors de cohesió més alts, mentre que l'angle de fregament intern no va variar significativament respecte al tractament B. En termes d'operacions de camp, els resultats obtinguts en aquesta tesi poden explicar l'augment del requeriment energètic en les operacions de conreu sobre sòls amb RAS (relació d'adsorció de sodi) alta. En l'àmbit de la teoria de l'estat crític, el tractament $A$ 
presenta una regió subcrítica reduïda respecte a $B$, cosa que hi conferiria una major tendència expansiva durant el tall. No obstant això, aquesta major tendència a l'expansió es donaria solament en termes relatius, atès que difícilment pot aconseguir valors de porositat com els d'un sòl menys sodificat a paritat de tensió normal. Es conclou que els sòls afectats per l'ús d'aigua de reg amb altes concentracions de sodi posseeixen agregats més tenaços amb major resistència al trencament i menor vulnerabilitat a la compressió. Així mateix, els sòls afectats pel sodi presenten un increment de la resistència al tall, dels valors de cohesió i de la regió supercrítica, la qual cosa els conferiria una major capacitat expansiva relativa durant el tall.

Paraules claus: agregats, reg, sodi, propietats mecàniques, estat crític 


\section{ABSTRACT}

Irrigation is a practice used in water deficits areas to increase production. Nevertheless, inadequate irrigation practices may deteriorate chemical and especially physical fertility. All irrigation water, contain soluble salts, sodium, chlorine, and other elements. It is expected that problems associated with saline and sodic soils will increase in the future despite of the human use of good quality waters. Irrigation with poor quality water affects physical and chemical soil properties, reducing plant growth. High ESP (Exchangeable sodium percentage) change pores location, increasing micropores with consequences in water and gases circulation as well as mechanical impedances derived from structure loses.

Mechanical study of agricultural soils includes different problems due to its polifasic-insaturated-granulated-porous and generally cohesive nature. The agricultural soils mechanic behaviour understanding has been limited always, since classical soil mechanical techniques had been developed for saturated soil studios. Critical State mechanical provides a theory whose principal objective is to relate charges or tensions applied to a soil with changes in porosity. This theory is a strong tool because it makes possible the study of soils in $p-q-v$ dimension, where $p$ is Normal Tension, $q$ is Shear Stress and $v$ is Specific Volume. It says that soils under shear deformation, finally reach a Critical State in which they flow without new changes. 
Tangencial shear machines are usually used in agricultural soils properties studios. Main advantages of this machine are that they can be used for shear as well as compression. Furthermore share stress measurement, horizontal and vertical movements, makes it very useful to obtain mechanical soil parameters with Critical State Theory and Coulomb Law.

Main objective of this work was increase knowledge about damage caused by irrigation with sodic waters on agricultural soils mechanical properties. Hypotheses were: 1). Sodium falls risks of soil compression, 2). Sodium increase aggregates tensile strength in anyone size and 3). Soil chemical alteration causes displacements in Columb lines and Chritical State.

Three reconstituted samples (Cardone, Ozzano y Cadriano) from three Italian localities were used. These soils were artificially sodified, simulating irrigation with highly sodic waters. Two treatments were obtain called $A$ and $B$, whose main difference was the higher sodic contain in the exchange complex in $\mathrm{Na}^{+}$with respect to B. Cadriano soil was evaluated using Brazilian test, whereas Cardone and Ozzano were put under share and compression. Furthermore, on Ozzano, tensile strength evaluations were made on individual aggregates. Results obtained on Cadriano soils don't show differences between treatments with respect to Compaction tension nor Tensile strength. In Ozzano single aggregates bigger ones had less tensile strength then smaller ones and $A$ treatment aggregates shows higher tensile strength $B$ treatment. In compression an tensile strength treatment 
Specific volume was the most affected parameters by sodic, showing A treatment lower porosity and lower slopes in its compression lines. About Coulomb parameters, A treatments shows generally higher tensile strength and cohesion values, whereas angle of internal friction don't change significantly with respect to $B$ treatment.

In field operations results obtained in this thesis can explain the higher energy requirement in tillage in high SAR soils (Sodium Adsorption Ratio). In Critical state theory, A treatment shows a sub-critical zone reduced with respect to $B$ which would confer it a higher expansive tendency during share. Nevertheless this higher expansive tendency would only be in relative terms since its difficult they reach porosity values like a lesser sodified soil at the same Normal Tension. Sodic effects on soil porosity had such a magnitude that they wouldn't allow to be assimilated by its higher expansive tendency. Its concludes that soil affected by high sodic irrigation water have stronger aggregates with higher tensile strength and lower compression vulnerability. Also sodic affected soils shows an increase in its tensile strength, its cohesion values and, finally, an increase in super-critical region which confer a higher expansive relative capacity during share.

Key words: aggregates, irrigation, sodium, mechanical properties, Critical State. 


\section{INTRODUCCION}

\section{El riego y sus posibles consecuencias}

La agricultura tiene entre otros objetivos la producción de alimentos y fibras para abastecer a los requerimientos de la humanidad que crece a ritmo exponencial. Se prevé que en las próximas décadas el incremento de las 2/3 partes de la superficie arable, se producirá incorporando áreas desérticas mediante la irrigación. Por otro lado el aumento de las 2/3 partes de la producción se originará a expensas de modificaciones en el rendimiento (Rhoades, 1997).

Las tierras irrigadas, representan aproximadamente el 15\% de las tierras cultivables en la actualidad y producen el $36 \%$ de los productos alimenticios mundiales. De acuerdo a datos de FAO (2006) el porcentaje de tierras arables regadas aumentó de un $16 \%$ en 1980 a un $20 \%$ en 2002 con $277 \times 10^{6}$ ha. Esto demuestra la importancia de la práctica, en este marco de necesidades crecientes.

El riego es una práctica que se utiliza en áreas con déficit de agua para incrementar la producción agrícola y ganadera. Sin embargo un manejo inadecuado del riego puede causar deterioros de la fertilidad química y especialmente física de los suelos. Esto también puede ocurrir cuando es implementado en sistemas no aptos para el uso del mismo, a causa de la naturaleza del suelo y/o del agua, en determinadas condiciones climáticas. 
Todas las aguas de riego, superficiales o subterráneas, contienen en mayor o menor medida sales solubles, sodio, cloro y otros elementos. Según Umali (1993) citado por Rhoades (1997), la salinización de los suelos bajo riego crece a razón de 1 a 2 Mha/año. Buringh (1977) citado por Rhoades (1997) estableció que al menos 3 ha de capa arable están siendo salinizadas por minuto. Vázquez (2003) comparando suelos regados y no regados encontró que el $\mathrm{pH}$ de los sectores regados fue mayor que el de los testigos y esto se relacionó con mayores retenciones hídricas a succiones de 0,03 y 1,5 MPa, así como con mayores límites de Atterberg. Choudhary et al. (2011) encuentran que en un suelo Ustochrept típico de India irrigado por 15 años con agua subterránea conteniendo altas concentraciones de sodio, el Porcentaje de Sodio de Intercambio (PSI) pasó de 4\% a 58\%, mientras que el mismo se mantuvo constante en el tratamiento control en el que el suelo fue regado con agua superficial sin problemas de sodio.

Ghassemi et al. (1995) citado por Rhoades (1997) realizaron una extensa revisión de otro fenómeno, que es la salinización del agua utilizada por el riego, lo que conduce a la salinización de las napas y de los cursos superficiales, aguas abajo en las cuencas hidrográficas. Esta revisión demostró que este fenómeno también está ampliamente difundido. Jalali y Ranjbar (2009) subrayan el riesgo que implica la utilización de enmiendas orgánicas a suelos bajo riego con problemas de sodificación. Estos autores sostienen que dichas enmiendas 
pueden contener algunos elementos que no son utilizados por los cultivos y al lixiviarse pueden causar la contaminación de aguas subterráneas.

Desde el punto de vista de la sodicidad, la problemática es aún más compleja. Los primeros trabajos de amplia difusión en este sentido fueron los del Laboratorio de Salinidad de Riverside, California. Sus investigadores reconocieron la necesidad de evaluar el riesgo potencial de daño causado por el contenido de sodio del agua, a través del contenido relativo de este catión respecto del calcio y el magnesio. Esta medida ha sido denominada "Relación de Adsorción de Sodio" (RAS) y es comparable a la utilizada en extractos de saturación de suelo. $\left(\mathrm{RAS}=\mathrm{Na}^{+} /\left(\left(\mathrm{Ca}^{2+}+\mathrm{Mg}^{2+}\right) / 2\right)^{1 / 2}\right)$.

La abundancia absoluta de sodio o la relativa respecto de otros elementos, puede causar severos trastornos en la circulación del agua y la renovación de los gases del suelo, motivados por el deterioro de la estructura que este elemento causa a consecuencia de su naturaleza dispersante de los coloides. El sodio por su baja carga, elevada capa de hidratación y baja polaridad, es poco retenido por el complejo de intercambio, representado por arcillas y materia orgánica especialmente. Esto deriva en sistemas con tendencia a la dispersión coloidal, susceptibilidad a la erosión, una arquitectura porosa intrincada e inestable con la consiguiente mala circulación del agua y los gases del suelo. Frente a este comportamiento, otros iones como calcio y en menor medida magnesio, fundamentalmente por su 
carga, se manifiestan como elementos agregantes, causantes de una estructura edáfica más apropiada para el crecimiento de las plantas (Richards, 1980 en Suarez, 1981).

Se espera que los problemas asociados con suelos salinos y sódicos se incrementen en el futuro debido al empobrecimiento de la calidad de las aguas de riego como consecuencia del uso de aquellas de buena calidad para consumo humano e industrial. Por lo tanto será necesario un estudio profundo del efecto de estas prácticas sobre las propiedades químicas, físicas y biológicas del recurso suelo. 


\section{ANTECEDENTES}

\subsection{Importancia de las propiedades mecánicas de los}

\section{suelos.}

La evolución de la mecánica de los suelos no saturados puede dividirse en tres períodos. En el primer período, antes de 1965, muchas de las investigaciones llevadas a cabo en los suelos no saturados fueron realizadas para investigar la validez del concepto de las tensiones efectivas para los suelos no saturados (Bishop, 1959 y Aitchison, 1960). Durante este período el concepto de las tensiones efectivas fue modificado con la finalidad de analizar el comportamiento de los suelos no saturados.

En el segundo período, de 1965 a 1987, muchas de las investigaciones se realizaron con la finalidad de investigar la posibilidad de usar dos variables de estado tensionales en lugar de una (Matyas y Radhakrishna, 1968 y Fredlund, 1979). La "tensión neta" (tensión total menos presión de aire de poros) y "succión" (presión de aire de poros menos presión de agua de poros) se trataron como las dos variables de estado tensional. Durante este período se desarrollaron estructuras independientes para modelar comportamientos en el cambio de volumen y de corte en los suelos no saturados en términos de las dos variables de estado tensional. Sin embargo el comportamiento del cambio de volumen y de corte se trató por separado. 
En el tercer período, desde 1987, varios investigadores han indagado en el comportamiento de los suelos no saturados en términos del concepto del estado crítico y trataron de investigar el límite elástico de los suelos no saturados cuando el suelo es sometido a un ciclo de carga y descarga (Alonso et al. 1990). Hasta entonces el comportamiento del cambio de volumen y de corte de los suelos no saturados se había tratado separadamente. En investigaciones recientes se ha comenzado a enlazar el comportamiento del cambio de volumen y la resistencia al corte de los suelos no saturados desarrollándose modelos elastoplásticos.

Asimismo ha surgido una evolución en los aparatos de laboratorio que ha permitido medir en forma más precisa estos comportamientos.

Aluko y Koolen (2001) insisten en la importancia del conocimiento del espacio poroso para una mejor comprensión de los procesos de rotura a los que están sometidos los suelos agrícolas estructurados.

Pons et al. (2000) reportaron que, en un suelo expandible en estado de saturación y estructura inestable, la macro porosidad desaparece o disminuye sensiblemente impidiendo el desarrollo radicular mientras, en un suelo bien estructurado, el desarrollo de las raíces no resulta perjudicado aún si la saturación provoca la máxima expansión.

El endurecimiento asociado al encostramiento y sellado de los horizontes superficiales en suelos dispersivos afecta la 
germinación y establecimiento de los cultivos en muchos suelos agrícolas (Barzegar et al., 1994ª) y a su vez, junto con la expansión y contracción de las arcillas, provocan importantes cambios en las propiedades mecánicas de los suelos (Borselli et al., 1996).

Por su parte, Bengough (1997), demostró que la elongación y desarrollo radicular resultan correlacionados en forma negativa con la resistencia mecánica del suelo, concluyendo que una resistencia a la penetración de 1,5 MPa puede ser suficiente para disminuir la elongación de las raíces del 20 al 75\% según la especie. Utilizando el test de corte directo, Willcocks (1981) demostró como el desarrollo del sistema radicular del sorgo resultó seriamente comprometido cuando la cohesión era superior a $20 \mathrm{kPa}$ con una humedad en peso del $6 \%$.

Masle y Passioura (1987) han demostrado que, aunque exista una adecuada disponibilidad de agua y nutrientes, las plantas crecen más lentamente en un suelo con elevada resistencia mecánica. Es por esta razón que puede asumirse que si un suelo es afectado por el sodio, mejora su transitabilidad y simultáneamente empeora su potencial productivo.

Whalley et al. (1995) puntualizaron que suelos diversos presentan relaciones diferentes entre resistencia a la penetración y densidad y, a paridad de agua y nutrientes, es la resistencia del suelo la que determina el crecimiento radicular.

La respuesta de un suelo ante una acción exterior, como es el caso de la fuerza que aplica la herramienta de trabajo de un apero 
de labranza, está condicionada por sus propiedades físicas. Los valores de resistencia mecánica varían considerablemente, tanto de un suelo a otro, como en un mismo suelo, ya que dependen del contenido de humedad, del tamaño de las partículas minerales, del tamaño y de la forma de los agregados y del grado de consolidación alcanzado por el mismo (Ashburner y Sims, 1984 citado por Durán García, 2002). Soane et al. (1982), en pruebas destinadas a evaluar la susceptibilidad de los suelos a la compactación bajo cultivo de caña de azúcar, encontraron que la misma no depende únicamente de la compresión ejercida por la maquinaria pesada sino también del tipo de materiales parentales que componen el suelo, textura, contenido de humedad (Larson et al., 1980), materia orgánica (Soane, 1990), estabilidad estructural (Baumgart y Horn, 1991), y de la sodicidad y salinidad (Barzegar et al., 1996; Barzegar et al., 2000). Derdoura y Angersb (1992) encontraron, mediante pruebas de compactación, que la sensibilidad a la misma estuvo correlacionada positivamente con el contenido de arcilla y materia orgánica. Seta y Karathanasis (1996) luego del agregado de una solución de $\mathrm{Na}_{2} \mathrm{CO}_{3}$ de $\mathrm{pH}=$ 9,5 a muestras de 6 diferentes suelos encontraron que el contenido de carbono orgánico no tuvo un rol significativo en la estabilidad de los coloides del suelo. Justificaron estos resultados por el bajo contenido de Materia Orgánica $(2,1 \%$ a $0,3 \%$ según el suelo) debido a la profundidad a la cual se extrajeron las muestras (horizonte subsuperficial B). 
La comprensión de los procesos de disgregación, y de la tensión de rotura resultante, en la estructura de un suelo como consecuencia del uso de agua salina y sódica en irrigación, pueden resultar claves para el mejoramiento de la estructura del suelo y el establecimiento de cultivos en regiones áridas y semiáridas del mundo (Barzegar et al., 1994ª).

\subsection{Efecto de la sodicidad sobre las propiedades}

\section{físicas de los suelos.}

Los problemas relacionados a la presencia de sodio afectan a $210 \times 10^{6}$ ha de suelo en el mundo, aproximadamente. Tal superficie involucra un gran número de regiones geográficas y climáticas concentrándose principalmente en Australia, ex Unión Soviética, Argentina y ciertos países africanos.

El perjuicio que el sodio puede acarrear sobre las propiedades edáficas, analizadas desde el punto de vista de su capacidad productiva, puede resumirse en 2 categorías, la toxicidad específica y la dispersión de los coloides con sus consecuencias en la circulación del agua y los gases así como impedancias mecánicas derivadas de la pérdida de estructura (Richards, 1980; Pizarro, 1985).

La existencia de altas concentraciones de $\mathrm{Na}^{+}$en la solución del suelo, favorece el desplazamiento de otros cationes en los sitios de intercambio y contribuye al incremento de la 
presencia de cargas repulsivas que provocan la dispersión de las partículas de arcilla (Bronick y Lal, 2005).

La presencia del ión $\mathrm{Na}^{+}$en la solución de un suelo agrícola puede ser debida a la existencia de dicho catión desde la génesis del mismo o ser inducida a través de la utilización de agua de riego con altas concentraciones de éste elemento (Rengasamy y Olsson, 1991). El efecto de la presencia excesiva del catión $\mathrm{Na}^{+}$ en la solución del suelo, como resultado del uso de aguas con gran concentración de éste elemento, trae aparejado no solo problemas inherentes a la fisiología de los cultivos sino también a la degradación estructural del suelo. La irrigación con aguas de pobre calidad ejerce alteraciones negativas en las propiedades físicas y químicas y, en consecuencia, reduce el crecimiento de las plantas. Los suelos sódicos son pobremente estructurados y representan casos extremos de degradación física (Dexter, 2004).

La USSL (USSL Staff, 1954) define suelos sódicos a aquellos en los cuales las propiedades físicas son influenciadas adversamente por la presencia del sodio a un PSI $>15$, asumiendo que éste límite debe ser considerado arbitrario. En relación a lo anteriormente expresado Agassi et al. (1981) y Kazman et al. (1983) estudiando la suceptibilidad de los suelos a formar costras superficiales han relevado comportamientos sódicos a niveles de PSI de 2 y 3.

La irrigación con agua de RAS moderado produce un aumento proporcional del contenido de sodio de intercambio (PSI) en el suelo (US Salinity Laboratory Staff, 1954), afectando sus 
propiedades físicas como la conductividad hidráulica (Uttam et al., 2008).

La acumulación de sodio disminuye la agregación de las partículas del suelo y la estabilidad de los agregados en húmedo por incrementos de las fuerzas de repulsión entre los coloides, fomentando la dispersión y el sellado de los suelos (Oster, 1994; Halliwell et al., 2001; Oster y Shainberg, 2001; Buckland et al., 2002; Pilatti et al., 2006).

El $\mathrm{Na}^{+}$es promotor del engrosamiento de la doble capa difusa alrededor de las partículas de arcilla, superando las fuerzas de atracción de Van der Walls, provocando la dispersión de los coloides, especialmente en minerales de tipo 2:1 (Rengasamy y Olsson, 1991). Richards (1956), a pesar de no establecer rangos explícitos, sugirió efectos de la textura, el área superficial y tipo de mineral arcilloso, contenido de silicatos y materia orgánica, sobre la acción del $\mathrm{Na}^{+}$en la problemática de la dinámica del agua en el suelo. Texturas finas o ricas en limo (más de $50 \%$ ), arcillas expandibles como la montmorillonita y bajo contenido de silicatos y materia orgánica, agravarían la problemática sódica. Soverini (2001) marcó la importancia de la composición mineralógica de las arcillas indicando que, en presencia de sodio, la mayor sensibilidad a la variación de las propiedades mecánicas se observan en arcillas ubicadas dentro de los grupos donde se hallan la esmectita y la montmorillonita.

Nannucci (2009) subraya que altos niveles de sodio, en presencia de humedad determinan procesos de expansión- 
contracción más evidentes, debidos a la mayor cantidad de arcilla dispersa la cual puede capturar o liberar una mayor cantidad de agua y en consecuencia se encuentran en grado de amplificar estos fenómenos de cambios volumétricos.

Barzegar et al. (1994) concluyeron que cuando los suelos son removidos en húmedo cierto contenido de arcillas es liberado. Luego, al secarse, se produce una reorganización en nuevos agregados donde los puntos de contacto entre partículas determinan el vínculo entre las mismas y por lo tanto la dureza del suelo. Altos contenidos de arcillas dispersas proveen mayor número de puntos de contacto entre partículas. La dureza de cada uno de los suelos estudiados por éstos autores fue modificada a raíz de los cationes de intercambio presentes en el suelo que generalmente decayó en orden $\mathrm{Na}>\mathrm{Na}-\mathrm{Mg}>\mathrm{Na}-\mathrm{Ca}>\mathrm{Mg}>\mathrm{Ca}-$ $\mathrm{Mg}>\mathrm{Ca}$, tal como disminuye su radio iónico. Los autores subrayaron que altos porcentajes de sodio de intercambio incrementan el contenido de arcillas dispersas y por lo tanto aumenta la dureza de los suelos. La dispersión de las arcillas no es influenciada solo por la presencia de sodio, sino también por el tipo de catión bivalente que lo acompaña. De hecho, ha sido demostrado (Emerson y Bakker, 1973) que agregados conteniendo $\mathrm{Na}$ y $\mathrm{Mg}$ evidenciaron dispersión a niveles de PSI más bajos que aquellos agregados que contenían $\mathrm{Na}$ y $\mathrm{Ca}$.

Los agregados de un suelo son partículas formadas a través de la combinación de corpúsculos minerales con sustancias orgánicas e inorgánicas (Bronick y Lal, 2005). Su 
disposición caracteriza la estructura (Lal, 1991) y por lo tanto son de fundamental importancia en la mecánica de los suelos agrícolas.

Rogowski (1964) demostró que la Tensión de Rotura (Tensile Strength) de partículas esféricas puede ser determinada a partir de ensayos de rotura muy simples utilizando las siguientes relaciones:

$$
\begin{aligned}
& Y=0.576 F^{\prime} / d^{2} \ldots . .(1) \\
& d=d m\left(m / m_{0}\right)^{1 / 3} \ldots(2) \\
& d m=\left(s_{1}+s_{2}\right) / 2 \ldots(3) \\
& m_{0}=\left(\sum m\right) / n \ldots \ldots(4)
\end{aligned}
$$

Donde $F^{\prime}$ es la fuerza polar de rotura (medida a través de la celda de carga) y $d$ es el diámetro esférico efectivo (ecuación 1); $d m$ es el diámetro de la clase granulométrica a la que pertenece el agregado correspondiente; $m$ representa el valor individual de masa del agregado y $m_{0}$ es la masa media de los agregados de la clase a la que pertenece (ecuación 2); $s_{1}$ y $s_{2}$ son el diámetro de la abertura de la malla del tamiz superior e inferior utilizados en la formación de cada una de las clases granulométricas (ecuación 3); $n$ es el número de partículas (ecuación 4). Dexter y Kroesbergen (1985), basándose en Rogowski (1964), describen varios métodos para la determinación de la tensión de rotura de agregados de suelo naturales o generados artificialmente.

Willat (1987) ha observado como la Resistencia a la Rotura de los agregados de un suelo Cambisol, disminuye con el 
aumento del diámetro de los mismos. Este autor concluye que los agregados de mayores dimensiones son más susceptibles a la compactación respecto aquellos más pequeños con el mismo grado de humedad. Draghi et al. (2009) obtuvieron los mismos resultados trabajando sobre un suelo sodificado mientras que no encuentran diferencias en la tensión de rotura entre tamaño de agregados en el tratamiento testigo. Dichos autores adjudicaron la falta de diferencias al elevado contenido de arcillas de los suelos ensayados $(73 \%)$ el cual pudo haber generado un valor de cohesión molecular tan alto en seco, que no permitiría manifestar el efecto de la variación del tamaño.

La presencia de arcillas dispersas en los agregados produce diversos efectos verificados sobre la mecánica de los suelos agrícolas. Dichos efectos son asociados, principalmente, a incrementos de la fuerza de tracción necesaria para la labranza, a la formación de costras que impiden la emergencia de las plantas y facilitan la erosión, a una menor porosidad (Mzezega et al., 2003) y a una mayor resistencia de los agregados a ser penetrados por las raíces (Rengasamy y Olsson, 1991). Barzegar et al. $\left(1994^{\mathrm{b}}\right)$ combinaron soluciones, con diversas concentraciones salinas, y muestras de un suelo sometido a diferentes rotaciones de cultivos (desde suelo virgen hasta siembra de trigo todos los años), encontrando que la estabilidad de los agregados disminuyó con el aumento de la RAS y que para una misma RAS la estabilidad de los agregados se incrementó al aumentar el contenido de materia orgánica de los mismos. Estos 
autores observaron también una correlación negativa entre la Tensión de Rotura y el MWD (mean wight diameter o diámetro medio efectivo), siendo éste último consecuencia de su estabilidad. Agregados más estables presentaron mayores valores de MWD y agregados menos estables a causa del tratamiento con soluciones de mayor RAS presentaron menores MWD y por ende menor estabilidad y mayor resistencia a rotura.

Taboada y Lavado (1996) reportaron que el módulo de ruptura (MOR) de agregados de un suelo Natraquol se incrementa con el incremento de la RAS. Este hecho se evidenció en 3 sub tratamientos: I) Humedad a saturación y secado al aire, II) Humedad a capacidad de campo y secado al aire y III) Control.

Rahimi et al. (2000) indagaron en el comportamiento de suelos sodificados artificialmente y sometidos a ciclos de humectación - desecación, observando que la Resistencia a Rotura de los agregados disminuye con el aumento de las arcillas dispersas debido a la RAS. Estos resultados se contradicen con aquellos observados precedentemente por Barzegar et al. $\left(1994^{b}\right)$. Rahimi et al (2000) justificaron éstas diferencias de comportamiento sosteniendo que las mismas son debidas al ciclo humectación - desecación que redujo la estabilidad de los agregados.

Barzegar et al. (1994 ${ }^{\text {b }}$ compararon la resistencia a rotura de diversos suelos sometidos a soluciones conteniendo $\mathrm{NaCl}$, $\mathrm{CaCl}_{2}$ y $\mathrm{MgSO}_{4}$ en diferentes proporciones, mediante la utilización del Brazilian Test, que se basa en la rotura de muestras de suelos 
en forma de discos o cilindros colocados de forma horizontal. Estos autores concluyen que los suelos sometidos a soluciones con mayor contenido de $\mathrm{Na}^{+}$presentaron mayor resistencia a rotura y mayor cantidad de arcillas dispersas espontáneamente que aquellos suelos sometidos a soluciones con mayor concentración de $\mathrm{Ca}^{++}$y $\mathrm{Mg}^{++}$.

Las arcillas dispersas por acción del sodio son lixiviadas en profundidad ocupando poros y provocando su sellado, por lo tanto la conductividad hidráulica y la infiltración son severamente afectadas (Agassi et al., 1985; Mamedov et al., 2001; Levy y Mamedov, 2002). Existen antecedentes suficientes que permiten afirmar que un elevado PSI conduce a un reordenamiento poroso, aumentando los microporos (Waldrom y Constantin, 1968; Costa y Aparicio, 2000; Varallyay, 2002; Ruiz Vera y Wu, 2006). Varallyay (2002) afirma que un alto porcentaje de sodio intercambiable (PSI) ocasiona una significativa modificación de la estructura y más concretamente de la conformación del espacio poroso, modificando la compactabilidad de los suelos. Nannucci (2009) encontró una mayor resistencia a la tracción en agregados con mayor contenido de sodio y menor sensibilidad a la compresión de los suelos atribuída a la presencia de arcilla dispersa que forma fuertes uniones, confiriendo a las muestras sódicas mayor resistencia a la compresión. Como el crecimiento radical implica una compresión del suelo, un suelo que resiste más la compresión es un suelo que limita en mayor medida el crecimiento radical (Falciani, 2009). Mitchell (1976) encontró que 
una estructura de partículas floculadas presenta grandes poros mientras que una dispersa tiene numerosos microporos y a tensiones mayores que la tensión de preconsolidación el efecto de incrementos de tensiones es mayor sobre las estructuras floculadas que sobre las dispersas.

Ante un incremento dado de tensión, los poros de mayor tamaño son comprimidos primero (Delage y Lefebvre, 1984; Griffiths y Joshi, 1989).

Hutson (1971) demostró, en suelos Rhodustalf típicos de Sudáfrica, que la dureza de la costra de 0 a $2 \mathrm{~cm}$ de profundidad de un suelo irrigado fue una función continua del PSI del agua de riego y que utilizando aguas con RAS de $3,8 \mathrm{mmol} / \mathrm{l}$ se incrementó la densidad superficial del suelo. La ajustada relación entre PSI y el contenido de arcillas dispersas en suelos vertisoles de Australia se asocia con la relación existente entre el contenido de arcillas dispersas y la Conductividad Hidráulica de las costras superficiales, siendo éste un patrón encontrado en muchos trabajos para gran variedad de suelos en muchas regiones del mundo (Kazman et al., 1983; Agassi et al., 1985; Ben-Hur et al., 1985; Miller, 1987; Levy et al., 1988; Miller y Scifres, 1988; Levy y Van der Watt, 1990; Smith et al., 1990; Shainberg et al., 1991; Miller et al., 1991; Gal et al., 1992; Sumner y Miller, 1992; Sumner, 1993).

La acción deletérea del $\mathrm{Na}^{+}$en la estructura del suelo agrícola, evidenciada por el mayor poder dispersivo de las arcillas, en comparación con otros cationes presentes en la solución 
(especialmente $\mathrm{Ca}$ y $\mathrm{Mg}$ ), ha sido estudiada por varios autores (Rengasamy y Olsson, 1991; Barzegar et al., 1994 b). Numerosos trabajos han encontrado que los suelos afectados por sodio se caracterizan por un aumento de su densidad (Amiotti y Bravo, 2006; Kaur et al., 2006; Jassogne et al., 2006; Currie et al., 2006).

Quirk y Murray (1991) determinaron la relación, directamente proporcional, existente entre RAS (Relación de Adsorción de Sodio) contenido en el agua de riego de suelos agrícolas y el umbral de concentración de electrolitos ( $\mathrm{Ca}, \mathrm{Mg}$ ). Estos autores definen dicho umbral como la concentración de electrolitos mínima requerida para mantener el suelo en una condición de estructura permeable a un determinado grado de saturación de $\mathrm{Na}^{+}$de los coloides. De hecho, Dubey y Mondal (1994), encontraron que la aplicación de agua salina sobre un suelo Aquic Natrustalf incrementó significativamente la producción del cultivo de arroz comparado con la utilización de agua no salina.

Parker (1984) encuentra una fuerte correlación $\left(r^{2}=0,82\right)$ entre el contenido de arcillas dipersas y la dureza de la costra medida a traves del Módulo de Ruptura en suelos Alfisoles de Georgia. La resistencia a la penetración de éstos suelos, medida con penetrómetro, se duplicó cuando se pasó de un RAS de 0 a 7 .

Otra propiedad física habitualmente relacionada a la naturaleza del complejo de intercambio ha sido la consistencia del suelo, la cual surge de la combinación de las fuerzas de adhesión y cohesión de las partículas del suelo. Los límites líquido y 
plástico de Atterberg (Forsythe, 1975) fueron desarrollados para poner en evidencia aspectos ligados a la consistencia. Estos límites se definen como la cantidad de agua retenida cuando el suelo manifiesta un comportamiento de fluido (límite líquido) y adhesión-plasticidad (límite plástico). Smith et al. (1985) hallaron que la sodicidad y la salinidad, comunes en suelos secos de regiones semiáridas, pueden respectivamente aumentar 0 disminuir los límites de Atterberg. Esto demuestra que modificaciones químicas del extracto de saturación causadas por el riego, son responsables de alteraciones físicas derivadas de la arquitectura porosa del suelo, tales como la retención hídrica dentro del rango del agua útil y los límites de Atterberg.

Spugnoli et al. (2002) evidenciaron como el $\mathrm{Na}^{+}$influyó sobre las propiedades mecánicas, aumentando la resistencia al corte y a la compactación y disminuyendo el espacio hipercrítico en el ámbito de la Teoría del Estado Crítico en suelos Haploxeralf y Udertic Ustochrept sodificados artificialmente. Dichos autores simularon un proceso de sodificación por la utilización de agua de riego con alta concentración de sales, luego los suelos fueron sometidos a compactación uniaxial y corte mediante el empleo de Caja de Corte Directo.

Es muy probable que a consecuencia del incremento del área regada acompañado del uso de agua de mala calidad, la superficie de suelos afectados por sodio se aumente, por lo que será importante profundizar el conocimiento sobre el 
comportamiento mecánico de los mismos para determinar las implicancias sobre aspectos tales como la labranza y el tránsito.

\subsection{Efecto de los ciclos de humectación - desecación} sobre las propiedades físicas de los suelos.

A la complejidad de las reales condiciones de un suelo agrícola con respecto a sus propiedades mecánicas, se suma el efecto de ciclos de desecación - humectación, a los que son expuestos en condiciones normales de campo.

Utomo y Dexter (1981) encontraron que los agregados de un suelo sometido a humidificación - desecación sufrieron micro fracturas que redujeron su resistencia a rotura, siendo más notable éste efecto en agregados de mayor tamaño.

Rajaram y Erbach, (1999) concluyen que un suelo arcilloso sometido a ciclos de humectación - desecación sufrió un cambio en sus propiedades físicas disminuyendo la estabilidad de los agregados e incrementando la resistencia a la penetración (evaluada mediante penetrómetro de cono), cohesión, adhesión, fricción interna y tamaño de sus agregados. La disminución de la estabilidad de los agregados había sido observada por los mismos autores (1998) sobre un suelo franco - arcilloso sometido también a ciclos de humectación - desecación. La dispersión de arcillas generada por el humedecimiento, proceso que se acentúa en un suelo sódico, conduce a un reordenamiento de las partículas más finas y microagregados que luego, durante el ciclo 
de desecación, provocan un efecto de verdadera cementación (Hettiaratchi, 1987).

Rengasamy y Olsson (1991) detallaron los procesos de dispersión que ocurren en agregados de un suelo sódico en comparación con los que ocurren con los agregados de un suelo rico en Ca sometidos a idénticos ciclos de humectación desecación.

Barzegar et al. (1995) concluyeron que la Tensión de Rotura, de suelos con diferentes clases de arcillas y sometidos a compactación, decreció con el incremento del número de ciclos de humectación - desecación. Kay y Dexter (1992) estudiaron la variación en la resistencia de los agregados relacionándola a efectos combinados de condiciones que favorecen la dispersión de arcillas y un incremento subsiguiente en la resistencia por cementación al secarse y ciclos de humectación-secado que resultarían en un decrecimiento de la resistencia. La pérdida de resistencia es debida a una combinación de entrampamiento de aire e hinchazón diferencial (Grant y Dexter, 1989).

Taboada y Lavado (1996) trabajaron sobre un suelo sodificado con diferentes niveles de RAS, en el cual las muestras fueron humedecidas a diferentes porcentajes y sometidas a presión, secándolas luego al aire y midiendo los módulos de ruptura (MOR) de agregados individuales. El tratamiento llevado a humedad de saturación y posterior secado no tuvo diferencias con el tratamiento testigo (no humedecido). 
Zhang et al. (1997) señalaron que el agregado de turba a suelos arcillosos, sometidos a compactación y ciclos de humectación - desecación, no logró regenerar la estructura degradada por los tratamientos antes mencionados.

Rao et al. (2001) trabajaron sobre el impacto de ciclos de humectación - desecación en suelos expansibles de India. Si bien éste trabajo no contemplaba suelos agrícolas, concluyeron que en suelos con mayor contenido de materia orgánica, los ciclos de humectación - desecación provocaron fenómenos de expansión contracción más moderados, menor resistencia a la compactación y menor densidad aparente (aún después del secado) que los suelos con menor contenido de materia orgánica. Las dinámicas de expansión - contracción impuestas por los ciclos de variación de humedad en campo, más allá de los fenómenos de cementación hallados en los suelos, aportan un efecto propio en la determinación de las variaciones de la resistencia mecánica en el tiempo (Hettiaratchi, 1987). A bajos niveles de PSI el principal mecanismo que actúa en la degradación física de los suelos es la dispersión. Solo a valores de PSI $>15$ el rol de los procesos de expansión contracción se vuelve dominante en determinar las alteraciones de las propiedades físicas de los suelos (Shainberg y Letey, 1984). 


\subsection{Algunos antecedentes de la mecánica del suelo}

\section{agrícola.}

El estudio mecánico del suelo agrícola supone diversos problemas debido esencialmente a su naturaleza de sistema polifásico, insaturado, granular, poroso y generalmente cohesivo. A esto se suma su fuerte vinculación a procesos químicos, físicos y biológicos, la existencia de estructura y su heterogeneidad (Stepniewski et al. 2002). Todo esto determina la necesidad de aproximaciones y limitaciones en cada intento interpretativo y experimental.

La aplicación de esfuerzos externos al suelo, dependiendo de la intensidad de los mismos, puede permanecer en el ámbito del campo elástico, donde las deformaciones son reversibles (Ley de Hooke). En condiciones de esfuerzos superiores, el suelo alcanza la ruptura que puede ser frágil o plástica, sufriendo deformaciones irreversibles.

El pasaje entre los diversos comportamientos y por ende, la resistencia mecánica de un suelo, dependen fuertemente de su contenido de agua (que es la variable más importante en el comportamiento real de los suelos agrícolas) y de otros factores como los cationes adsorbidos, el contenido de arcilla y su dispersión. Cuando el contenido de humedad se acerca al de saturación, el suelo puede asumir comportamientos de tipo fluido.

En líneas generales, la aplicación de los esfuerzos (compresiones) en sustancial isotropía sobre un volumen de suelo 
causa la ruptura y la deformación por compactación (o consolidación en el caso de suelos saturados), mientras que la presencia, entre los esfuerzos principales, de un esfuerzo de intensidad preponderante (esfuerzo desviatórico), causa rotura por corte.

El parámetro más utilizado para cuantificar el nivel de compactación del suelo es el de la masa volumétrica aparente seca ( $\left.p_{\text {aps }}\right)$.

Blackwell y Seoane (1981) propusieron uno de los primeros modelos de medición de la variación del citado parámetro en condiciones de campo en dependencia del tráfico de maquinaria agrícola, evidenciando entre otras, la relevancia de la presión de contacto rueda - suelo, y de la carga total absoluta aplicada.

La validez de la $p_{\text {aps }}$ como indicador funcional es actualmente objeto de discusión en el ámbito científico. Hakanson y Lipiec (2000) confirmaron la utilidad de éste parámetro solo en forma de densidad aparente relativa para la comparación entre suelos diferentes. Utilizaron el grado de compactación, que expresa la densidad en términos porcentuales respecto a la densidad del suelo determinada en condiciones estandarizadas.

Más allá de las discusiones existentes, la $p_{\text {aps }}$ sigue siendo ampliamente utilizada en la caracterización del suelo agrícola como testimoniaron Chen et al. (1988), quienes han elaborado y propuesto un modelo que prevé la variación de la masa volumétrica en 9 tipos de labranza del suelo integrando los 
resultados de una amplia cantidad de trabajos de investigación conducidos durante 18 años.

En relación con la característica porosa del suelo agrícola, Alakukku (1996) diferencia entre porosidad total, macro y microporosidad, interpretando en base a éstos parámetros la acción de compactación debida al pasaje de maquinaria agrícola con elevada carga axial sobre dos tipos de suelos (un Vertisol y un Molisol con gran contenido de materia orgánica). En dicho trabajo encuentra una notable diversidad en la acción de los pesos sobre las componentes del sistema poroso, diferente según el tipo de suelo, y sobre todo, la persistencia por 3 años de severos efectos de compactación en el horizonte superficial así como también en profundidad, no obstante las regulares acciones de rotura y elaboración anuales.

El daño sufrido en horizontes no superficiales no es evidenciado en el trabajo realizado por Gysi et al. (2000), quienes midieron la porosidad, la masa volumétrica y la consolidación directamente a campo y en pruebas de laboratorio luego del pasaje de una cosechadora, encontrando fenómenos de compactación relevante solo hasta los $25 \mathrm{~cm}$ de profundidad. Estos autores también propusieron y validaron un modelo matemático para la estimación de los movimientos o desplazamientos de masa del suelo, del potencial hídrico y de la porosidad según la profundidad.

Un estudio profundo de los problemas relacionados al sistema poroso ha sido realizado por Kirby $\left(1991^{\circ}\right)$, quien 
investigó los efectos sobre la variación en la permeabilidad al aire de suelos expuestos a compresión y corte con muestras reconstituidas artificialmente, preparadas con y sin orientación preferencial de los macroporos. En el ámbito de la teoría del estado crítico, Kirby $\left(1991^{\circ}\right)$ relacionó la falla por corte con la expansión o reducción del volumen total del suelo y sus efectos sobre la funcionalidad del sistema poroso, revelando una disminución de la permeabilidad aun en casos expansivos con orientación preferencial de macroporos, lo que evidencia el rol primordial de la continuidad de los mismos.

O'Sullivan et al. (1999), confirmaron el efecto fundamental de las deformaciones, en particular de corte, sobre la eficiencia del sistema poroso en un suelo franco en ausencia de una orientación preferencial de sus macroporos, midiendo la permeabilidad y difusión de la fase gaseosa que resultaron fuertemente reducidas luego de ocurrida la falla por cizalla.

Numerosos aportes en los últimos años afrontan e interpretan algunos fenómenos particulares típicos de suelos agrícolas insaturados. Uno de dichos aportes es el de Earl (1997) que propone una teoría específica para explicar, en base a la relación entre esfuerzo normal y esfuerzo lateral, el comportamiento real del suelo. Dicho autor, llevó a cabo un ensayo de penetración con planchas, distinguiendo tres fases según la variación de dicha relación: compactación a esfuerzo lateral constante, compactación a esfuerzo lateral creciente y compactación y desplazamiento lateral del suelo. 
Zhang et al. (2001) afrontaron, con una nueva metodología experimental específicamente desarrollada, el estudio de la resistencia mecánica del suelo a nivel superficial, donde las fuerzas de adhesión son inferiores respecto a los estratos más profundos a causa de la ausencia de confinamiento en la interfase suelo - aire.

Hadas et al. (1988) mostraron como los modelos predictivos de las interacciones suelo - máquina eran más eficaces en la dinámica inherente a la tracción que a la labranza. También evidenciaron que, en general, tales modelos brindaban mejores resultados en lo referente a la eficiencia energética en las operaciones culturales que en el ámbito de la predicción de las condiciones cualitativas del suelo luego de dichas operaciones.

En relación a esto es importante remarcar el aporte de Hettiaratchi (1988) quien sostuvo la validez del empleo de la mecánica del estado crítico en la interpretación de las alteraciones físicas del suelo inducidas por las operaciones culturales, especialmente en relación al desarrollo radicular. El mismo autor subrayó como, en cada caso, la contribución de la teoría mecánica del suelo agrícola puede tener un papel determinante para el diseño de implementos de labranza.

La actual tendencia del uso de la mecánica del suelo, encaminada a brindar soluciones predictivas no solo en lo referente a la eficiencia energética en el laboreo, puede ser ejemplificada con el trabajo de Barzegar et al. (2003) quienes trabajaron en la región semiárida de Irán combinando diversas 
técnicas de elaboración del horizonte antrópico. Estos autores arribaron a la conclusión que el uso del cincel, en ese caso en particular, no solo es aconsejable por su rendimiento energético, sino también por la conservación de la estabilidad estructural de los agregados y la reducción de la susceptibilidad a la erosión hídrica. Un trabajo posterior de Barzegar et al. (2004), en la misma región, teniendo en cuenta la importancia de la distribución de las dimensiones de los agregados en la realización de los cultivos, arribaron a la conclusión que, tanto las distintas formas de elaboración de la cama de siembra, como el contenido de humedad del suelo en ese momento, afectan tanto el tamaño como la relación porcentual de los agregados.

Dexter y Bird (2001) plantean un método para estimar la "humedad óptima de trabajo" basándose en la curva de retención hídrica, con el objetivo de establecer el rango de humedad más apropiado para trabajar y preparar un suelo determinado, desde una perspectiva ligada a la preservación y al resultado cualitativo del laboreo del suelo.

\subsection{Teoría del Estado Crítico.}

La comprensión del comportamiento mecánico de los suelos agrícolas ha sido siempre limitada, ya que las técnicas clásicas de la mecánica de suelos han sido principalmente desarrolladas para el estudio de suelos saturados. 
Las técnicas clásicas de la mecánica del suelo son principalmente concentradas en la impedancia al corte de suelos rígido-plásticos idealizados y en la aplicación de soluciones a problemas de estabilidad de estructuras. Estos análisis no contemplan el comportamiento al corte del suelo anterior 0 posteriormente a su falla, y por lo tanto no es posible deducir las interacciones "Cultivo" y "Compactación" mediante estos métodos, ya que durante el desarrollo de éstos eventos se ven asociados también, cambios en el espacio poroso del suelo.

La mecánica del Estado Crítico provee una teoría cuyo principal objetivo es el de relacionar las cargas o tensiones a las que es sometido un suelo con los cambios en el espacio poroso, y por lo tanto, es de gran relevancia en el estudio de problemas de "Cultivo" y "Compactación".

El comportamiento mecánico del suelo puede ser cuantificado a través de los cambios en el espacio poroso como respuesta a la aplicación de cargas. El espacio poroso de un suelo puede ser fácilmente relacionado con su Volumen Específico " $v$ ", definido como el volumen ocupado por una unidad de masa siendo el valor inverso de la densidad.

La variación del volumen específico de un suelo tensionado puede ser representada en un gráfico tridimensional de ejes ortogonales representados por $p, q$ y $v$, donde $p$ representa la Tensión Normal Media y $q$ la tensión desviatórica. Esta ultima componente $(q)$ esta asociada a los esfuerzos de corte inducidos por los implementos de laboreo en suelos agrícolas. 
Todos los posibles estados existentes en un elemento de suelo pueden ser representados por puntos en el espacio $p-q-v$.

La Teoría del Estado Crítico desarrollada por el profesor Roscoe y colaboradores en la Universidad de Cambridge y su posterior adaptación por Hettiaratchi y O'Callaghan (1980), es utilizada en trabajos realizados por un gran número de autores como Kirby $\left(1991^{\mathrm{a}}, 1991^{\mathrm{b}}, 1991^{\mathrm{c}}, 1994,1997\right)$, O'Sullivan et al. (1994, 1999), Leeson y Campbell (1983), Macari et al. (2003).

Hettiaratchi y O'Callaghan (1980) dieron una versión simplificada de la teoría y sus aplicaciones en el campo del laboreo en suelos agrícolas y en la caracterización de las propiedades mecánicas de suelos no saturados.

Esta teoría es una potente herramienta para explicar las deformaciones de suelos en un extenso rango de condiciones (Kirby, 1994), ya que brinda la posibilidad de estudiar los suelos dentro del espacio $p-q-v$. La misma establece que "los suelos bajo deformación de corte, finalmente alcanzan un Estado Crítico en el que fluyen sin nuevos cambios en $p-q-v$ ".

El lugar en el espacio $p-q-v$ en el que se alcanza el Estado Crítico es único para cada suelo y es llamado Línea de Estado Crítico (Critical State Line o C.S.L.). Este concepto indica el estado final alcanzado por un suelo tensionado y las direcciones en el espacio $p-q-v$ a que los cambios en tensiones y volumen específico pueden conducir cuando el suelo ha sido deformado. 
No todas las combinaciones de $p, q$ y $v$ son posibles en la práctica y ciertas fronteras limitan los valores que poseen. Estas fronteras son referidas como Fronteras de Estado y los posibles valores de $p-q-v$ trazados por un elemento de suelo durante la deformación son denominados Caminos de Estado. Dichos Caminos de Estado deben permanecer en todo momento dentro o sobre las Fronteras de Estado, pero nunca pueden cruzarlas.

Las Fronteras de Estado son representadas por 3 superficies indicadas con los nombres: Roscoe, Hvorslev y Superficie de Tensión ( $T$-Surface). La intersección de la superficie Roscoe con la Hvorslev define la Línea de Estado Crítico (Critical State Line o C.S.L.), mientras la intersección de la Superficie Roscoe con el plano $q=0$ representa la Línea de Consolidación Normal, llamada también Línea Virgen (N.C.L o L.V.) y reproduce la variación de volumen específico durante la compresión uniaxial.

El límite entre la superficie Hvorslev y la Superficie de Tensión es más difícil de trazar experimentalmente. Sin embargo, la superficie de tensión, se puede construir fácilmente sabiendo que su inclinación es conocida e igual a 3:1 (Hettiaratchi, 1987)(Figura 1).

Todo el espacio de estado encerrado por las superficies Roscoe, Hvorslev y Superficie de Tensión representa la fase elástica del suelo tensionado. Dentro de este espacio los caminos son todos recuperables ante la descarga. Si el camino de estado toca 0 atraviesa una frontera el suelo puede presentar rotura y adquirir deformaciones plásticas permanentes o tener fallas 
físicas. Estos casos, en los que los Caminos de Estado conducen a la falla del material, son de gran relevancia en los estudios sobre laboreo y compactación en suelos agrícolas.

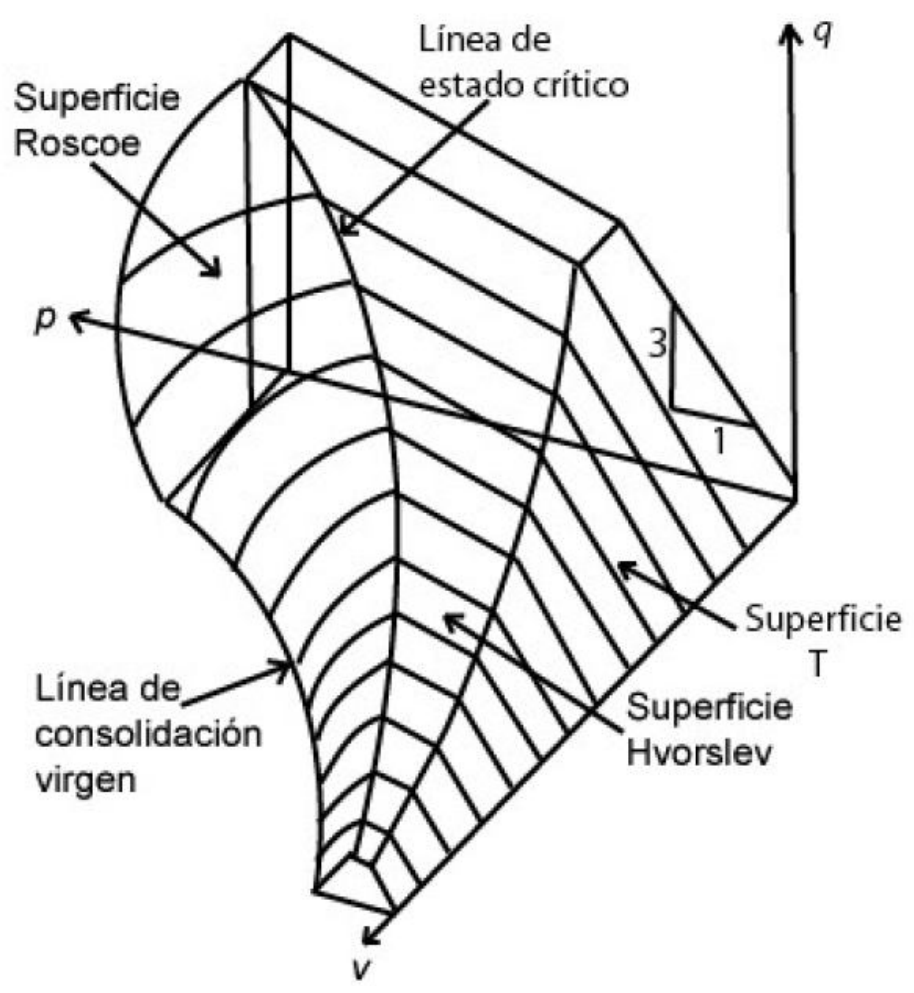

Figura 1: fronteras de Estado en el espacio $p-q-v$.

Para un suelo con una humedad determinada, el muro vertical imaginario que se obtiene proyectando la Línea de Consolidación Normal y la Línea de Estado Crítico sobre el plano $q=0$ divide el espacio en dos secciones llamadas super-crítica (que contiene el origen de los ejes $p, q$ y $v$ ) y sub-crítica (aquella más alejada del origen)(Figura 2). En general se considera que un 
suelo ubicado en la región sub-crítica se encuentra asociado a una condición de ligera sobre-consolidación y presentara falla de tipo dúctil. Por el contrario un suelo ubicado en la región supercrítica se encuentra asociado a una condición de fuerte sobreconsolidación y fallará de forma frágil.

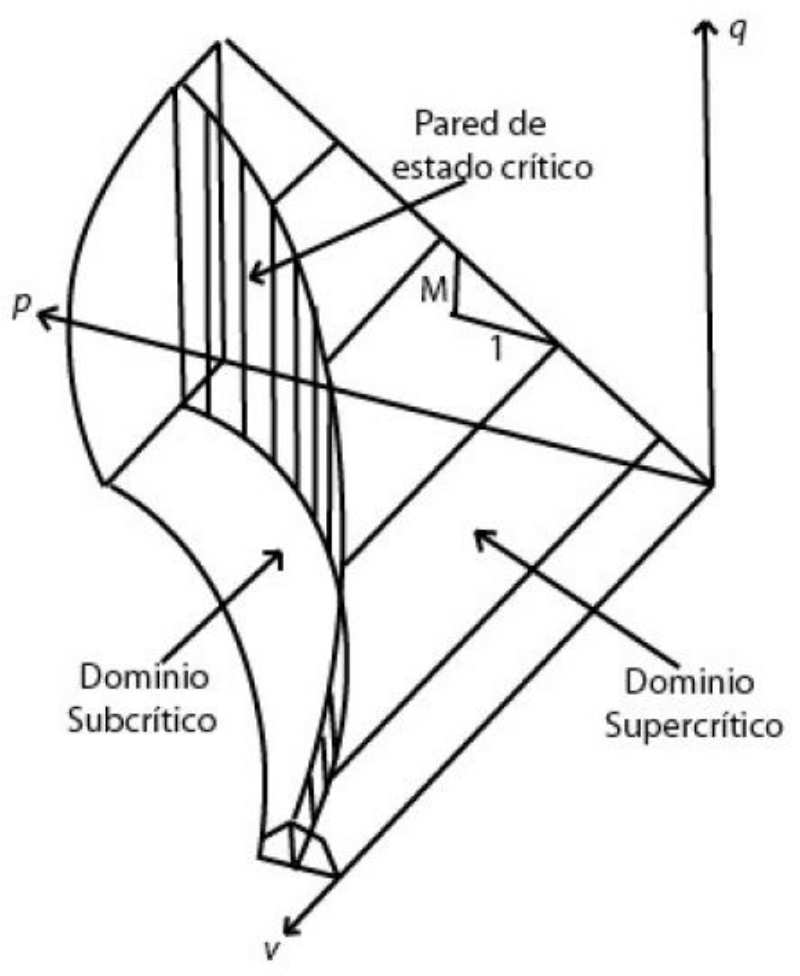

Figura 2: Dominio Subcrítico y Supercrítico en el espacio $p-v$.

Para definir con mayor claridad la Línea de Consolidación Normal o Línea Virgen es necesario remitirnos a la Curva de Compresión. La compresión puede ser definida como una disminución en la relación porosa. Para obtener la Curva de Compresión se utiliza el ensayo de compresión uniaxial. La curva 
tiene ciertas características, a bajas tensiones hay relativamente poca compresión y el suelo retorna a su volumen original luego de la descarga, mientras que a altas tensiones el suelo se comprime mucho más, y ante decrecimientos de la tensión se expande pero no hasta su relación porosa original.

Por lo tanto, la compresión uniaxial involucra tensiones elásticas (recuperables con la descarga) y plásticas (no recuperables con la descarga). La tensión que divide estos dos comportamientos es usualmente llamada Tensión de Preconsolidación, Pc (Figura 3), y la curva formada a tensiones mayores que Pc es Ilamada Línea de Consolidación Virgen (LCV) caracterizada por su pendiente $\lambda$.

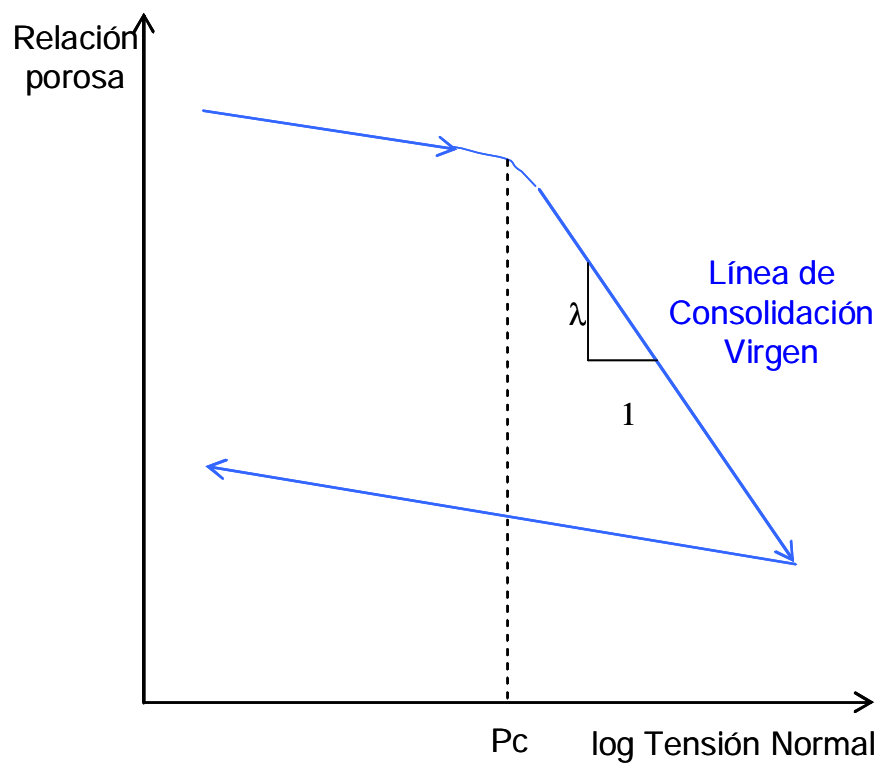

Figura 3: Curva de Compresión donde se ubica la Línea Virgen y Pc. 
Una vez superado $\mathrm{Pc}$ un suelo responderá ante la descarga siguiendo una línea llamada de Rebote (Rebound).

Pc se incrementa cuando la densidad se aumenta y cuando el contenido de agua decrece. Sin embargo numerosos autores discrepan en la incidencia que tiene la densidad inicial del suelo sobre la Tensión de preconsolidación.

Alexandrou y Earl (1998) hallaron que en suelos franco arenosos los valores de $\mathrm{Pc}$ fueron directamente proporcionales a la densidad inicial, mientras que en suelos arcillosos Pc dependió únicamente del contenido hídrico.

Mosaddeghi et al. (2003) sostienen que el incremento de la Tensión de Preconsolidación fue marcadamente independiente de la densidad inicial del suelo pero marcadamente dependiente de la humedad. Lebert y Horn (1991) indicaron que la relación existente entre Pc y la densidad del suelo disminuye a medida que aumenta el contenido de arcilla. Chaplain et al. (2011) realizaron pruebas de compresión en suelos de dos localidades de Francia, en cada una de ellas extrajeron muestras indisturbadas de suelos insaturados bajo dos condiciones, Labranza y Sin Labranza. Estos autores no encontraron una correlación significativa entre Pc y la Relación Porosa del suelo, en un caso por la gran dispersión de la nube de puntos (Labranza), y en el otro porque Pc permaneció constante en el rango de valores de Relación de Poros ensayados (Sin Labranza).

En ciertos suelos casi incompresibles (como arenas y suelos cementados) la distinción entre la parte inicial de la curva y 
la línea de consolidación virgen suele no ser clara. En estos suelos Pc es difícil de definir, o está quizás fuera de los rangos de tensión sobre los que las mediciones son efectuadas. En algunos suelos los puntos experimentales forman una curva continua y nuevamente Pc es difícil de definir como un valor particular. Sin embargo, puede ser identificado un rango de tensiones, debajo del cual la compresión es limitada y sobre el cual no lo es (Kirby, $\left.1991^{\mathrm{a}}\right)$.

En un gráfico semilogaritmico $v-\ln (p)$, la Línea de Estado Crítico y la Línea de Consolidación Normal son representadas sobre el plano $q=0$ por dos líneas rectas paralelas (Hettaratchi, 1987). En dicho gráfico las Líneas de Consolidación Normal y de Estado Crítico responden a las ecuaciones:

Línea de Consolidación Normal:

$$
\mathrm{LCN}=v=\mathrm{N}-\lambda \cdot \ln (p) \ldots .(5)
$$

Línea de Estado Crítico:

$$
\mathrm{LEC}=v=\Gamma-\lambda \cdot \ln (p) \ldots \ldots(6)
$$

Nótese que ambas líneas tienen la misma pendiente $\lambda$ (ecuaciones 5 y 6 ) por lo que resultan paralelas. No obstante el término independiente $\mathrm{N}$ (ecuación 5 ) es mayor que $\Gamma$ (ecuación 6) por lo que la Línea de Estado Crítico se encuentra a la izquierda de la Línea de Consolidación Normal.

Partiendo de un punto ubicado en el dominio super-crítico (Superficie Hvorslev), cualquier tensión de corte aplicada (q) dará lugar a un aumento de volumen, hasta que alcance la Línea de 
Estado Crítico donde la acción de rotura continuará a volumen constante (Figura 4). Al contrario, partiendo de una condición subcrítica (Superficie Roscoe), la deformación portará una disminución de volumen (compactación)(Figura 5).

La Línea de Estado Crítico puede ser también representada en un gráfico bidimensional $p-q$ con $v=0$ (ecuación 7). En éste caso la Línea de Estado Crítico queda definida por la ecuación:

$$
q=M . p \ldots .(7)
$$

Donde $M$ es la pendiente de la Línea de Estado Crítico. El parámetro friccional $M$ tiene una influencia marginal en la proporción de ambas superficies (Roscoe y Hvorslev) (Hettiaratchi, 1987). 

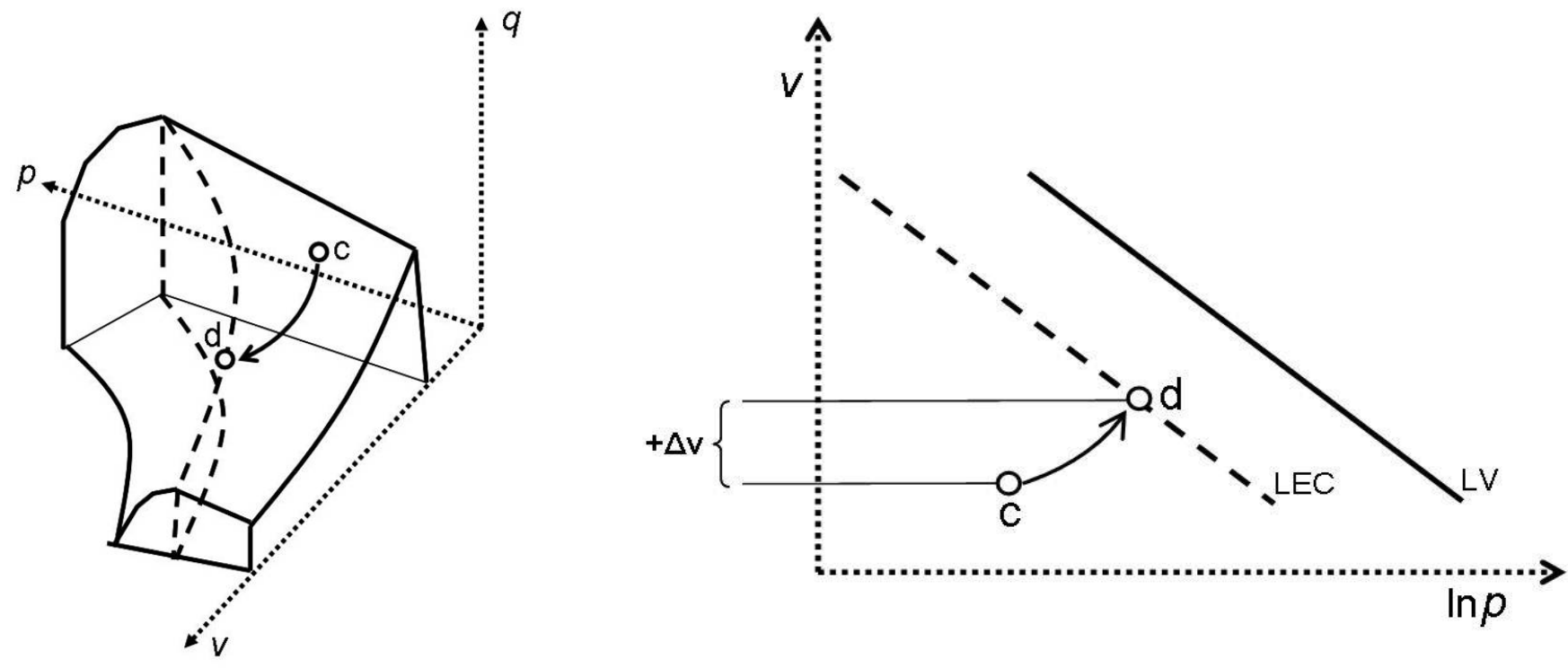

Figura 4: Expansión: Un suelo representado por el punto "c" ubicado en la región súper crítica alcanza la Línea de Estado Crítico "d" presentando un aumento de su volumen específico. En un gráfico $p-q-v$ (izquierda) y en un gráfico $v-\ln (p)$ (derecha). 

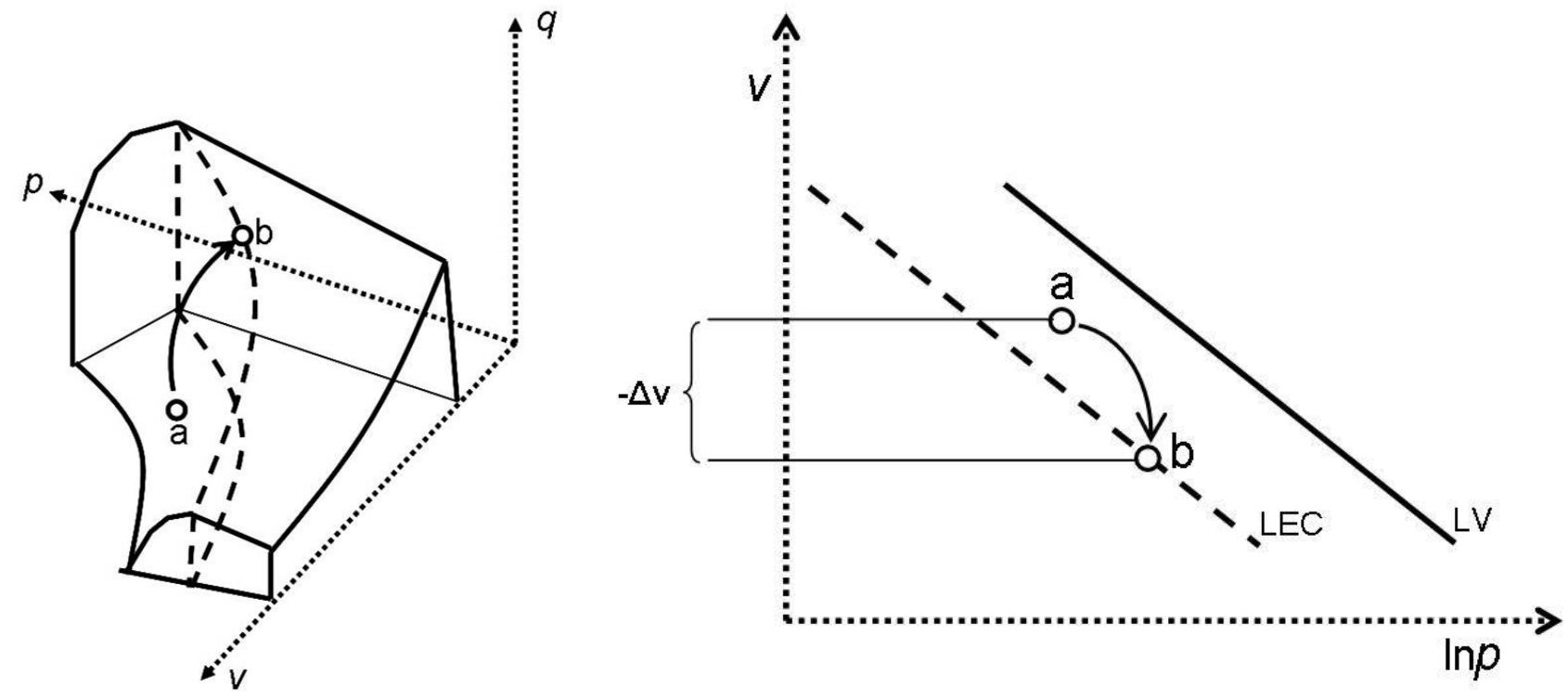

Figura 5: Contracción: Un suelo representado por el punto "a" ubicado en la región sub crítica alcanza la Línea de Estado Crítico "b" presentando una disminución de su volumen específico. En un gráfico $p-q-v$ (izquierda) y en un gráfico $v-\ln (p)$ (derecha). 


\subsection{Ley de Coulomb-Mohr}

La ley de Coulomb-Mohr cuyas bases fueron escritas por el primero (1776), establece que "La falla de un material ocurre si los esfuerzos de cizalla sobre cualquier plano se igualan a la resistencia al corte".

De la ley de Coulomb se desprende que la resistencia al corte de suelos en términos generales tiene dos componentes:

a). Fricción $(\operatorname{tg} \varphi)$ que se debe a la trabazón entre partículas y al roce entre ellas cuando están sometidas a esfuerzos normales.

b). Cohesión (c) que se debe a las fuerzas internas que mantienen unidas a las partículas en una masa.

Como en la ecuación " $\tau=c+\sigma_{n}{ }^{*} \operatorname{tg} \varphi$ " (8) existen dos cantidades desconocidas ( y $y$ ), se requiere obtener dos valores, como mínimo de esfuerzo normal y esfuerzo de corte para obtener una solución.

Como el esfuerzo cortante " $\tau$ " y el esfuerzo normal efectivo $\sigma_{\mathrm{n}}$ (ecuación 8) tienen el mismo significado dado la construcción del círculo de Mohr, en lugar de resolver una serie de ecuaciones simultáneas para c y para tg $\varphi$, es posible dibujar en un plano de ejes coordenados los valores de " $\tau$ " contra $\sigma_{n}$ para los diferentes ensayos (generalmente con " $\tau$ " como ordenadas), dibujar una línea a través del lugar geométrico de los puntos, y establecer la 
pendiente de la línea como el ángulo y la intersección con el eje " $\tau$ " como la cohesión c (Figura 6).

Para materiales no cohesivos, la cohesión debería ser cero por definición y la ecuación de Coulomb se convierte en:

$$
\tau=\sigma_{n}{ }^{*} \operatorname{tg} \varphi \ldots .(9)
$$

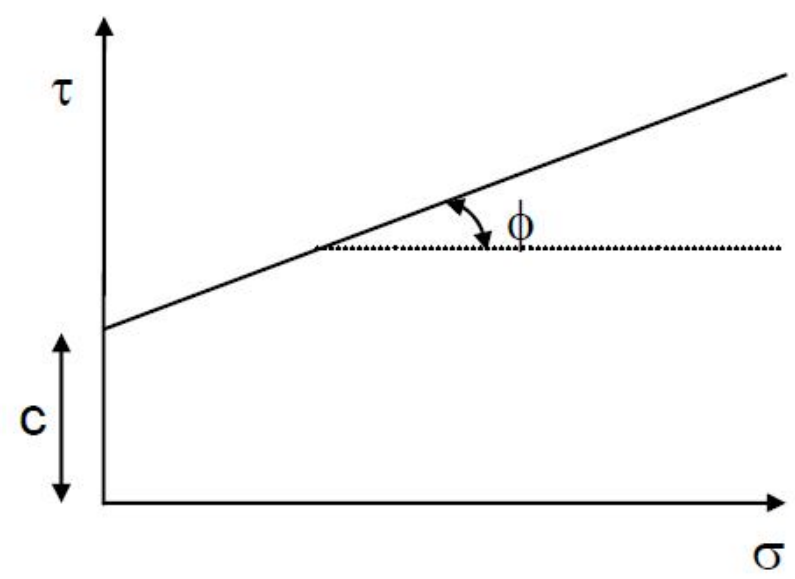

Figura 6: Recta de Coulomb.

De acuerdo a Sánchez-Girón (1996) la cohesión es la propiedad por la que se mantienen unidas entre sí las distintas partículas y agregados del suelo, distinguiéndose dos tipos de cohesión: a) cohesión molecular y b) cohesión superficial. La cohesión molecular se encuentra presente sólo en las arcillas y se debe a un balance entre las fuerzas de Coulomb (repulsivas) y las de Van der Waals (atractivas). Si de la resultante de ambas fuerzas predominan las primeras ocurre la repulsión (dispersión) y cuando lo hacen las últimas se origina una atracción (floculación). 
Los parámetros de Coulomb son considerablemente afectados por la humedad del material. Arvidsson y Keller (2011) en ensayos de campo realizados sobre 15 diferentes sitios, encuentran una fuerte correlación entre el contenido de humedad y la dureza del suelo, donde la cohesión y la resistencia a la penetración (medida con penetrómetro) decrecieron rápidamente con el incremento de la humedad del suelo. El efecto de la succión desaparece al llegar al estado seco, ocurriendo lo mismo al llegar al estado de saturación. Esto implica la existencia de un cierto máximo intermedio que se puede producir para grados de saturación bajos. Este aspecto ha sido señalado por Lloret y Alonso (1985) y comprobado experimentalmente por Escario y Sáez (1986) realizando ensayos de corte directo con succión controlada.

En el presente trabajo se determinarán y compararán los valores de cohesión y ángulo de rozamiento interno entre suelos tratados con soluciones con diferentes grados de sodicidad.

\subsection{Métodos e instrumentos de medición de las} propiedades mecánicas de los suelos.

Una útil y profunda revisión de los métodos de medición de la resistencia mecánica de los suelos es realizada por Okello (1991) quien brindó un panorama de los sistemas disponibles, concluyendo que los más apropiados en agricultura son el penetrómetro de cono y el bevámetro, esencialmente por la 
posibilidad de su uso en el campo. De hecho, uno de los métodos tradicionalmente más empleados en la medición rápida y sintética de la capacidad portante y tractiva del suelo y, por ende, de su susceptibilidad a la compactación y degradación física es el uso del penetrómetro directamente "in situ".

Jorajuría et al. (1997) emplearon la resistencia a la penetración en campo y la densidad a una profundidad de $60 \mathrm{~cm}$ con el fin de comparar los efectos del pasaje de tractores de diferente peso a paridad de presión de contacto neumático / suelo y para un diverso número de pasajes sobre una pradera artificial en Argentina.

Este tipo de instrumento brinda útiles indicaciones prácticas, pero no permite, por si mismo, inducciones científicamente fundadas sobre las reales causas de las diferencias relevadas a nivel físico y estructural, ni explicaciones de los procesos de alteración que tienen lugar en correspondencia con el tráfico y la labranza. Un ejemplo del uso del bevámetro es el de Sánchez-Hermosilla et al. (1999), quienes pusieron a punto un instrumento combinado para la medición de corte superficial torsional y de penetración de planchas de diferente diámetro, acoplable al tractor. La unión de las dos modalidades de prueba en la misma máquina permite obtener indicaciones sobre la resistencia del estrato superficial del suelo a cargas normales y tangenciales.

La metodología de laboratorio seguramente más exacta y completa para la determinación de las propiedades mecánicas de 
suelos es el test triaxial. Utilizado también en la ingeniería civil, el test triaxial permite el control de todos los esfuerzos actuantes en la masa del suelo analizado. Para lograr esto, la muestra es introducida en una membrana sumergida en líquido a presión controlada, que permite cambiar los valores de los esfuerzos principales de confinamiento. Uno de los ejemplos más avanzados es ofrecido por Wulfsohn et al. (1998) quienes han puesto a punto un sistema de medida individual de la presión de la fase líquida y de la fase gaseosa en la muestra de suelo durante el desarrollo del método, como así también la valoración distinta de la variación de volumen de la muestra en sus componentes líquida y gaseosa.

Un método de relativamente práctica aplicación en laboratorio es el de Compresión Uniaxial Confinada, empleado esencialmente en valorar la resistencia o vulnerabilidad a la compactación, y en consecuencia, a la traficabilidad. El resultado de la utilización de dicho método es la obtención de la Curva de Compresión. La compresión, (como se mencionara anteriormente) puede ser definida como una disminución en la relación porosa. Un criterio sobre ésta última basado en éste método fue propuesto por Baldi et al. (1990), integrando las indicaciones de las curvas de compresión a diferentes valores de humedad con modelos meteorológicos previsionales con el fin de determinar los días útiles y tiempos de espera para las operaciones culturales en condiciones óptimas. 
Existen también métodos que consideran el rol de la estructura en el interior del suelo, poniendo especial atención sobre las propiedades mecánicas de los agregados singulares. Watts et al. (1996) se han ocupado de la relación entre estabilidad estructural y aplicación de energía impuesta por la elaboración del suelo, siempre a nivel de agregados individuales. Así han desarrollado un simple y específico sistema mecánico que permite aplicar diversos niveles de energía a los agregados naturales, consistente en repetidos impactos trámite una masa.

Czarnes et al. (1999) proponen un método simplificado para el estudio del comportamiento mecánico de agregados artificiales remodelados en forma esférica, representativos del horizonte superficial, investigando el comportamiento de plasticidad, resistencia y rotura de los agregados a diferentes potenciales hídricos y al variar el contenido de arcilla.

En el ámbito de los métodos de prueba de laboratorio que hacen referencia a las deformaciones y a la falla por esfuerzo de corte, las máquinas de corte tangencial poseen amplio uso, incluso para el estudio de las propiedades de los suelos agrícolas.

Las principales ventajas de éste tipo de equipo son que puede ser utilizado tanto para el corte como la compresión de las muestras. Además, la medida del esfuerzo de corte, del desplazamiento horizontal y vertical, lo convierten en un test muy completo y cuyo uso es totalmente compatible con la obtención de importantes parámetros de la mecánica del suelo a través de la Teoría del Estado Crítico y Ley de Coulomb. Blunden et al. (1993) 
subrayaron la importancia de la velocidad de actuación de la fuerza de corte, ya que aquellas alcanzadas en pruebas de laboratorio resultaron diversas con respecto a las que realmente se desarrollan en el campo. De ésta manera, estos autores, propusieron una máquina de corte directo de alta velocidad de actuación, obtenida mediante el impulso de un pistón neumático, capaz de desarrollar una velocidad de $1 \mathrm{~m} / \mathrm{s}$ y de medir simultáneamente la deformación vertical de la muestra. La caja de corte simple es particularmente usada en la investigación del comportamiento del suelo durante la ocurrencia de falla (O'Sullivan et al., 1999). Este tipo de equipo es utilizado para la medición de las propiedades mecánicas de horizontes superficiales o antrópicos agrícolas por Kirby $\left(1991^{\mathrm{a}}, 1991^{\mathrm{b}}\right)$, Spugnoli et al. (2002), Durán Garcia (2002). Las principales ventajas de éste tipo de equipo, son que puede ser utilizado tanto para el corte como la compresión de las muestras, y que, como demostrara Kirby $\left(1991^{\circ}\right)$ a través de la medida del esfuerzo de corte, el desplazamiento horizontal y vertical, es un test muy completo y cuyo uso es totalmente compatible con la obtención de importantes parámetros de la mecánica del suelo a través de la Teoría del Estado Crítico y Ley de Coulomb. 
El diagrama esfuerzo-deformación que se obtiene de una muestra de suelo sometida a esfuerzo de corte puede parecerse a una de las curvas de la (Figura 7) en dependencia de las condiciones del suelo.

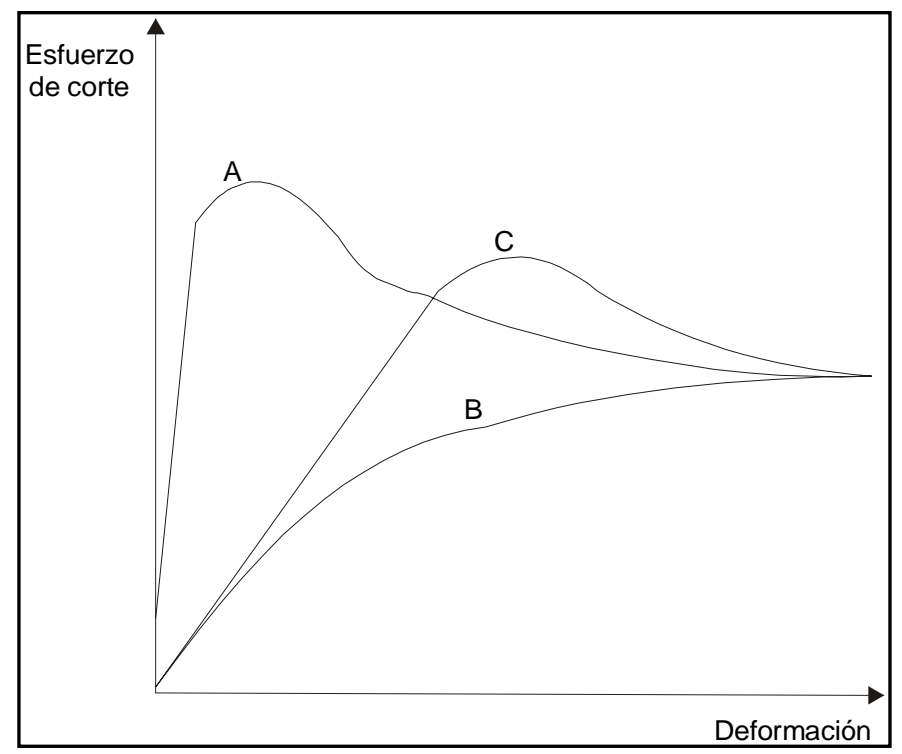

Figura 7: Diagrama de esfuerzo de corte-deformación en tres condiciones: A: cementado, B: Suelto, C: Denso

Un suelo altamente cementado tendrá un punto bien definido de falla, como se observa en la curva A. Los suelos sueltos pueden carecer de un punto de falla definido y el esfuerzo máximo incrementarse exponencialmente con la deformación que alcanza algún valor máximo cómo se observa en la curva B. La curva $C$ es para un suelo que está compactado pero no cementado. La resistencia del suelo se refiere al valor del 
esfuerzo de cizalla sobre un plano dentro de la muestra del suelo donde la falla se ha presentado por ruptura o agrietamiento.

Para las curvas $A$ y $C$ este punto está bien definido pero no para la curva $B$, donde no se distingue la falla del suelo. En el caso de la curva $\mathrm{B}$, se considera que la falla tiene lugar por cedencia o flujo plástico y, en este caso, se toma como resistencia al corte el valor asintótico.

Estas curvas deformación-esfuerzo de corte son para una tensión normal determinada sobre la muestra. Si la tensión normal cambia, el valor del esfuerzo de cizalla máximo también cambiará y consecuentemente el diagrama cambiará.

Un incremento en la tensión normal causaría un incremento del esfuerzo de corte máximo. Por tal razón la resistencia al corte es una función de la tensión normal en el plano de falla. 


\section{OBJETIVOS}

Objetivo General:

- Conocer los cambios que ocasiona el agua salino-sódica en las propiedades mecánicas de suelos agrícolas.

Objetivos Particulares:

- Evaluar los cambios de las propiedades mecánicas de suelos que han sufrido una salinización-sodificación artificial, simulando los efectos de una irrigación con agua con alto contenido de sodio.

- Inferir aspectos vinculados a la traficabilidad y labranza de suelos sodificados a través del uso de la Mecánica de CoulombMohr y del Estado Crítico. 


\section{HIPÓTESIS}

- El sodio disminuye la vulnerabilidad a la compresión de los suelos.

- El sodio aumenta la resistencia a la rotura de los agregados independientemente de su tamaño.

- La alteración química del suelo provoca desplazamientos en las líneas de Coulomb y de Estado Crítico. 


\section{MATERIALES Y MÉTODOS}

\subsection{Suelos}

\subsubsection{Suelos utilizados en las pruebas de compresión y}

corte y resistencia a rotura de agregados individuales.

Se utilizaron muestras reconstituidas en laboratorio de dos suelos provenientes de distintas localidades de Italia. Dichos suelos fueron sometidos a tratamientos de sodificación artificial, simulando los efectos de una irrigación con agua con alto contenido de sales de sodio.

La clasificación taxonómica de los suelos se detalla en la Tabla 1.

Las dos series de suelos utilizadas pertenecen a dos tipos de materiales pedológicos no salinos, ricos en materiales arcillosos. Uno más rico en materiales esmectíticos, pobre en sesquióxidos de hierro y aluminio y no calcáreo (Ozzano). El otro más caolinítico, calcáreo y rico en sesquióxidos (Cardone).

Ambos suelos se diferencian por algunas características derivadas de su naturaleza pedológica, determinadas por su proveniencia geográfica.

La serie Montefalcone (OZ), proveniente de la zona Emiliana, se caracteriza por la presencia de arcillas gris amarillentas, próximas a la clase de colores 2,5Y. La serie Cutino 
(CD) del área Barese es de tipo laterítico, de color rojo, y próximo a la clase de colores $5-7,5 Y$ R.

Tabla 1: Clasificación Taxonómica y origen de ambos suelos (Soil Taxonomy, 1994).

\begin{tabular}{|c|c|c|c|c|}
\hline $\begin{array}{c}\text { Suelo } \\
\text { (simbología) }\end{array}$ & $\begin{array}{c}\text { Clasificación } \\
\text { USDA }\end{array}$ & Serie & $\begin{array}{l}\text { Horizonte } \\
\text { estudiado }\end{array}$ & Proveniencia \\
\hline $\begin{array}{l}\text { Cardone } \\
\text { (CD) }\end{array}$ & $\begin{array}{c}\text { Pachic } \\
\text { Haploxeralf } \\
\text { (fine, mixed } \\
\text { thermic) }\end{array}$ & Cutino & $\begin{array}{c}\text { Ap, mapa } \\
\text { de suelos } \\
\text { Apulia }\end{array}$ & $\begin{array}{c}\text { Explotación } \\
\text { asociada con } \\
\text { la Facoltá di } \\
\text { Agraria - } \\
\text { Universitá di } \\
\text { Bari }\end{array}$ \\
\hline $\begin{array}{c}\text { Ozzano } \\
\text { (Oz) }\end{array}$ & $\begin{array}{c}\text { Udertic } \\
\text { Ustochrepts } \\
\text { (fine, mixed } \\
\text { mesic) }\end{array}$ & Montefalcone & $\begin{array}{c}\text { Ap, } \\
\text { mapa de } \\
\text { suelos } \\
\text { Emilia- } \\
\text { Romagna }\end{array}$ & $\begin{array}{c}\text { Campo } \\
\text { experimental } \\
\text { de la Facoltá } \\
\text { di Agraria - } \\
\text { Universitá di } \\
\text { Bologna }\end{array}$ \\
\hline
\end{tabular}

Desde el punto de vista químico, la condición original de ambos suelos es de $\mathrm{pH}$ neutro. CD presenta bajo contenido de Carbonatos, confirmado por su naturaleza de Alfisol con horizontes superficiales descarbonizados, mientras que OZ es medianamente bien dotado según la clasificación de Giardini (1992). En el caso de OZ es particularmente notoria su baja presencia de $\mathrm{Na}^{+}$en el complejo de intercambio. Todos los 
análisis químicos fueron realizados por el Laboratorio Neotron de acuerdo a los procedimientos aprobados por la Italian Society of Soil Sience (Violante, 2000).

En la Tabla 2 se observan los resultados analíticos preliminares para ambos suelos.

Tabla 2: Composición y características químicas de los suelos evaluados.

\begin{tabular}{|c|c|c|c|}
\hline Análisis & Unidad & Cardone & Ozzano \\
\hline C.I.C & $\begin{array}{c}\text { meq/100g } \\
\text { secos }\end{array}$ & 31,68 & 29,54 \\
\hline Materia Orgánica & $\mathrm{g} / \mathrm{kg}$ & 33,90 & 15,93 \\
\hline Carbonatos & $\mathrm{g} / 100 \mathrm{~g}$ secos & 0,50 & 3,90 \\
\hline $\mathrm{CE}_{25^{\circ} \mathrm{C}}$ & $\mathrm{mS} / \mathrm{cm}$ & 0,30 & 0,03 \\
\hline $\mathrm{Na}^{+}$ & $\begin{array}{c}\text { meq/100g } \\
\text { secos }\end{array}$ & 0,19 & 0,053 \\
\hline $\mathrm{Na}^{+} / \mathrm{C} . \mathrm{I} . \mathrm{C}$ & $\%$ & 0,60 & 0,179 \\
\hline $\mathrm{Ca}^{++}$ & $\begin{array}{c}\text { meq/100g } \\
\text { secos }\end{array}$ & 26,30 & 26,06 \\
\hline $\mathrm{Ca}^{++} / \mathrm{C} . \mathrm{I} . \mathrm{C}$ & $\%$ & 83,00 & 88,21 \\
\hline $\mathrm{pH}$ en $\mathrm{H}_{2} \mathrm{O}$ & $-\log \left[\mathrm{H}^{+}\right]$ & 7,10 & 7,30 \\
\hline Nitrógeno Total (N) & $\mathrm{g} / \mathrm{kg} \mathrm{seco}$ & 1,80 & 0,739 \\
\hline Fósforo Total $(\mathrm{P})$ & $\mathrm{g} / \mathrm{kg} \mathrm{seco}$ & 0,882 & 0,611 \\
\hline Potasio de intercambio $\left(\mathrm{K}^{+}\right)$ & $\begin{array}{c}\mathrm{meq} / 100 \mathrm{~g} \\
\text { seco }\end{array}$ & 1,58 & 0,411 \\
\hline
\end{tabular}




\begin{tabular}{|c|c|c|c|}
\hline $\begin{array}{l}\text { Magnesio de intercambio } \\
\qquad(\mathrm{Mg})\end{array}$ & $\begin{array}{l}\text { meq } / 100 \mathrm{~g} \\
\text { seco }\end{array}$ & 1,36 & 2,94 \\
\hline Calcio Total (Ca) & $\mathrm{g} / \mathrm{kg} \mathrm{seco}$ & 12,04 & 25,85 \\
\hline Sodio Total $(\mathrm{Na})$ & $\mathrm{g} / \mathrm{kg} \mathrm{seco}$ & 3,74 & 7,11 \\
\hline Potasio Total (K) & $\mathrm{g} / \mathrm{kg} \mathrm{seco}$ & 19,33 & 12,34 \\
\hline Magnesio Total (Mg) & $\mathrm{g} / \mathrm{kg} \mathrm{seco}$ & 6,85 & 7,23 \\
\hline Hierro orgánico (Fe) & $\mathrm{g} / \mathrm{kg} \mathrm{seco}$ & 0,736 & 0,406 \\
\hline $\begin{array}{l}\text { Óxido de Hierro libre (como } \\
\qquad \mathrm{Fe})\end{array}$ & $\mathrm{g} / \mathrm{kg} \mathrm{seco}$ & 0,147 & 0,270 \\
\hline Aluminio orgánico (Al) & $\mathrm{g} / \mathrm{kg} \mathrm{seco}$ & 0,458 & 0,228 \\
\hline $\begin{array}{l}\text { Óxido de Aluminio libre } \\
\text { (como } \mathrm{Al} \text { ) }\end{array}$ & $\mathrm{g} / \mathrm{kg} \mathrm{seco}$ & 0,344 & 0,107 \\
\hline K/C.I.C. & $\%$ & 5,0 & 1,39 \\
\hline Mg/C.I.C. & $\%$ & 4,3 & 9,96 \\
\hline Azufre(como $\left.\mathrm{SO}_{4}^{--}\right)$ & $\mathrm{mg} / \mathrm{kg} \mathrm{seco}$ & 1464,81 & 673,09 \\
\hline
\end{tabular}

La mineralogía de las arcillas de los suelos Cardone y Ozzano se observa en la Tabla 3.

Tabla 3: Mineralogía de las arcillas.

\begin{tabular}{c|c}
\hline \hline Suelo & Minerales de arcilla \\
\hline Cardone (CD) & Illita, Caolinita \\
\hline Ozzano (OZ) & Vermiculita, Illita, Esmectita, \\
& Caolinita \\
\hline \hline
\end{tabular}


La diferencia más importante entre ambos suelos es la presencia de vermiculita y esmectita en Ozzano. La vermiculita es un filosilicato de tipo 2:1 con presencia de $\mathrm{Mg}$ en el espacio interestrato y caracterizada por una elevada superficie específica de aproximadamente $600-800 \mathrm{~m}^{2} / \mathrm{g}$, que aumenta las dimensiones del complejo de intercambio y por ende la actividad químico física del suelo. La esmectita presenta un comportamiento similar a la vermiculita. La illita presenta superficies de $70-120 \mathrm{~m}^{2} / \mathrm{g}$, mientras la caolinita, notoriamente no expansible, presenta valores del orden de $10-20 \mathrm{~m}^{2} / \mathrm{g}$.

Textura:

A continuación se detallan los porcentajes de las tres fracciones granulométricas (arena, limo y arcilla) de ambos suelos de acuerdo a USDA e ISSS (Tabla 4) y su clase textural de acuerdo a USDA (Thompson y Troeh, 1982) (Tabla 5).

Tabla 4: Fracciones granulométricas de Cardone y Ozzano según USDA e ISSS.

Cardone (CD)

\begin{tabular}{c|c|c|c|c}
\hline \hline $\begin{array}{c}\text { Clase } \\
\text { granular }\end{array}$ & USDA & $\begin{array}{c}\% \\
\text { Textura }\end{array}$ & ISSS & $\begin{array}{c}\% \\
\text { Textura }\end{array}$ \\
\hline Arena Total & $2-0,05 \mathrm{~mm}$ & 8,46 & $2-0,02 \mathrm{~mm}$ & 20,94 \\
\hline Limo & $\begin{array}{c}0,05- \\
0,002 \mathrm{~mm}\end{array}$ & 56,48 & $\begin{array}{c}0,02- \\
0,002 \mathrm{~mm}\end{array}$ & 44,00 \\
\hline Arcilla & $<0,002 \mathrm{~mm}$ & 35,06 & $<0,002 \mathrm{~mm}$ & 35,06 \\
\hline \hline
\end{tabular}


Ozzano (OZ)

\begin{tabular}{c|c|c|c|c}
\hline $\begin{array}{c}\text { Clase } \\
\text { granular }\end{array}$ & USDA & $\begin{array}{c}\% \\
\text { Textura }\end{array}$ & ISSS & $\begin{array}{c}\% \\
\text { Textura }\end{array}$ \\
\hline Arena Total & $2-0,05 \mathrm{~mm}$ & 13,69 & $2-0,02 \mathrm{~mm}$ & 30,27 \\
\hline Limo & $\begin{array}{c}0,05- \\
0,002 \mathrm{~mm}\end{array}$ & 47,68 & $\begin{array}{c}0,02- \\
0,002 \mathrm{~mm}\end{array}$ & 33,10 \\
\hline Arcilla & $<0,002 \mathrm{~mm}$ & 36,63 & $<0,002 \mathrm{~mm}$ & 36,63 \\
\hline
\end{tabular}

Tabla 5: Clasificación Textural de ambos suelos.

\begin{tabular}{c|c|c}
\hline Suelo & USDA & ISSS \\
Cardone (CD) & Franco arcillo - limoso & Arcillo - limoso \\
Ozzano (OZ) & Franco arcillo - limoso & Arcilla poco densa \\
\hline
\end{tabular}

\subsubsection{Procedimiento utilizado en la sodificación de los}

\section{suelos.}

Ambos suelos (Cardone y Ozzano) fueron homogéneamente tratados en el Dipartimento di Agronomia di Bologna con dos soluciones de diferente R.A.S (Relación de Adsorción de Sodio). Dichas soluciones se obtuvieron a partir de la disolución de $\mathrm{CINa}$ y $\mathrm{Cl}_{2} \mathrm{Ca}$ en agua destilada.

Se sumergieron $15 \mathrm{~kg}$ de cada suelo en piletas preparadas con cada una de las 2 soluciones, mezclando y dejando en contacto por 24 horas. A posteriori, el líquido sobrenadante fue 
decantado y reemplazado con igual volumen de la misma solución. La operación fue repetida 3 veces (Patruno et al., 2002).

A continuación el suelo fue dejado drenar en estratos de aproximadamente $5 \mathrm{~cm}$ sobre tela apoyada en arena. Finalizados los tratamientos se realizó la determinación de $\mathrm{pH}$, conductividad eléctrica del extracto saturado, RAS y PSI (Tabla 6:).

Producto de éstos procedimientos se obtuvieron 2 tratamientos llamados A y $B$, cuya diferencia fundamental fue el mayor contenido de $\mathrm{Na}^{+}$en el complejo de intercambio de $\mathrm{A}$ respecto al tratamiento $\mathrm{B}$.

Tabla 6: pH, CE, RAS y PSI de los suelos tratados

\begin{tabular}{c|c|c|c|c}
\hline & $\mathrm{pH}$ & $\mathrm{CE}$ & $\begin{array}{c}\text { RAS (del extracto } \\
\text { saturado) }\end{array}$ & $\begin{array}{c}\text { PSI (\% de Na de } \\
\text { Intercambio) }\end{array}$ \\
\hline CDA & 7,80 & 0,918 & 4,34 & 4,83 \\
\hline CDB & 7,1 & 0,30 & 1,44 & 1,64 \\
\hline OZA & 8,09 & 0,982 & 9,85 & 5,21 \\
\hline OZB & 7,3 & 1,37 & 2,86 & 1,26 \\
\hline
\end{tabular}

La ventaja de trabajar con suelos sodificados artificialmente radica en obtener suelos con diferente grado de Sodicidad conteniendo idénticas proporciones de arena - limo y arcilla, materia orgánica, tipo de materiales de arcillas, etc. 


\subsubsection{Suelo utilizado en las pruebas de Brazilian Test.}

Se usaron muestras reconstituidas en laboratorio de un suelo denominado Cadriano. Dicho suelo fue sometido a tratamiento de sodificación artificial, simulando los efectos de una irrigación con agua con alto contenido de sodio, al igual que en los suelos utilizados en las pruebas de corte. Como resultado se obtuvo un tratamiento con mayor contenido de $\mathrm{Na}$ en solución (COA) y por otro lado un tratamiento con menor contenido de $\mathrm{Na}$ en solución (COB). Los análisis químicos fueron realizados por el Laboratorio Neotron de acuerdo a los procedimientos aprobados por la Italian Society of Soil Sience (Violante, 2000).

La clasificación taxonómica de Cadriano (serie Cadriano) es Udic Ustochrepts fine, mixed mesic (Soil Taxonomy, 1994) y Haplic Calcisol (FAO, 1988). En la Tabla 8 se observan los resultados analíticos preliminares de Cadriano.

A continuación se detallan los porcentajes de las tres fracciones granulométricas (arena, limo y arcilla) de Cadriano (Tabla 7). La textura resultante es Franco arcillo - limoso (USDA).

Tabla 7: Fracciones granulométricas de Cadriano según USDA.

\begin{tabular}{c|c|c}
\hline \hline \multicolumn{3}{|c}{ Cadriano (CO) } \\
\hline \hline Clase granular & USDA & $\%$ Textura \\
\hline Arena Total & $2-0,05 \mathrm{~mm}$ & 10,93 \\
\hline Limo & $0,05-0,002 \mathrm{~mm}$ & 50,20 \\
\hline Arcilla & $<0,002 \mathrm{~mm}$ & 38,37 \\
\hline \hline
\end{tabular}


Las arcillas que contiene Cadriano son, principalmente, Illita (59\%) y Caolinita (<10\%) que como se comentó anteriormente para los suelos Ozzano y Cardone, poseen baja superficie específica (illita: $70-120 \mathrm{~m}^{2} / \mathrm{g}$, caolinita: $10-20 \mathrm{~m}^{2} / \mathrm{g}$ ).

Tabla 8: Composición y características químicas de Cadriano.

\begin{tabular}{c|c|c}
\hline Análisis & Unidad & Cadriano \\
\hline $\mathrm{pH}$ (estracto saturado 1:5) & & 6,60 \\
\hline $\mathrm{C} . \mathrm{I.C}$ & $\mathrm{meq} / 100 \mathrm{~g}$ secos & 15,35 \\
\hline Materia Orgánica & $\mathrm{g} / \mathrm{kg}$ & 16,0 \\
\hline $\mathrm{Na}^{+}$ & $\mathrm{meq} / 100 \mathrm{~g}$ secos & 0,123 \\
\hline $\mathrm{Na}^{+} / \mathrm{C} . \mathrm{I} . \mathrm{C}$ & $\%$ & 0,8 \\
\hline $\mathrm{Ca}^{++}$ & $\mathrm{meq} / 100 \mathrm{~g} \mathrm{secos}$ & 12,18 \\
\hline $\mathrm{Ca}^{++} / \mathrm{C} . \mathrm{I.C}$ & $\%$ & 79,35 \\
\hline${\mathrm{pH} \text { en } \mathrm{H}_{2} \mathrm{O}}_{\text {Potasio de intercambio }\left(\mathrm{K}^{+}\right)}$ & -log $\left[\mathrm{H}^{+}\right]$ & 6,6 \\
\hline Magnesio de intercambio $/ 100 \mathrm{~g} \mathrm{seco}$ & 0,29 \\
\hline (Mg) & $\mathrm{meq} / 100 \mathrm{~g} \mathrm{seco}$ & 1,2 \\
\hline $\mathrm{K} / \mathrm{C} . \mathrm{I.C}$. & $\%$ & 1,89 \\
\hline $\mathrm{Mg} / \mathrm{C} . \mathrm{I.C}$. & $\%$ & 7,82 \\
\hline
\end{tabular}

Finalizados los tratamientos de sodificación se realizó la determinación del la RAS y el PSI para ambos tratamientos (COA y COB) (Tabla 9). 
Tabla 9: RAS y PSI para ambos tratamientos de Cadriano (COA y $\mathrm{COB})$.

\begin{tabular}{c|c|c}
\hline \hline & RAS (del extracto saturado) & PSI (\% de Na de Intercambio) \\
\hline COA & 5,26 & 3,11 \\
\hline COB & 0,18 & 0,123 \\
\hline
\end{tabular}

En todas las pruebas realizadas se consideró como "Testigo" al tratamiento B (con la aplicación de la solución con menor contenido de $\mathrm{Na}^{+}$). No se emplearon los suelos prístinos como testigos ya que los mismos no habían sido sometidos a la secuencia de baños y percolaciones que sí recibieron los tratamientos A y B. Al partirse de condiciones físico-mecánicas diferentes (derivadas de los tratamientos de baños y percolaciones), se imposibilitó la comparación del suelo prístino con el resto de los tratamientos ya que de encontrarse cualquier diferencia de comportamiento en las pruebas realizadas no podría ser adjudicada exclusivamente al efecto de la salinidad y/o sodicidad.

\subsection{Pruebas preliminares.}

\subsubsection{Pruebas de estabilidad de agregados en agua.}

Con el objetivo de realizar una primera y rápida observación sobre la existencia o no de diferencias en el comportamiento de los tratamientos en ambos suelos destinados 
a los ensayos de corte y compresión ( $C D$ y OZ), se realizaron dos tipos de pruebas, una de disgregación y una de dispersión. En ambas pruebas la evaluación se realizó de forma visual.

a).Prueba de disgregación.

Se introdujeron en dos cajas de petri conteniendo agua destilada, $2 \mathrm{~g}$ secos al aire de cada tratamiento y se los dejó en reposo sin aplicación de ninguna acción mecánica por un tiempo de 10 minutos.

b). Prueba de dispersión.

Se introdujeron $5 \mathrm{~g}$ secos al aire de cada tratamiento en recipientes de vidrio conteniendo agua destilada, dejándolos luego en reposo por 5 horas.

\subsubsection{Pruebas de expansión - contracción.}

Con el objetivo de evaluar la acción del ion $\mathrm{Na}^{+}$en la capacidad expansiva de un suelo agrícola se efectuó una prueba de expansión - contracción del tratamiento COA (alto contenido de $\mathrm{Na}$ ) en contraposición con el tratamiento $\mathrm{COB}$ (menos sodificado).

Para éste ensayo una porción de ambos materiales fue colocada en estufa a $105^{\circ} \mathrm{C}$ durante $48 \mathrm{~h}$ para la determinación de su contenido hídrico. El resto del material fue tamizado utilizándose la fracción de agregados menor a 0,5 mm.

Ambos tratamientos fueron colocados en contenedores (tortas) y sometidos a un ciclo de humidificación - desecación al 
aire hasta alcanzar, aproximadamente, la humedad inicial. Se colocó una masa de $660 \mathrm{~g}$ de suelo seco al aire por torta y tratamiento.

La determinación de la expansión - contracción se realizó a través de la medición de altura de la torta en contraste con los bordes del contenedor mediante el uso de un calibre. Se efectuaron un total de 10 mediciones de altura en diferentes puntos de la torta.

La medición del volumen de las tortas se realizó en tres momentos: al realizarse las tortas (momento 0), capacidad de campo y secado al aire. Los diferentes contenidos hídricos fueron calculados mediante método gravimétrico.

\subsection{Pruebas de resistencia a rotura de agregados}

\section{individuales.}

Estas pruebas fueron realizadas con el suelo Ozzano, el cual fue clasificado en tres clases granulométricas mediante tamizado obteniéndose las siguientes Clases de dimensiones de agregados:

I. agregados de $5-3,36 \mathrm{~mm}$ de diámetro.

II. agregados de 3,36-2 $\mathrm{mm}$ de diámetro.

III. agregados de $2-0,5 \mathrm{~mm}$ de diámetro.

Fueron sometidos a rotura 20 agregados de cada una de las clases granulométricas I, II y III obtenidas por tamizado de ambos tratamientos (OZA y OZB). 
La Resistencia a Tracción de un suelo es el valor de tensión tractiva que provoca su rotura (Hillel, 1998)(Figura 8).

Cada uno de los agregados fue pesado y colocado sobre un plato que se elevó hasta alcanzar un plato superior empujado por un pistón accionado por un motor eléctrico (Figura 9). El plato superior se encontraba conectado a una celda de carga utilizada para medir la fuerza $(F)$ de rotura (Utomo y Dexter, 1981; Barzegar et al., 1995).

La Fuerza de Rotura se determinó mediante una celda de carga TEKKAL SU/50 (FS: $50 \mathrm{Kg}$; Salida FE: $2 \mathrm{mV} / \mathrm{V}$; Alimentación: 10 V) (Figura 10 y Figura 11).

La metodología que se empleó para el cálculo de la Resistencia a Tracción $(Y)$, corresponde a aquella utilizada por Dexter y Kroesbergen (1985).

Se utilizaron las siguientes relaciones:

$$
\begin{aligned}
& Y=0,576 F^{\prime} / d^{2} . .(1) \\
& d=d_{m}\left(m / m_{0}\right)^{1 / 3} . .(2) \\
& d_{m}=\left(s_{1}+s_{2}\right) / 2 \ldots(3) \\
& m_{0}=(\Sigma m) / n \ldots . .(4)
\end{aligned}
$$

Donde $F$ ' es la fuerza polar de rotura (medida a través de la celda de carga) y $d$ es el diámetro esférico efectivo (ecuación $1) ; d_{m}$ es el diámetro medio de la clase de agregados correspondiente, $m$ representa el valor individual de masa del agregado y $m_{0}$ es la masa media de los agregados dentro de una misma clase (ecuación 2); $s_{1}$ y $s_{2}$ son el diámetro de la apertura 
de malla del tamiz superior e inferior utilizados en la formación de cada una de las clases de agregados (ecuación 3); $n$ es el número de agregados testeados por clase de agregados $(n=20)$ (ecuación 4).

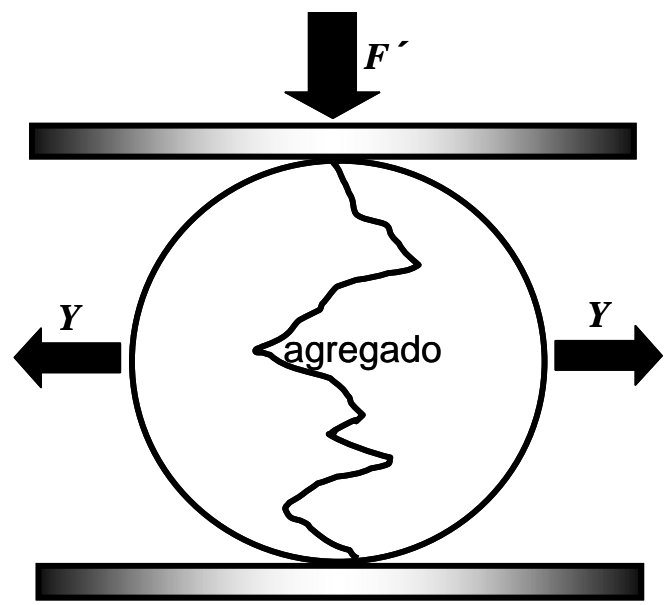

Figura 8: Determinación de la resistencia a la tracción de un agregado.

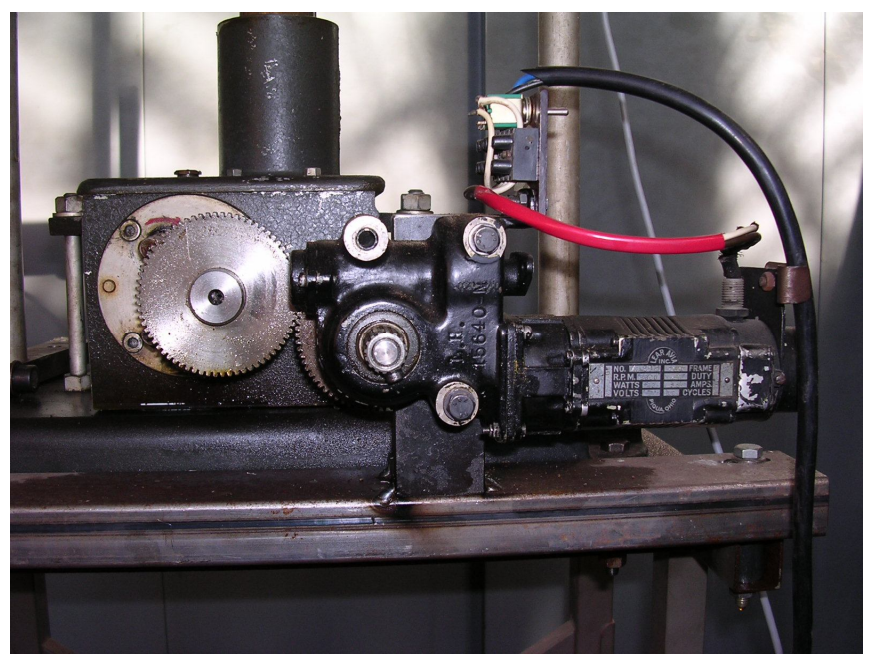

Figura 9: Motor y sistema de empuje del plato inferior 


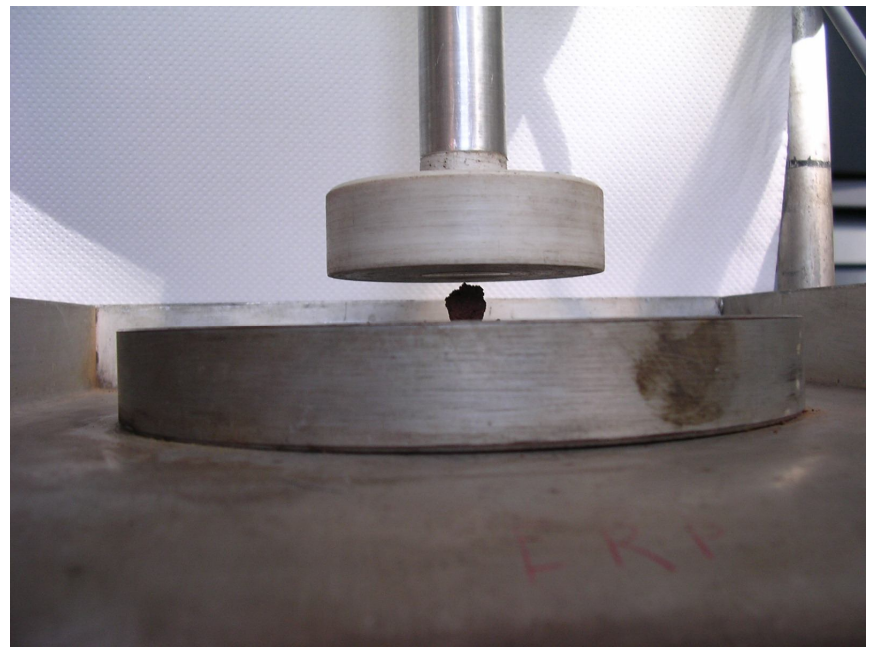

Figura 10: Platos utilizados para determinar la resistencia a la tracción

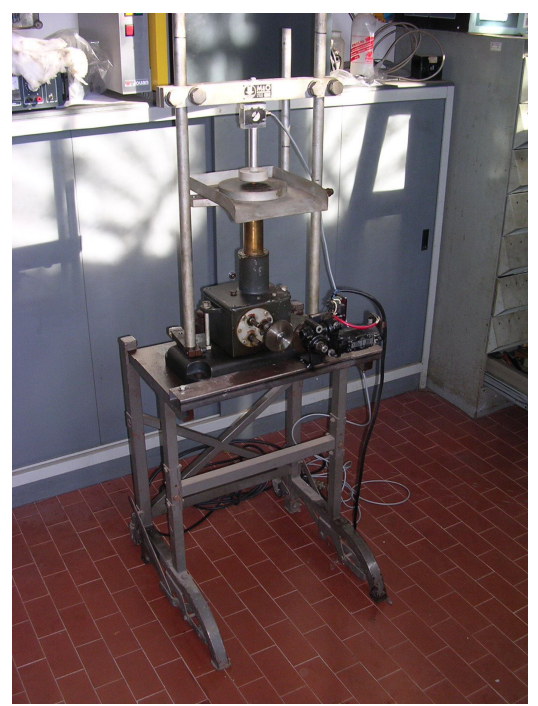

Figura 11: Vista general de la máquina utilizada para la determinación de la resistencia a tracción de agregados individuales. 


\subsection{Pruebas de resistencia a rotura mediante Brazilian}

$\underline{\text { Test. }}$

El Brazilian Test consiste en provocar la ruptura por aplastamiento de un cilindro colocado en posición horizontal entre dos platos. Las fuerzas actuantes en ambos polos del cilindro, resultan en la generación de dos fuerzas perpendiculares a la dirección de las primeras, que ejercen una tracción sobre las dos mitades del cilindro (Draghi et al., 2009). El aumento progresivo de la fuerza vertical produce un aumento proporcional de la tensión hasta el punto de la ruptura tangencial.

El aplastamiento de los cilindros se efectuó por el ascenso del plato inferior móvil. La fuerza de rotura se obtuvo con una celda de carga vinculada al plato superior fijo. Los valores de fuerza fueron registrados por un colector de datos.

La ecuación utilizada en el cálculo de la resistencia es la siguiente (10)(Kirkham et al., 1959):

$$
\sigma_{t}=2 F / \pi D h \ldots(10)
$$

Donde: $\sigma_{t}$ : Tensión de rotura; $F$ : Fuerza de Rotura; $D$ : Diámetro del cilindro; $h$ : Altura del cilindro.

Partiendo de la utilización del Brazilian Test se ha intentado evidenciar la existencia de diferencias en el comportamiento mecánico, y específicamente en la Resistencia a Tracción, de un suelo sodificado artificialmente en contraste a un testigo no 
sodificado. Para esto se utilizó la metodología seguida por Aluko y Koolen (2001), que consiste en la formación de cilindros de suelo húmedo seguido de su compactación, desecación y finalmente rotura mediante el Brazilian Test.

Ambos tratamientos del suelo Cadriano (CO) fueron tamizados y sus agregados clasificados en 5 clases granulométricas, calculando las proporciones porcentuales de cada una de las categorías con respecto al total.

Fueron realizadas 5 repeticiones de cada uno de los tratamientos denominados COA (mayor contenido de sodio) y COB (menor contenido de sodio).

Los cilindros (muestras) fueron formados respetando la composición granulométrica de COA (Tabla 10).

Tabla 10: Composición Granulométrica Porcentual de los tratamientos $\mathrm{COA}$ y $\mathrm{COB}$.

\begin{tabular}{cccc}
\hline Clase & $\begin{array}{c}\text { Diámetro de partículas } \\
(\mathrm{mm})\end{array}$ & $\begin{array}{c}\text { COA \% del } \\
\text { Total }\end{array}$ & $\begin{array}{c}\text { COB \% del } \\
\text { Total }\end{array}$ \\
\hline I & $>5$ & $0 \%$ & $37,94 \%$ \\
II & $5-3,35$ & $3 \%$ & $57,20 \%$ \\
III & $3,35-2$ & $44,5 \%$ & $2,66 \%$ \\
IV & $2-0,5$ & $52,5 \%$ & $0,64 \%$ \\
V & $<0,5$ & $0 \%$ & $1,56 \%$ \\
\hline
\end{tabular}

Se determinó la humedad de ambos tratamientos colocando muestras en estufa a $105{ }^{\circ} \mathrm{C}$. Se procedió a la medición de la densidad seca y porosidad inicial. 
La humedad inicial a $105^{\circ} \mathrm{C}$ de ambos materiales fue: COA: 1,94 $\%$; COB: 2, 91\%.

El suelo se humidificó al $20 \%$ de humedad final usando un pulverizador manual. Se mezcló manualmente y se colocó en atmósfera cerrada por $24 \mathrm{~h}$ para su homogeneización.

Este material fue introducido en cilindros de bronce de 51 $\mathrm{mm}$ de diámetro a razón de $80 \mathrm{~g}$ de suelo seco al aire, para cada uno de los cilindros de suelo formados. Luego de ésta operación los cilindros fueron compactados mediante la utilización de un pistón conectado a una celda de carga de $220 \mathrm{~kg}$, hasta lograr una reducción de la porosidad de aproximadamente un $25 \%$ respecto a la inicial registrando la magnitud de la presión necesaria para dicha compresión.

Después de la compactación los cilindros fueron dejados en atmósfera cerrada por $24 \mathrm{~h}$ para su homogeneización y transcurrido éste tiempo se les permitió el secado al aire por $72 \mathrm{~h}$ (Figura 12).

Terminada la desecación el material fue extraído de los cilindros de bronce y sometido a Brazilian Test empleando la misma máquina de compresión uniaxial utilizada en la rotura de agregados individuales con una celda de carga de $50 \mathrm{~kg}$. (Figura 11 y Figura 13). Se calculó luego la Tensión de Rotura (Tensile Strength $\mathrm{N} / \mathrm{cm}^{2}$ ). Después de la rotura, el material fue introducido en estufa a $105{ }^{\circ} \mathrm{C}$ y su humedad determinada por método gravimétrico. 


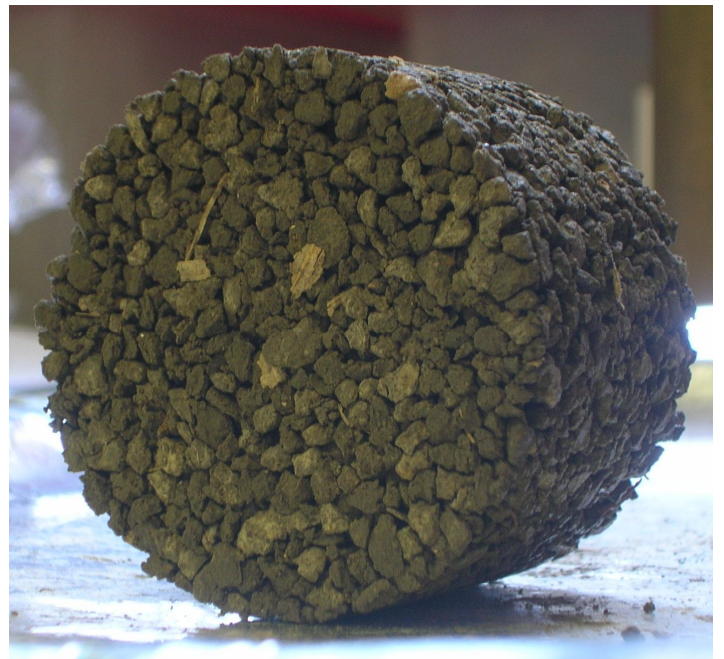

Figura 12: Cilindro listo para ser sometido a Brazilian Test.

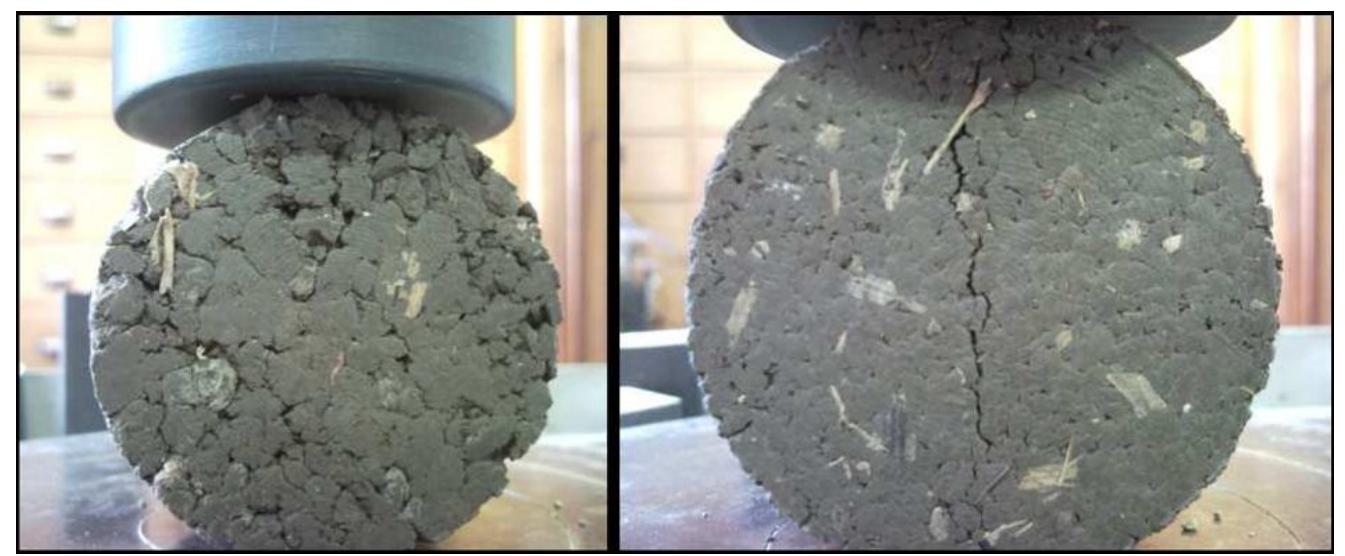

Figura 13: Cilindro colocado en la máquina (izquierda) y cilindro comprimido exhibiendo rotura (derecha). 


\subsection{Ensayos de Compresión y Corte.}

Estos ensayos se llevaron a cabo con los suelos Cardone y Ozzano. Se determinó la humedad inicial de los suelos introduciendo en estufa a $105^{\circ} \mathrm{C}$ por $48 \mathrm{~h}, 100 \mathrm{~g}$ secos al aire de cada uno de los tratamientos de ambos suelos en contenedores de aluminio. La humedad fue calculada por método gravimétrico.

Los ensayos de Compresión y Corte se realizaron al 18\% y $8 \%$ de humedad $(\mathrm{p} / \mathrm{p})$, en ambos tratamientos de Cardone y al $5 \%$ y $15 \%(p / p)$ para los tratamientos de Ozzano.

Para el caso de Cardone, el material de ambos tratamientos fue triturado con un molino específico para la molienda de suelos con el fin de disgregar los grandes terrones. El material resultante de ésta trituración fue tamizado con mallas de $2 \mathrm{~mm}$ y $0,5 \mathrm{~mm}$, seleccionando la fracción de suelo comprendida en ese rango (Figura 14 y Figura 15). El material mayor a $2 \mathrm{~mm}$ fue molido y tamizado nuevamente.

El suelo Ozzano fue clasificado en cuatro clases granulométricas mediante tamizado (de igual forma que en las pruebas de rotura de agregados individuales), obteniéndose las siguientes Clases de dimensiones de agregados (Figura 16):

I. agregados de $5-3,36 \mathrm{~mm}$ de diámetro.

II. agregados de $3,36-2 \mathrm{~mm}$ de diámetro.

III. agregados de $2-0,5 \mathrm{~mm}$ de diámetro.

IV. agregados menores de $0,5 \mathrm{~mm}$ de diámetro. 
Los agregados de un tamaño superior a la clase I fueron pasados por el molino para su trituración y vueltos a tamizar.

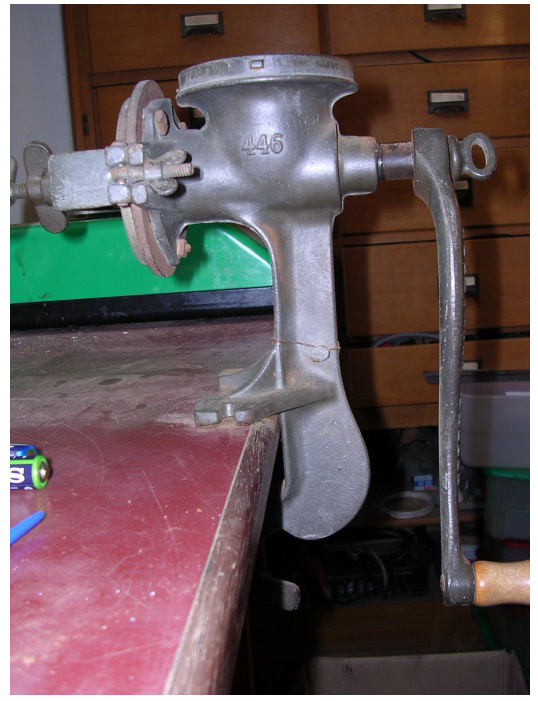

Figura 14: Molino utilizado en la molienda de los suelos (vista lateral).

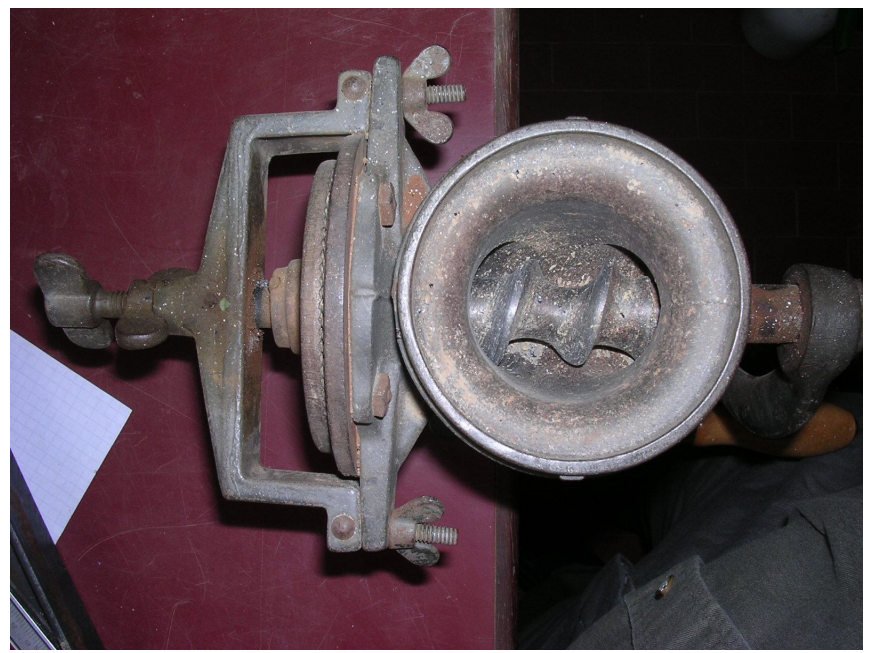

Figura 15: Molino utilizado en la molienda de los suelos (vista de planta). 


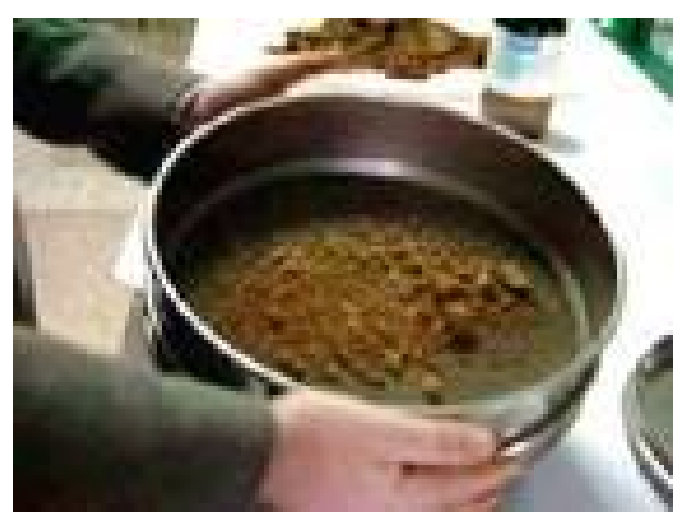

Figura 16: Tamizado del suelo.

\subsubsection{Ensayos con material sometido a ciclo} humectación - desecación.

Palancar (2007) luego de realizar ensayos preliminares rechazó la implementación de éste tipo de pruebas por requerir un procedimiento largo, lento y tedioso. Sin embargo se consideró que el efecto de humedecimiento - desecación puede resaltar el efecto de cambios de las condiciones mecánicas de los suelos sodificados favoreciendo la dispersión de las arcillas. Las muestras que fueron sometidas a compresión y corte (probetas) se extrajeron de contenedores (tortas) de $190 \mathrm{~mm}$ de diámetro donde previamente fue introducida una masa de $900 \mathrm{~g}$ de cada tratamiento de Cardone y $800 \mathrm{~g}$ de cada tratamiento de Ozzano de las clases granulométricas II y III. 
Preparación de las tortas:

Sobre contenedores de fondo perforado se colocaron papeles de filtro que permitieron el libre movimiento del agua pero no la lixiviación de arcillas dispersas fuera del contenedor. Sobre dicho papel se colocó la masa de suelo para su tratamiento.

Las tortas fueron humedecidas con agua destilada por capas suelo - agua en número de 3 por 2 respectivamente, utilizando para ello un pulverizador manual. Luego de la humectación se dejaron en reposo por 24 horas para su homogeneización. El volumen de agua utilizado fue el necesario para arribar al $20 \%$ de humedad p/p. Inmediatamente después, las tortas fueron sometidas a una breve compactación de 0,03 $\mathrm{kPa}$ por un tiempo de 10 minutos, tras lo cual fueron selladas con una película de nylon y dejadas en reposo por $24 \mathrm{~h}$.

Tanto la humidificación como la precompactación y el reposo, se realizaron con el objetivo de permitir una reorganización estructural del material (aunque ésta fuese limitada), y a su vez obtener muestras de partida homogéneas en cuanto a humedad y precompactación.

Transcurridas $24 \mathrm{~h}$ las muestras fueron llevadas a humedad de saturación. Este proceso se realizó por sumergimiento de las mismas en agua destilada, ya que el efecto deletéreo del $\mathrm{Na}^{+}$es más evidente con el uso de ésta que con el empleo de agua salobre. Para esto, se utilizaron contenedores en los que se depositaron las tortas y a los que se les agregó agua lentamente, hasta que por el fenómeno de vasos comunicantes y 
capilaridad, las muestras se vieron completamente saturadas. El sumergimiento se realizó de ésta manera con el objetivo de no provocar una disgregación forzada por el efecto del rápido aumento de la presión del aire dentro de los poros de los agregados (Rengasamy y Olsson, 1991).

Se mantuvo ésta situación por un tiempo de 30' para conseguir la evacuación total de aire y que se verificaran los fenómenos de disgregación y dispersión por efecto del sodio.

Luego de esto, la muestra se dejó percolar durante $24 \mathrm{~h}$ y posteriormente se procedió a introducirlas en estufa a $45^{\circ} \mathrm{C}$ hasta arribar a la humedad de $8 \%$ y $18 \%$ para Cardone y $15 \%$ para Ozzano (Figura 17).

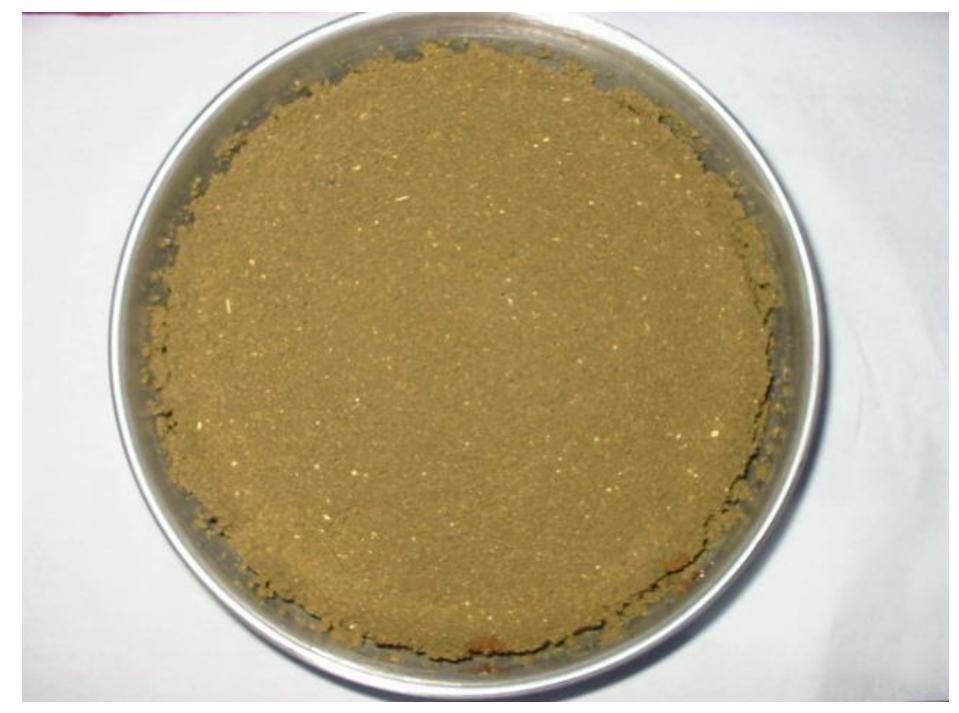

Figura 17: Torta de donde eran extraídas las probetas 
Alcanzada la humedad objetivo, las tortas fueron extraídas de la estufa y selladas con película de nylon por $24 \mathrm{~h}$ con el objetivo de lograr la homogeneización de la humedad ya que secadas a estufa las muestras tienden a perder mayor cantidad de agua por la superficie, generándose un gradiente vertical de humedad en la masa de suelo.

Las muestras (probetas) se extrajeron por medio de un cilindro con uno de sus bordes filoso a modo de saca bocados. Dicho cilindro poseía el mismo diámetro interno que la caja de corte directo (Figura 18).

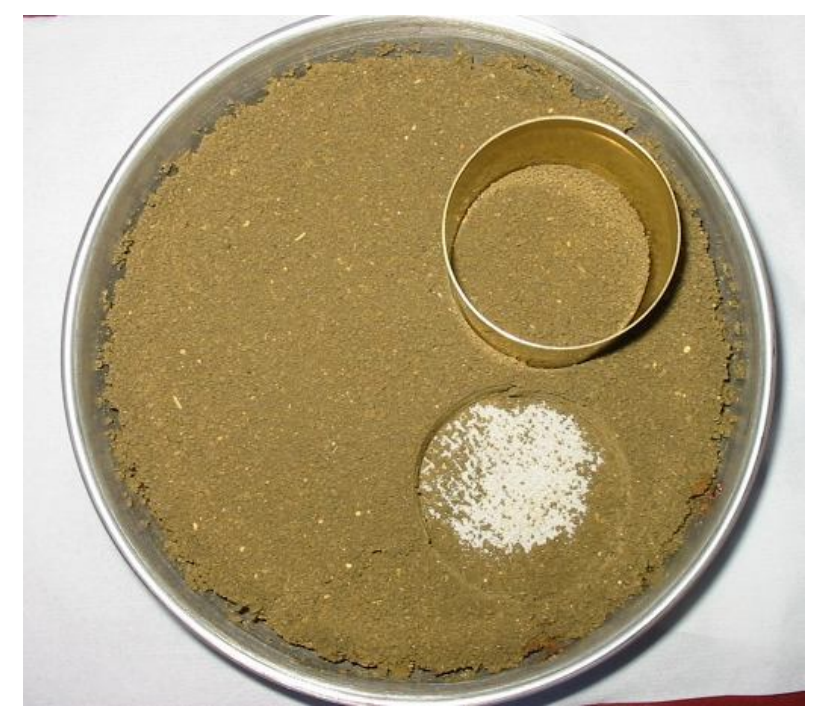

Figura 18: Extracción de las probetas con la utilización del cilindro de bronce. 
Luego de extraído, cada cilindro se ubicó sobre la boca de la caja de corte que a su vez hizo de celda de compresión uniaxial. Con un pistón del mismo diámetro que el cilindro y por presión manual se desplazó la probeta y se introdujo en la caja de corte (Figura 19). Sobre la probeta se colocó una tapa de aluminio para aplicar luego la Tensión Normal por medio de un tornillo solidario a una palanca (Figura 25).

Las muestras se comprimieron hasta arribar a una presión de $605 \mathrm{kPa}$, valor con el cual Palancar (2007) encontró mayores diferencias de comportamiento en suelos salinizados sodificados. La presión se transmitió a la muestra de suelo a través de un brazo de palanca que multiplicó por 5 la presión ejercida sobre la tapa superior de la probeta, por lo que se necesitó agregar $1 / 5$ del peso necesario para llegar a dicha presión. Los pesos fueron agregados manualmente. El peso total a colocar en el extremo de la palanca para alcanzar los $605 \mathrm{kPa}$ de presión fue de $39 \mathrm{~kg}$. Los pesos parciales agregados fueron 5 , $7,9,14,19,29$ y $39 \mathrm{~kg}$ correspondientes con tensiones normales de $77,108,139,217,294,449$ y $605 \mathrm{kPa}$. El tiempo total empleado para la compresión fue de 195 segundos por lo que existió un lapso de tiempo de 30 segundos entre la colocación de los sucesivos pesos para permitir el sedimento de la muestra.

La compresión de las muestras se llevó a cabo para obtener las Líneas de Compresión y Líneas Vírgen características de los tratamientos. 
Luego de la compresión se procedió al corte de las probetas por medio de la caja de corte directo. En los tratamientos de Cardone los cortes fueron realizados a una Relación de Tensión (tensión normal al corte, expresada como \% de la tensión máxima alcanzada en la compresión, $605 \mathrm{kPa}$ ) del $80 \%, 40 \%$ y $30 \%$ (Figura 20). Para los tratamientos de Ozzano los cortes se realizaron al $60 \%$ y $20 \%$ de Relación de Tensión.

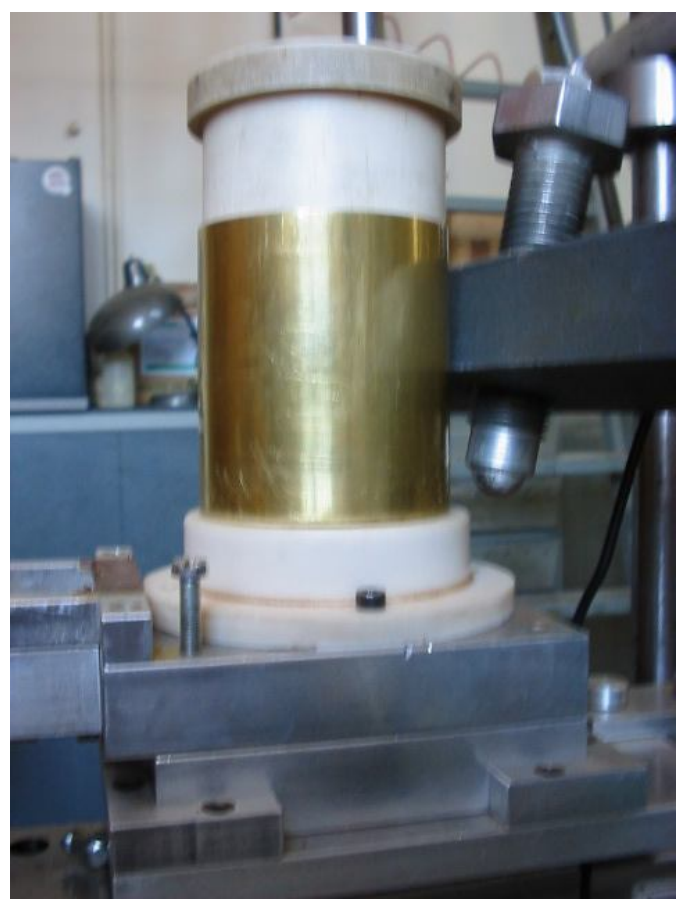

Figura 19: Introducción de la probeta en la caja de corte. 


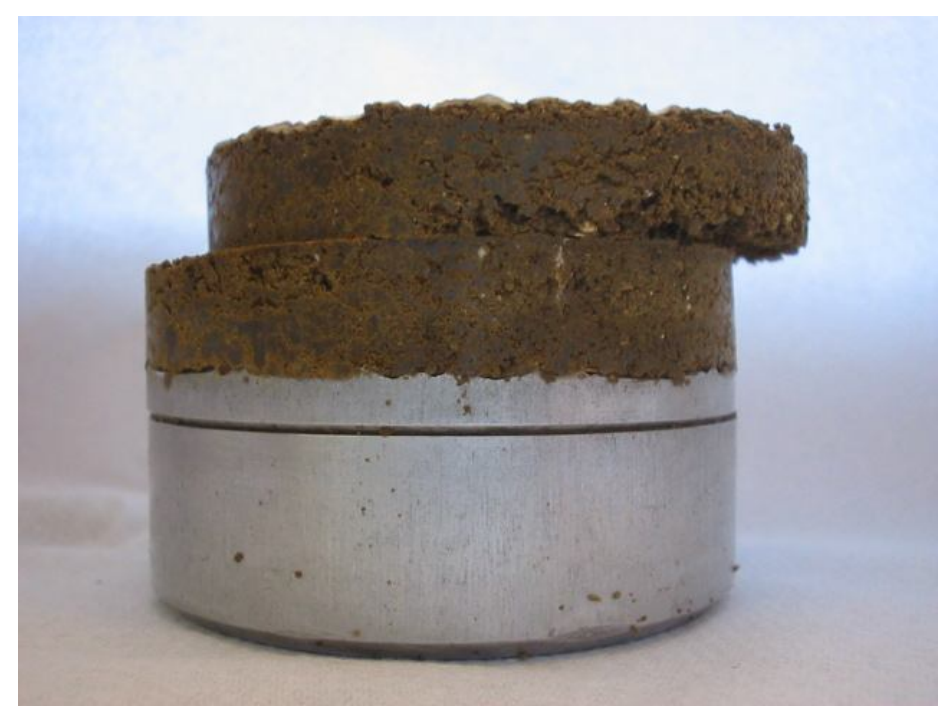

Figura 20: Muestra extraída de la caja una vez terminado el corte.

\subsubsection{Ensayos con material no sometido a ciclos} humectación - desecación (material indisturbado).

Este ensayo se llevó a cabo con el suelo Ozzano. El objetivo fue comparar el comportamiento de las diferentes clases granulométricas entre sí, como la respuesta de ambos tratamientos (OZA y OZB) en las condiciones de humedad con las que llegaron al D.I.A.F.

Para esto se utilizaron muestras de $100 \mathrm{~g}$ de suelo, en número de 4, para cada clase granulométrica de cada tratamiento, menos para el OZB clase I, que debido a la poca cantidad de dicha granulometría, solo se pudieron realizar 3 muestras. 
El procedimiento de compresión y corte fue similar al realizado en las pruebas sobre material sometido a ciclos de humectación - secado. Cada una de las muestras fue introducida en la caja de corte y sometida a compresión uniaxial (Durán García, 2002), arribando a una tensión normal final de $605 \mathrm{kPa}$. El corte de las mismas se realizó inmediatamente después de la compresión.

Las muestras de cada clase granulométrica en cada uno de los tratamientos fueron sometidas a corte con una Relación de Tensión diferente una de la otra. De las 4 muestras, 2 fueron cortadas con una Relación de tensión del $60 \%$, una del $20 \%$ y otra del 10\%; en el caso antes mencionado de OZB clase I, no se realizó el corte al 10\% de Relación de Tensión.

\subsubsection{Descripción de la Caja de Corte.}

La caja de corte simple es particularmente usada en la investigación del comportamiento del suelo durante la ocurrencia de falla (O'Sullivan et al., 1999). Este tipo de equipo es utilizado para la medición de las propiedades mecánicas de horizontes superficiales o antrópicos agrícolas por Kirby $\left(1991^{\mathrm{a}}, 1991^{\mathrm{b}}\right)$, Spugnoli (2000), Durán Garcia (2002), etc.

En el presente trabajo se utilizó dicho equipo, tanto para el corte como la compresión de las muestras, ya que, como demostrara Kirby $\left(1991^{\circ}\right)$ a través de la medida del esfuerzo de corte, el desplazamiento horizontal y vertical, permite la obtención 
de importantes parámetros de la mecánica del suelo a través de la teoría del Estado Crítico y la Ley de Coulomb (Figura 23).

La medición del movimiento vertical durante el corte, consiente la diferenciación del comportamiento súper - crítico de aquel sub - crítico, vale decir, permite evaluar si la trayectoria del suelo dentro del espacio $p-q-v$ alcanza el Estado Crítico dando lugar a una expansión o contracción. La línea de Consolidación Normal (Línea Virgen) fue determinada mediante prueba de compresión uniaxial, en la que se determinó tanto la tensión normal de compresión como el desplazamiento vertical.

La caja de corte utilizada fue diseñada y construida en el D.I.A.F. (Dipartamento di Ingegneria Agraria e Forestale de la Universitá degli Studi di Firenze, Italia) y posee las medidas indicadas en la Figura 21 y Figura 22. La mitad inferior se desplaza sobre cojinetes empujada por un eje que a su vez recibe el movimiento circular de un motor paso a paso y lo convierte en movimiento horizontal lineal (entre eje y motor existe un reductor de revoluciones, Figura 24). La mitad superior de la caja de corte se encuentra fija y unida a una celda de carga que mide la fuerza realizada por el suelo sobre la misma a causa del desplazamiento de la mitad inferior.

La caja de corte posee dos tornillos que permiten separar las dos mitades unas décimas de milímetro para evitar el rozamiento entre las mismas durante el desplazamiento. Con el fin de asegurar la perfecta alineación de ambas placas, antes de la colocación de cada probeta, posee dos tornillos que unen 
solidariamente estas placas antes de la introducción del suelo y se retiran en el momento del corte.

Acoplado al sistema de la caja de corte existe un tornillo unido al brazo de una palanca con un factor multiplicativo de 5 que permite realizar la compresión de las muestras (Figura 25).

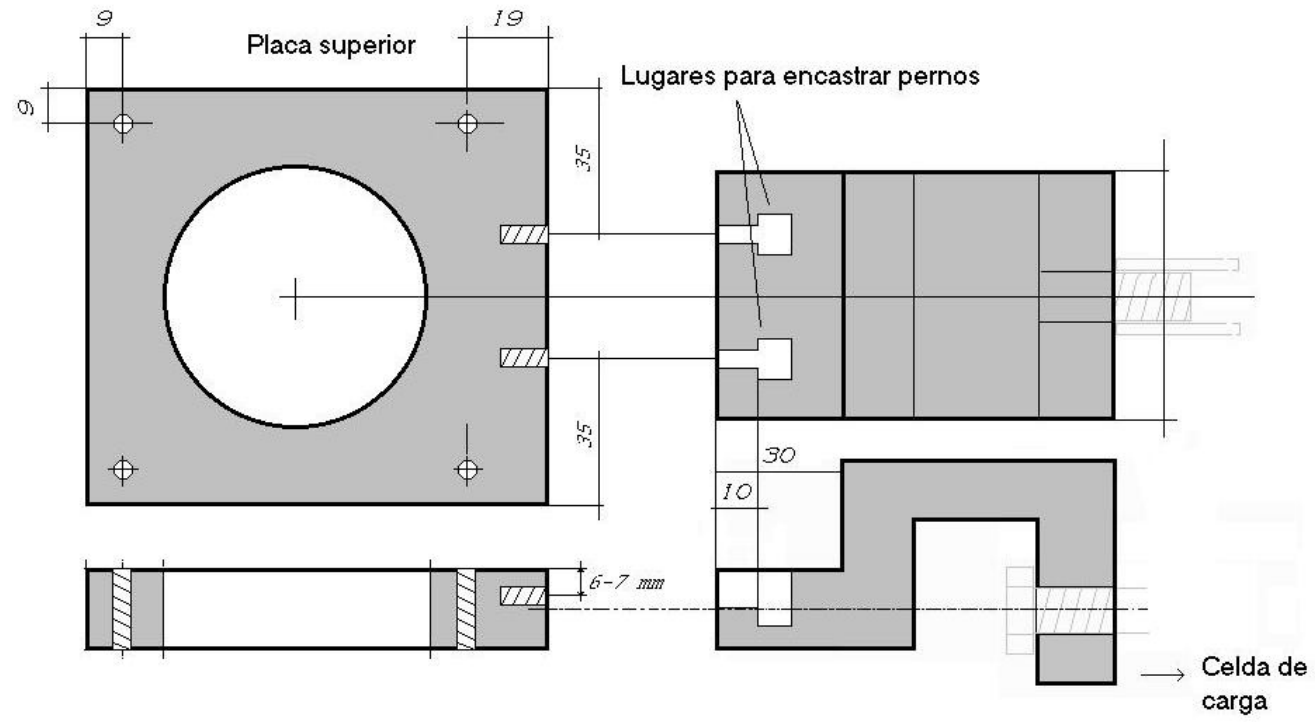

Figura 21: Sección en planta de la caja de corte (arriba) y vertical (abajo). 


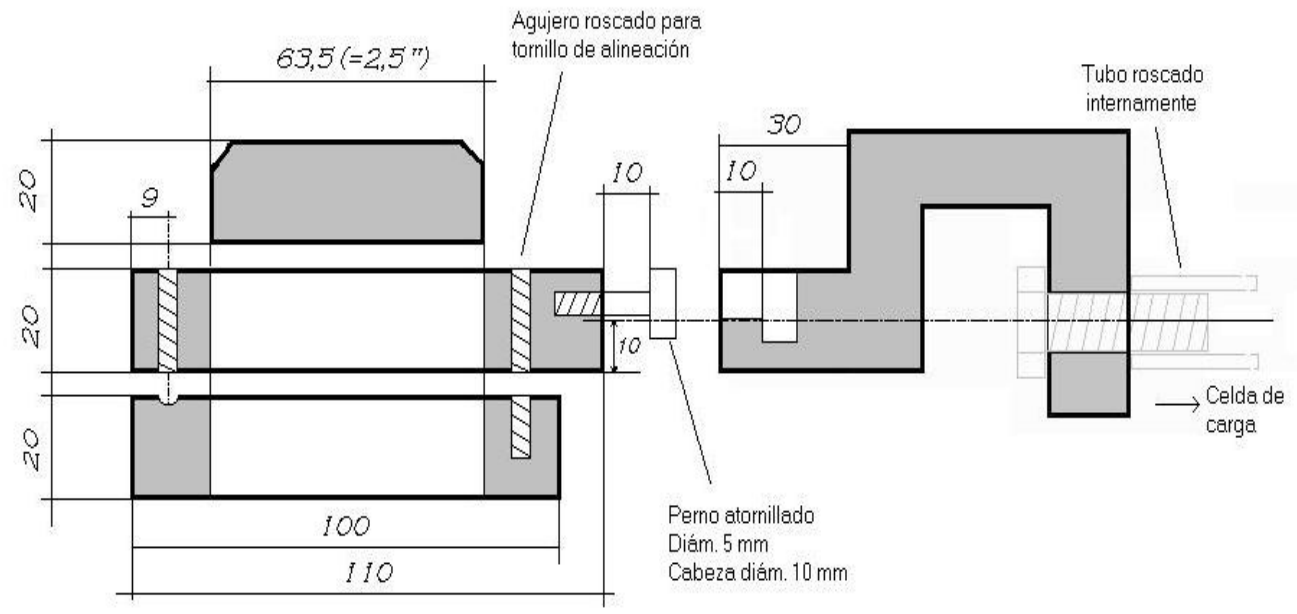

Figura 22: Sección vertical de la caja de corte.

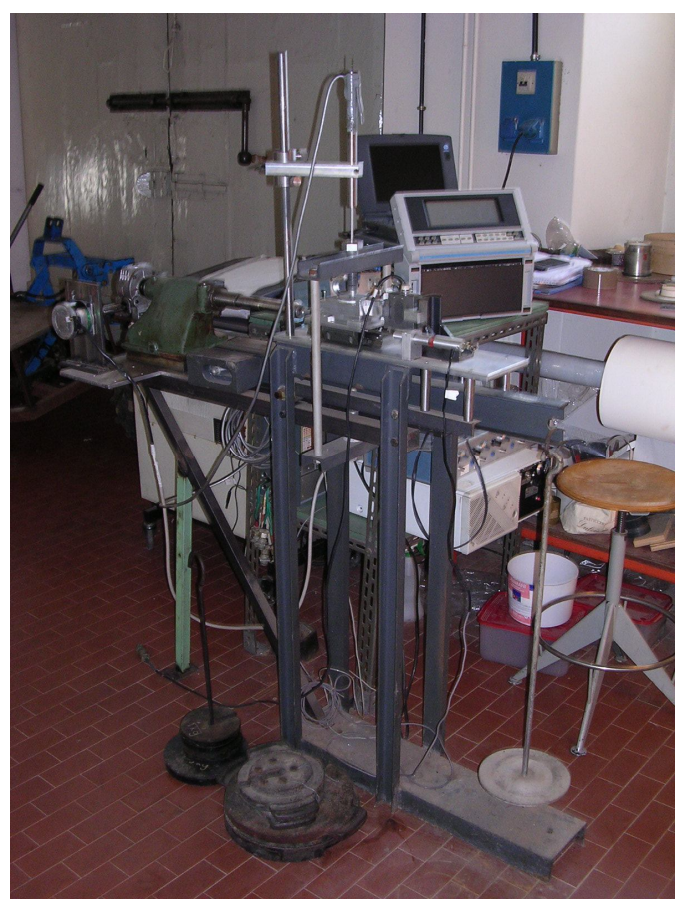

Figura 23: Vista general de la Caja de Corte Directo construida en el DIAF. 


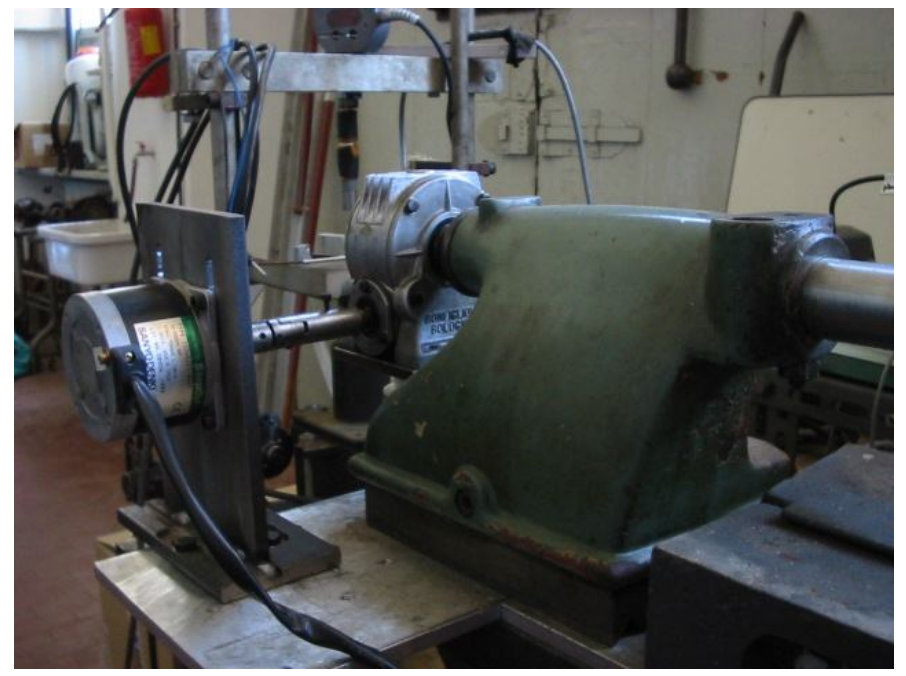

Figura 24: Motor eléctrico "paso a paso", reductor y eje telescópico de movimiento horizontal encargado de dar el movimiento de traslación a la parte inferior de la caja de corte.

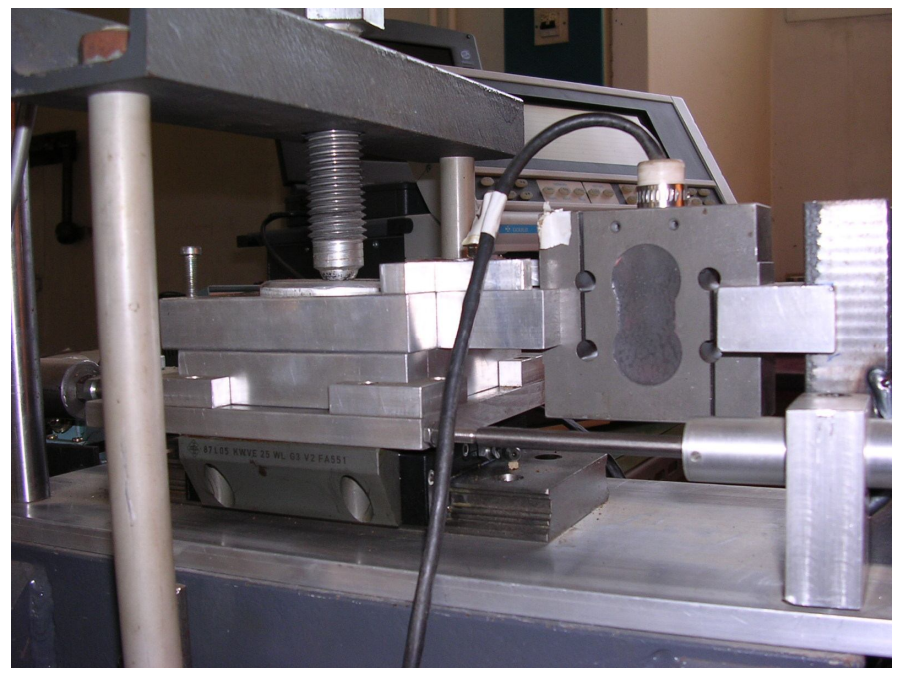

Figura 25: Caja de corte, se observa la parte inferior móvil, la parte superior unida a una celda de carga y tornillo unido al brazo de palanca. 


\subsubsection{Adquisición y registro de las señales.}

La Fuerza de corte, a partir de la cual se calculó luego la tensión de Corte fue medida mediante una celda de carga con una sensibilidad de $2 \mathrm{mV} / \mathrm{V}$ (550 N de Fondo de Escala). Los desplazamientos fueron medidos a través de transductores L.V.D.T con una sensibilidad $130 \mathrm{mV} / \mathrm{mm}$ (desplazamiento horizontal), $780 \mathrm{mV} / \mathrm{mm}$ (desplazamiento vertical durante el corte) y de $130 \mathrm{mV} / \mathrm{mm}$ (desplazamiento vertical durante la compresión) (Figura 26).

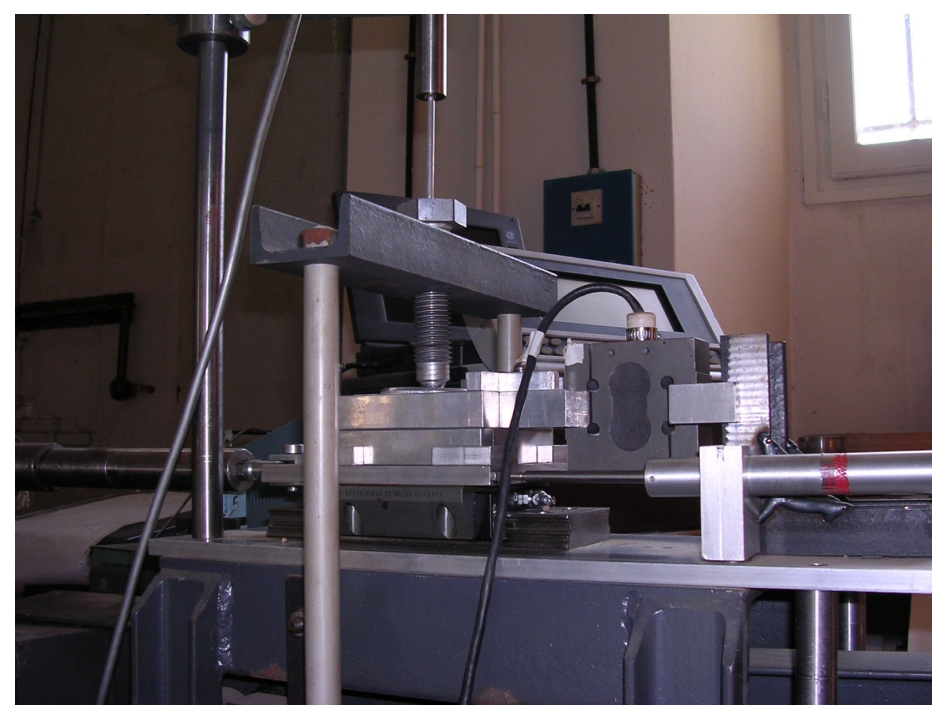

Figura 26: Caja de Corte, se observa el transductor de movimiento vertical utilizado durante la compresión uniaxial, transductor de movimiento horizontal y celda de carga encargada de medir la fuerza de corte. 
Tanto la adquisición como el registro y almacenamiento de los datos recibidos desde los distintos sensores se llevó a cabo con el colector de datos Gould TA11, el cual permitió registrar las 3 variables al mismo tiempo (desplazamiento horizontal, vertical y Fuerza de corte).

Dicho colector permitió almacenar los datos de voltaje correspondientes a las señales y luego transferirlos a un ordenador portátil (Figura 27).

Calibración de los distintos sensores.

Antes de realizar las pruebas se calibraron los 4 sensores conectados al instrumento:

< Sensor de desplazamiento vertical que aplicado sobre la parte superior del tornillo de la palanca midió el desplazamiento vertical durante la compresión.

< Sensor de desplazamiento vertical retráctil que aplicado sobre la parte superior del tornillo de la palanca midió el desplazamiento vertical durante el corte.

< Sensor de desplazamiento horizontal que aplicado en la placa inferior (móvil) de la caja de corte midió el desplazamiento horizontal de la misma durante el corte.

< Celda de carga que aplicada a la placa superior de la caja de corte midió el esfuerzo de corte mientras se realizó el desplazamiento horizontal.

La calibración de los mismos se realizó de modo diverso. Los sensores de desplazamiento vertical fueron tarados por medio de un espesímetro (instrumento que consta de láminas 
metálicas de espesor diverso) y distintos suplementos de altura conocida, se verificó la proporcionalidad de su señal tanto gráfica como en voltaje mediante un voltímetro. El sensor de desplazamiento horizontal fue tarado liberando el extremo fijo y haciéndolo avanzar distancias conocidas medidas con calibre y verificando la señal gráfica y de voltaje.

La celda de carga fue tarada colocándola en posición vertical y agregándole pesos discretos, se verificó la proporcionalidad de su señal tanto gráficamente como con voltímetro.

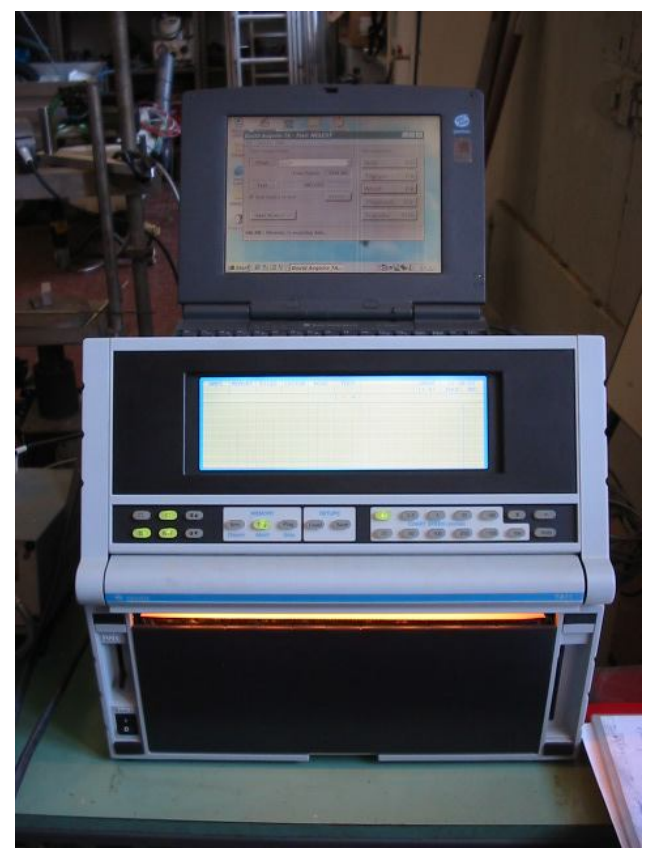

Figura 27: Colector de Datos Gould TA11 y ordenador portátil utilizados en la adquisición y almacenamiento de las señales. 
De cada ensayo de compresión se registró la altura sin muestra (altura cero), la altura inicial de la muestra y la variación de la altura con la compresión.

En cada ensayo de corte fue registrada la altura inicial de la muestra con la presión a la que iba a ser cortada y durante la prueba de corte propiamente dicha fue registrado el desplazamiento vertical (expansión o contracción de la muestra), el desplazamiento horizontal y el esfuerzo de corte.

\subsubsection{Cálculo de la Presión de Preconsolidación y obtención de la Línea Virgen (LV).}

Para realizar el cálculo de Pc fue utilizado el Método de Casagrande (1936).

En un gráfico semilogarítmico Volumen específico vs. Log Tensión Normal se deben realizar las siguientes operaciones (Figura 28):

1. Ubicar el punto de máxima curvatura.

2. Trazar una recta tangente en el punto 1.

3. Trazar una recta horizontal en el punto 1.

4. Trazar una bisectriz entre la recta tangente 2 y la recta horizontal 3.

5. Prolongar la recta de la curva de carga Normalmente Consolidada.

6. La intersección entre las rectas 4 y 5 determinan el valor de Tensión Normal ${ }_{P c}$. 


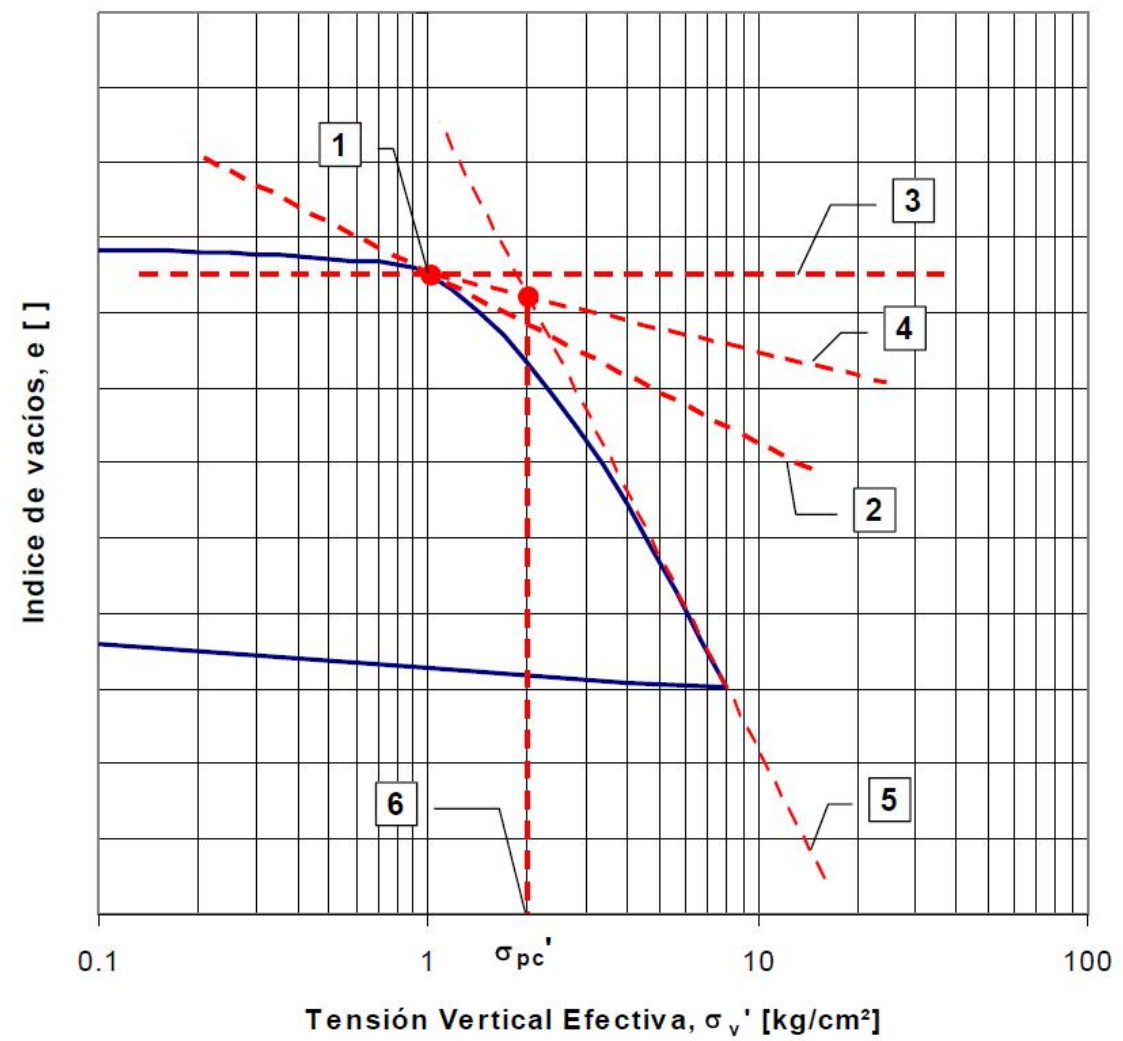

Figura 28: Obtención gráfica de la tensión de preconsolidación $(\mathrm{Pc})$.

Los puntos que se ubican por delante de Pc son aquellos pertenecientes a la Línea Virgen la cual se traza mediante la regresión de dichos puntos.

\subsubsection{Cálculo de la Línea de Estado Crítico.}

Para hallar la ubicación de la Línea de Estado Crítico respecto a la Línea Virgen fue utilizada la regresión entre la 
Relación de Volumen y la Relación de Tensión Normal de las muestras durante el corte en un gráfico semi - logarítmico. Luego se utilizó la ecuación de la Línea de Recarga obtenida a partir del valor de volumen específico al que arriba la muestra una vez descargada, finalizada la compresión, y el valor de volumen específico que se obtiene al ser recargada la muestra hasta la tensión Normal a la que se realizaría el corte.

Procedimiento:

Con los datos de Relación de Tensión y relación de volumen (relación entre la diferencia de volumen posterior y previo al corte con el volumen previo al corte) se realizaron las regresiones para cada suelo y tratamiento. Para calcular la relación de volumen se utilizó la ecuación (11): $\mathrm{RV}=(\mathrm{Vf}-\mathrm{Vi}) / \mathrm{Vi}$ $=$ hf.Af - hi.Ai / hi.Ai, Siendo $V$ el volumen de la muestra; $h$ la altura y A el área; los prefijos "f" e "i" indican final e inicial respectivamente. Como Af y Ai son iguales, (pues el área de la celda de corte es la misma al inicio y al final del corte), se simplifican quedando hf - hi / hi. Como ejemplo de dicha Regresión se muestra la Figura 29.

A continuación se debe hallar el valor de Tensión Normal de Corte donde la Relación Volumétrica se hace cero $(\mathrm{y}=0)$, es decir que no hay cambio de volumen de la muestra durante el corte y por lo tanto se encuentra sobre la Línea de Estado Crítico. 


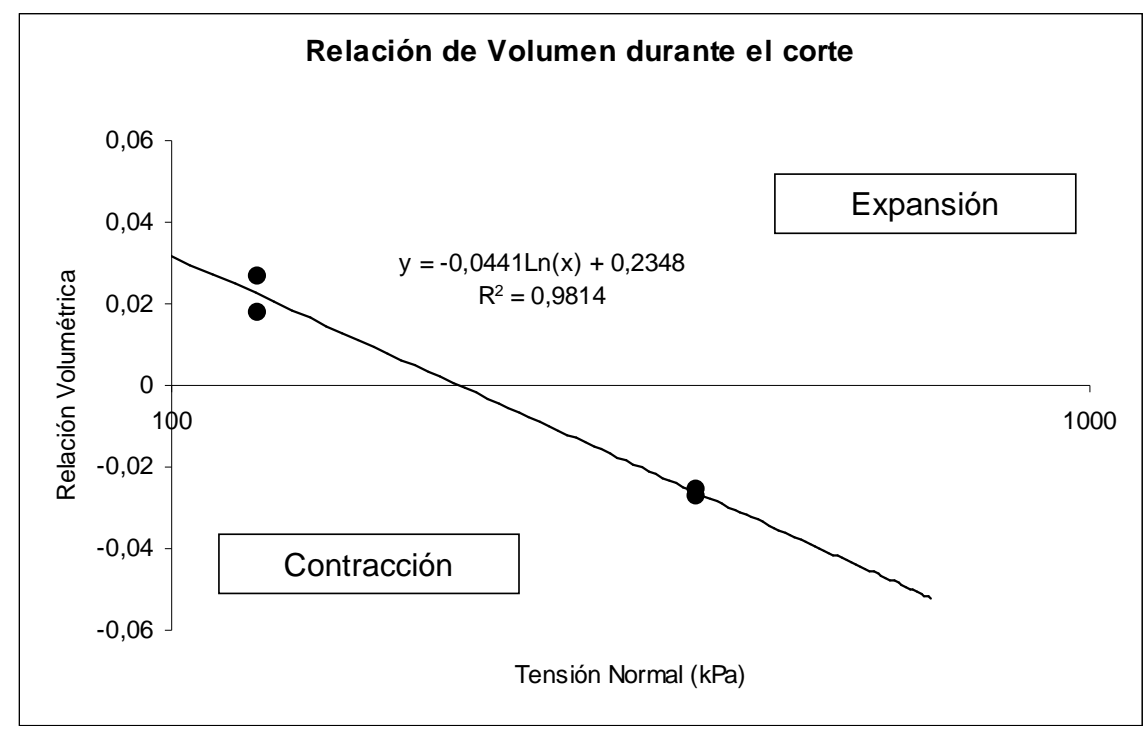

Figura 29: Regresión Log Tensión Normal - Relación volumétrica para hallar el estado crítico.

Para hallar la ecuación de la recta de la Línea de Estado Crítico debe hallarse primero el Volumen Específico que corresponde a esa Tensión Normal mediante la ecuación de la Línea de Recarga. La Figura 30 muestra un gráfico a modo de ejemplo donde es señalada la Línea de Recarga.

Una vez obtenido un punto $(x, y)$ de la Línea de Estado Crítico y sabiendo que su pendiente es igual a la de la Línea Virgen se determina la ecuación de la Línea de Estado Crítico. 


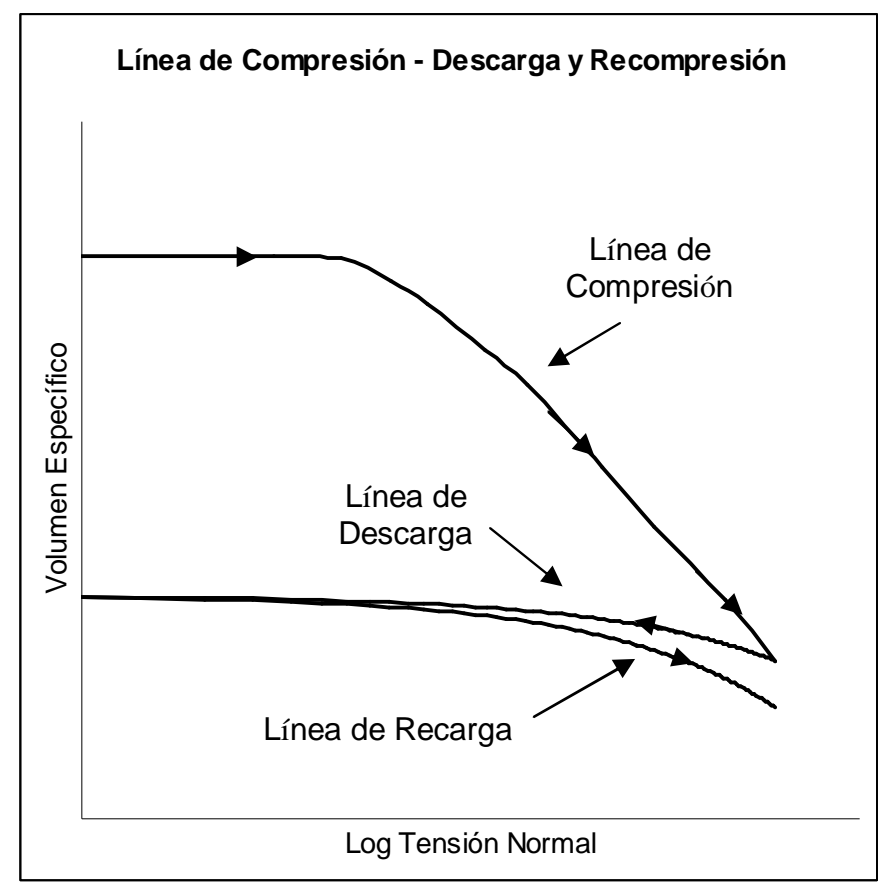

Figura 30: Línea de descarga y de rebote en el ensayo de compresión

\subsection{Tratamiento estadístico de los resultados.}

Luego de cada ensayo los datos fueron trasladados del colector Gould TA 11 al ordenador portátil por medio de un programa propio del registrador. Los archivos registrados fueron transformados a formato ASCII para poder ser luego procesados con un programa de planilla de cálculo. Para realizar el procesamiento de los datos y las gráficas fue utilizado el programa Excel. 
Para el análisis estadístico de los datos se utilizó el programa Statgraphics Plus 4.1.

Los valores de Tensión de Rotura en las pruebas con agregados individuales al igual que los valores de Tensión de Rotura y Tensión de Compactación en las pruebas de Brazilian test, fueron evaluados mediante test de Diferencias Mínimas Significativas (DMS) al 5\%.

En las pruebas de Compresión y Corte se evaluaron:

El Volumen Específico Seco $\left(\mathrm{cm}^{3} / \mathrm{g}\right)$, analizado pre y pos compresión para ambos tratamientos ( $\mathrm{A}$ y B) mediante análisis de la varianza utilizando el test de Diferencias Mínimas Significativas (DMS) al 5\%. Éste método estadístico fue utilizado también para analizar los parámetros Pc (tensión de pre - consolidación), $\mathrm{N}$ y $\lambda$ (término independiente y pendiente de la Línea Virgen), humedad al corte y Tensión de Corte (Sokal y Rohlf, 1995). Las Líneas Virgen fueron a su vez evaluadas mediante regresión simple.

Los parámetros de Coulomb (c y $\operatorname{tg} \varphi$ ) y las rectas de Comportamiento Volumétrico Durante el Corte fueron evaluados a través de una regresión simple lineal. Se realizó una comparación estadística a través de la Comparación de Regresiones al 10\%.

Las diferencias de los parámetros $(\mathrm{N}-\Gamma)$ asociados a la posición de la Línea de Estado Crítico fueron analizadas utilizando el test DMS al 5\%, al igual que los valores medios de Tensión en los que se alcanza el Estado Crítico.

En la Figura 31 se observa un organigrama resumen de los ensayos realizados. 
Figura 31: Organigrama Resumen de los diferentes ensayos realizados sobre los distintos suelos.

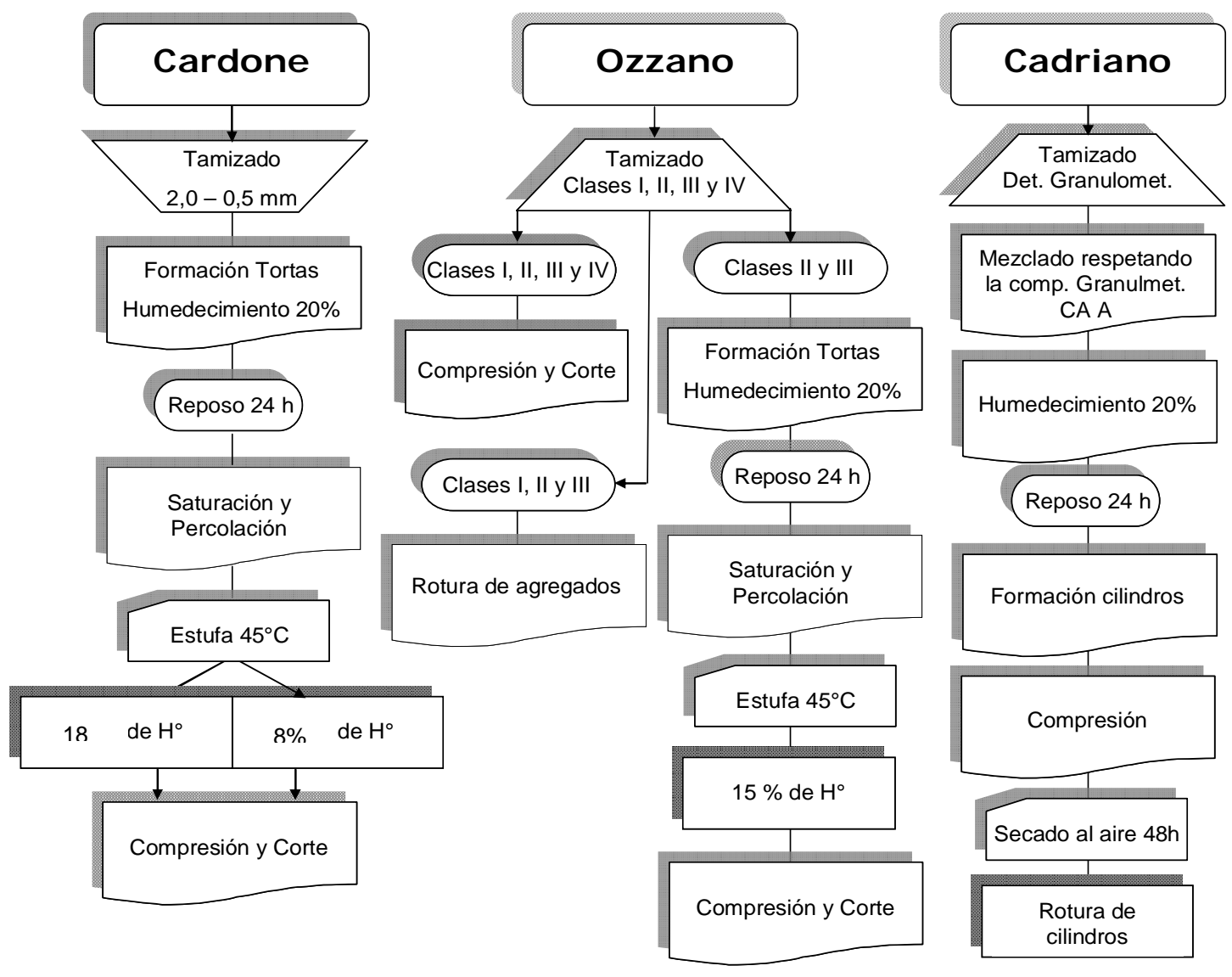




\section{RESULTADOS}

\subsection{Consideraciones previas.}

Con respecto a las diferencias entre suelos puede observarse que Cardone presentó un 10\% menos de arena y un $10 \%$ más de limo respecto a Ozzano siendo similar su contenido de arcilla (35,06\% vs. 36,63\%) (Textura ISSS). Cadriano posee un alto contenido de limo $(50,20 \%)$ fracción muy poco reactiva a los cationes presentes en la solución del suelo y un porcentaje de arcilla superior a los otros dos suelos (38,37\%). Asimismo, puede remarcarse la diferencia en la tipología de arcilla de los mismos, presentando Ozzano, vermiculita y esmectita.

La vermiculita es un filosilicato del tipo 2:1, caracterizada por una superficie específica muy alta, de alrededor de 600-800 $\mathrm{m}^{2} / \mathrm{g}$, aumentando la dimensión del complejo de intercambio y por lo tanto la actividad físico-química del suelo y con ella las posibilidades de agregación. Ocurre algo similar con la esmectita. Por otro lado, illita presenta superficies de $70-120 \mathrm{~m}^{2} / \mathrm{g}$, mientras la caolinita presenta valores muy bajos de solo $10-20 \mathrm{~m}^{2} / \mathrm{g}$. Adicionalmente, a la consideración de la superficie específica deben contemplarse las diferencias en la CIC de estos minerales arcillosos. Mientras que esmectita y vermiculita tienen entre $80 \mathrm{y}$

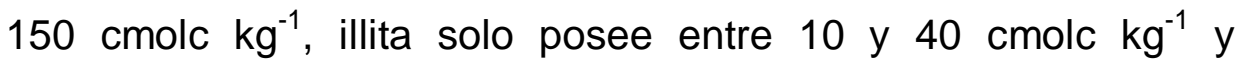
caolinita entre 1 y 10 cmolc $\mathrm{kg}^{-1}$. Estas considerables diferencias incidirían en la posibilidad de formación de puentes catiónicos, 
redundando en diferentes capacidades estructurantes en los suelos a nivel de partículas. Ambas propiedades repercutirían en la menor estabilidad de acuerdo a algunos autores (Churchman et al., 1993; Ward y Carter, 2004). Illita y caolinita son los tipos de arcillas presentes en Cardone (Alfisol) y Cadriano. Con respecto a las características químicas es de remarcar la importante cantidad de carbonatos que presenta Ozzano (Inceptisol) con valores de Materia Orgánica (MO) similares a Cadriano, siendo ambos superados por Cardone quien posee casi el doble de $\mathrm{MO}$ (33,9 $\mathrm{g} / \mathrm{kg}$ ). Tanto los carbonatos como la MO del suelo colaboran como ligantes entre las partículas y disminuirían la incidencia del efecto dispersivo del sodio.

\subsection{Pruebas preliminares.}

\subsubsection{Pruebas de Estabilidad de Agregados en Agua.}

La evaluación de éstas pruebas de estabilidad se realizó visualmente ya que su finalidad era la de obtener a priori una apreciación cualitativa sobre la existencia de diferencias en el comportamiento entre ambos tratamientos de cada suelo a ensayar.

a). Prueba de disgregación.

Luego de 10' se observó que los agregados de los tratamientos con menor contenido de sodio (B) disgregaron sustancialmente más que aquellos más sodificados $(A)$ en ambos 
materiales (CD y OZ) (Figura 32). Esto pudo deberse a que los agregados de los tratamientos $\mathrm{B}$ tendrían una porosidad mayor y al ser sumergidos en agua destilada la presión de ésta sobre el aire encerrado en el interior provocó la ruptura casi instantánea del agregado. Los agregados del tratamiento A mostraron una masividad mayor y por ende el agua habría penetrado en el interior más lentamente atenuando la disgregación.
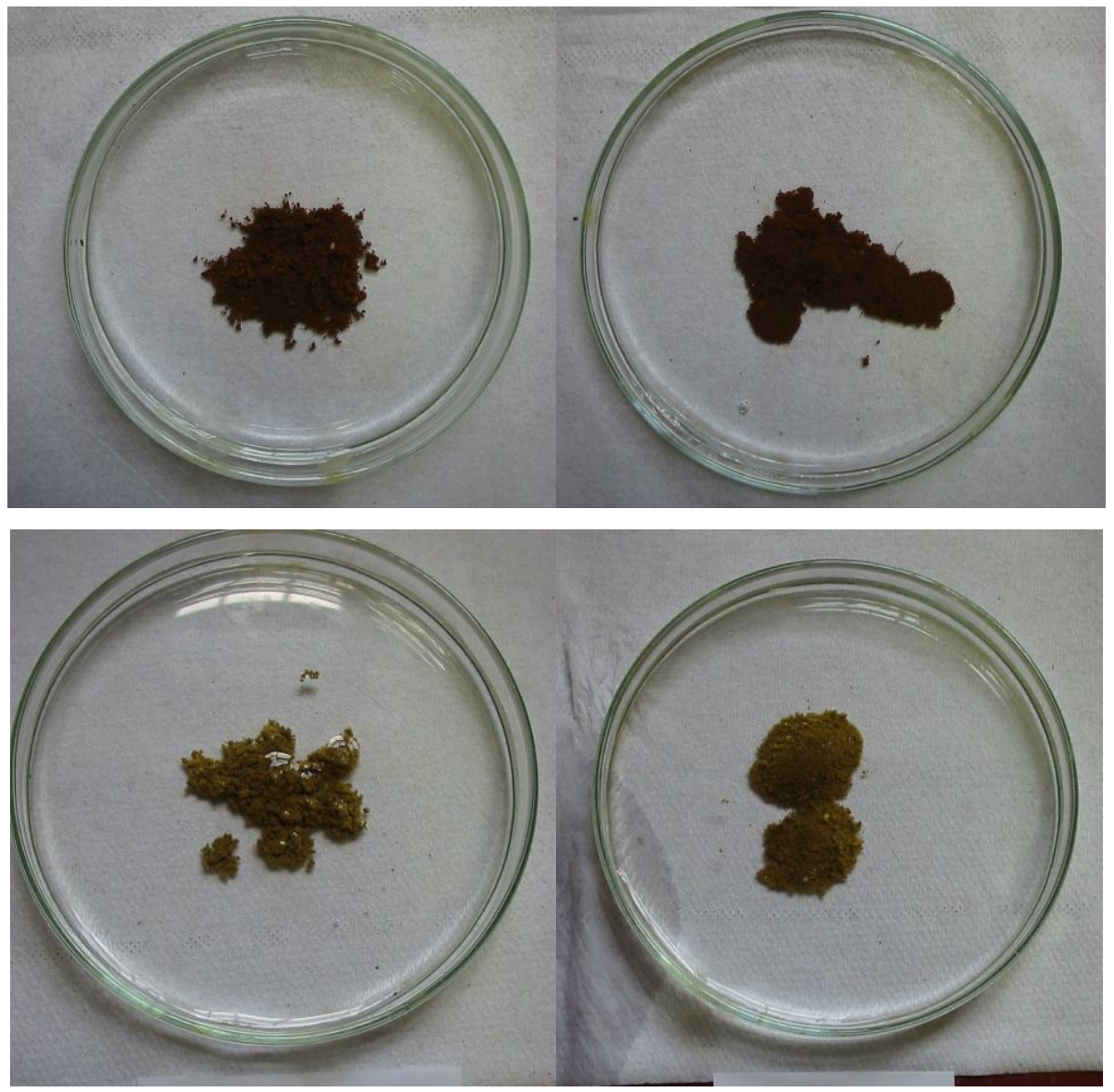

Figura 32: Pruebas de disgregación: arriba izquierda CDA, arriba derecha CDB, abajo izquierda OZA, abajo derecha OZB. 
b). Prueba de dispersión.

Transcurridos 30' se observó que CDA y OZA habían dispersado notablemente más que los tratamientos $B$, hecho que se evidenció por la opacidad del agua debido a la presencia de las arcillas dispersas y a su vez la formación de un halo de material muy fino alrededor del agregado, sobre el fondo del recipiente (Figura 33). Este hecho es explicable a través de la acción dispersante del sodio al saturar (total o parcialmente) las cargas negativas de las arcillas reemplazando otros cationes como el $\mathrm{Ca}^{++}$y el $\mathrm{Mg}^{++}$cuya presencia facilita la floculación de las arcillas.

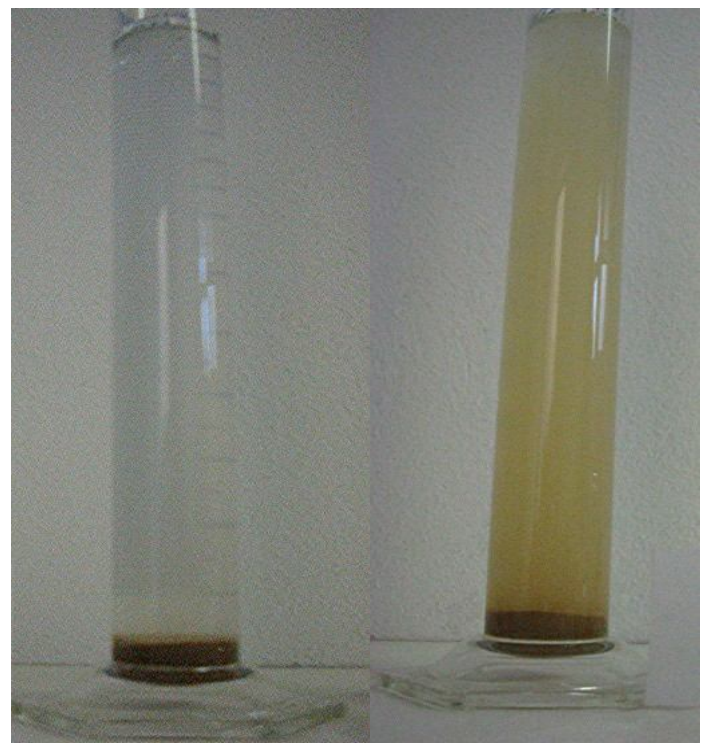

Figura 33: Prueba de dispersión, OZB (izquierda) y OZA (derecha). 


\subsubsection{Prueba de expansión - contracción.}

En el tratamiento con niveles más altos de sodio, se observaron procesos de expansión - contracción más evidentes que llevaron a cambios de su densidad (Tabla 11, Tabla 12 y Figura 34). Nannucci (2009) subraya que altos niveles de sodio, en presencia de humedad determinan procesos de expansióncontracción más evidentes, debidos a la mayor cantidad de arcilla dispersa que puede capturar o liberar una mayor cantidad de agua y en consecuencia se encuentra en grado de amplificar estos fenómenos de cambios volumétricos. Este hecho se verificó también en el valor de humedad a Capacidad de Campo donde, partiendo de porcentajes de humedad iniciales muy similares, el suelo más sódico presentó una mayor absorción de agua (Tabla 13).

Tabla 11: Variación de la densidad en cada momento de medición y por tratamiento.

\begin{tabular}{cccc}
\hline \multirow{2}{*}{ Tratamiento } & \multicolumn{3}{c}{ Densidad $\left(\mathrm{g} / \mathrm{cm}^{3}\right)$} \\
\cline { 2 - 4 } & Inicial & $\begin{array}{c}\text { Capacidad de } \\
\text { Campo }\end{array}$ & $\begin{array}{c}\text { Secado } \\
\text { al aire }\end{array}$ \\
\hline COA & 1,27 & 0,938 & 1,70 \\
COB & 1,25 & 1,14 & 1,49 \\
\hline \hline
\end{tabular}

Debido a la fuerte contracción en diámetro sufrida por COA, aspecto que transferido a un medio semi - infinito como el suelo 
agrícola puede interpretarse como una fractura, éste tratamiento perdió un mayor volumen de agua que $\mathrm{COB}$ en el mismo tiempo, arribando los dos prácticamente a la misma humedad final (Tabla 13).

Tabla 12: Variación porcentual de volumen de las muestras respecto al volumen inicial.

\begin{tabular}{ccc}
\hline \hline \multirow{2}{*}{ Tratamiento } & $\Delta$ Volumen & $\Delta$ Volumen \\
& $\begin{array}{c}\text { Capacidad de } \\
\text { Campo }(\%)\end{array}$ & $\begin{array}{c}\text { Secado al aire } \\
(\%)\end{array}$ \\
\hline COA & $(+) 26,29$ & $(-) 25,31$ \\
COB & $(+) 8,75$ & $(-) 16,11$ \\
\hline \hline
\end{tabular}

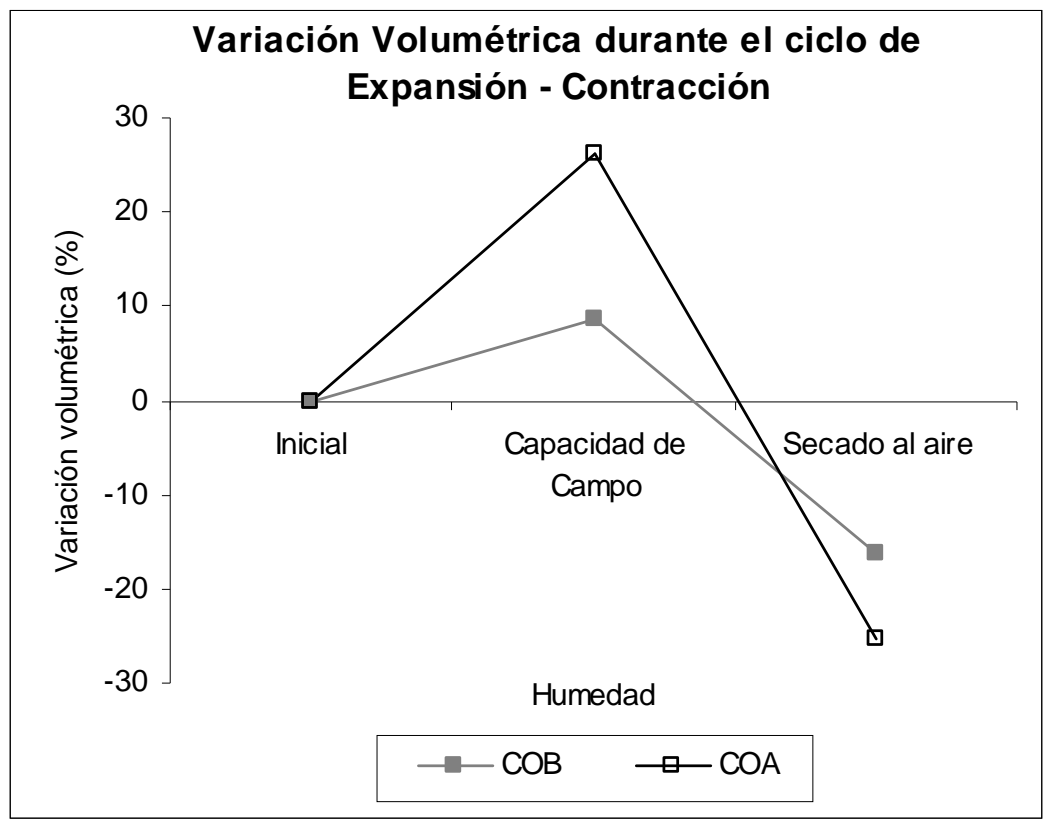

Figura 34: Variación volumétrica en \% durante el ciclo Expansión Contracción. 
Tabla 13: Humedad, altura y diámetro de la muestra en cada momento de medición y por tratamiento.

\begin{tabular}{cccc|ccc|ccc}
\hline \hline \multirow{3}{*}{ Trat. } & \multicolumn{3}{c}{ Inicial } & \multicolumn{3}{c|}{$\begin{array}{c}\text { Capacidad de } \\
\text { Campo }\end{array}$} & \multicolumn{3}{c}{ Secado al aire } \\
\cline { 2 - 11 } & $\mathrm{H}^{\circ}$ & $\mathrm{h}$ & $\mathrm{d}$ & $\mathrm{H}^{\circ}$ & $\mathrm{h}$ & $\mathrm{d}$ & $\mathrm{H}^{\circ}$ & $\mathrm{h}$ & $\mathrm{d}$ \\
& $(\%)$ & $(\mathrm{mm})$ & $(\mathrm{mm})$ & $(\%)$ & $(\mathrm{mm})$ & $(\mathrm{mm})$ & $(\%)$ & $(\mathrm{mm})$ & $(\mathrm{mm})$ \\
\hline COA & 1,70 & 18,00 & 190 & 79,14 & 24,42 & 190 & 1,80 & 16,50 & 171,5 \\
\hline COB & 1,80 & 18,25 & 190 & 55,62 & 20,00 & 190 & 1,70 & 17,25 & 179 \\
\hline \hline
\end{tabular}

\subsection{Pruebas de resistencia a rotura de agregados individuales.}

Se recuerdan las categorías de agregados que fueron ensayadas mediante éste método:

I. agregados de 3,36-5 mm de diámetro.

II. agregados de $2-3,36 \mathrm{~mm}$ de diámetro.

III. agregados de 0,5-2 mm de diámetro.

Los resultados de las pruebas mostraron que los agregados de mayores dimensiones presentaron una resistencia a rotura menor a aquellos de dimensiones inferiores (Tabla 14 y Figura 35). Dexter (1988) señala que agregados de mayores dimensiones poseen poros más grandes respecto a los poros existentes en agregados más chicos. Los poros de mayor diámetro presentan planos de falla más susceptibles a la rotura que aquellos de diámetros inferiores y, por lo tanto, los primeros colapsarían más fácilmente ante la compresión otorgándole a los agregados mayores más susceptibilidad a la rotura. 
Utomo y Dexter (1981) encontraron que los agregados de un suelo sometido a humidificación - desecación sufrieron micro - fracturas que redujeron su resistencia a rotura, siendo más notable éste efecto en agregados de mayor tamaño. Willat (1987) ha observado como, a humedad constante, la Resistencia a la Rotura de los agregados de un suelo Cambisol, disminuye con el aumento del diámetro de los mismos. Este autor concluye que los agregados de mayores dimensiones son más susceptibles a la compactación respecto a aquellos más pequeños con el mismo grado de humedad. Draghi et al. (2009), en cambio, no encontraron diferencias en la tensión de rotura entre tamaños de agregados en el tratamiento testigo (no sodificado). Estos autores adjudicaron la falta de diferencias al elevado contenido de arcillas de los suelos ensayados (73\%) el cual pudo haber generado un valor de cohesión molecular tan alto en seco, que no permitiría manifestar el efecto de la variación del tamaño. Sin embargo los mismos autores sí encontraron diferencias de resistencia a rotura entre los diferentes tamaños de agregados en el tratamiento sodificado, presentando mayor resistencia a menor tamaño de agregado.

En lo referente a Tensión de Rotura en función de la sodicidad, se observó que el tratamiento $A$ presentó valores superiores al tratamiento menos sodificado B. En el caso del tratamiento $A$, las arcillas dispersas habrían conferido mayor resistencia a la rotura respecto a los agregados del tratamiento $B$ (Tabla 15, Figura 35 y Figura 36 ). Estos resultados son 
respaldados por Barzegar et al. $\left(1994^{\mathrm{b}}\right)$ en relación a la labor dispersiva del sodio en un suelo fino. Estos autores observaron también una correlación negativa entre la Tensión de Rotura y el Diámetro Medio Efectivo denominado MWD (mean wight diameter), siendo éste último consecuencia de su estabilidad. Agregados más estables presentaron mayores valores de MWD y agregados menos estables a causa del tratamiento con soluciones de mayor RAS presentaron menores MWD y por ende menor estabilidad y mayor resistencia a rotura.

Falciani (2009) en su tesis doctoral, encontró diferencias significativas en la Tensión de Rotura de agregados pertenecientes a dos tratamientos, uno sodificado y un testigo, en la clase granulométrica comprendida entre $3,35 \mathrm{~mm}-2 \mathrm{~mm}$. En dicho trabajo el suelo sodificado presentó $255,28 \mathrm{kPa}$ mientras que el testigo presentó valores medios de Resistencia a Rotura de $122,87 \mathrm{kPa}$. Sin embargo el mismo autor no halló diferencias en la Resistencia a Rotura entre el tratamiento sodificado y el testigo para la clase de tamaño de agregados menor a $2 \mathrm{~mm}$.

En línea con lo hallado en esta tesis, Taboada y Lavado (1996) reportaron que el módulo de ruptura (MOR) de agregados de un suelo Natracuol se incrementó con el incremento de la RAS.

Rahimi et al. (2000) indagaron en el comportamiento de suelos sodificados artificialmente y sometidos a ciclos de humectación - desecación, observando que la Resistencia a Rotura de los agregados disminuye con el aumento de las arcillas dispersas debido a la RAS. Estos resultados se contradicen con 
aquellos observados precedentemente por Barzegar et al. (1994 ${ }^{\mathrm{b}}$ ). Rahimi et al (2000) explicaron que éstas diferencias de comportamiento son debidas al ciclo humectación - desecación que redujo la estabilidad de los agregados. Nannucci (2009) encontró una mayor resistencia a la tracción en agregados con mayor contenido de sodio y menor sensibilidad a la compresión de los suelos atribuída a la presencia de arcilla dispersa que forma fuertes uniones, confiriendo a las muestras sódicas mayor resistencia a la compresión.

Tabla 14: Comparación de Tensión de Rotura "Y" (kPa) entre clases de agregados individuales sometidos a tracción para ambos tratamientos (A y B).

\begin{tabular}{c|c}
\hline Tratamiento & $\mathrm{Y}(\mathrm{kPa})$ \\
\hline \hline A I & $181,5 \mathrm{~b}$ \\
All & $234,9 \mathrm{~b}$ \\
A III & $440,9 \mathrm{a}$ \\
\hline \hline B I & $68,7 \mathrm{~b}$ \\
B II & $121,0 \mathrm{~b}$ \\
B III & $277,5 \mathrm{a}$
\end{tabular}

Letras diferentes denotan diferencias estadísticas significativas (LSD $p<0,05)$. 
Tabla 15: Comparación entre tratamientos A vs. B de Tensión de Rotura "Y" ( $\mathrm{kPa}$ ) de agregados individuales de las clases I, II y III.

\begin{tabular}{c|c}
\hline Tratamiento & $\mathrm{Y}(\mathrm{kPa})$ \\
\hline \hline A I & $181,5 \mathrm{a}$ \\
$\mathrm{B} \mathrm{I}$ & $68,7 \mathrm{~b}$ \\
\hline AlI & $234,9 \mathrm{a}$ \\
B II & $121,0 \mathrm{~b}$ \\
\hline A III & $440,9 \mathrm{a}$ \\
B III & $277,5 \mathrm{~b}$
\end{tabular}

Letras diferentes denotan diferencias estadísticas significativas (LSD $p<0,05)$.

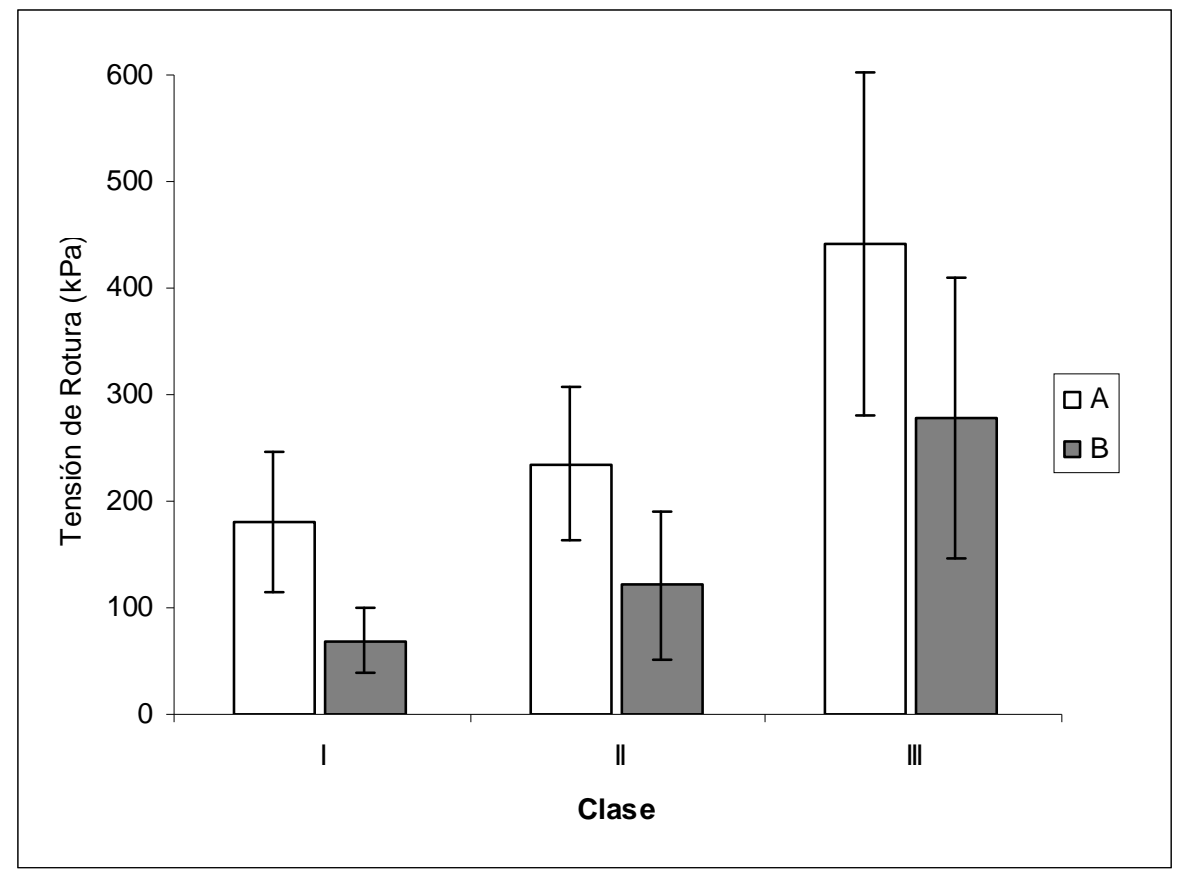

Figura 35: Tensión de Rotura de agregados individuales OZA vs. OZB, Clases I, II y III. 


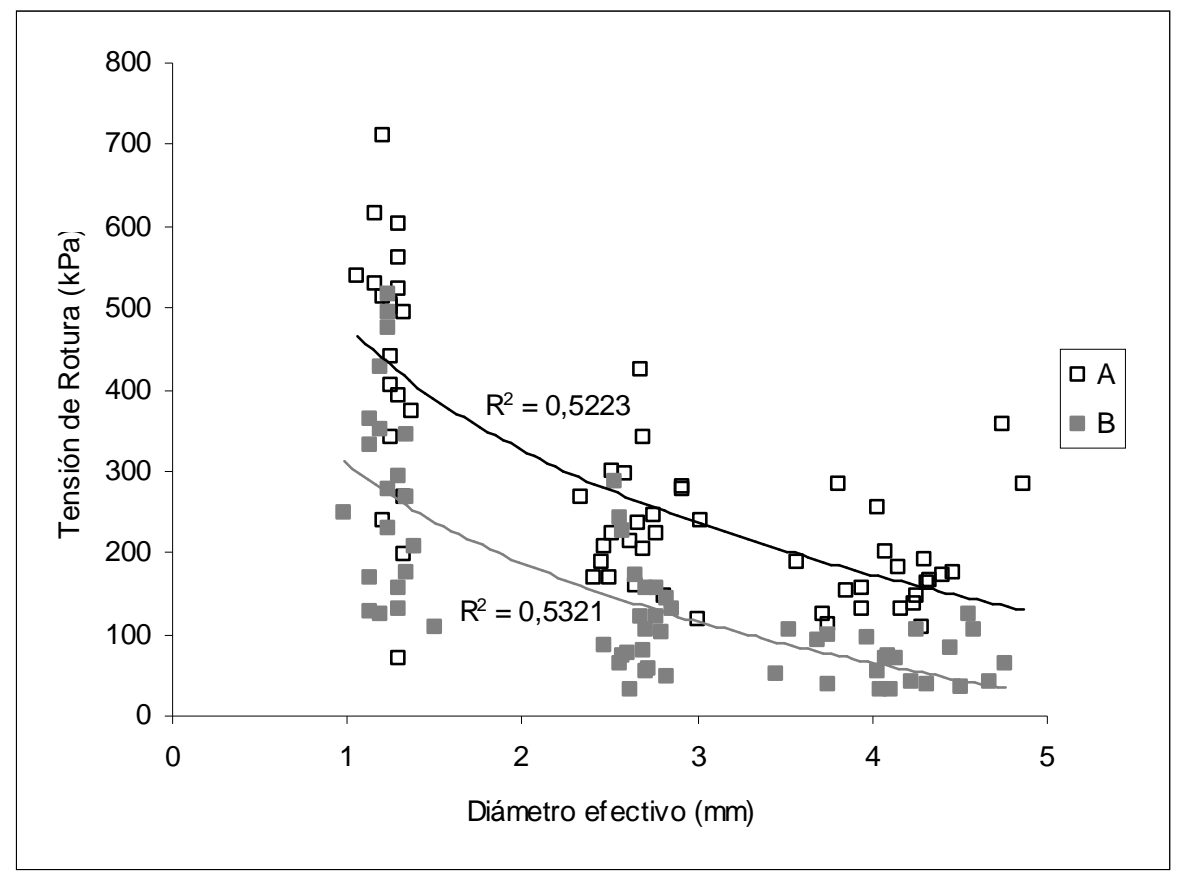

Figura 36: Tensión de Rotura de agregados individuales de ambos tratamientos (A y B) en función de su diámetro efectivo.

\subsection{Pruebas de resistencia a rotura mediante Brazilian}

\section{Test.}

Los resultados de las pruebas conducidas sobre 5 repeticiones de cada uno de los tratamientos se indican en la Tabla 16. Si bien los valores medios de Compactación (Figura 37) y Resistencia a Tracción (Figura 38) fueron superiores en el tratamiento sodificado (COA) no han presentado diferencias significativas en comparación con el tratamiento COB, 
observándose una variabilidad considerable de éstos valores dentro de cada uno de los tratamientos.

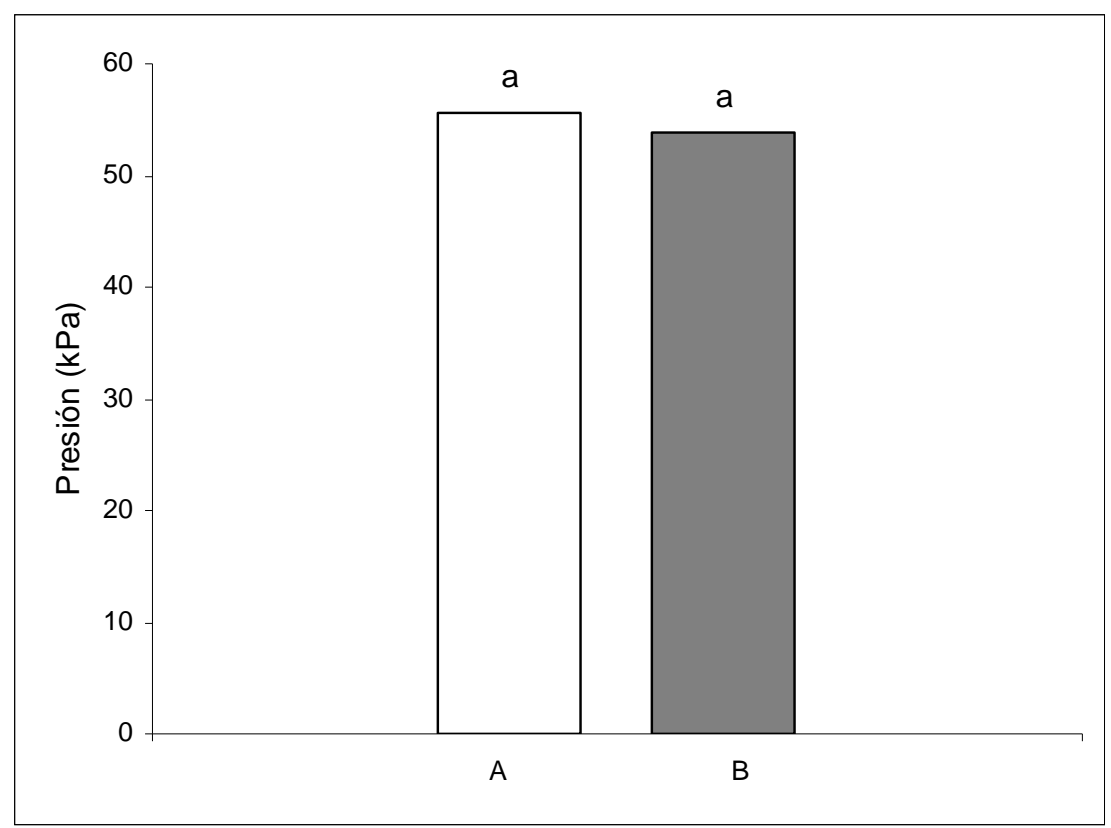

Figura 37: Tensión de Compactación de Cilindros de COA vs.

COB. (Letras diferentes denotan diferencias significativas).

Probablemente, las diferencias no significativas de los valores de Compactación y Resistencia a la Tracción sean debidas a que la humidificación al $20 \%$ no haya sido suficiente para provocar una dispersión considerable de las arcillas (en COA) como lo permitiría una total saturación. Nannucci (2009) mediante Brazilian test, encontró diferencias significativas contrastando un suelo tratado con una solución sódica con otro no tratado humedeciendo las muestras al 25\%. Falciani (2009), 
utilizando el mismo test, suelo y humedad, solamente encontró valores de Resistencia a la Tracción mayores en el tratamiento testigo respecto al tratamiento sodificado en aquellas muestras preparadas a paridad de tensión de compresión y con suelo tamizado. En aquellas muestras realizadas a paridad de tensión de compresión y sobre suelo no tamizado no halló ninguna diferencia entre ambos tratamientos. A paridad de volumen y suelo tamizado, la resistencia a la tracción tampoco difirió entre ambos tratamientos al igual que en las muestras preparadas a paridad de volumen y suelo no tamizado (como en el presente ensayo).

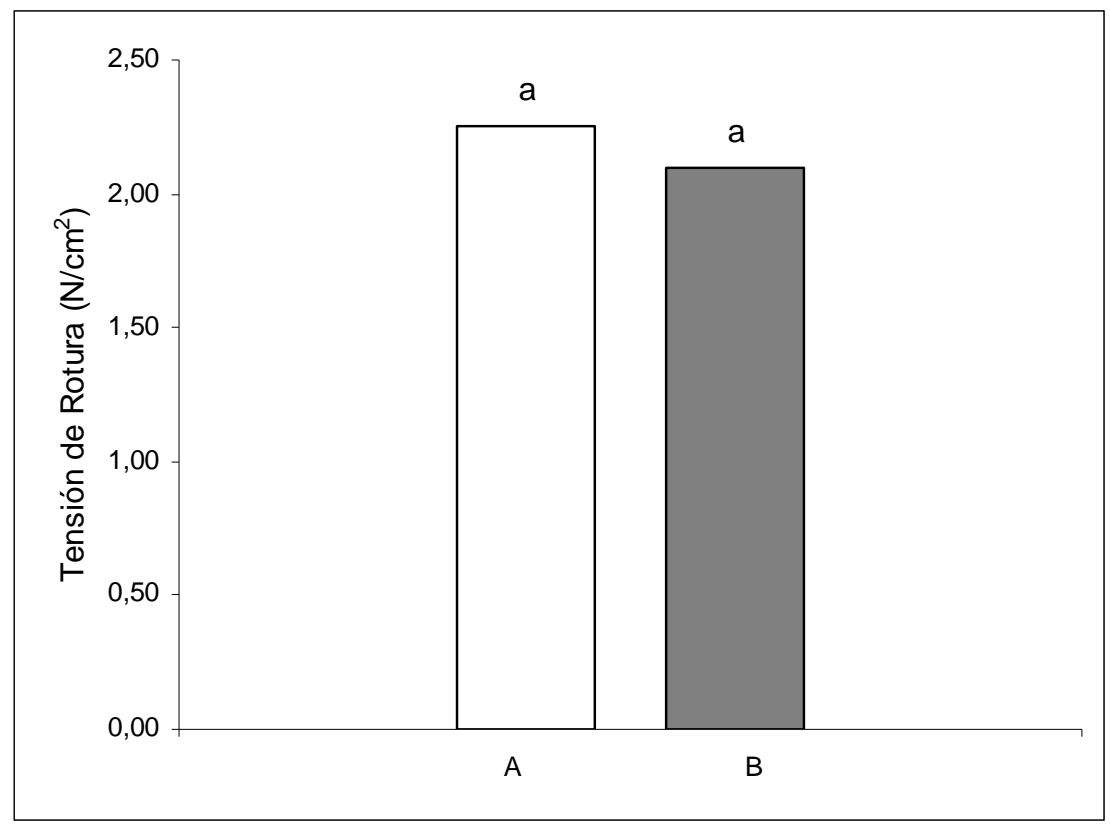

Figura 38: Tensión de Rotura de Cilindros por Brazilian Test de COA vs. COB.(Letras diferentes denotan diferencias significativas). 
Barzegar et al.(1994 $)$ compararon la resistencia a rotura de diversos suelos sometidos a soluciones conteniendo $\mathrm{NaCl}$, $\mathrm{CaCl}_{2}$ y $\mathrm{MgSO}_{4}$ en diferentes proporciones, luego llevados sucesivamente a Límite Plástico y Límite Líquido, finalmente secados al aire y sometidos a Brazilian Test. Estos autores encontraron que suelos sometidos a soluciones con mayor contenido de $\mathrm{Na}^{+}$presentaron mayor resistencia a rotura y mayor cantidad de arcillas dispersas espontáneamente que aquellos suelos sometidos a soluciones con mayor concentración de $\mathrm{Ca}^{++} \mathrm{y}$ $\mathrm{Mg}^{++}$. El contenido de humedad (\% p/p) a Límite Líquido de los 5 suelos estudiados en dicho trabajo fue: 0,323-0,338-0,556$0,246-0,274$, en todos los casos superiores a la humedad a la que fueron llevados ambos tratamientos en esta tesis. 
Tabla 16: Resultados de las pruebas de Brazilian Test.

\begin{tabular}{|c|c|c|c|c|c|c|c|c|c|}
\hline \multirow[b]{2}{*}{ Muestra } & \multicolumn{2}{|c|}{ Pre compactación } & \multirow[b]{2}{*}{$\begin{array}{l}\text { Compactación } \\
\qquad(\mathrm{kPa})\end{array}$} & \multicolumn{2}{|c|}{ Pos compactación } & \multicolumn{3}{|c|}{ Secado al aire } & \multirow{2}{*}{$\begin{array}{c}\text { Tensión } \\
\text { de } \\
\text { Rotura } \\
\left(\mathrm{N} / \mathrm{cm}^{2}\right)\end{array}$} \\
\hline & $\begin{array}{c}\text { Densidad } \\
\left(\mathrm{g} / \mathrm{cm}^{3}\right)\end{array}$ & $\begin{array}{l}\text { Porosidad } \\
\text { (\%) }\end{array}$ & & $\begin{array}{c}\text { Densidad } \\
\left(\mathrm{g} / \mathrm{cm}^{3}\right)\end{array}$ & $\begin{array}{l}\text { Porosidad } \\
\text { (\%) }\end{array}$ & $\begin{array}{c}\text { Densidad } \\
\left(\mathrm{g} / \mathrm{cm}^{3}\right)\end{array}$ & $\begin{array}{l}\text { Porosidad } \\
\text { (\%) }\end{array}$ & $\begin{array}{c}\text { Humedad } \\
(\%)\end{array}$ & \\
\hline COA 1 & 0,71 & 73,13 & 73,3 & 1,26 & 52,33 & 1,32 & 50,20 & 6,6 & 1,39 \\
\hline COA 2 & 0,76 & 71,47 & 40,5 & 1,46 & 44,86 & 1,36 & 48,57 & 9,8 & 1,74 \\
\hline COA 3 & 0,81 & 69,40 & 40,5 & 1,09 & 58,72 & 1,21 & 54,26 & 12,1 & 1,55 \\
\hline COA 4 & 0,84 & 68,42 & 70,1 & 1,27 & 52,02 & 1,31 & 50,40 & 7,9 & 2,80 \\
\hline COA 5 & 0,82 & 69,08 & 53,2 & 1,27 & 52,02 & 1,34 & 49,59 & 10,9 & 3,89 \\
\hline $\begin{array}{c}\text { Media } \\
\text { COA }\end{array}$ & 0,78 & 70,41 & 55,5 & 1,26 & 52,39 & 1,31 & 50,71 & 9,5 & 2,26 \\
\hline COB 1 & 0,83 & 68,56 & 40,2 & 1,31 & 50,74 & 1,37 & 48,36 & 5,0 & 1,79 \\
\hline COB 2 & 0,83 & 68,76 & 49,0 & 1,27 & 52,02 & 1,41 & 46,64 & 8,0 & 1,99 \\
\hline COB 3 & 0,84 & 68,42 & 57,4 & 1,31 & 50,41 & 1,41 & 46,82 & 8,9 & 2,50 \\
\hline COB 4 & 0,90 & 65,87 & 54,2 & 1,29 & 51,23 & 1,31 & 50,40 & 13,5 & 1,88 \\
\hline COB 5 & 0,90 & 65,87 & 68,4 & 1,29 & 51,23 & 1,36 & 48,57 & 8,3 & 2,38 \\
\hline $\begin{array}{c}\text { Media } \\
\text { COB }\end{array}$ & 0,86 & 67,55 & 53,8 & 1,30 & 51,13 & 1,37 & 48,19 & 8,7 & 2,10 \\
\hline
\end{tabular}




\subsection{Pruebas de Compresión y Corte. 10.5.1. Curvas de Compresión.}

A continuación se muestran los gráficos de las Líneas de Compresión y tablas de análisis estadísticos obtenidos de la Compresión Uniaxial para todos los tratamientos de ambos suelos (CD $18 \%$ de $\mathrm{H}^{\circ}$, CD $8 \%$ de $\mathrm{H}^{\circ}$, OZ $15 \%$ de $\mathrm{H}^{\circ}$ y OZ $5 \%$ de $\mathrm{H}^{\circ}$ ) (Figura 40 a Figura 49 y Tabla 17 a Tabla 21).

Se recuerdan de forma esquemática las diferentes pruebas realizadas de compresión y corte (Figura 39) y las categorías de agregados que fueron ensayadas en el suelo Ozzano:

I. agregados de $3,36-5 \mathrm{~mm}$ de diámetro.

II. agregados de $2-3,36 \mathrm{~mm}$ de diámetro.

III. agregados de 0,5-2 mm de diámetro.

IV. agregados $<0,5 \mathrm{~mm}$ de diámetro.

Tabla 17: Volumen Específico Inicial y Final de los tratamientos del suelo Cardone.

\begin{tabular}{c|c|c}
\hline \hline Tratamiento & Vol. Esp. Inicial $\left(\mathrm{cm}^{3} / \mathrm{g}\right)$ & Vol. Esp. Final $\left(\mathrm{cm}^{3} / \mathrm{g}\right)$ \\
\hline CDA $18 \% \mathrm{H}^{\circ}$ & $0,824 \mathrm{a}$ & $0,596 \mathrm{a}$ \\
$\mathrm{CDB} 18 \% \mathrm{H}^{\circ}$ & $0,840 \mathrm{a}$ & $0,540 \mathrm{~b}$ \\
\hline $\mathrm{CDA} 8 \% \mathrm{H}^{\circ}$ & $0,847 \mathrm{~b}$ & $0,700 \mathrm{~b}$ \\
$\mathrm{CDB} 8 \% \mathrm{H}^{\circ}$ & $0,982 \mathrm{a}$ & $0,837 \mathrm{a}$ \\
\hline \hline
\end{tabular}

Letras diferentes en la misma columna denotan diferencias estadísticas significativas $($ LSD $p<0,05)$ 


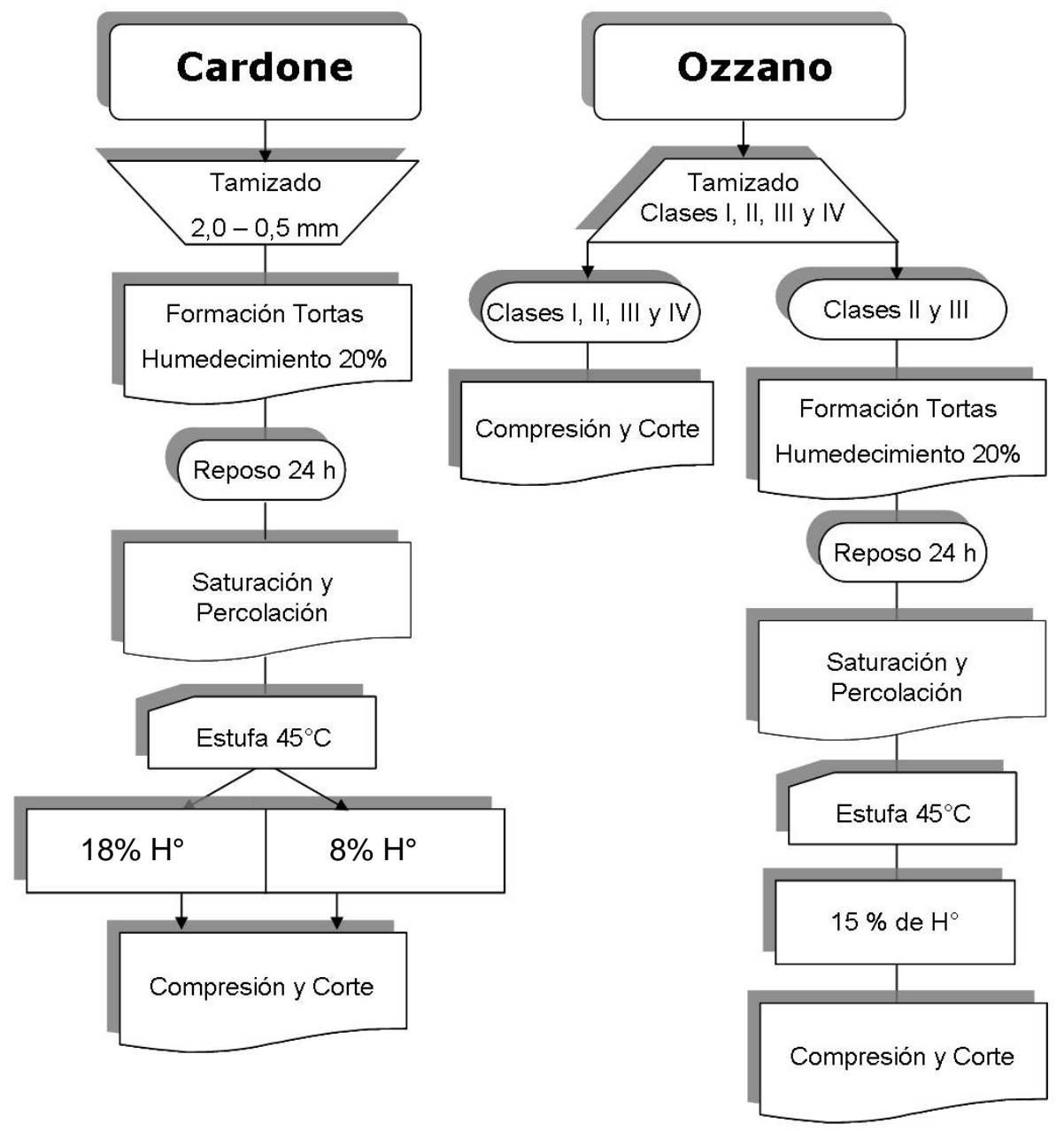

Figura 39: organigrama ilustrativo de las pruebas conducidas con compresión y corte. 


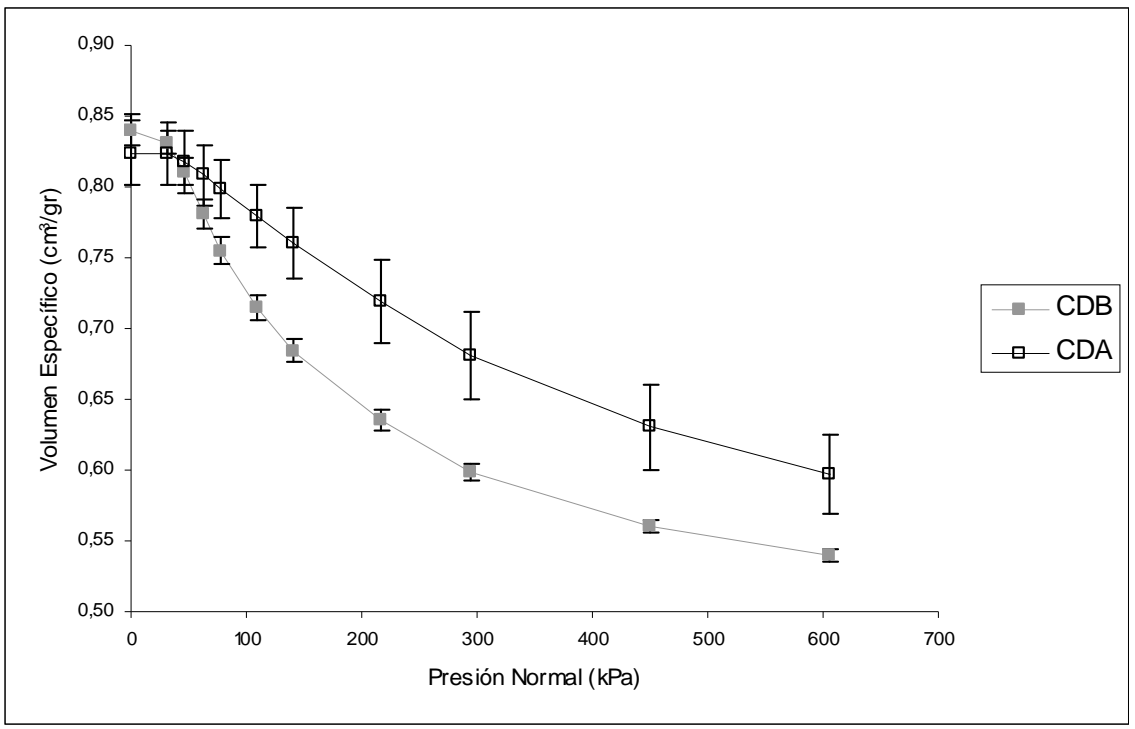

Figura 40 : Líneas de Compresión CDA vs CDB al 18\% de humedad.

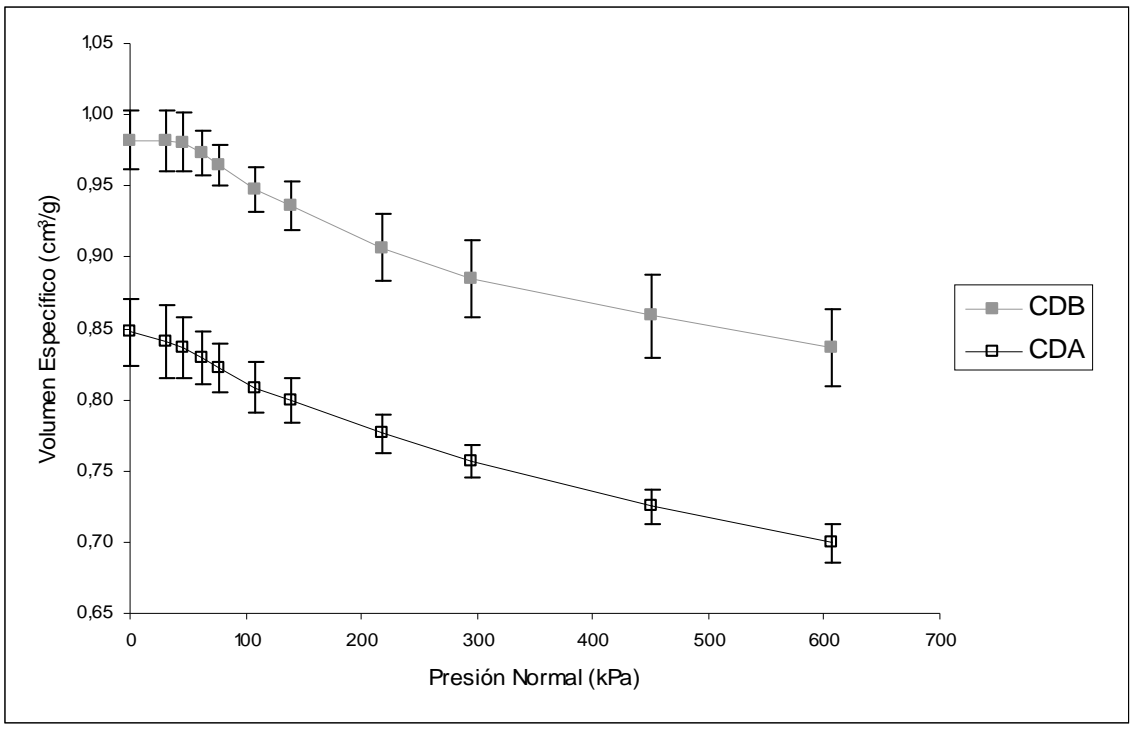

Figura 41: Líneas de Compresión CDA vs. CDB al 8\% de humedad. 


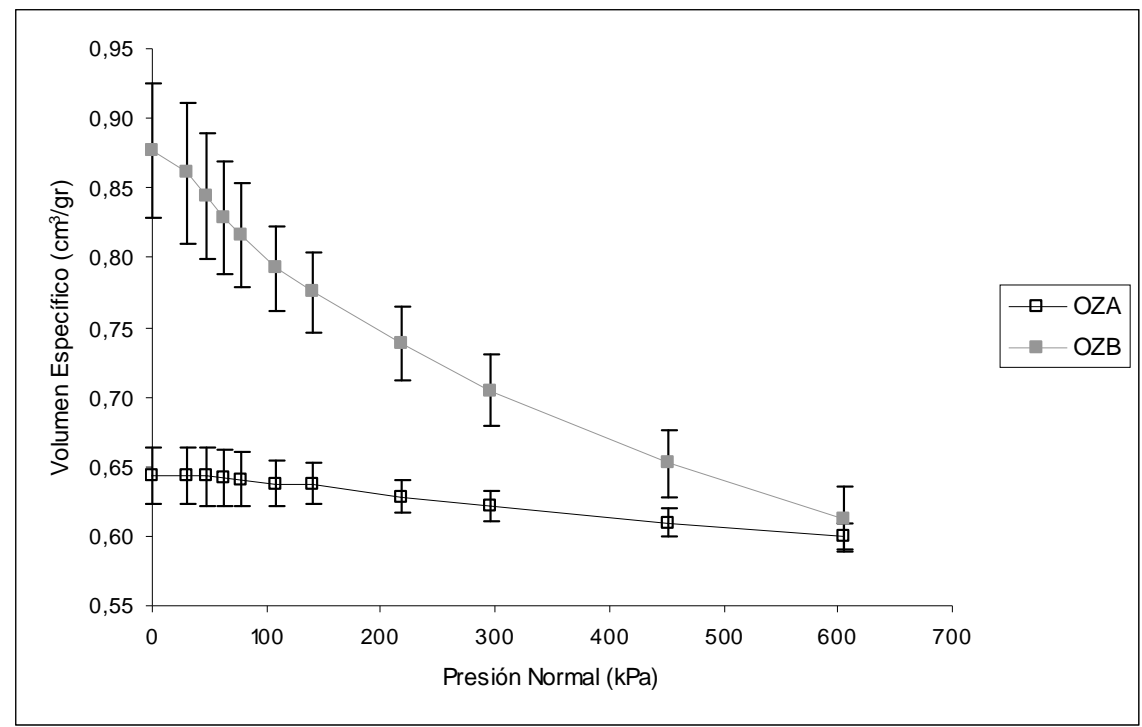

Figura 42: Líneas de Compresión OZA vs. OZB Clase II al 15\% de humedad.

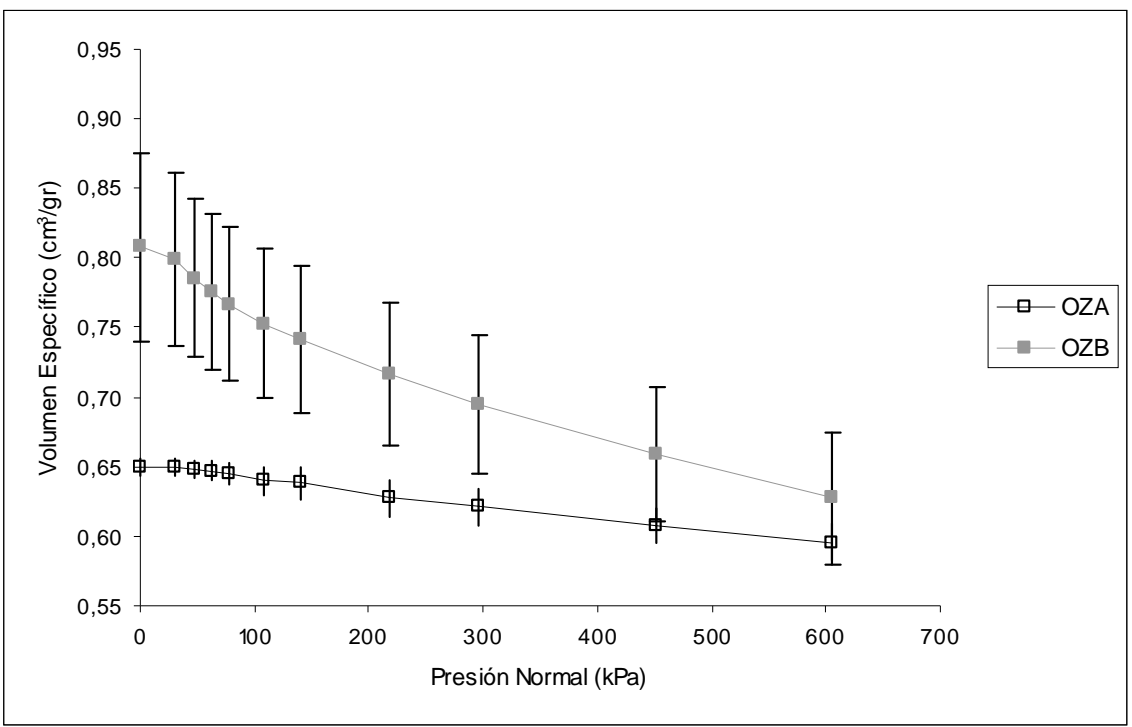

Figura 43: Líneas de Compresión OZA vs. OZB Clase III al 15\% de humedad. 
Tabla 18: Comparación del Volumen Específico Inicial y Final de OZA vs. OZB al $15 \%$ de $H^{\circ}$ y para ambas clases de agregados ensayadas (II y III).

\begin{tabular}{|c|c|c|c|c|}
\hline \multirow{2}{*}{ Tratamiento } & \multicolumn{2}{|c|}{$\begin{array}{l}\text { Vol. Esp. Inicial }\left(\mathrm{cm}^{3} / \mathrm{g}\right) \\
\end{array}$} & \multicolumn{2}{|c|}{ Vol. Esp. Final $\left(\mathrm{cm}^{3} / \mathrm{g}\right)$} \\
\hline & II & III & II & III \\
\hline OZA $15 \%$ de $\mathrm{H}^{\circ}$ & $0,644 \quad b$ & $0,650 \quad b$ & $0,599 \quad \mathrm{a}$ & 0,596 \\
\hline OZB $15 \%$ de $\mathrm{H}^{\circ}$ & $0,877 \quad a$ & $0,808 \quad a$ & 0,612 & 0,627 \\
\hline
\end{tabular}

Letras diferentes en la misma columna denotan diferencias estadísticas significativas $($ LSD $p<0,05)$

Tabla 19: Comparación de Volumen Específico Inicial y Final de Clase II vs. III para ambos tratamientos de Ozzano al 15\% de humedad.

\begin{tabular}{|c|c|c|c|c|}
\hline Clase Gr. & \multicolumn{2}{|c|}{ Vol. Esp. Inicial $\left(\mathrm{cm}^{3} / \mathrm{g}\right)$} & \multicolumn{2}{|c|}{ Vol. Esp. Final $\left(\mathrm{cm}^{3} / \mathrm{g}\right)$} \\
\hline OZ 15\% de $\mathrm{H}^{\circ}$ & OZA & OZB & OZA & OZB \\
\hline II & 0,644 & 0,877 & $0,599 \quad a$ & 0,612 \\
\hline III & 0,650 & 0,808 & $0,596 \quad a$ & 0,627 \\
\hline
\end{tabular}

Letras diferentes en la misma columna denotan diferencias estadísticas significativas $($ LSD $p<0,05)$

Tabla 20: Comparación de Vol. Esp. Inicial y Final entre Clases granulométricas (I a IV) para ambos tratamientos de Ozzano al $5 \%$ de humedad.

\begin{tabular}{ccccccccc}
\hline \hline Clase Gr. & \multicolumn{3}{c}{ Vol. Esp. Inicial (cm3/g) } & \multicolumn{4}{c}{ Vol. Esp. Final (cm3/g) } \\
\cline { 2 - 9 } OZ 5\% & $H^{\circ}$ OZ A & \multicolumn{2}{c}{ OZ B } & \multicolumn{2}{c}{ OZ A } & \multicolumn{2}{c}{ OZ B } \\
\hline I & 1,01 & a & 1,21 & a & 0,89 & a & 0,81 & a \\
II & 0,98 & b & 1,15 & b & 0,87 & b & 0,82 & a \\
III & 0,94 & c & 0,99 & c & 0,84 & c & 0,85 & a \\
IV & 0,82 & d & 0,89 & d & 0,68 & d & 0,74 & b \\
\hline
\end{tabular}

Letras diferentes en la misma columna denotan diferencias estadísticas significativas (LSD $\mathrm{p}<0,05)$ 


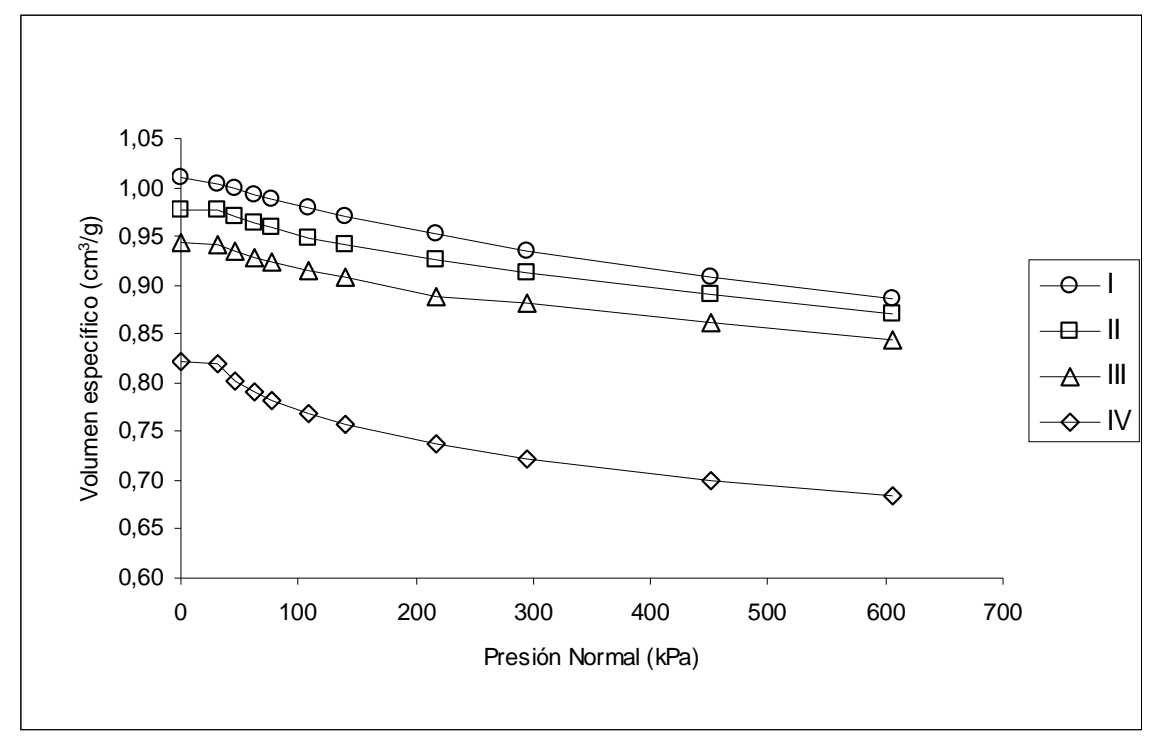

Figura 44: Líneas de Compresión de OZA al 5\% de humedad, Todas las Clases Granulométricas.

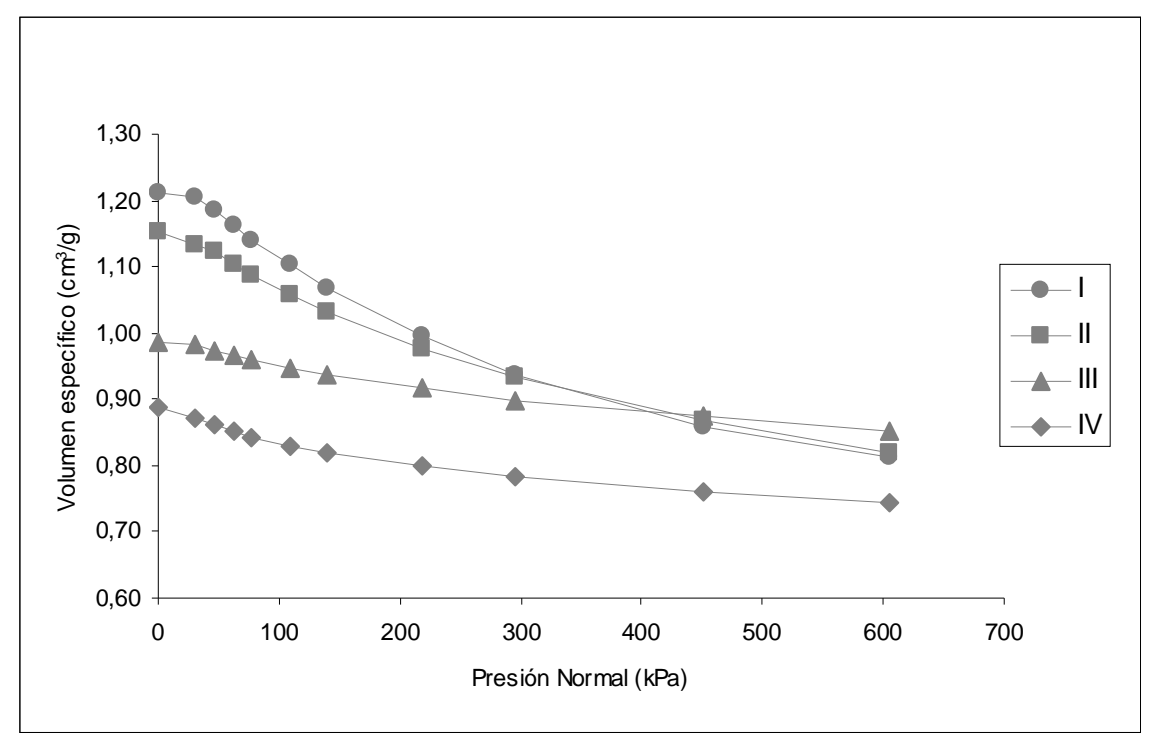

Figura 45: Líneas de Compresión de OZB al 5\% de humedad, Todas las Clases Granulométricas. 


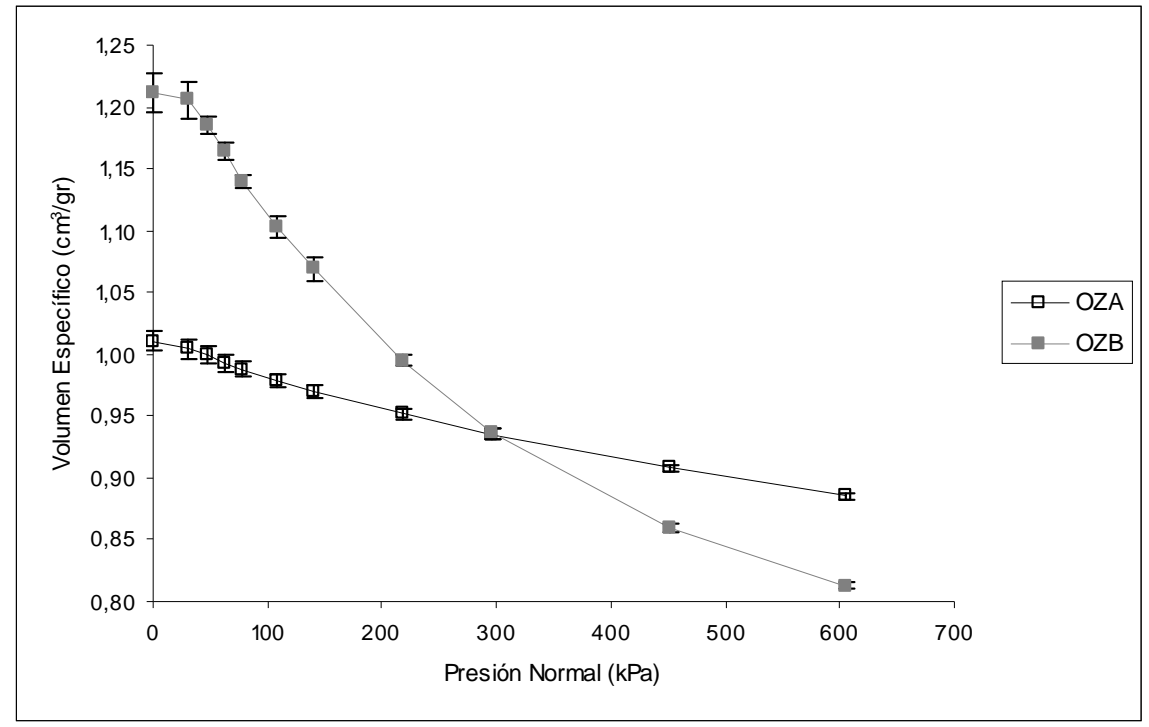

Figura 46: Líneas de Compresión OZA vs. OZB Clase I al 5\% de humedad.

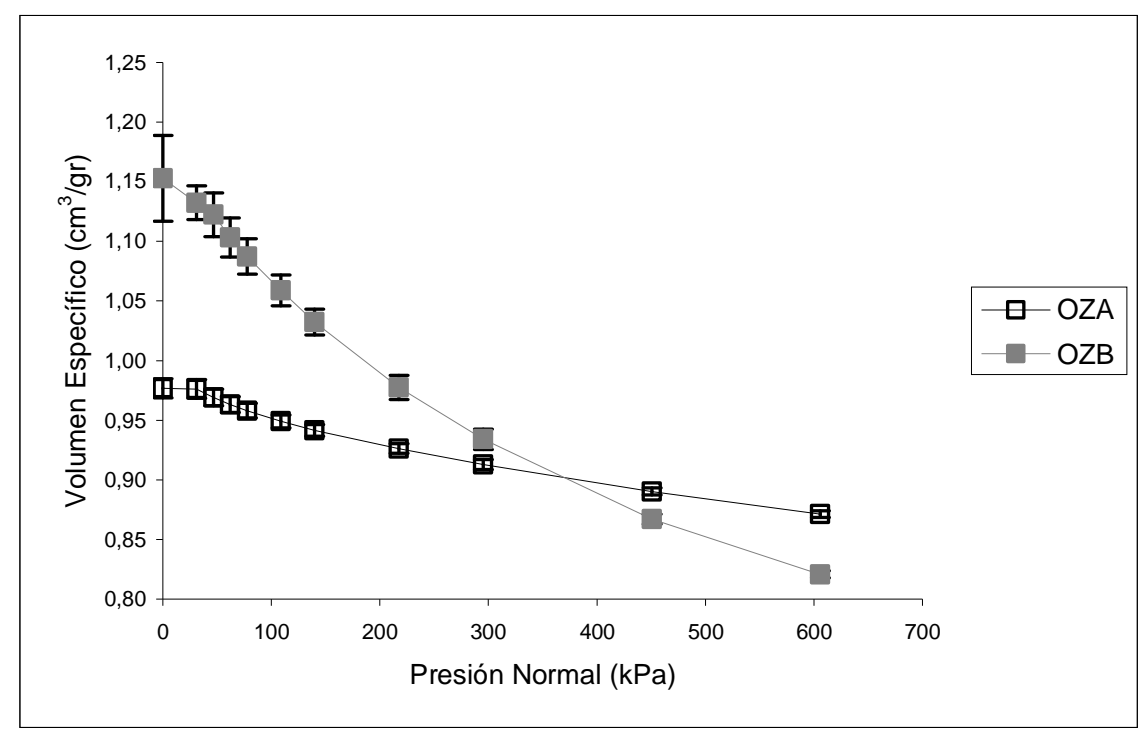

Figura 47: Líneas de Compresión de OZA vs. OZB Clase II al 5\% de humedad. 


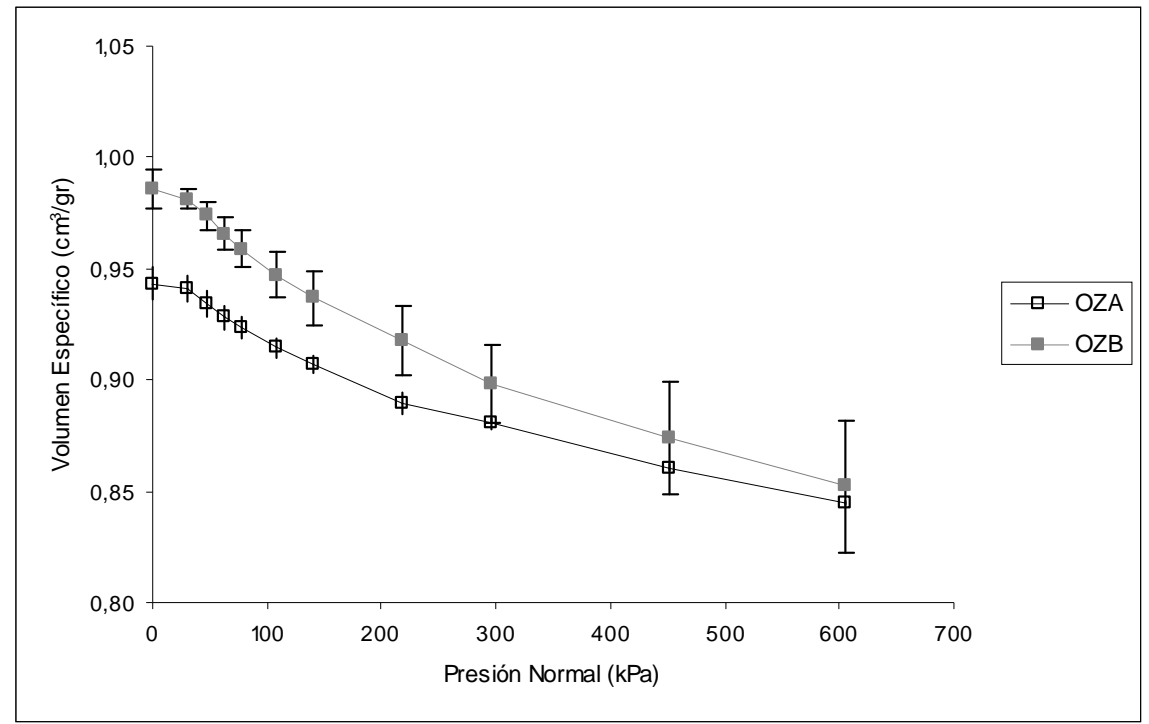

Figura 48: Líneas de Compresión OZA vs. OZB Clase III al 5\% de humedad.

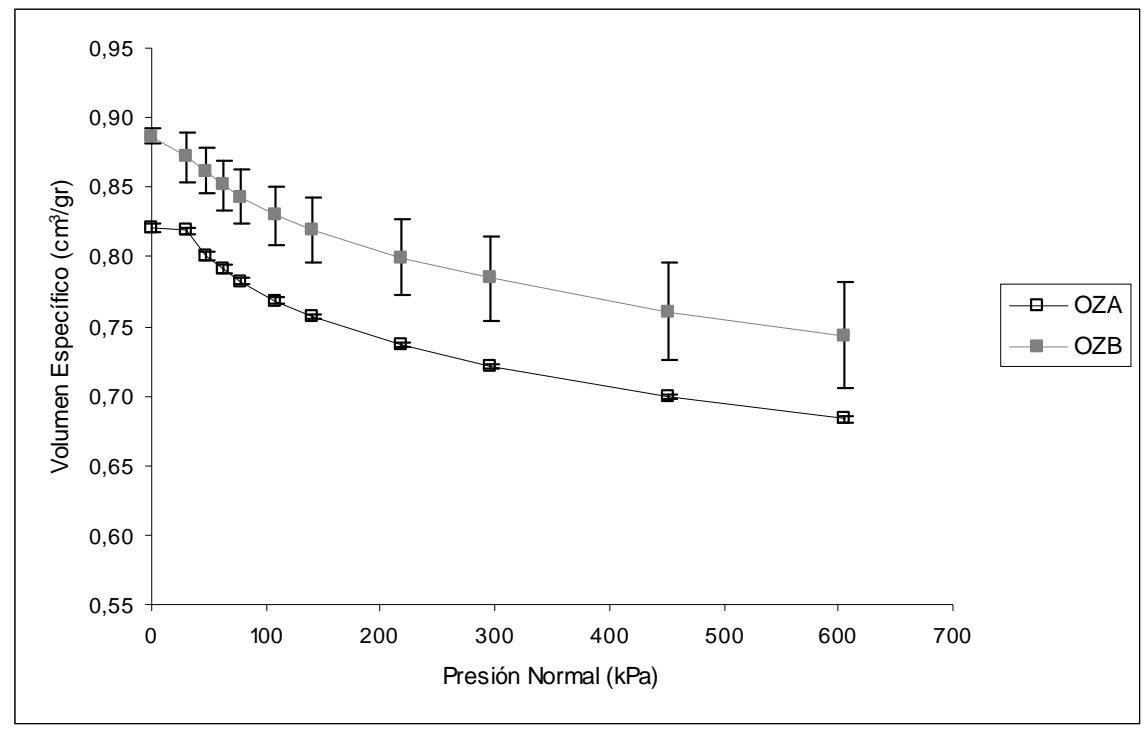

Figura 49: Líneas de Compresión OZA vs. OZB Clase IV al 5\% de humedad. 
Tabla 21: Comparación de Volumen Específico Inicial y Final entre tratamientos A vs. B para todas las Clases de agregados de Ozzano al $5 \%$ de humedad.

\begin{tabular}{|c|c|c|c|c|c|c|c|c|}
\hline \multirow{2}{*}{ Tratamiento } & \multicolumn{4}{|c|}{ Vol. Esp. Inicial $(\mathrm{cm} 3 / \mathrm{g})$} & \multicolumn{4}{|c|}{ Vol. Esp. Final $(\mathrm{cm} 3 / \mathrm{g})$} \\
\hline & $T$ & II & III & IV & $T$ & II & III & IV \\
\hline OZA $5 \% \mathrm{H}^{\circ}$ & $1,01 \mathrm{~b}$ & $0,98 \mathrm{~b}$ & $0,94 \mathrm{~b}$ & $0,82 \mathrm{~b}$ & $0,89 a$ & $0,87 \mathrm{a}$ & $0,84 \mathrm{a}$ & $0,68 \mathrm{~b}$ \\
\hline OZB $5 \% \mathrm{H}^{\circ}$ & $1,21 \mathrm{a}$ & $1,15 \mathrm{a}$ & $0,99 a$ & $0,89 a$ & $0,81 \mathrm{~b}$ & $0,82 \mathrm{~b}$ & $0,85 \mathrm{a}$ & $0,74 \mathrm{a}$ \\
\hline
\end{tabular}

Letras diferentes en la misma columna denotan diferencias estadísticas significativas (LSD $\mathrm{p}<0,05)$.

Las Líneas de Compresión y el análisis estadístico de los valores de Volumen Específico Inicial y Final permiten, en parte, conocer el comportamiento de los suelos a la aplicación de Tensiones Normales y por ende su susceptibilidad a la compresión. Otro aspecto fundamental para conocer dicho comportamiento es el análisis de las Líneas Virgen, especialmente su pendiente $(\lambda)$, analizadas más adelante.

De los gráficos y tablas expuestos se desprende, en primera instancia, las diferencias encontradas en los valores de Volumen Específico Inicial donde los tratamientos más sodificados (A) presentaron valores más bajos de éste parámetro (Tabla 17, Tabla 18 y Tabla 21). Numerosos trabajos han encontrado que los suelos afectados por sodio se caracterizan por un aumento de su densidad (Amioti y Bravo, 2006; Kaur et al., 2006; Jassogne et al., 2006; Currie et al., 2006). Rengasamy y Olsson (1991) manifestaron que la presencia de arcillas dispersas en los agregados produce diversos efectos verificados sobre la 
mecánica de los suelos agrícolas. Dichos efectos son asociados, principalmente, a incrementos de la fuerza de tracción necesaria para la labranza, a la formación de costras que impiden la emergencia de las plantas y facilitan la erosión, a una menor porosidad y a una mayor resistencia de los agregados a ser penetrados por las raíces.

Puede hipotetizarse que los agregados de los tratamientos B estaban a su vez constituidos por aglomeración de agregados más pequeños, otorgándoles mayor porosidad lo que redundaría en valores de Volumen especifico Inicial mayores y ayudaría a entender las diferencias observadas en las pruebas preliminares de disgregación. Esto explicaría también como las curvas de compresión del tratamiento $\mathrm{OZ}$ al $5 \%$ de humedad se van asemejando entre los tratamientos $\mathrm{A}$ y $\mathrm{B}$ a medida que disminuye el tamaño de los agregados (Figura 46 a Figura 49). Los agregados de mayor tamaño de B estarían conformados por un mayor número de pequeños agregados y a medida que su diámetro disminuye conforme las diferentes clases granulométricas, su porosidad intra-agregado disminuiría arribando al caso de la Clase IV donde encontraríamos prácticamente partículas individuales (Figura 45) y por lo tanto comportamientos más similares. Por otro lado los agregados de los tratamientos A presentarían una constitución masiva, densa y fuertemente cementada por acción de las arcillas dispersas, otorgándole mayor densidad (menor Volumen Específico Inicial). A su vez, en aquellos tratamientos sometidos a humectación - 
desecación se habría favorecido la dispersión de las arcillas de los tratamientos $A$, las que se ubicarían en los espacios interagregados disminuyendo así su porosidad (Figura 42, Figura 43 y Tabla 18).

De la observación de las formas que adoptan las Curvas de Compresión y con la ayuda de las tablas donde se muestran los valores medios de Volumen Específico y la existencia o no de diferencias, se puede observar un comportamiento disímil entre los tratamientos más sodificados y aquellos con menor contenido de sodio (Tabla 17, Tabla 18 y Tabla 21). En general, la reducción de Volumen Específico ante la aplicación de Tensiones normales fue menos pronunciada en los tratamientos A (más sodificados), debido posiblemente a la mayor densidad y cementación de las uniones intra-agregados como fue expresado en párrafos anteriores. A su vez en aquellos tratamientos con ciclos humedecimiento - desecación las arcillas dispersas ubicadas en los espacios inter-agregados habrían incrementado la tenacidad de las uniones entre agregados favoreciendo así el aumento de la resistencia a la compresión además de provocar una densificación del material (Hettiaratchi, 1987). En el caso de los tratamientos B, la mayor porosidad de sus agregados, y por ende mayor friabilidad, habría conferido menor resistencia a la compresión uniaxial y por lo tanto mayores reducciones de Volumen Específico que su contraparte A.

Un suelo más poroso y con agregados más friables es más fácilmente compactable debido a que ante la aplicación de 
tensiones normales sus agregados no solo se romperán con mayor facilidad en agregados de menor tamaño sino que a su vez esos agregados más pequeños tendrán poros donde reacomodarse y alojarse presentando menor resistencia a la compresión.

En el caso específico de $O Z$ al $15 \%$ de humedad se observó que en ambos tratamientos ( $\mathrm{A}$ y B), el comportamiento de las dos clases granulométricas fue similar (II y III), no encontrándose diferencias significativas en los parámetros Volumen Específico Inicial y Final entre ambas clases para un mismo Tratamiento (Tabla 19). La ausencia de diferencias de comportamiento entre diferentes dimensiones de agregados (en OZ al $15 \%$ ) podría ser debida a que durante el proceso de humidificación - desecación realizado sobre los materiales, los agregados habrían sufrido procesos de disgregación y/o dispersión que habrían reducido el tamaño de los agregados (en mayor proporción en la clase II) disminuyendo las diferencias en el tamaño final de los agregados entre ambas clases y por ende su comportamiento ante la compresión uniaxial. Obsérvese que en las pruebas de Ozzano al $5 \%$ de humedad (en la que no hubo ciclo humectación - desecación) sí se verificaron diferencias entre clases (Tabla 20).

En el caso de OZA al 5\% de humedad (Figura 44), el Volumen Específico Inicial de los ensayos realizados sobre las diferentes clases granulométricas, presentó un gradiente desde la clase I a IV, manteniendo el mismo gradiente en los valores de Volumen 
Específico Final (Tabla 20). No obstante ésta diferencia de Volumen Específico, el casi paralelismo de las curvas de compresión da idea de la alta densidad de los agregados de éste suelo con mayor contenido de sodio.

Para el caso de OZB al 5\% de humedad la disminución de diferencias entre los valores de volumen especifico Final entre clases granulométricas denotaría la mayor susceptibilidad a la compresión de los agregados de mayor tamaño con respecto a los más pequeños ya que los primeros, partiendo de valores específicos iniciales más altos, arriban a situaciones similares de éste parámetro acortando sus diferencias (Tabla 20 y Figura 45) en contraposición a OZA.

\subsubsection{Tensión de Preconsolidación (Pc).}

De la Tabla 22 se desprende que, en general, se observó un incremento de los valores de $\mathrm{Pc}$ en los suelos con mayor contenido de sodio y sometidos a ciclos humedecimiento desecación. Como se mencionó anteriormente, el efecto dispersivo del sodio produjo un reordenamiento de las arcillas dispersas ubicándose en los espacios inter e intra agregados provocando una disminución de su volumen específico, fenómeno que pudo haber influido en el aumento de Pc. Sin embargo numerosos autores discrepan en la incidencia que tiene la densidad inicial del suelo sobre la Tensión de preconsolidación. Alexandrou y Earl (1998) encentraron que en suelos franco - 
arenosos los valores de Pc fueron directamente proporcionales a la densidad inicial, mientras que en suelos arcillosos Pc dependió únicamente del contenido hídrico. Imhoff et al. (2004) encontraron una estrecha relación entre la tensión de preconsolidación y densidad aparente, contenido de agua y de arcilla, en tres suelos de diferentes textura (arenoso, franco y arcilloso). Mosaddeghi et al. (2003) sostienen que el incremento de la Tensión de Preconsolidación fue marcadamente independiente de la densidad inicial del suelo pero marcadamente dependiente de la humedad. Lebert y Horn (1991) indicaron que la relación existente entre Pc y la densidad del suelo disminuye a medida que aumenta el contenido de arcilla.

En el caso de CD al $8 \%$ de humedad es posible que la fuerte disminución de agua sufrida en el ciclo humedecimiento desecación haya producido fracturas en el interior de la masa de suelo. Estas fracturas habrían ofrecido poca resistencia a la compresión uniaxial permitiendo una considerable disminución del Volumen Específico aún a Tensiones Normales bajas, reduciendo su Pc sin presentar diferencias significativas $(p<0,05)$ con respecto a su par menos sodificado. Barzegar et al. (1995) concluyeron que la Tensión de Rotura de suelos con diferentes clases de arcillas y sometidos a compactación, decreció con el incremento del número de ciclos de humectación - desecación. 
Tabla 22: Comparación del parámetro PC entre tratamientos A vs. $B$ para ambos suelos ensayados (CD y OZ).

\begin{tabular}{ccc}
\hline \multicolumn{3}{c}{ Tensión de Preconsolidación } \\
\hline \multicolumn{3}{c}{ CD 8\% de H } \\
\hline Tratamiento & $\mathrm{Pc}(\mathrm{kPa})$ & $\mathrm{p}<0,05$ \\
CDA & 63,83 & $\mathrm{a}$ \\
CDB & 74,62 & $\mathrm{a}$ \\
\hline \multicolumn{3}{c}{ CD 18\% de Ho } \\
\hline Tratamiento & $\mathrm{Pc}(\mathrm{kPa})$ & $\mathrm{p}<0,05$ \\
CDA & 71,87 & $\mathrm{a}$ \\
CDB & 39,48 & $\mathrm{~b}$ \\
\hline \multicolumn{3}{c}{ OZ 5\% de Ho } \\
\hline Tratamiento & $\mathrm{Pc}(\mathrm{kPa})$ & $\mathrm{p}<0,05$ \\
OZA I & 61,16 & $\mathrm{a}$ \\
OZB I & 56,69 & $\mathrm{a}$ \\
\hline OZA II & 53,81 & $\mathrm{~b}$ \\
OZB II & 63,45 & $\mathrm{a}$ \\
\hline OZA III & 51,26 & $\mathrm{a}$ \\
OZB III & 54,93 & $\mathrm{a}$ \\
\hline OZA IV & 35,79 & $\mathrm{a}$ \\
OZB IV & 46,16 & $\mathrm{a}$ \\
\hline & OZ 15\% de $\mathrm{H}^{\circ}$ & $\mathrm{P}$ \\
\hline Tratamiento & $\mathrm{Pc}(\mathrm{kPa})$ & $\mathrm{p}<0,05$ \\
OZA II & 94,55 & $\mathrm{a}$ \\
OZB II & 55,45 & $\mathrm{~b}$ \\
\hline OZA III & 89,91 & $\mathrm{a}$ \\
OZB III & 52,71 & $\mathrm{~b}$
\end{tabular}

Letras diferentes denotan diferencias estadísticas significativas (LSD $p<0,05)$ 
En Ozzano al 5\% de humedad prácticamente no existieron diferencias de Pc entre los materiales más y menos sodificados en las diferentes clases granulométricas ensayadas. Este resultado pudo deberse a que el material fue introducido en la cámara de compresión y corte en forma granular permitiendo que ambos tratamientos se comportaran de forma similar a tensiones normales bajas.

\subsubsection{Líneas Virgen.}

La Línea de Consolidación Virgen (también llamada línea de consolidación normal) responde a la ecuación (5) $v=N+\lambda$ $\ln (p)$ donde " $v$ " es el Volumen específico $=1 /$ densidad aparente (valor inverso de la densidad aparente) y " $p$ " es la Tensión Normal aplicada. Habitualmente se dibujan las Líneas Virgen en gráficos semilogarítmicos colocando en el eje de las $\mathrm{x}$ el In de la Tensión Normal y en el de las y el Volumen Específico $\left(\mathrm{cm}^{3} / \mathrm{g}\right)$.

A continuación se detallan los gráficos de las Líneas Virgen (Figura 50 a Figura 61) y tablas de análisis estadísticos de su pendiente $(\lambda)$ y término independiente $(\mathrm{N})$ (Tabla 23 a Tabla 26) para todos los tratamientos de ambos suelos (CD $8 \%$ de $\mathrm{H}^{\circ}$, CD $18 \%$ de $\mathrm{H}^{\circ}$, OZ $5 \%$ de $\mathrm{H}^{\circ}$ y OZ $15 \%$ de $\mathrm{H}^{\circ}$ ). 


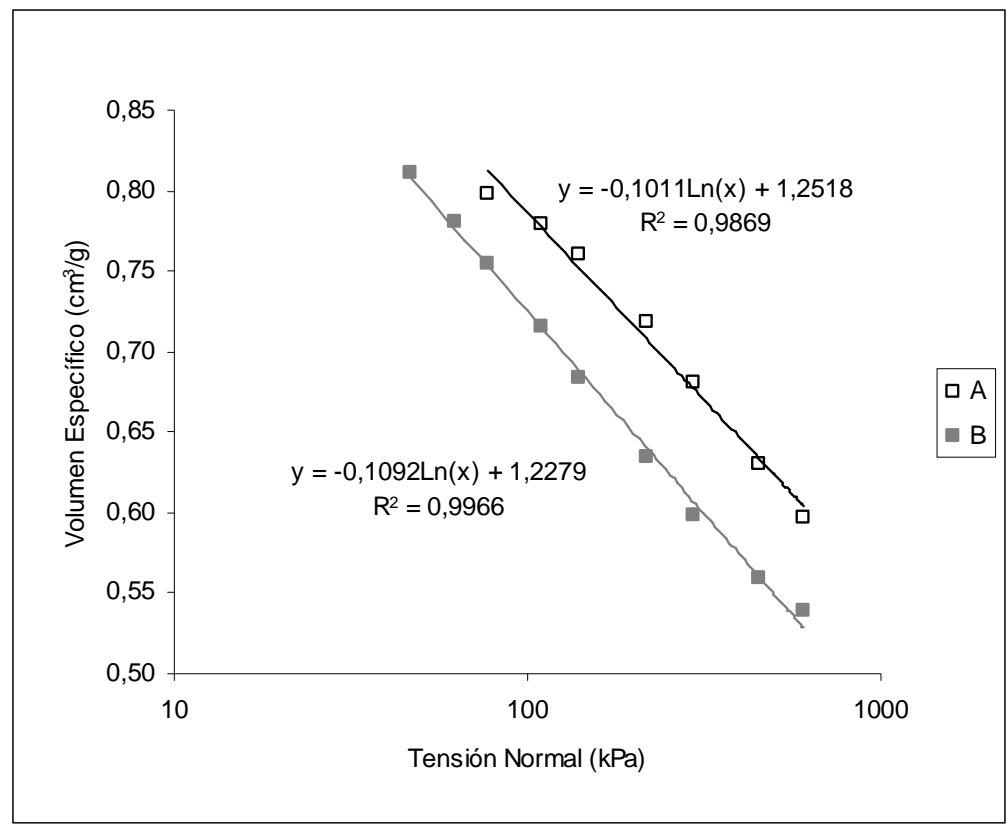

Figura 50: Líneas Virgen de CDA vs. CDB al 18\% de humedad.

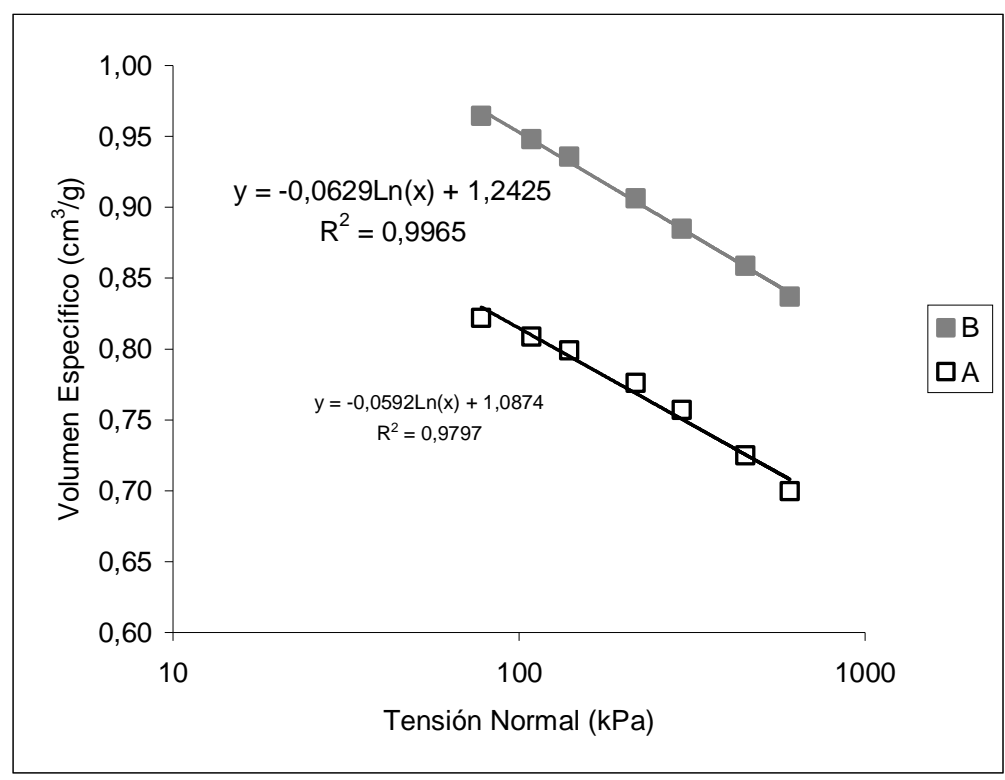

Figura 51: Líneas Virgen de CDA vs. CDB al 8\% de humedad. 


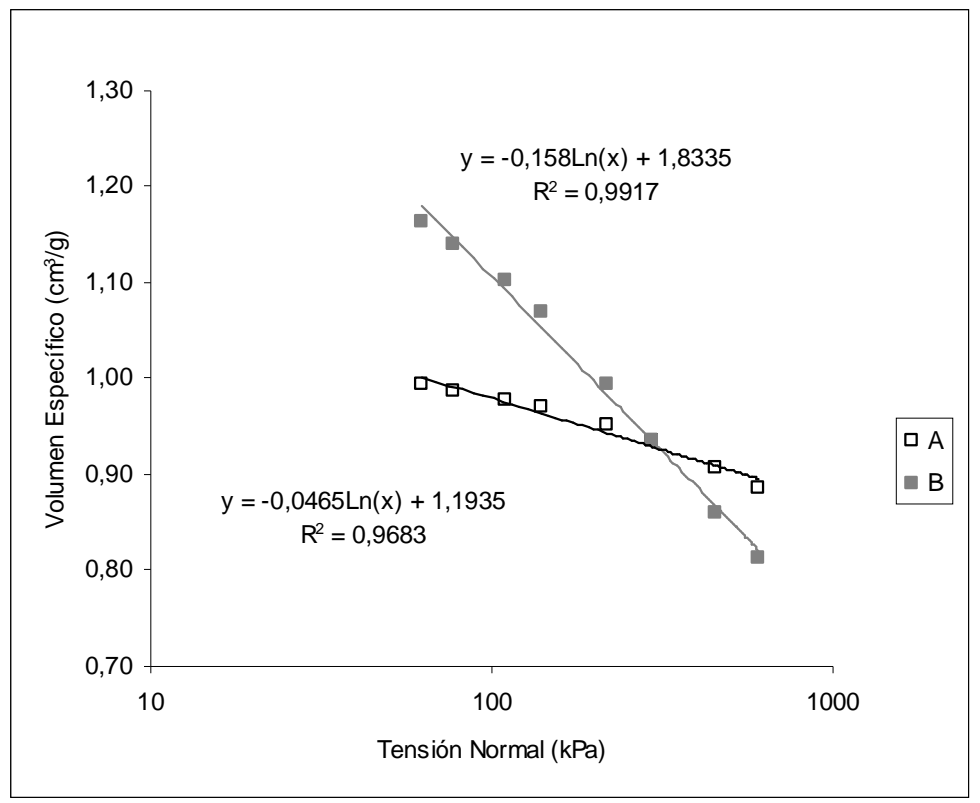

Figura 52: Líneas Virgen OZA vs. OZB Clase I al 5\% de humedad.

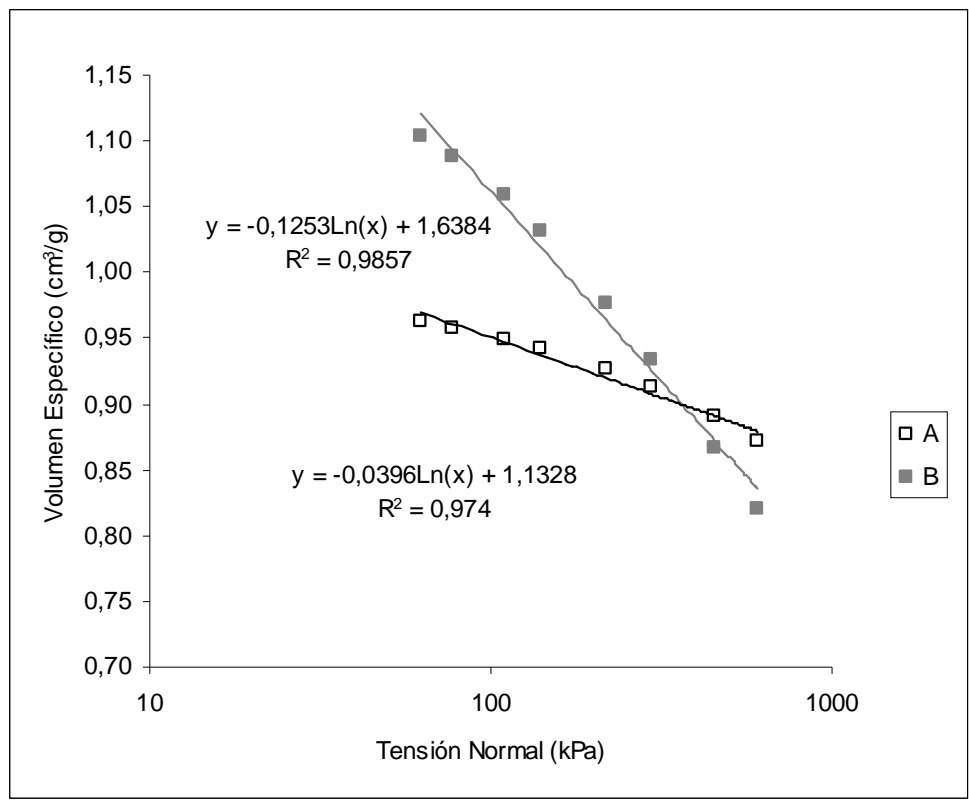

Figura 53: Líneas Virgen OZA vs. OZB Clase II al 5\% de humedad. 


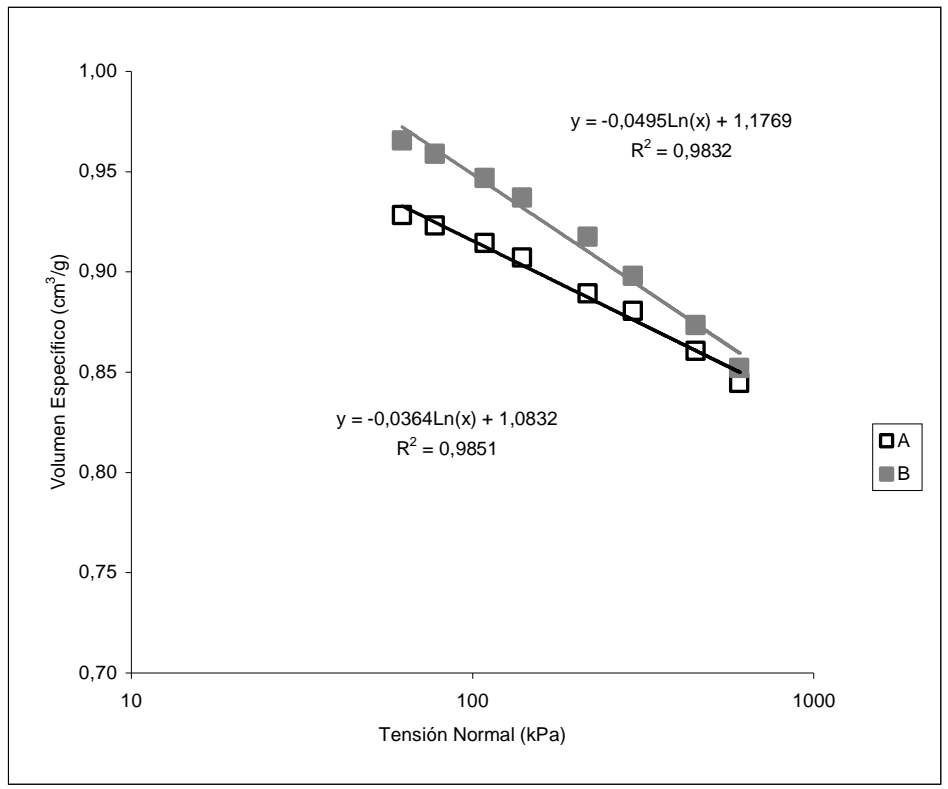

Figura 54: Líneas Virgen de OZA vs. OZB Clase III al 5\% de humedad.

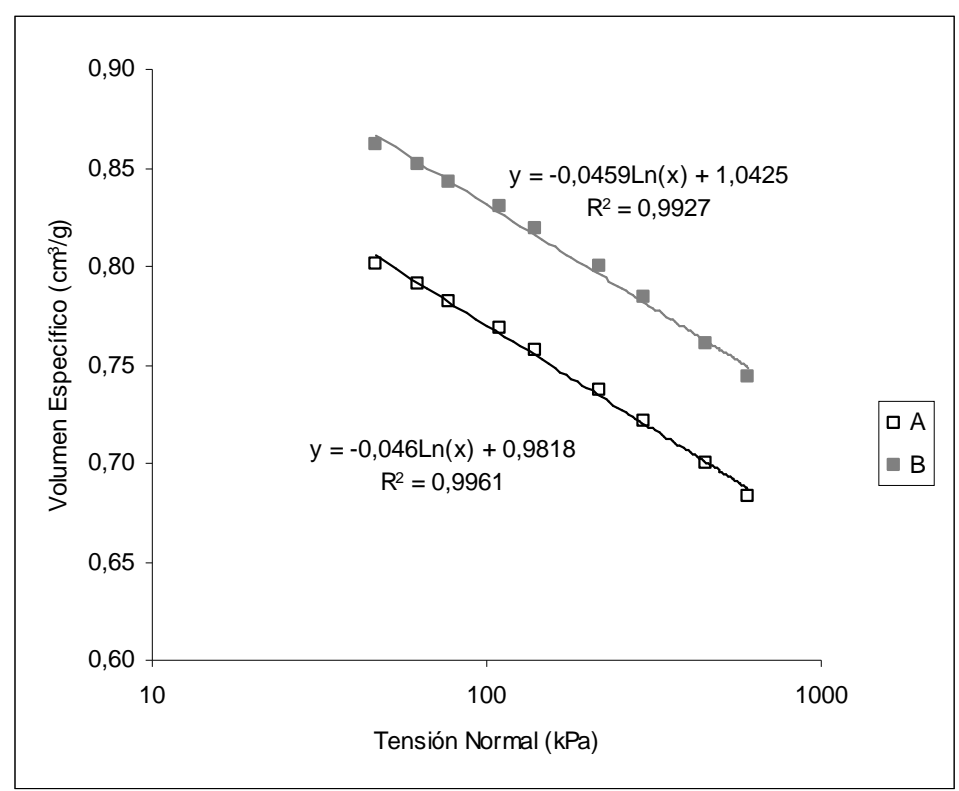

Figura 55: Líneas Virgen OZA vs. OZB Clase IV al 5\% de humedad. 


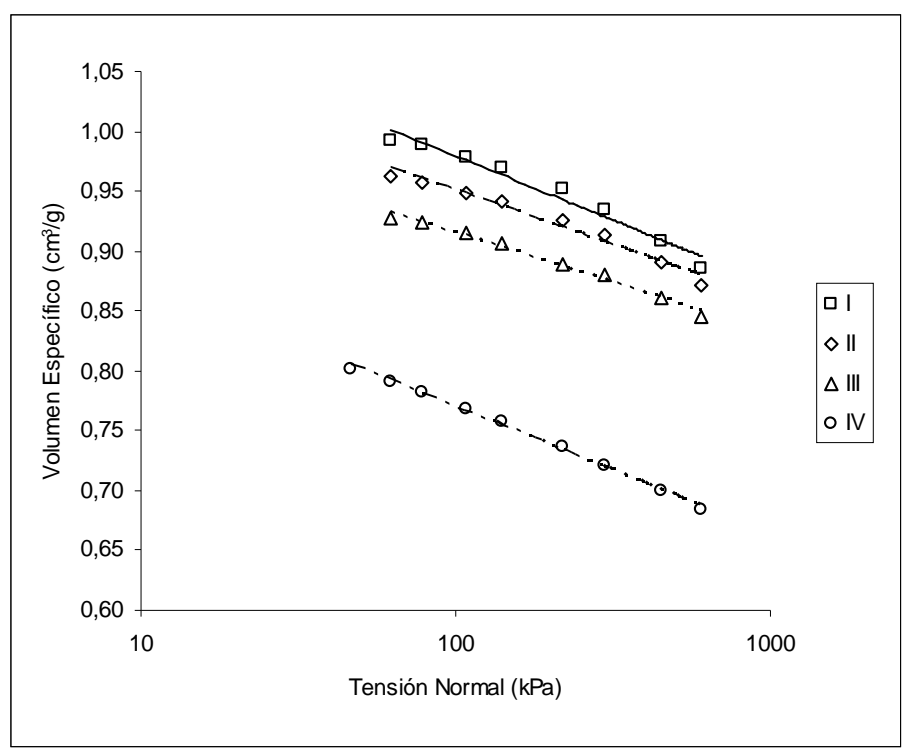

Figura 56: Líneas Virgen de OZA al 5\% de humedad, Todas las Clases Granulométricas.

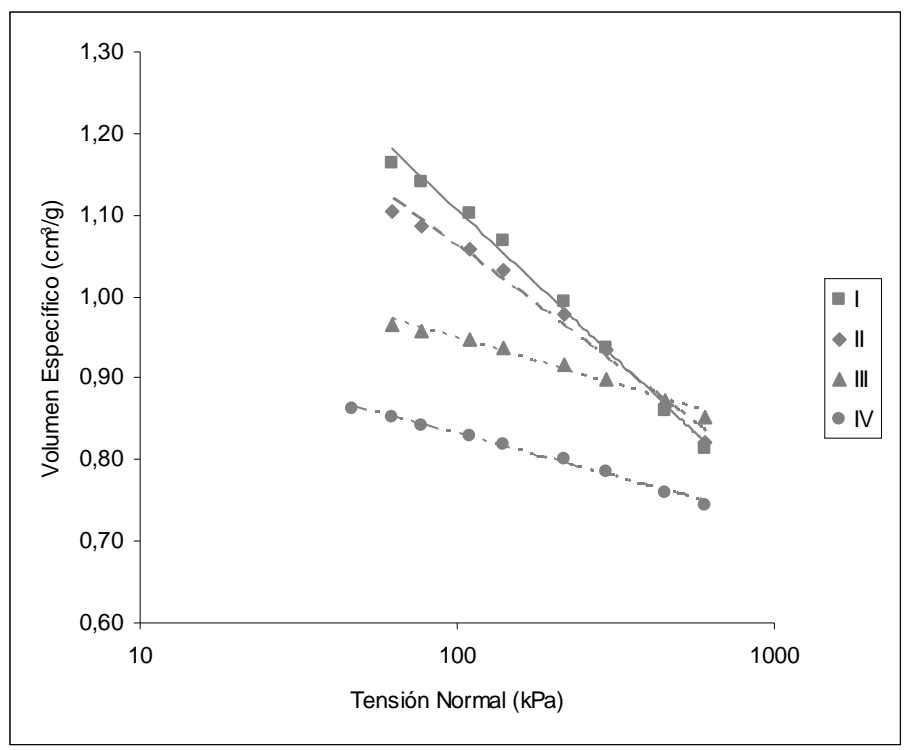

Figura 57: Líneas Virgen OZB al 5\% de humedad, Todas las Clases Granulométricas. 


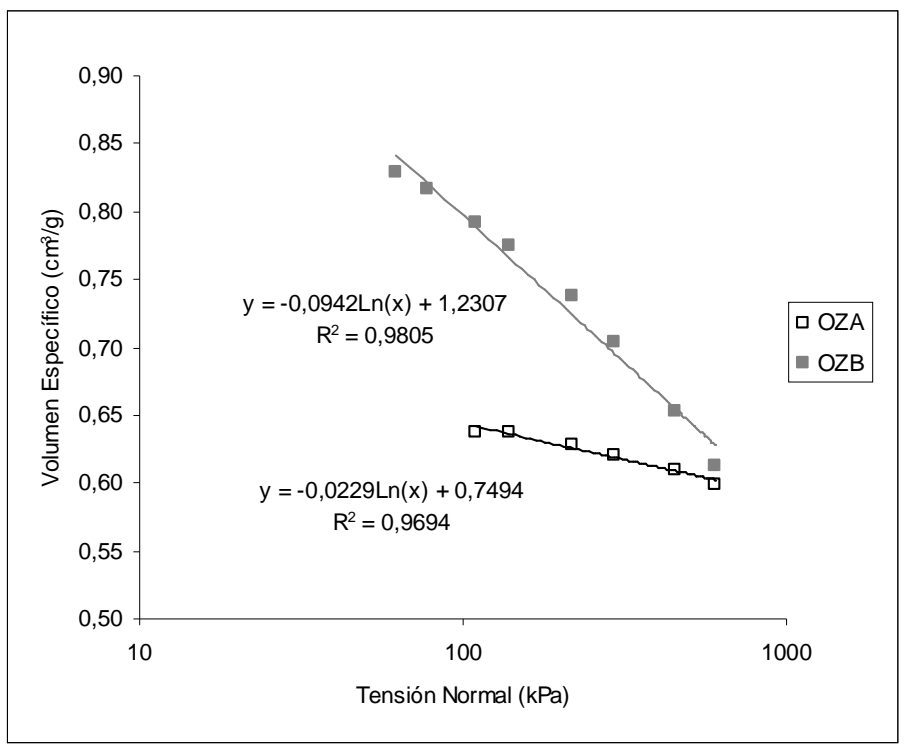

Figura 58Líneas Virgen OZA vs. OZB Clase II al 15\% de humedad.

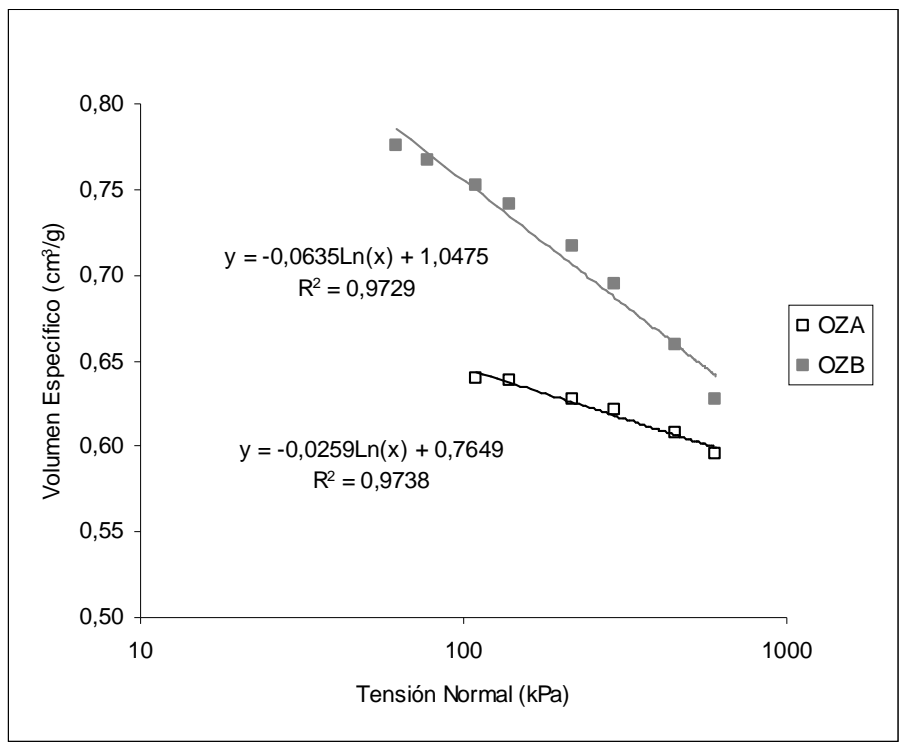

Figura 59: Líneas Virgen OZA vs. OZB Clase III al 15\% de humedad. 


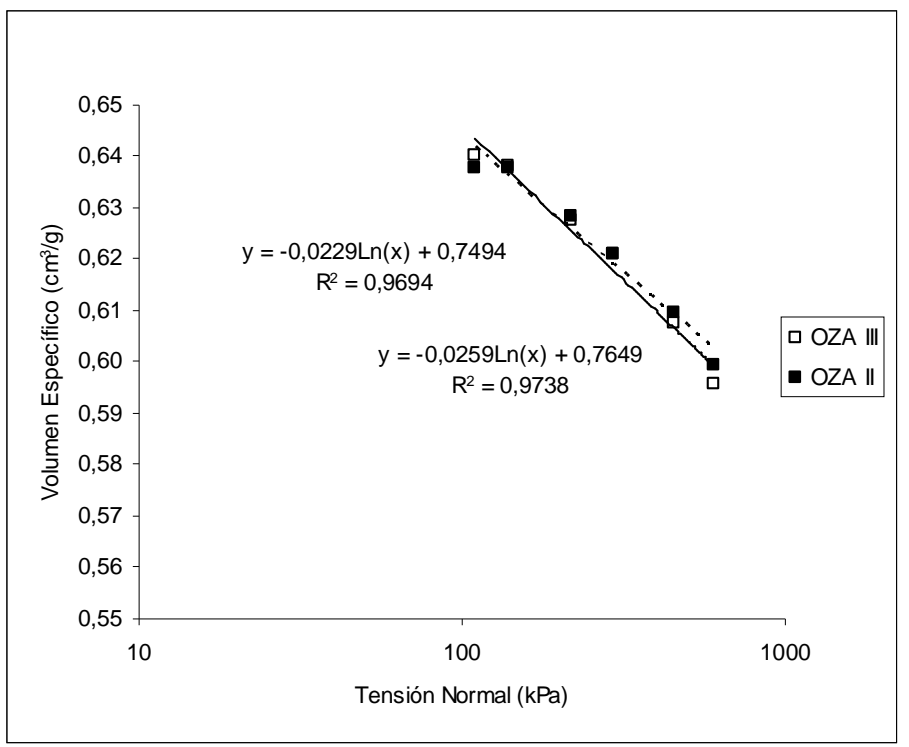

Figura 60: Líneas Virgen OZA Clase II vs. Clase III al 15\% de humedad.

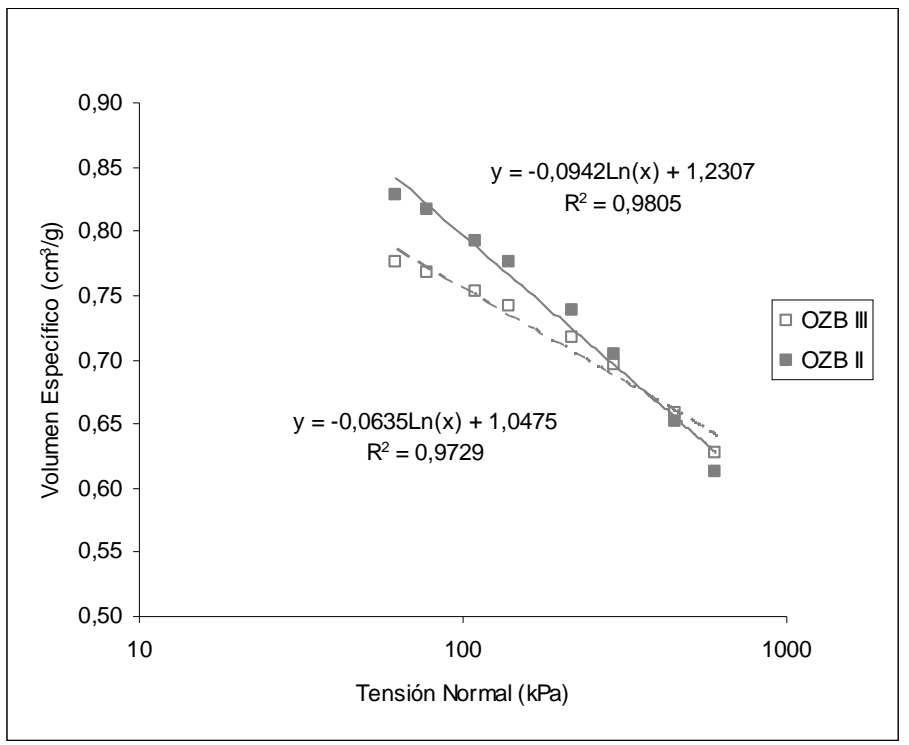

Figura 61: Líneas Virgen OZB Clase II vs. Clase III al 15\% de humedad. 
Los valores de $\lambda$ (pendiente de la Línea de Consolidación Virgen), valor del término independiente (N) y las diferencias estadísticas entre tratamientos se visualizan en la Tabla 23.

Las diferencias encontradas en el término independiente de las Líneas Virgen (N) confirman el análisis de los resultados realizado precedentemente, al comparar los valores de Volumen Específico Inicial entre los tratamientos de ambos suelos (Tabla 17, Tabla 18 y Tabla 21).

En la Tabla 23 se observa claramente como el parámetro $\mathrm{N}$ fue mayor, en casi todos los casos en el tratamiento $B$ lo que denota la mayor porosidad inicial respecto al tratamiento $\mathrm{A}$. La mayor densidad inicial del tratamiento A estaría de acuerdo con lo descripto por Hutson (1971) quien demostró, que la dureza de un suelo irrigado de 0 a $2 \mathrm{~cm}$ de profundidad fue una función continua del PSI del agua de riego y que utilizando aguas con RAS de $3,8 \mathrm{mmol} / \mathrm{l}$ se incrementó la densidad superficial del suelo.

En el caso de $\mathrm{OZ}$ al $5 \%$ de humedad, el comportamiento del término $\mathrm{N}$ en las diferentes clases granulométricas para un mismo tratamiento (Tabla 25), sigue la misma tendencia que aquella encontrada en los valores de Volumen Específico Inicial (Tabla 20). Los agregados de mayor tamaño presentaron mayor porosidad inicial y mayor $\mathrm{N}$, independientemente del tratamiento. 
Tabla 23: Comparación de pendientes de Línea Virgen $(\lambda)$ y término independiente $(\mathrm{N})$ entre A y B para todos los tratamientos.

\begin{tabular}{ccc}
\hline \multicolumn{3}{c}{ Pendientes de LV } \\
\hline \multicolumn{3}{c}{ CD $8 \%$ de $\mathrm{H}^{\circ}$} \\
\hline Cratamiento & $\mathrm{N}$ \\
CDA & $-0,059 \mathrm{a}$ & $1,087 \mathrm{~b}$ \\
& $-0,065 \mathrm{a}$ & $1,243 \mathrm{a}$ \\
\hline CD 18\% de $\mathrm{H}^{\circ}$ \\
\hline Cratamiento & $\lambda$ & $\mathrm{N}$ \\
CDB & $-0,103 \mathrm{a}$ & $1,252 \mathrm{a}$ \\
\hline Tratamiento & $-0,109 \mathrm{a}$ & $1,228 \mathrm{a}$ \\
\hline OZA I & $-0,047 \mathrm{a}$ & $1,194 \mathrm{~b}$ \\
OZB I & $-0,158 \mathrm{~b}$ & $1,834 \mathrm{a}$ \\
\hline OZA II & $-0,040 \mathrm{a}$ de $\mathrm{H}^{\circ}$ & $1,133 \mathrm{~b}$ \\
OZB II & $-0,125 \mathrm{~b}$ & $1,638 \mathrm{a}$ \\
\hline OZA III & $-0,036 \mathrm{a}$ & $1,083 \mathrm{~b}$ \\
OZB III & $-0,050 \mathrm{a}$ & $1,177 \mathrm{a}$ \\
\hline OZA IV & $-0,046 \mathrm{a}$ & $0,982 \mathrm{~b}$ \\
OZB IV & $-0,046 \mathrm{a}$ & $1,043 \mathrm{a}$ \\
\hline Tratamiento & OZ 15\% de H & \\
\hline OZA II & $-0,027 \mathrm{a}$ & $0,749 \mathrm{~b}$ \\
OZB II & $-0,095 \mathrm{~b}$ & $1,231 \mathrm{a}$ \\
\hline OZA III & $-0,030 \mathrm{a}$ & $0,765 \mathrm{~b}$ \\
OZB III & $-0,064 \mathrm{~b}$ & $1,048 \mathrm{a}$ \\
\hline
\end{tabular}

Letras diferentes en la misma columna denotan diferencias estadísticas significativas (LSD $p<0,05)$ 
Del análisis de los gráficos y tablas se desprende que en general los tratamientos con mayor contenido de sodio presentaron pendientes $(\lambda)$ menos pronunciadas que los tratamientos $\mathrm{B}$.

Existen antecedentes suficientes que permiten afirmar que un elevado PSI conduce a un reordenamiento poroso, aumentando los microporos (Waldrom y Constantin, 1968; Costa y Aparicio, 2000; Varallyay, 2002; Ruiz Vera y Wu, 2006).

Si bien en el material utilizado no puede hablarse de estructura como tal, debido a que se parte de suelo molido y tamizado, puede hipotetizarse que la acción del sodio en el tratamiento $\mathrm{A}$ ha conducido a un reordenamiento poroso en el material remanente, disminuyendo el número de poros mayores, más compresibles. Varallyay (2002) afirma que un alto porcentaje de sodio intercambiable (PSI) ocasiona una significativa modificación de la estructura y más concretamente de la conformación del espacio poroso, modificando la compactabilidad de los suelos. Pons et al. (2000) reportaron que, en un suelo expandible en estado de saturación y estructura inestable, la macroporosidad desaparece 0 disminuye sensiblemente impidiendo el desarrollo radicular mientras, en un suelo bien estructurado, el desarrollo de las raíces no resulta perjudicado aún si la saturación provoca la máxima expansión.

Mitchell (1976) encontró que una estructura de partículas floculadas presenta grandes poros mientras que una dispersa tiene numerosos microporos y a tensiones mayores que la tensión 
de preconsolidación $(\mathrm{Pc})$ el efecto de incrementos de tensiones es mayor sobre las estructuras floculadas que sobre las dispersas. En relación con la característica porosa del suelo agrícola, Alakukku (1996) diferencia entre porosidad total, macro y microporosidad, interpretando en base a éstos parámetros la acción de compactación debida al pasaje de maquinaria agrícola con elevada carga axial sobre dos tipos de suelos (un Vertisol y un Molisol con gran contenido de materia orgánica). En dicho trabajo encuentra que en suelos arcillosos el pasaje con altos pesos redujo la porosidad casi tanto como el valor de macroporosidad, dando a entender que la reducción de la porosidad total se realizó mediante la destrucción de su macroporosidad.

Ante un incremento dado de tensión, los poros de mayor tamaño son comprimidos primero (Delage y Lefebvre, 1984; Griffiths y Joshi, 1989). Hipotetizando que agregados grandes conformaran poros de mayor tamaño que aquellos donde predominan agregados chicos y además, como se ha comprobado en esta Tesis, los agregados de mayor tamaño presentan menor resistencia a la rotura, suelos donde predominen agregados grandes tendrían una menor resistencia a la compresión uniaxial. Esto se observa fácilmente en el tratamiento $\mathrm{B}$ de $\mathrm{OZ}$ al $5 \%$ de humedad. En este caso las pendientes de las Líneas Virgen siguen un orden claro en función del tamaño de agregados de cada una de las clases (Figura 57). Las clases superiores (mayor cantidad de macroporos y menor resistencia a 
rotura) presentaron pendientes mayores que las clases con agregados de menores dimensiones (Tabla 24). Sin embargo, éste hecho no se verifica en el tratamiento $A$ de $O Z$ al $5 \%$ de humedad donde las pendientes de la Línea Virgen de las diferentes clases granulométricas no siguen un orden claro, pudiendo hipotetizarse que el grado de cementación alcanzado por los agregados de éste tratamiento es tan importante que deja en segundo plano el efecto del tamaño de agregados, macroporosidad y su influencia sobre la susceptibilidad a la compresión.

Tabla 24: Comparación de pendientes de LV entre todas las clases granulométricas (I a IV) para ambos tratamientos (A y B) de OZ al $5 \%$ de humedad.

\begin{tabular}{c|c|c}
\hline \multicolumn{3}{c}{ Pendientes de LV $(\lambda)$} \\
\hline \multicolumn{3}{c}{ OZ $5 \%$ de $\mathrm{H}^{\circ}$} \\
\hline Tratamiento & OZA & OZB \\
Clase I & $-0,047 \mathrm{~b}$ & $-0,158 \mathrm{c}$ \\
Clase II & $-0,040 \mathrm{a}$ & $-0,125 \mathrm{~b}$ \\
Clase III & $-0,036 \mathrm{a}$ & $-0,050 \mathrm{a}$ \\
Clase IV & $-0,046 \mathrm{~b}$ & $-0,046 \mathrm{a}$ \\
\hline
\end{tabular}

Letras diferentes en la misma columna denotan diferencias estadísticas significativas $($ LSD $p<0,05)$ 
Tabla 25: Comparación de Términos Independientes de la ecuación de LV entre todas las clases granulométricas (I a IV) para ambos tratamientos de $\mathrm{OZ}$ al $5 \%$ de humedad.

Termino Independiente de LV (N)

\begin{tabular}{c|c|c}
\hline \multicolumn{3}{|c}{ OZ 5\% de $\mathrm{H}^{\circ}$} \\
\hline Tratamiento & OZA & OZB \\
Clase I & $1,194 \mathrm{a}$ & $1,834 \mathrm{a}$ \\
Clase II & $1,133 \mathrm{~b}$ & $1,638 \mathrm{~b}$ \\
Clase III & $1,083 \mathrm{c}$ & $1,177 \mathrm{c}$ \\
Clase IV & $0,982 \mathrm{~d}$ & $1,043 \mathrm{~d}$ \\
\hline
\end{tabular}

Letras diferentes en la misma columna denotan diferencias estadísticas significativas $($ LSD $p<0,05)$

Tabla 26: Comparación de pendientes de LV entre las clases II vs. III para ambos tratamientos (A y B) de OZ al 15\% de humedad.

\begin{tabular}{c|c|c}
\hline \multicolumn{3}{c}{ Pendientes de LV $(\lambda)$} \\
\hline \multicolumn{3}{c}{ OZ 15\% de $\mathrm{H}^{\circ}$} \\
\hline Tratamiento & OZA & OZB \\
Clase II & $-0,027$ a & $-0,096 \mathrm{~b}$ \\
Clase III & $-0,030 \mathrm{a}$ & $-0,063 \mathrm{a}$ \\
\hline
\end{tabular}

Letras diferentes en la misma columna denotan diferencias estadísticas significativas $($ LSD $p<0,05)$ 
Tabla 27: Comparación de Términos Independientes de LV entre las clases II vs. III para ambos tratamientos de OZ al 15\% de humedad.

\begin{tabular}{c|c|c}
\hline \multicolumn{3}{c}{ Termino Independiente de LV (N) } \\
\hline \multicolumn{3}{c}{ OZ 15\% de $\mathrm{H}^{\circ}$} \\
\hline Tratamiento & OZA & OZB \\
Clase II & $0,749 \mathrm{a}$ & $1,231 \mathrm{a}$ \\
Clase III & $0,765 \mathrm{a}$ & $1,048 \mathrm{~b}$ \\
\hline
\end{tabular}

Letras diferentes en la misma columna denotan diferencias estadísticas significativas

$($ LSD $p<0,05)$

Contrariamente a lo encontrado en éste trabajo, Palancar (2007) observó diferencias significativas tanto en el Volumen Específico Inicial como en la pendiente de la recta de Inceptisoles (como Ozzano) presentando el tratamiento más sódico mayores valores en sus pendientes, estableciendo que en los Inceptisoles, existe una mayor velocidad de compresión del tratamiento más sodificado. Esa mayor velocidad de compresión permitió que un mayor volumen másico inicial para el más sodificado se tradujese en un Volumen Específico Final similar. Sin embargo, coincidiendo con ésta tesis, el mismo autor halló en sus resultados que en los Alfisoles (como Cardone) no existieron diferencias significativas (Tabla 23).

El suelo Cardone al $18 \%$ y $8 \%$ de humedad (Figura 50 y Figura 51) no presentó diferencias significativas entre los valores de pendiente de las Líneas Virgen entre ambos tratamientos (A y B). Posiblemente la ausencia de diferencias se deba al mayor 
contenido de Materia Orgánica de éste suelo $(34 \mathrm{~g} / \mathrm{kg}$, el doble que Ozzano) la cual contribuye de manera importante a la estructuración atenuando el efecto negativo del sodio. Seta y Karathanasis (1996) luego del agregado de una solución de $\mathrm{Na}_{2} \mathrm{CO}_{3}$ de $\mathrm{pH}=9,5$ a muestras de 6 diferentes suelos encontraron que el contenido de carbono orgánico no tuvo un rol significativo en la estabilidad de los coloides del suelo. Justificaron estos resultados por el bajo contenido de Materia Orgánica (21 $\mathrm{g} / \mathrm{kg}$ a $3 \mathrm{~g} / \mathrm{kg}$ según el suelo) debido a la profundidad a la cual se extrajeron las muestras (horizonte subsuperficial B). Barzegar et al. $\left(1994^{\text {b }}\right)$ combinaron soluciones, con diversas concentraciones salinas, y muestras de un suelo sometido a diferentes rotaciones de cultivos (desde suelo virgen hasta siembra de trigo todos los años), encontrando que la estabilidad de los agregados disminuyó con el aumento de la RAS y que para una misma RAS la estabilidad de los agregados se incrementó al aumentar el contenido de materia orgánica de los mismos. Rao et al. (2001) trabajaron sobre el impacto de ciclos de humectación desecación en suelos expansibles de India. Si bien éste trabajo no contemplaba suelos agrícolas, concluyeron que en suelos con mayor contenido de materia orgánica, los ciclos de humectación desecación provocaron fenómenos de expansión - contracción más moderados, menor resistencia a la compactación y menor densidad aparente que los suelos con menor contenido de materia orgánica. Derdoura y Angersb (1992) encontraron, mediante pruebas de compactación, que la sensibilidad a la 
compactación estuvo correlacionada positivamente con el contenido de arcilla y materia orgánica. Otra característica de Cardone que pudo soslayar el efecto del sodio es la naturaleza de sus arcillas (illita y caolinita) de baja superficie específica y por ende menor capacidad de intercambio catiónico en contraste con Ozzano el cual contiene arcillas de mayor superficie específica (vermiculita y esmectita) lo que pudo favorecer una mayor interacción con el $\mathrm{Na}^{+}$(Cavazza et al., 2002 y Guarnieri et al., 2005). Seta y Karathanasis (1996) encontraron que el efecto dispersivo del sodio es más evidente y significativo sobre las arcillas del tipo 2:1 (como la esmectita). Soverini (2001) marcó la importancia de la composición mineralógica de las arcillas indicando que, en presencia de sodio, la mayor sensibilidad a la variación de las propiedades mecánicas se observa en arcillas ubicadas dentro de los grupos donde se hallan la esmectita y la montmorillonita.

En el caso de Ozzano al $5 \%$ de $\mathrm{H}^{\circ}$ se hallaron diferencias de $\lambda$ en las LV de las clases I y II entre ambos tratamientos pero no en las clases III y IV, debido posiblemente al menor contenido de macroporos de las clases menores respecto aquellas de agregados mayores, lo que conferiría al tratamiento B una pendiente similar al tratamiento más sódico (Tabla 23). Por otra parte, Ozzano al $5 \%$ de humedad no fue sometido a ciclos de humectación - desecación. Este procedimiento, acentúa la dispersión de las arcillas y las partículas finas se reordenan ocupando los espacios vacíos de acuerdo a lo expuesto por Chen 
y Banin (1975), contribuyendo a la destrucción de macroporos y acentuando las diferencias entre ambos tratamientos, como se observó en OZ al 15\% de humedad (Figura 58 y Figura 59).

Respecto al comportamiento entre las clases II y III de OZ al $15 \%$ de $\mathrm{H}^{\circ}$ para ambos tratamientos $\mathrm{A}$ y $\mathrm{B}$ (Figura 60 y Figura 61), se observa la misma tendencia hallada en las Líneas de Compresión, donde posiblemente, el ciclo humedecimiento desecación provocó la disminución de diferencias en el tamaño de agregados entre las clases II y III. En lo concerniente a OZB al $15 \%$ de humedad se observó que la clase II reportó valores de $\mathrm{N}$ mayores y pendiente más pronunciada respecto a la clase III (Tabla 27) a pesar de la ausencia de diferencias en sus valores de Volumen Específico Inicial (Tabla 19). Si bien la Clase II, con agregados mayores a la III, pudo haber sufrido una mayor disgregación durante el ciclo humedecimiento - desecación, tal efecto no habría sido tan importante como para producir cambios más profundos en el comportamiento ante la compresión. Esto se verifica por una mayor pendiente de la Línea Virgen $(\lambda)$ y término independiente $\mathrm{N}$ como sería esperable en un suelo con mayor macroporosidad. En el caso de OZA al $15 \%$ de $\mathrm{H}^{\circ}$ estas diferencias no fueron encontradas en la comparación entre ambas clases (II y III) (Tabla 26). En este caso al igual que OZA al 5\% de humedad es probable que el grado de cementación alcanzado por los agregados de éste tratamiento fuese tan importante que dejase en segundo plano el efecto del tamaño de agregados, 
macroporosidad y su influencia sobre la susceptibilidad a la compresión.

De lo analizado a partir de las Curvas de Compresión, Presión de Preconsolidación y Línea Virgen se podría confirmar la menor susceptibilidad a la compresión de los suelos con mayor contenido de sodio (A).

\subsubsection{Tensión de Corte y parámetros de Coulomb.}

Se realizaron las regresiones lineales entre la tensión tangencial (o cortante) y la tensión normal de cada suelo y tratamiento (Figura 62 a Figura 74), obteniendo las rectas de Coulomb, con los valores de cohesión (C) y ángulo de rozamiento interno $(\operatorname{tg} \varphi)($ Tabla 29).

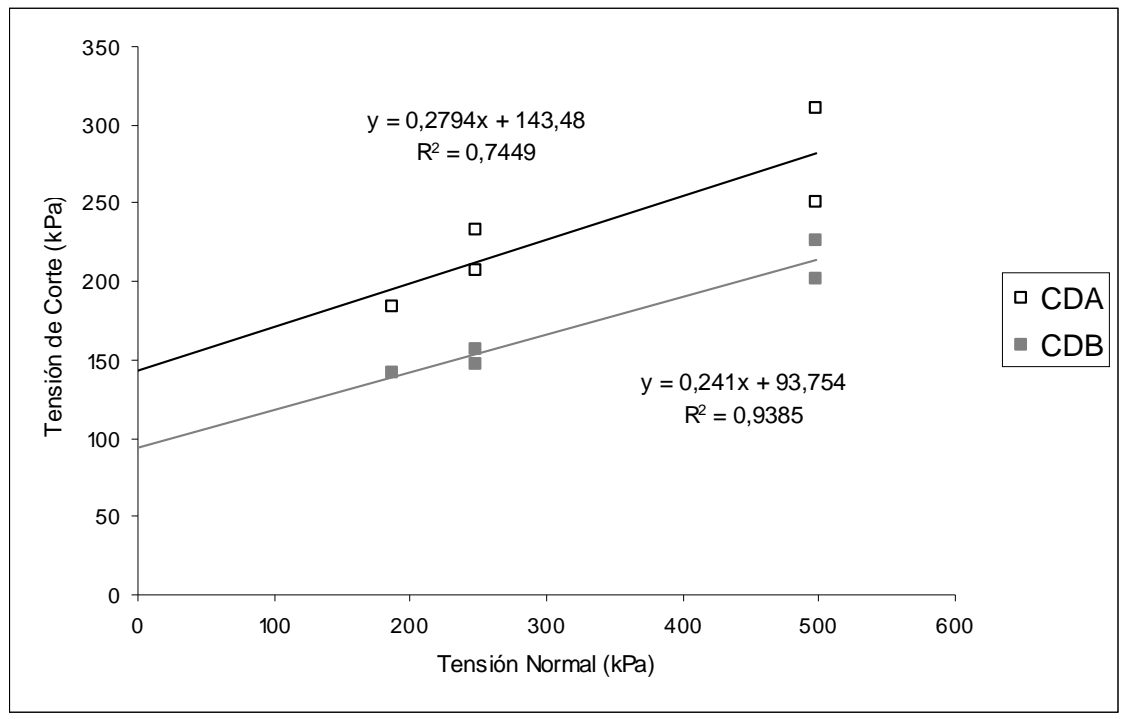

Figura 62: Rectas de Coulomb de CDA vs. CDB al $18 \%$ de humedad. 


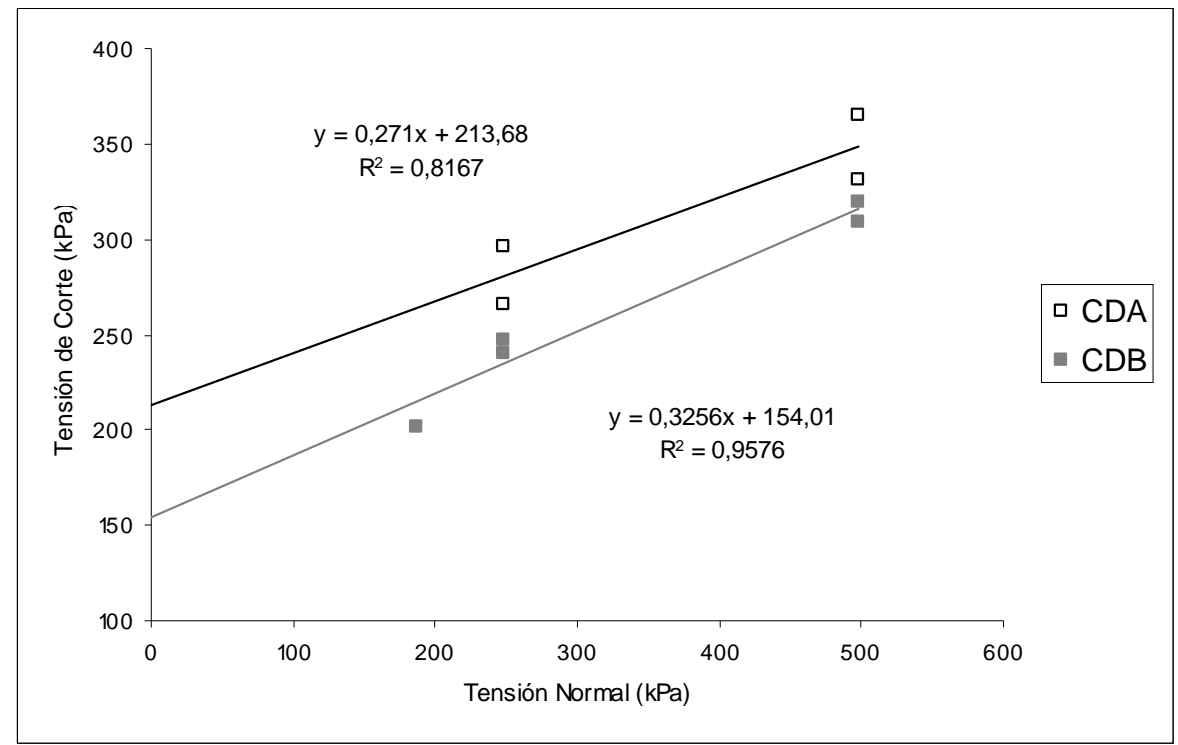

Figura 63: Rectas de Coulomb de CDA vs. CDB al $8 \%$ de humedad.

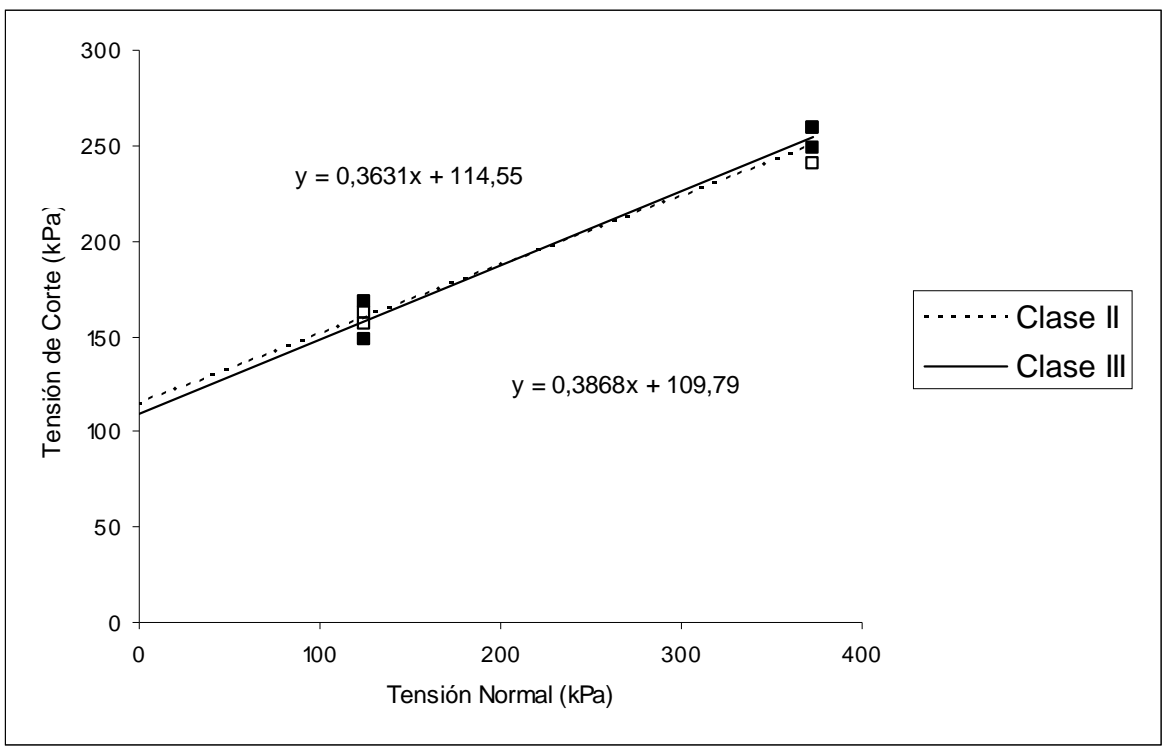

Figura 64: Rectas de Coulomb de OZB II vs. OZB III al 15\% de humedad. 


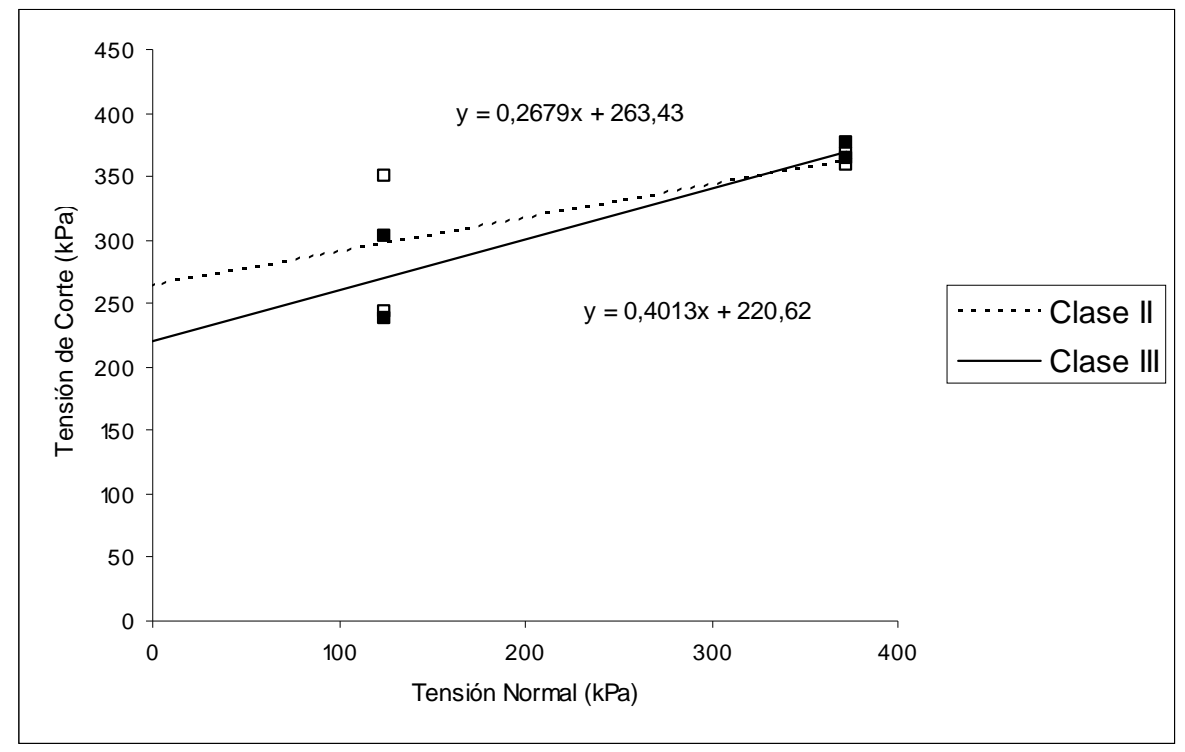

Figura 65: Rectas de Coulomb de OZA II vs. OZA III al 15\% de humedad.

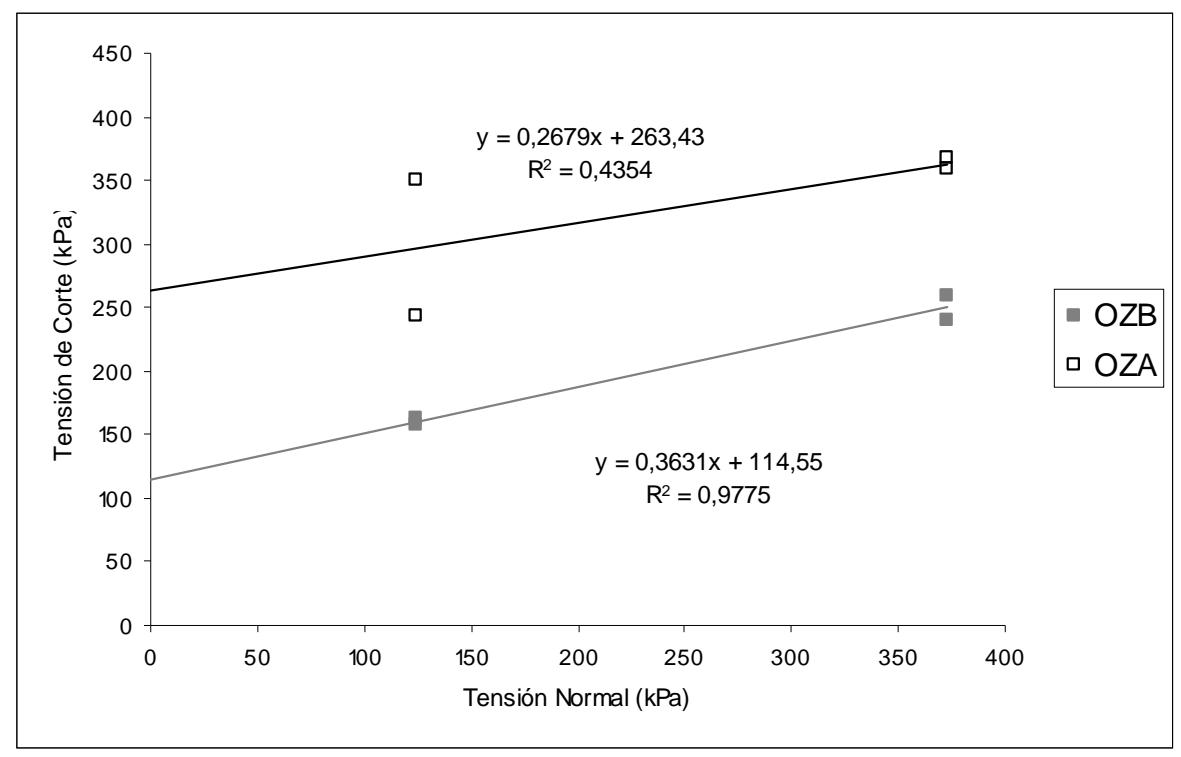

Figura 66: Rectas de Coulomb de OZA vs. OZB Clase II al 15\% de humedad. 


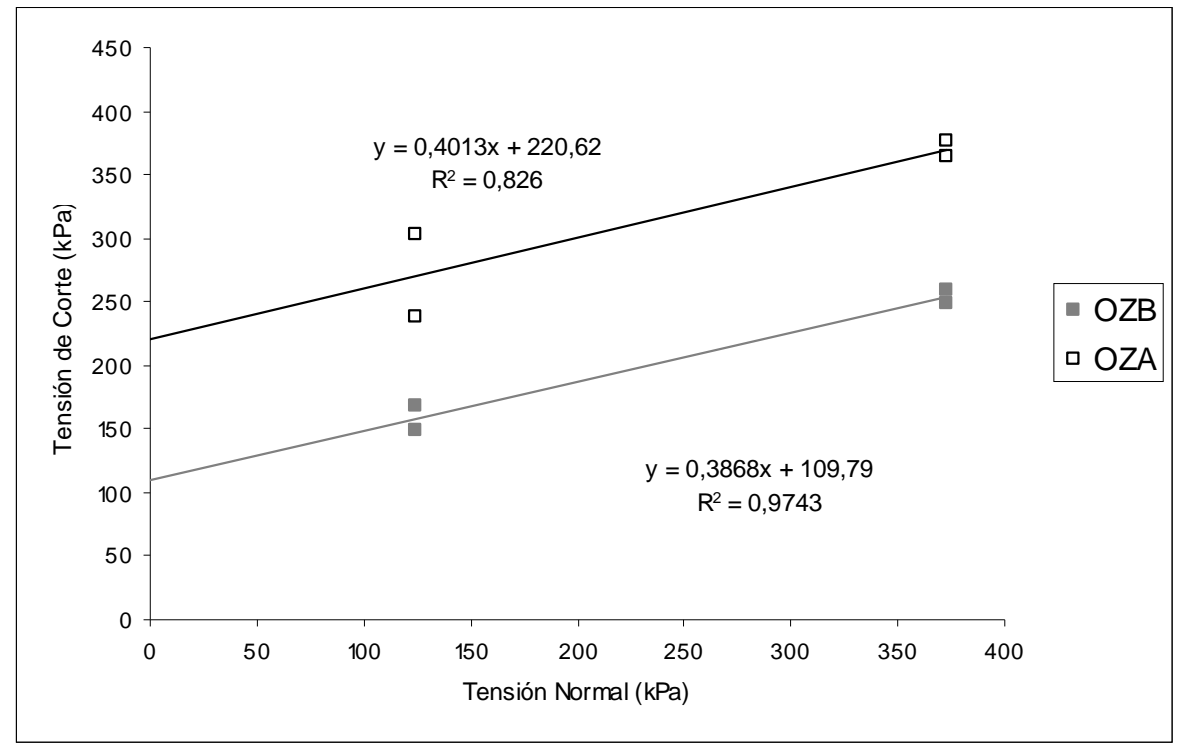

Figura 67: Rectas de Coulomb de OZA vs. OZB Clase III al 15\% de humedad.

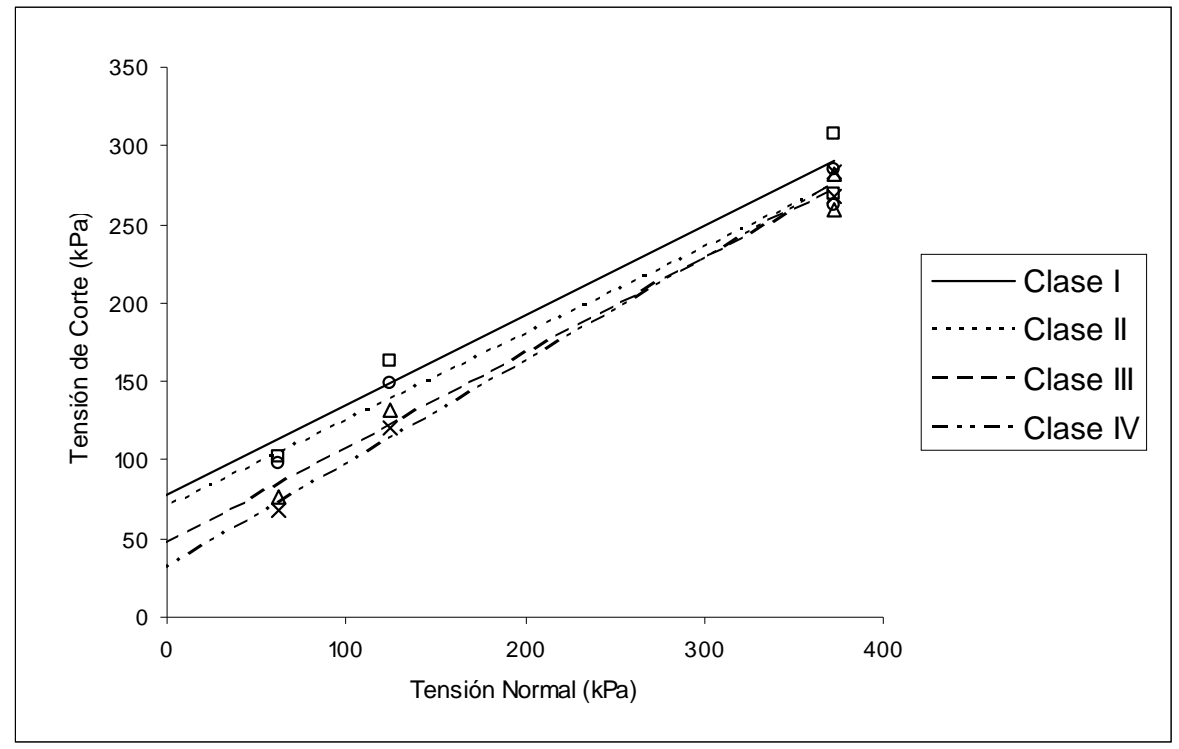

Figura 68: Rectas de Coulomb de OZA al 5\% de humedad, Todas las Clases Granulométricas. 


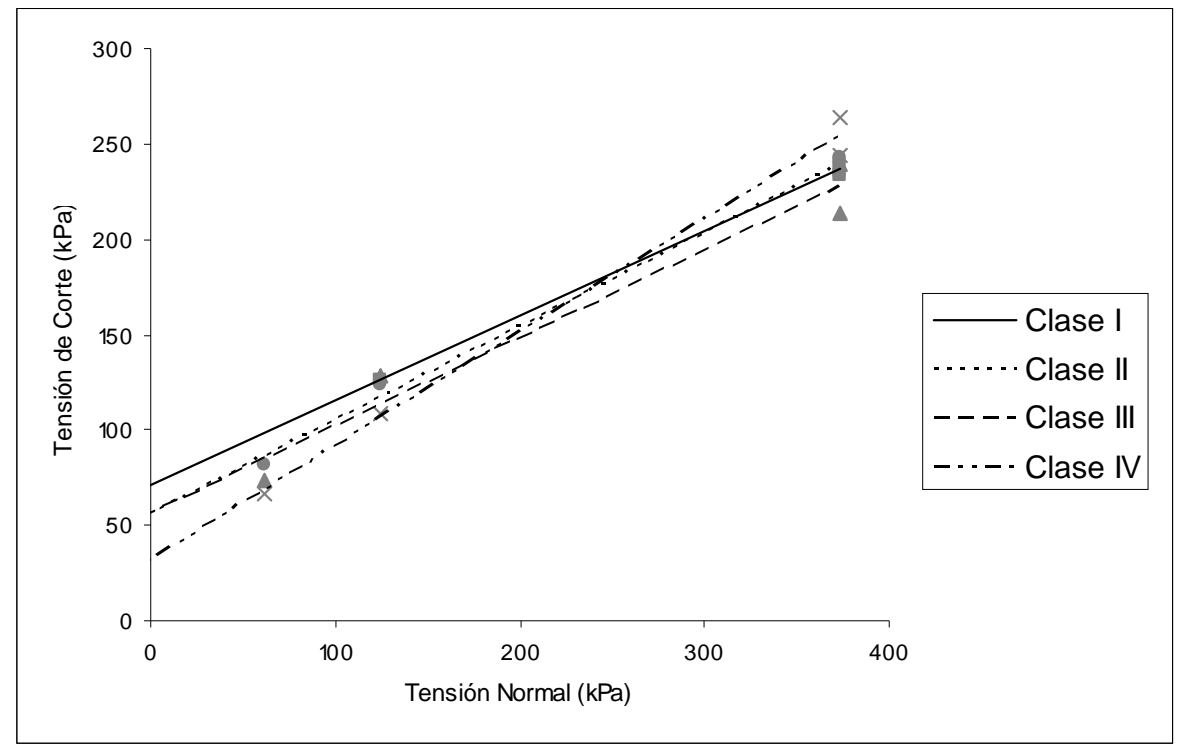

Figura 69: Rectas de Coulomb de OZB al 5\% de humedad, Todas las Clases Granulométricas.

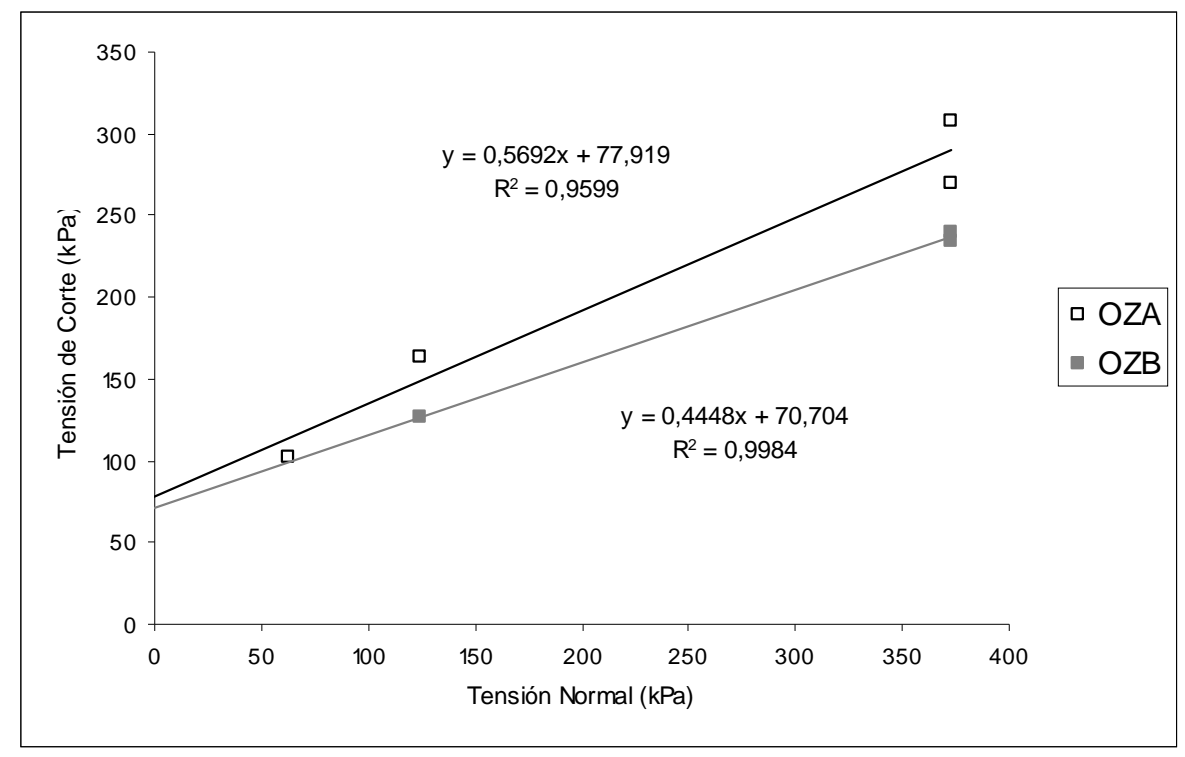

Figura 70: Rectas de Coulomb OZA vs. OZB Clase I al 5\% de humedad. 


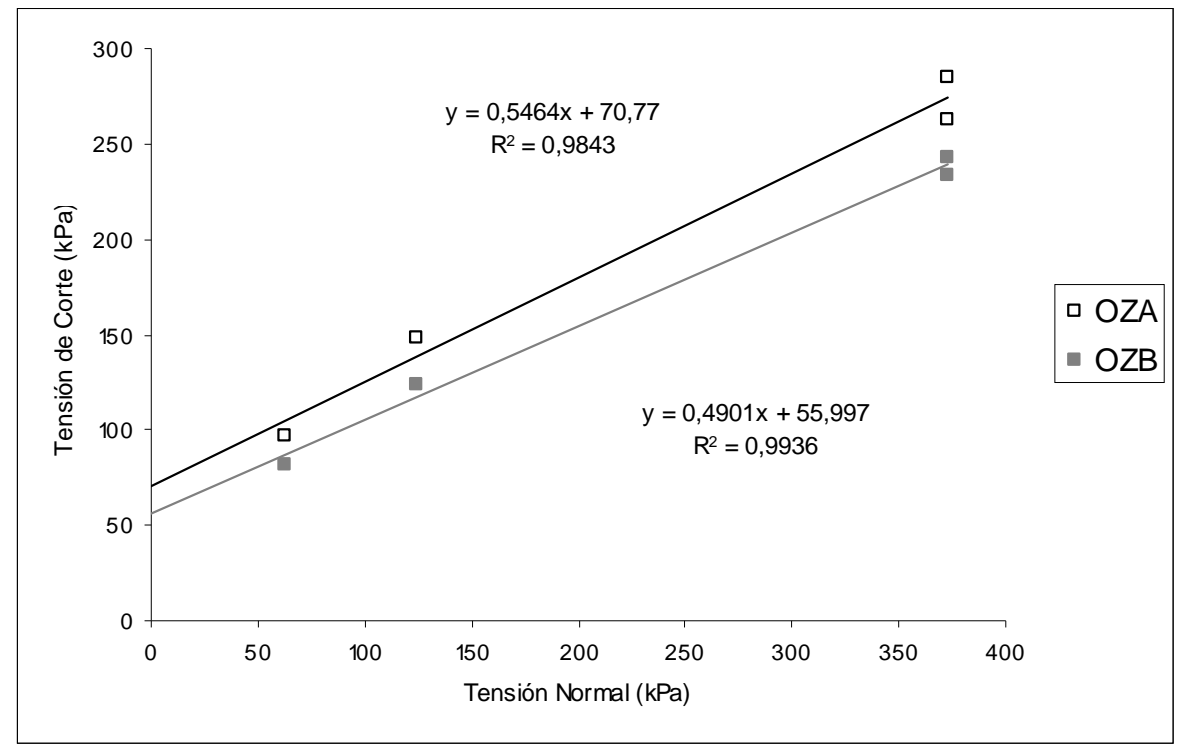

Figura 71: Rectas de Coulomb OZA vs. OZB Clase II al 5\% de humedad.

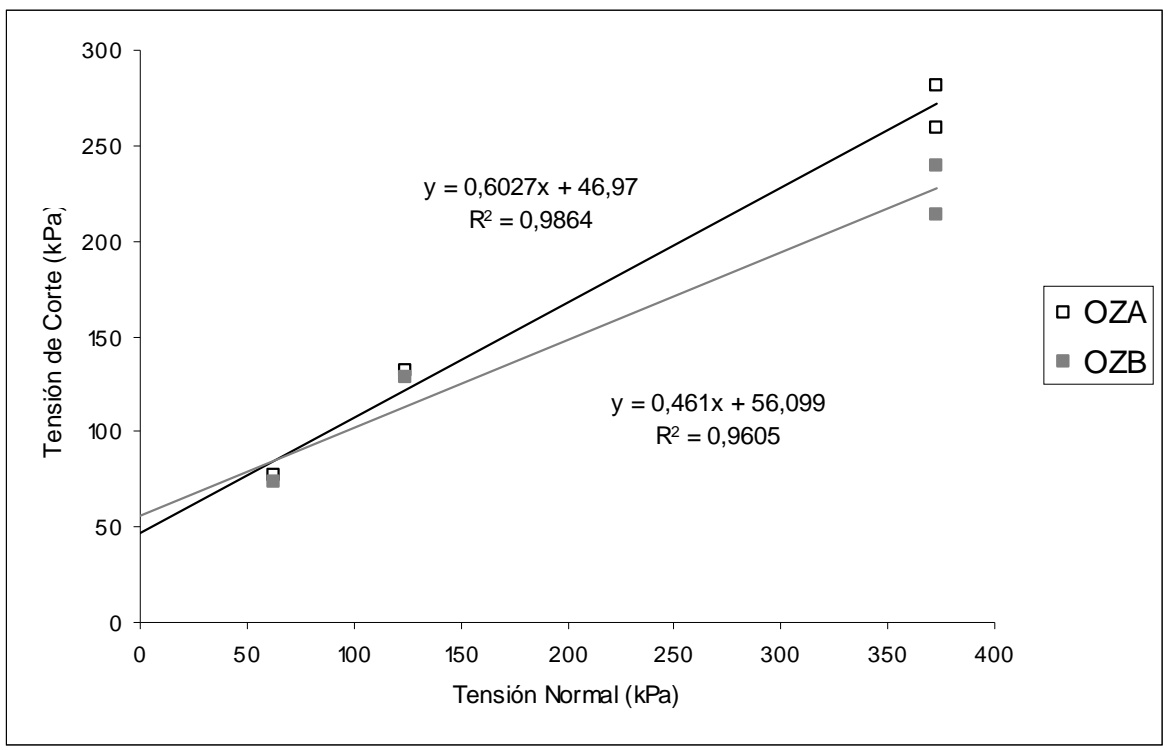

Figura 72: Rectas de Coulomb OZA vs. OZB Clase III al 5\% de humedad. 


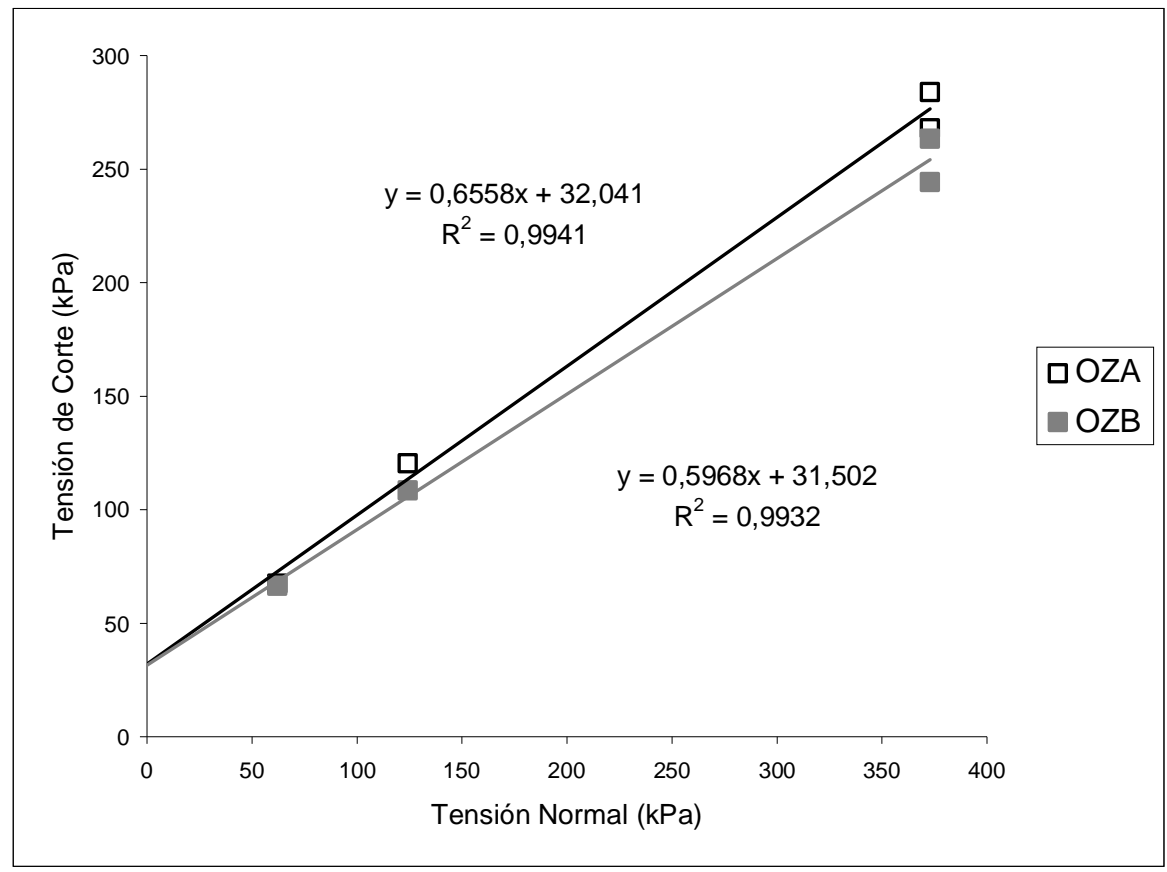

Figura 73: Rectas de Coulomb OZA vs. OZB Clase IV al 5\% de humedad.

Los términos independientes de las ecuaciones de las rectas de regresión entre los puntos indican los valores de cohesión (c), mientras que las pendientes representan las tangentes de los ángulos de rozamiento interno $(\operatorname{tg} \varphi)$. De aquí se deducen entonces ambos valores que son volcados y comparados en la Tabla 29 y en la Tabla 30 , junto con los valores de Tensión de Corte a diferentes tensiones Normales. En la Tabla 28 se detallan los valores de humedad de las muestras inmediatamente luego del corte. En los tratamientos llevados a cabo con material seco y sin tratamiento humedecimiento - 
desecación no se determinó su humedad luego del corte ya que se trató de suelo secado al aire. En el análisis estadístico del contenido de humedad inmediatamente después del corte no se hallaron diferencias significativas entre los tratamientos ensayados (Tabla 28).

Se desprende de la Tabla 29 que en general ambos suelos tuvieron una tendencia a presentar valores de Tensión de Corte más altos en los tratamientos $\mathrm{A}$ respecto de $\mathrm{B}$.

En el caso de $\mathrm{OZ}$ al $5 \%$ de humedad no se observaron diferencias de Tensión de Corte en las clases III y IV entre ambos tratamientos ( $\mathrm{A}$ y $\mathrm{B}$ ), posiblemente debido a la similitud en la constitución de los agregados como ha sido detallado al presentar las Líneas Vírgenes de éstos tratamientos (Figura 73 y Figura 74).

Tabla 28: Humedad al corte promedio por tratamiento (\%p/p)

\begin{tabular}{c|c}
\hline Tratamiento & $\mathrm{H}^{\circ}$ media \%p/p \\
\hline CDA 8\% & $8,6 \mathrm{a}$ \\
CDB 8\% & $7,8 \mathrm{a}$ \\
\hline CDA 18\% & $18,2 \mathrm{a}$ \\
CDB 18\% & $17,6 \mathrm{a}$ \\
\hline OZB II 15\% & $15,2 \mathrm{a}$ \\
OZB III 15\% & $14,7 \mathrm{a}$ \\
OZA II 15\% & $15,9 \mathrm{a}$ \\
OZA III 15\% & $15,5 \mathrm{a}$ \\
\hline
\end{tabular}

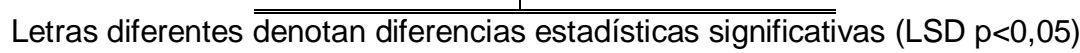


Tabla 29: Comparación de A vs. B de las Tensiones de Corte ( $\mathrm{kPa})$ a diferentes Tensiones Normales ensayadas $(\mathrm{kPa})$, Cohesión $(\mathrm{kPa})$ y Angulo de Rozamiento Interno $(\operatorname{tg} \varphi)$ para todos los tratamientos de ambos suelos (CD y OZ).

\begin{tabular}{|c|c|c|c|c|c|c|c|c|}
\hline \multirow{2}{*}{ Tratamiento } & \multicolumn{6}{|c|}{ Tensión Normal (kPa) } & \multirow{2}{*}{$\mathbf{C}(\mathrm{kPa})$} & \multirow{2}{*}{$\operatorname{tg} \varphi$} \\
\hline & 497 & 372 & 248 & 186 & 124 & 62 & & \\
\hline $\begin{array}{l}\text { CDA 8\% } \\
\text { CDB 8\% }\end{array}$ & $\begin{array}{l}348,40 \mathrm{a} \\
314,21 \mathrm{a}\end{array}$ & & $\begin{array}{l}281,04 \mathrm{a} \\
243,50 \mathrm{a}\end{array}$ & 201,07 & & & $\begin{array}{l}213,68 \mathrm{a} \\
154,01 \mathrm{~b}\end{array}$ & $\begin{array}{l}0,271 \mathrm{a} \\
0,326 \mathrm{a}\end{array}$ \\
\hline CDA 18\% & $280,95 \mathrm{a}$ & & $220,10 a$ & 184,1 & & & $143,48 \mathrm{a}$ & $0,279 \mathrm{a}$ \\
\hline CDB $18 \%$ & $213,93 \mathrm{a}$ & & $151,97 b$ & 141,42 & & & $93,75 b$ & $0,241 \mathrm{a}$ \\
\hline OZA I 5\% & & $288,76 \mathrm{a}$ & & & 163,02 & 101,82 & $77,92 \mathrm{a}$ & $0,569 \mathrm{a}$ \\
\hline OZB I 5\% & & $236,56 \mathrm{~b}$ & & & 125,99 & & $70,70 \mathrm{~b}$ & $0,445 \mathrm{a}$ \\
\hline OZA II 5\% & & $273,59 a$ & & & 148,11 & 97,19 & $70,77 \mathrm{a}$ & $0,546 a$ \\
\hline OZB II 5\% & & $238,10 \mathrm{~b}$ & & & 123,42 & 81,25 & $56,00 \mathrm{~b}$ & $0,490 \mathrm{a}$ \\
\hline OZA III 5\% & & $270,76 a$ & & & 131,65 & 76,62 & $46,97 \mathrm{a}$ & $0,603 \mathrm{a}$ \\
\hline OZB III 5\% & & $226,53 \mathrm{a}$ & & & 128,05 & 73,03 & $56,10 \mathrm{a}$ & $0,461 \mathrm{a}$ \\
\hline OZA IV 5\% & & $275,90 \mathrm{a}$ & & & 120,34 & 67,37 & $32,04 \mathrm{a}$ & $0,656 \mathrm{a}$ \\
\hline OZB IV 5\% & & $253,79 a$ & & & 108,51 & 66,34 & $31,50 \mathrm{a}$ & $0,597 \mathrm{a}$ \\
\hline & & & & & & & & \\
\hline OZA II 15\% & & 363,32 a & & & 296,73 a & & $263,43 a$ & $0,268 \mathrm{a}$ \\
\hline OZB II 15\% & & $249,93 \mathrm{~b}$ & & & 159,68 a & & $114,55 \mathrm{~b}$ & $0,363 \mathrm{a}$ \\
\hline OZA III 15\% & & $370,27 a$ & & & $270,50 \mathrm{a}$ & & $220,62 \mathrm{a}$ & $0,401 \mathrm{a}$ \\
\hline OZB III 15\% & & $254,04 \mathrm{~b}$ & & & $157,88 \mathrm{~b}$ & & $109,79 a$ & $0,387 \mathrm{a}$ \\
\hline
\end{tabular}

Letras diferentes en la misma columna denotan diferencias estadísticas significativas (LSD p<0,05 para el parámetro Tensión de Corte y Comparación de Regresiones $\mathrm{p}<0,10)$. 
Respecto a los tratamientos de OZ al 15\% de humedad, no se hallaron diferencias de comportamiento entre ambas clases ensayadas (II y III) en cada uno de los tratamientos (Tabla 30), Figura 65 y Figura 66). Las similitudes se reflejan en la ausencia de diferencias significativas en los valores de Tensión de Corte para todas las relaciones de Tensión Normal ensayada, como también en los valores de Cohesión y sus pendientes (Angulo de Rozamiento Interno). La hipótesis planteada sobre este tratamiento intentando explicar la ausencia de diferencias en las Curvas de Compresión (Tabla 19), explicaría también la similitud de comportamiento entre ambas clases de un mismo suelo de los parámetros de Coulomb. La misma asume que durante el proceso de humidificación - desecación realizado sobre los materiales, los agregados podrían haber sufrido procesos de disgregación y/o dispersión más o menos pronunciados, lo que habría reducido el tamaño de los agregados (en mayor proporción en la clase II) disminuyendo las diferencias en el tamaño final de los agregados entre ambas clases y por ende también en su comportamiento al corte. 
Tabla 30: Comparación entre Clases Granulométricas de las Tensiones de Corte $(\mathrm{kPa})$ a diferentes Tensiones Normales ensayadas $(\mathrm{kPa})$, Cohesión $(\mathrm{kPa})$ y Angulo de Rozamiento Interno $(\operatorname{tg} \varphi)$ para los tratamientos OZ 5\% y OZ 15\% de humedad.

\begin{tabular}{|c|c|c|c|c|c|}
\hline \multirow{2}{*}{ Tratamiento } & \multicolumn{3}{|c|}{ Tensión de Corte (KPa) } & \multirow{2}{*}{$\mathbf{C}(\mathrm{kPa})$} & \multirow{2}{*}{$\operatorname{tg} \varphi$} \\
\hline & 372 & 124 & 62 & & \\
\hline OZA I $5 \%$ & $288,76 \mathrm{a}$ & 163,02 & 101,82 & $77,92 \mathrm{a}$ & $0,569 \mathrm{a}$ \\
\hline OZA II 5\% & $273,59 \mathrm{a}$ & 148,11 & 97,19 & $70,77 \mathrm{a}$ & $0,546 \mathrm{a}$ \\
\hline OZA III 5\% & $270,76 \mathrm{a}$ & 131,65 & 76,62 & $46,97 \mathrm{a}$ & $0,603 \mathrm{a}$ \\
\hline OZA IV 5\% & $275,90 \mathrm{a}$ & 120,34 & 67,37 & $32,04 \mathrm{a}$ & $0,656 \mathrm{a}$ \\
\hline OZB I 5\% & $236,56 \mathrm{a}$ & 125,99 & & $70,70 \mathrm{a}$ & $0,445 \mathrm{~b}$ \\
\hline OZB II 5\% & $238,10 \mathrm{a}$ & 123,42 & 81,25 & $56,00 \mathrm{a}$ & $0,490 \mathrm{~b}$ \\
\hline OZB III 5\% & $226,53 \mathrm{a}$ & 128,05 & 73,03 & $56,10 \mathrm{a}$ & $0,461 \mathrm{ab}$ \\
\hline OZB IV 5\% & $253,79 a$ & 108,51 & 66,34 & $31,50 \mathrm{a}$ & $0,597 \mathrm{a}$ \\
\hline OZA II 15\% & $363,32 \mathrm{a}$ & 296,73 a & & 263,43 a & 0,268 a \\
\hline OZA III 15\% & $370,27 \mathrm{a}$ & $270,50 \mathrm{a}$ & & $220,62 \mathrm{a}$ & $0,401 \mathrm{a}$ \\
\hline OZB II 15\% & $249,93 \mathrm{a}$ & $159,68 \mathrm{a}$ & & $114,55 \mathrm{a}$ & $0,363 \mathrm{a}$ \\
\hline OZB III 15\% & $254,04 \mathrm{a}$ & $157,88 \mathrm{a}$ & & $109,79 \mathrm{a}$ & $0,387 \mathrm{a}$ \\
\hline
\end{tabular}

Letras diferentes en la misma columna denotan diferencias estadísticas significativas (LSD p <0,05 para el parámetro Tensión de Corte y Comparación de Regresiones $p<0,10)$. 
El comportamiento general en ambos suelos (CD y OZ) fue el de presentar valores más altos de Cohesión de los tratamientos más sodificados (A) (Tabla 29). Esto se puede evidenciar en los gráficos de las rectas de Coulomb donde se aprecia que los tratamientos con mayor contenido de sodio (A) poseen, en casi todos los casos, una mayor ordenada al origen con respecto al tratamiento B. Otro comportamiento en común para ambos suelos fue el de no presentar diferencias de los ángulos de rozamiento interno de las rectas de Coulomb (Tabla 29). Spugnoli et al. (2002) evidenciaron como el $\mathrm{Na}^{+}$influyó sobre las propiedades mecánicas, aumentando la resistencia al corte.

Se recurrió al modelo de cohesión molecular y superficial planteado por Sánchez-Girón (1996) para intentar explicar los mayores valores de cohesión en el tratamiento con mayor contenido de sodio. Dicho tratamiento alcanzó un PSI mayor a su par menos sodificado (B) lo que habría posibilitado al $\mathrm{Na}+$ ejercer su influencia en el material, saturando el complejo de intercambio y generando una pérdida de cohesión molecular en húmedo, debido a que es un catión monovalente y de gran radio iónico hidratado. Esto habría conducido a un aumento en la distancia de la doble capa difusa, superando las fuerzas de atracción de Van der Walls, generando en definitiva una pérdida de cohesión molecular en húmedo (Rengasamy y Olsson, 1991), con lo que la razón de la alta cohesión encontrada en los materiales CDA y OZA cortados al $18 \%$ y $15 \%$ de humedad debería buscarse en el parámetro cohesión superficial (Figura 63, Figura 67 y Figura 68). 
El aumento en la distancia de la doble capa difusa del tratamiento $A$, habría resultado finalmente en una tendencia a la dispersión, destruyéndose los poros mayores con el consecuente incremento de los poros pequeños (Chen y Banin, 1975) de menor diámetro y mayor capilaridad y tensión superficial, lo cual habría redundado en un aumento de la cohesión superficial. Por lo tanto, el aumento de la tensión cortante verificado en los tratamientos $\mathrm{A}$, podría adjudicarse a un aumento de la cohesión superficial. Si bien la cohesión molecular en el momento del corte no habría sido importante (debido a la humedad con que se realizaron los cortes), la presencia del $\mathrm{Na}^{+}$habría favorecido el predominio de las fuerzas de repulsión determinando un incremento de los coloides dispersos, con generación de poros pequeños, que derivaría en una mayor cohesión superficial y en una mayor tensión cortante.

El comportamiento de CD cortado al $8 \%$ de humedad (Figura 64) puede ser explicado por el modelo utilizado por Hettiaratchi (1987) y Rengasamy y Olsson (1991). El humedecimiento habría provocado, en un primer momento, un mayor distanciamiento de la doble capa difusa con su consecuente aumento de la dispersión y disminución de los macroporos. Finalmente, la fuerte desecación hasta el $8 \%$ de humedad habría inducido una fuerte cementación de las arcillas dispersas aumentando la cohesión molecular. Esto explicaría lo hallado en el presente trabajo donde las mayores diferencias en el 
comportamiento al corte se encontraron en aquellos tratamientos que sufrieron un ciclo de humectación - desecación.

Rahimi et al. (2000) valoraron el efecto de la conductividad eléctrica y la relación de adsorción de sodio sobre suelos con distintos contenidos de $\mathrm{MO}$ en condiciones de laboratorio. Los suelos tenían un contenido de arcilla uniforme, predominantemente illita y se diferenciaban principalmente por su contenido de Materia Orgánica (MO). Los tratamientos consistieron en soluciones con dos Conductividades Eléctricas (CE) $(0,5$ y $4 \mathrm{dS} / \mathrm{m})$ y tres niveles de RAS $(0,5$ y 15). La resistencia a la tensión dependió del contenido de MO, CE y RAS. Con el incremento de RAS disminuyó la resistencia (en contraposición con lo encontrado en el tratamiento con mayor contenido de sodio de esta Tesis). Rahimi et al. (2000) explican que estas diferencias de comportamiento son debidas a los ciclos de humectación-desecación que redujeron la estabilidad de los agregados. Utomo y Dexter (1981) coinciden en que los eventos de humectación y secado, pueden causar una disminución en la resistencia. La pérdida de resistencia es debida a una combinación de entrampamiento de aire e hinchazón diferencial (Grant y Dexter, 1989). Las características del suelo y el procedimiento de humectación en estos eventos pueden resultar en la producción de cantidades de materiales cementantes insuficientes, resultando preponderantes los procesos que aflojan las zonas de falla sobre los de cementación. En estas circunstancias, la extensión del aflojamiento se incrementa con la 
tasa de humectación y el número de ciclos de humectaciónsecado. Kay y Dexter (1992) estudiaron la variación en la resistencia de los agregados relacionándola a efectos combinados de condiciones que favorecen la dispersión de arcillas y un incremento subsiguiente en la resistencia por cementación al secarse y ciclos de humectación-secado que resultarían en un decrecimiento de la resistencia. En la presente tesis habría prevalecido el efecto cementante de la arcilla por sobre el efecto debilitante del proceso humectación-secado. Dicho ciclo habría derivado en una mayor dispersión de las arcillas de los tratamientos A. Durante la desecación, las arcillas ubicadas en los espacios inter-agregados provocaron la cementación del material generando mayor resistencia al corte. En este sentido, Rajaram y Erbach (1999) concluyen que un suelo arcilloso sometido a ciclos de humectación - desecación sufrió un cambio en sus propiedades físicas incrementando la resistencia a la penetración (evaluada mediante penetrómetro de cono), cohesión, adhesión, fricción interna y tamaño de sus agregados. Barzegar et al. (1994) explicaron que cuando los suelos son removidos en húmedo cierto contenido de arcillas es liberado de los agregados, luego al secarse, se produce una reorganización en nuevos agregados donde los puntos de contacto entre partículas determina el vínculo entre las mismas y por lo tanto la dureza del suelo. Altos contenidos de arcillas dispersas proveen mayor número de puntos de contacto entre partículas. La dureza de cada uno de los suelos estudiados por éstos autores fue modificada a 
raíz de los cationes de intercambio presentes en el suelo que decayó en orden $\mathrm{Na}>\mathrm{Na}-\mathrm{Mg}>\mathrm{Na}-\mathrm{Ca}>\mathrm{Mg}>\mathrm{Ca}-\mathrm{Mg}>\mathrm{Ca}$, tal como disminuye su radio iónico. Los autores subrayaron que altos porcentajes de sodio de intercambio incrementan el contenido de arcillas dispersas y por lo tanto aumenta la dureza de los suelos.

En las pruebas con Ozzano cortado al 5\% de humedad y sin ciclos de humidificación - desecación se hallaron diferencias significativas en los valores de Cohesión de las clases I y II siendo mayor en el tratamiento A, mientras que en las clases III y IV no se hallaron diferencias entre tratamientos. Lloret y Alonso (1985) junto con Escario y Sáez (1986) comprobaron, con ensayos de succión controlada, que el efecto de la succión desaparece al llegar al estado seco, ocurriendo lo mismo al llegar al estado de saturación. Esto implica la existencia de un cierto máximo intermedio que se puede producir para grados de saturación bajos. Lo dicho por estos autores explicaría la ausencia de diferencias encontradas en los valores de cohesión entre tratamientos de las clases III y IV ya que debido al menor tamaño de éstas clases no se habría producido la ruptura de sus agregados sino un deslizamiento entre las partículas.

En el caso de las clases de mayor tamaño (I y II) las diferencias pueden ser atribuibles a las características intrínsecas de los agregados. Al tratarse de un conjunto de agregados sueltos y secos pero contenidos en una caja de corte, los valores de cohesión hallados en éstas clases pueden ser debidos a las tensiones de rotura de cada uno de los agregados individuales 
actuando en forma conjunta a través de la superficie de corte. En éste trabajo de tesis los agregados del tratamiento $A$ presentaron valores de tensión de rotura superiores (Tabla 15) y por lo tanto presentaron mayores valores de cohesión al ser cortados.

Para el caso de OZ al 5\% de humedad y para un mismo tratamiento, la resistencia al corte podría haber sido mayor en las clases granulométricas superiores debido al efecto de rodamiento de un agregado sobre otro, fenómeno conocido como dilatancia (Hillel, 1998; Spugnoli et al., 2002). Si bien en general se observa una tendencia en forma de gradiente de la Clase I a la IV en los valores de Tensión de Corte, la hipótesis del rodamiento de agregados fue refutada luego de planteadas las rectas de Coulomb (Figura 69 y Figura 70), alegando que si efectivamente las diferencias hubiesen sido debidas al tamaño de agregados, debiera haber sido mayor el trabajo demandado para el desplazamiento de las partículas de mayor tamaño entre sí, lo cual se hubiera reflejado en mayores ángulos de rozamiento interno en las Clases granulométricas mayores respecto a las menores (Tabla 30). Sin embargo, los ángulos de rozamiento interno prácticamente no variaron entre las diferentes clases para un mismo tratamiento. Puede hipotetizarse que los agregados de dimensiones mayores sufrieron rotura durante el corte generando agregados de menor tamaño que se ubicaron en los espacios inter-agregados y por ende soslayando el efecto de dilatancia. Solo se halló diferencias en el Angulo de Fricción interna de las clases I y II con la clase IV de OZB donde ésta última presentó un 
ángulo de fricción interna superior a aquellas clases de agregados de mayor tamaño (Tabla 30). Los agregados de la Clase IV (menores a $0,5 \mathrm{~mm}$ ) no tuvieron la posibilidad de un fácil reacomodamiento entre los espacios inter-agregados aumentando así el ángulo de fricción interna.

En los dos suelos estudiados el parámetro que se ha modificado de la ecuación de Coulomb es la cohesión permaneciendo el ángulo de rozamiento interno invariable con las diferentes soluciones de riego. Es previsible que el efecto de la sodicidad varíe con la condición textural de los suelos, siendo mucho más susceptibles a la problemática los suelos de textura fina ya que el componente cohesivo se halla principalmente en las partículas de arcilla y limo, estando prácticamente ausente en las arenas. Richards (1956), a pesar de no establecer rangos explícitos, sugirió efectos de la textura, el área superficial y tipo de mineral arcilloso, contenido de silicatos y materia orgánica, sobre la acción del $\mathrm{Na}^{+}$en la problemática de la dinámica del agua en el suelo. Texturas finas o ricas en limo (más de $50 \%$ ), arcillas expandibles como la montmorillonita y bajo contenido de silicatos y materia orgánica, agravarían la problemática sódica.

\subsubsection{Líneas de Estado Crítico}

a). Comportamiento Volumétrico ante el corte.

Con los datos de relación de tensión (relación entre la tensión normal al momento del corte y la tensión normal máxima 
previa de $605 \mathrm{kPa}$ ) y relación de volumen (relación entre la diferencia de volumen posterior y previo al corte con el volumen previo al corte) se realizaron las regresiones para cada suelo y tratamiento (Figura 74 a Figura 81). Para calcular la relación de volumen se utilizó la ecuación (12): $\mathrm{RV}=(\mathrm{Vf}-\mathrm{Vi}) / \mathrm{Vi}=\mathrm{hf}$.Af hi.Ai / hi.Ai, siendo "V" el volumen, "h" la altura y "A" el área de la muestra; los prefijos "f" e "i" indican "final" e "inicial" respectivamente. Como Af y Ai son iguales, (pues el área de la celda de corte es la misma al inicio y al final), se simplifican quedando $R V=h f-h i / h i(13)$.

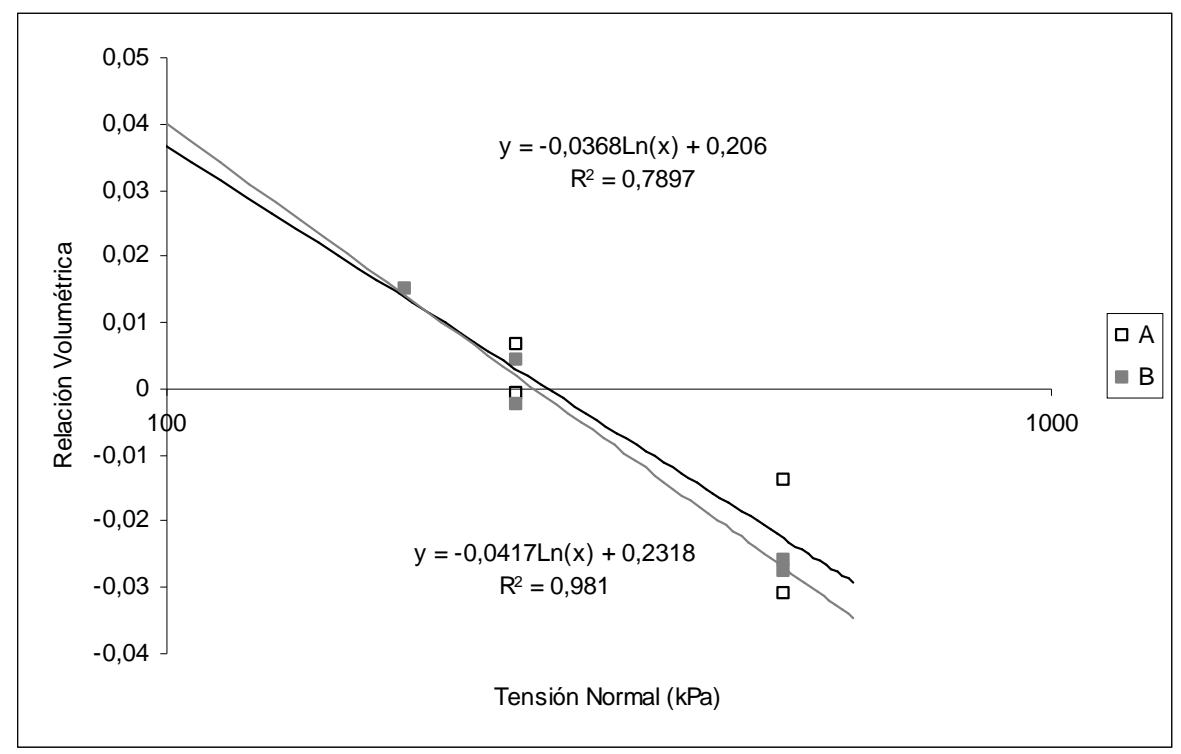

Figura 74: Relación de Volumen durante el corte CDA vs. CDB al $8 \%$ de humedad. 


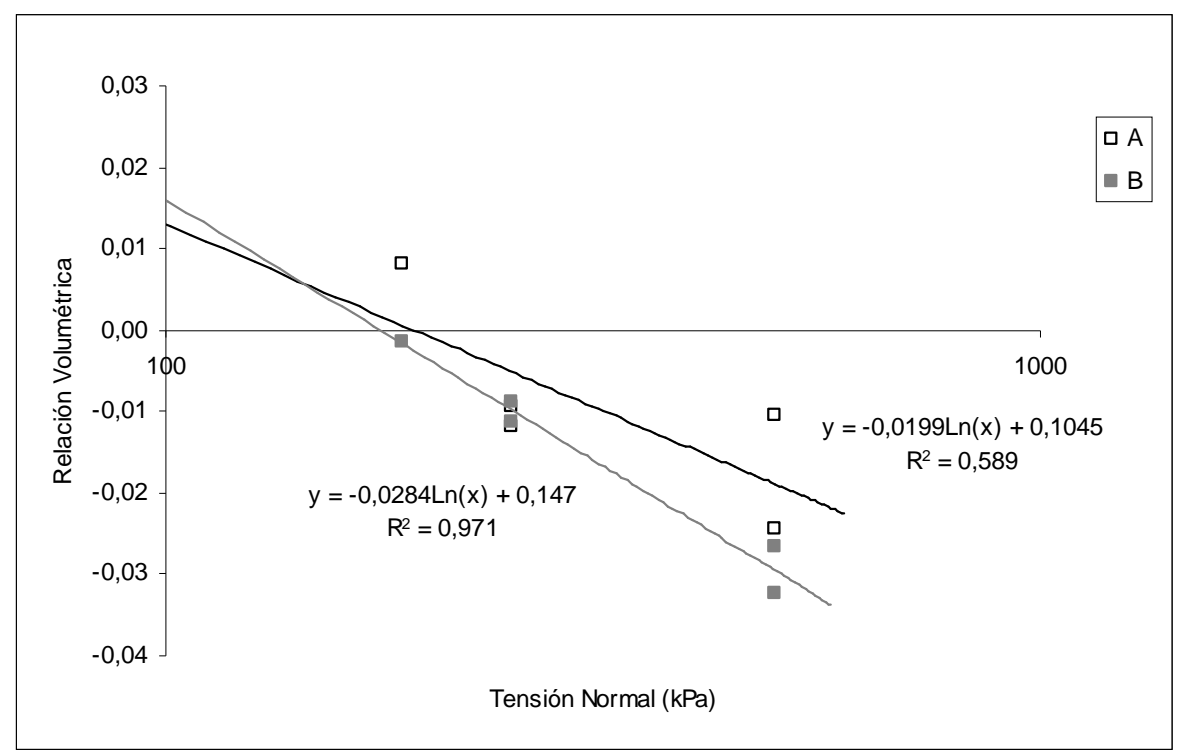

Figura 75: Relación de Volumen durante el corte CDA vs. CDB al $18 \%$ de humedad.

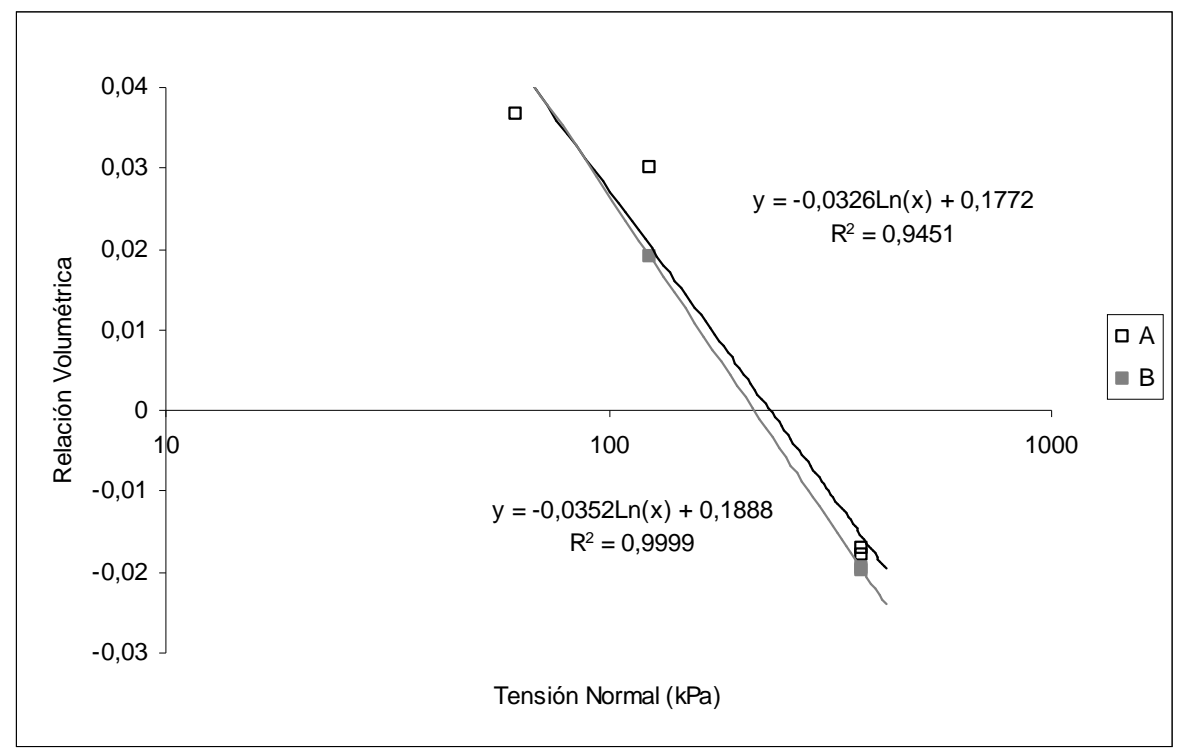

Figura 76: Relación de Volumen durante el corte OZA vs. OZB Clase I al $5 \%$ de humedad. 


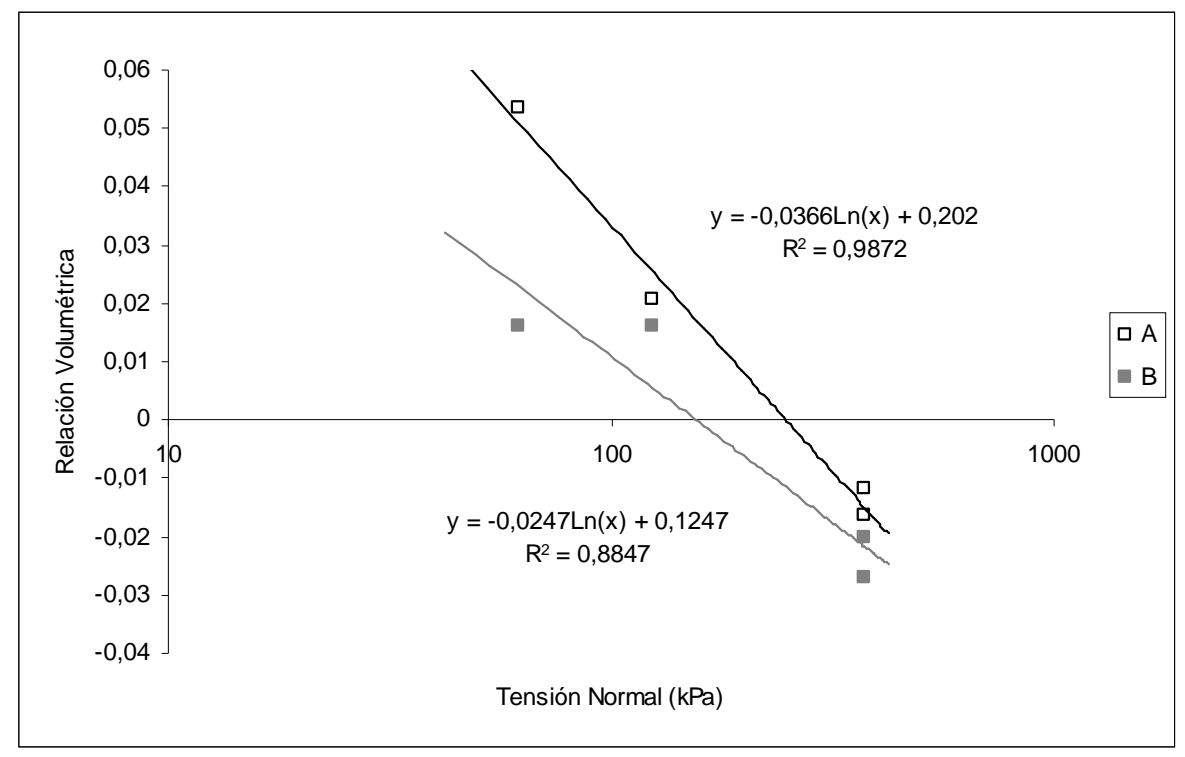

Figura 77: Relación de Volumen durante el corte OZA vs. OZB Clase II al $5 \%$ de humedad.

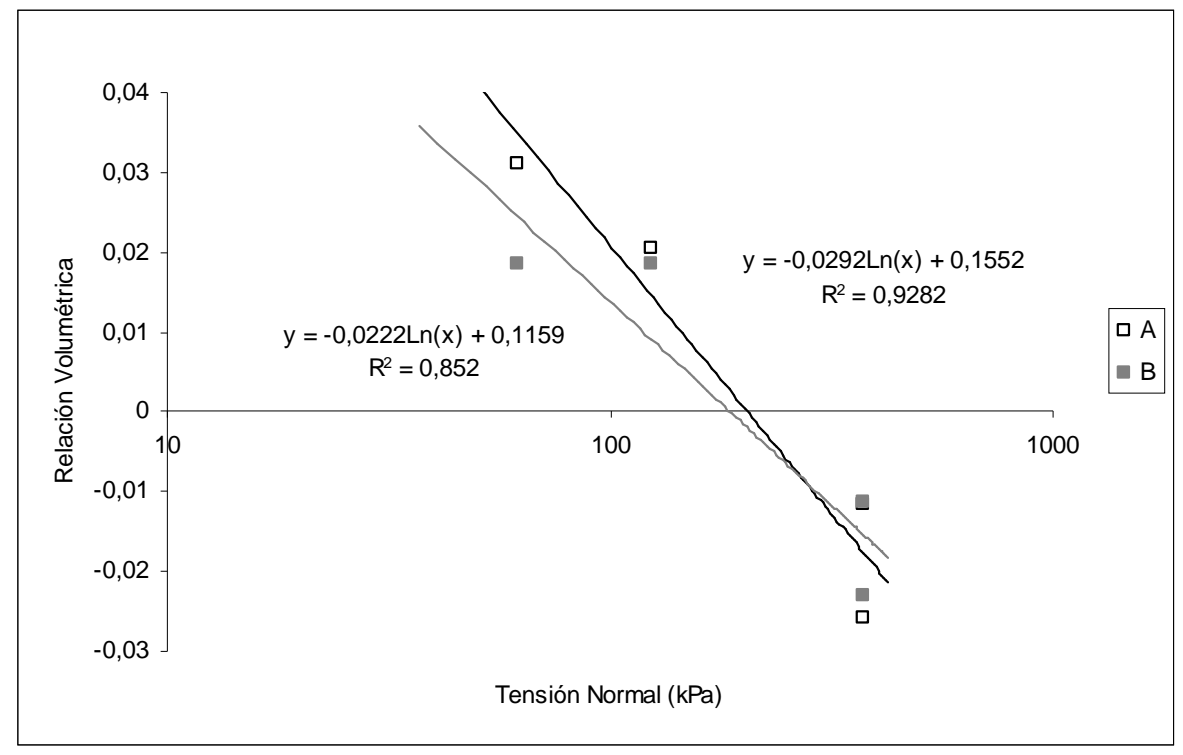

Figura 78: Relación de Volumen durante el corte OZA vs. OZB Clase III al 5\% de humedad. 


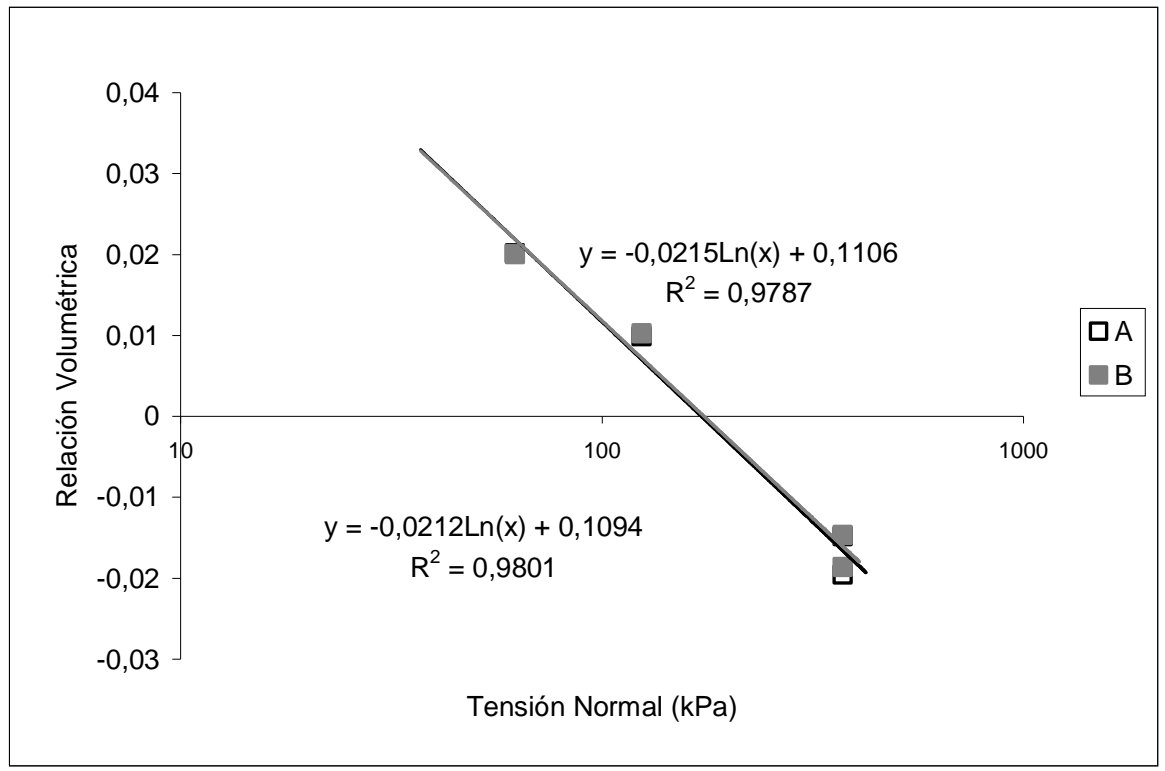

Figura 79: Relación de Volumen durante el corte OZA vs. OZB Clase IV al 5\% de humedad.

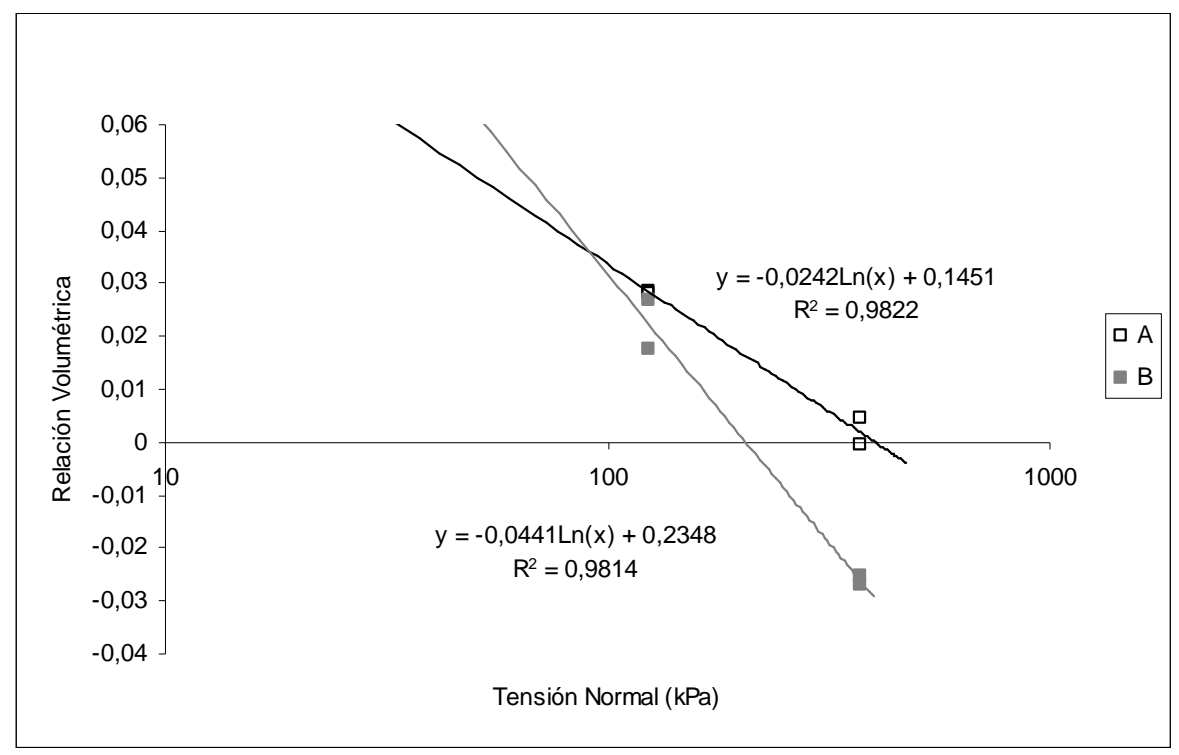

Figura 80: Relación de Volumen durante el corte OZA vs. OZB Clase II al 15\% de humedad. 


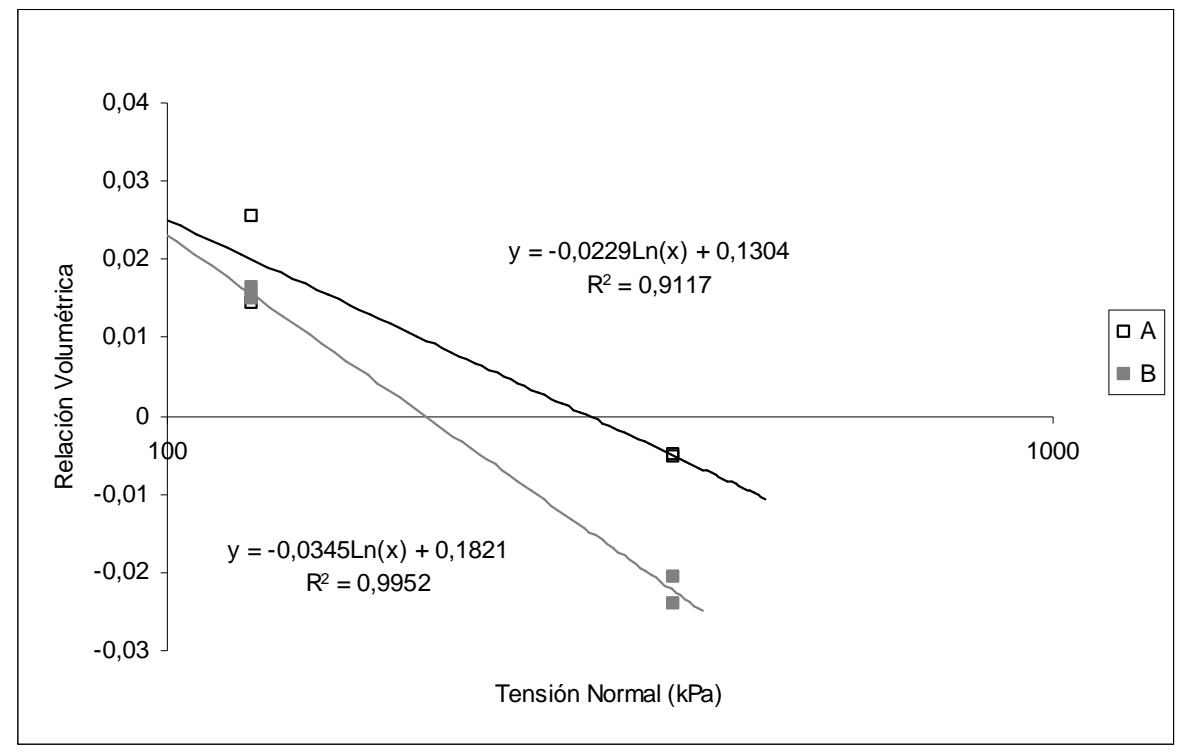

Figura 81: Relación de Volumen durante el corte OZA vs. OZB Clase III al $15 \%$ de humedad.

Los suelos que experimentaron un desplazamiento positivo (hacia arriba) de la muestra durante el corte, sufrieron una expansión o disminución de la densidad mientras que aquellos que experimentaron un desplazamiento negativo (hacia abajo), se comprimieron o aumentaron su densidad.

Si bien los gráficos indican un comportamiento diferente entre tratamientos, solo en el suelo Ozzano cortado al $15 \%$ de humedad se hallaron diferencias entre tratamientos ( $\mathrm{A}$ y $\mathrm{B}$ ) en las regresiones de las rectas de expansión-contracción al corte (Tabla $31)$. 
La Tabla 32 muestra una mayor tendencia a la expansión de los tratamientos A, lo que se evidencia por la mayor Tensión Normal a la que se alcanza el Estado Crítico. Esta tendencia puede explicarse apelando al probable sistema poroso existente en este tratamiento, donde predominarían poros de menor diámetro de acuerdo a lo expuesto por Barzegar et al. (1994), Jayawardane y Chan (1994), Costa y Aparicio (2000), Varallyay (2002) y Vázquez (2003). Los poros de menor diámetro de los tratamientos con mayor contenido de sodio no habrían tenido la capacidad de alojar pequeños agregados o partículas minerales con lo cual en el momento del corte estas partículas, al moverse unas sobre otras, no habrían encontrado huecos suficientemente grandes, resultando en una tendencia mayor a la expansión durante el corte respecto al tratamiento menos sodificado (B). El tratamiento $\mathrm{B}$ en cambio, con poros de dimensiones mayores, habría tenido más capacidad de alojar dichas partículas y consecuentemente mayor tendencia a comprimirse ante el esfuerzo cortante. Habría resultado más sencillo, comprimir durante el corte un material donde predominan poros de mayor tamaño (como en el tratamiento B) que uno donde prevalecen los de menor tamaño (tratamiento A). 
Tabla 31: Comparación de A vs. B de la ordenada al origen y pendientes de las rectas de Relación Volumétrica al corte para CD y OZ en todos sus tratamientos.

\begin{tabular}{ccc}
\hline \hline Tratamiento & Ordenada al origen & Pendiente \\
\hline \hline CD 8\% A & $0,206 \mathrm{a}$ & $-0,0368 \mathrm{a}$ \\
CD 8\% B & $0,232 \mathrm{a}$ & $-0,0417 \mathrm{a}$ \\
\hline CD 18\% A & $0,1045 \mathrm{a}$ & $-0,0199 \mathrm{a}$ \\
CD 18\% B & $0,147 \mathrm{a}$ & $-0,0284 \mathrm{a}$ \\
\hline OZ 5\% A I & $0,1772 \mathrm{a}$ & $-0,0326 \mathrm{a}$ \\
OZ 5\% B I & $0,1888 \mathrm{a}$ & $-0,0352 \mathrm{a}$ \\
\hline OZ 5\% A II & $0,202 \mathrm{a}$ & $-0,0366 \mathrm{a}$ \\
OZ 5\% B II & $0,1247 \mathrm{a}$ & $-0,0247 \mathrm{a}$ \\
\hline OZ 5\% A III & $0,1552 \mathrm{a}$ & $-0,0292 \mathrm{a}$ \\
OZ 5\% B III & $0,1159 \mathrm{a}$ & $-0,0222 \mathrm{a}$ \\
\hline OZ 5\% A IV & $0,1106 \mathrm{a}$ & $-0,0215 \mathrm{a}$ \\
OZ 5\% B IV & $0,1094 \mathrm{a}$ & $-0,0212 \mathrm{a}$ \\
\hline OZ 15\% A II & $0,1451 \mathrm{~b}$ & $-0,0242 \mathrm{a}$ \\
OZ 15\% B II & $0,2348 \mathrm{a}$ & $-0,0441 \mathrm{~b}$ \\
\hline OZ 15\% A III & $0,1304 \mathrm{~b}$ & $-0,0229 \mathrm{a}$ \\
OZ 15\% B III & $0,1821 \mathrm{a}$ & $-0,0345 \mathrm{~b}$
\end{tabular}

Letras diferentes en la misma columna denotan diferencias estadísticas significativas (Comparación de Regresiones LSD $p<0,10$ ) 
Tabla 32: Tensión Normal (TN)(kPa) a la que se alcanza el Estado Crítico para ambos suelos (CD y OZ) y todos sus tratamientos.

\begin{tabular}{|c|c|c|c|}
\hline \multirow{2}{*}{ Suelo } & \multirow{2}{*}{ Prueba } & \multicolumn{2}{|c|}{ Tratamiento } \\
\hline & & TN A $(\mathrm{kPa})$ & $\mathrm{TN} B(\mathrm{kPa})$ \\
\hline \multirow{2}{*}{ Cardone } & CD 8\% de $\mathrm{H}^{\circ}$ & 269,8 & 259,5 \\
\hline & CD $18 \%$ de $\mathrm{H}^{\circ}$ & 190,8 & 177,0 \\
\hline \multirow{7}{*}{ Ozzano } & $\mathrm{OZ} \mathrm{I}$ al $5 \%$ de $\mathrm{H}^{\circ}$ & 229,43 & 213,5 \\
\hline & OZ II al $5 \%$ de $\mathrm{H}^{\circ}$ & 249,42 & 155,8 \\
\hline & OZ III al $5 \%$ de $\mathrm{H}^{\circ}$ & 203,40 & 185,07 \\
\hline & OZ IV al $5 \%$ de $\mathrm{H}^{\circ}$ & 171,43 & 174,0 \\
\hline & OZ II al $15 \%$ de $\mathrm{H}^{\circ}$ & 401,76 & 205,26 \\
\hline & OZ III al $15 \%$ de $\mathrm{H}^{\circ}$ & 205,26 & 196,03 \\
\hline & Media & $240,16 a$ & $195,77 b$ \\
\hline
\end{tabular}

$\overline{\text { Letras diferentes denotan diferencias estadísticas significativas (LSD } p<0,05)}$

b). Obtención de la Línea de Estado Crítico.

Con las ecuaciones de regresión de Comportamiento Volumétrico durante el Corte se determinó la tensión normal máxima a la que se debería someter a la muestra durante el corte para que no existiese compresión o expansión durante la falla (Estado Crítico). Puede verse que en ambos suelos (Cardone y Ozzano) el tratamiento B (menos sodificado) alcanzó el estado crítico con menores valores absolutos de tensión normal respecto al tratamiento $A(L S D p<0,05)$ (Tabla 32). Esto implica que en los suelos sódicos la probabilidad de recibir compresiones adicionales al ser cortados disminuiría con respecto a los no sódicos 
(aumentaría la probabilidad de expandirse con el corte, aumentaría el dominio supercrítico).

Recordando que la LEC y la LV son representadas en un gráfico semilogarítmico $v-\ln (p)$ por dos líneas rectas paralelas (Hettiaratchi, 1987) definidas por las ecuaciones 5 y 6 :

$$
\begin{aligned}
& \text { LV: } v=\mathrm{N}-\lambda \cdot \ln (p) \ldots(5) \\
& \text { LEC: } v=\Gamma-\lambda \cdot \ln (p) \ldots(6)
\end{aligned}
$$

Se realizaron los gráficos que muestran la posición de la Línea de Estado Crítico respecto a la Línea Virgen para todos los tratamientos de ambos suelos ensayados (Figura 82 a Figura 89).

En la Tabla 33 observamos los términos independientes de las ecuaciones de la Línea Virgen (N) y de la Línea de Estado Crítico $(\Gamma)$, el término $(\mathrm{N}-\Gamma)$ (Tabla 34) representa la distancia que existe en términos relativos entre la LV y la LEC entre ambos tratamientos (LSD $p<0,05)$. 


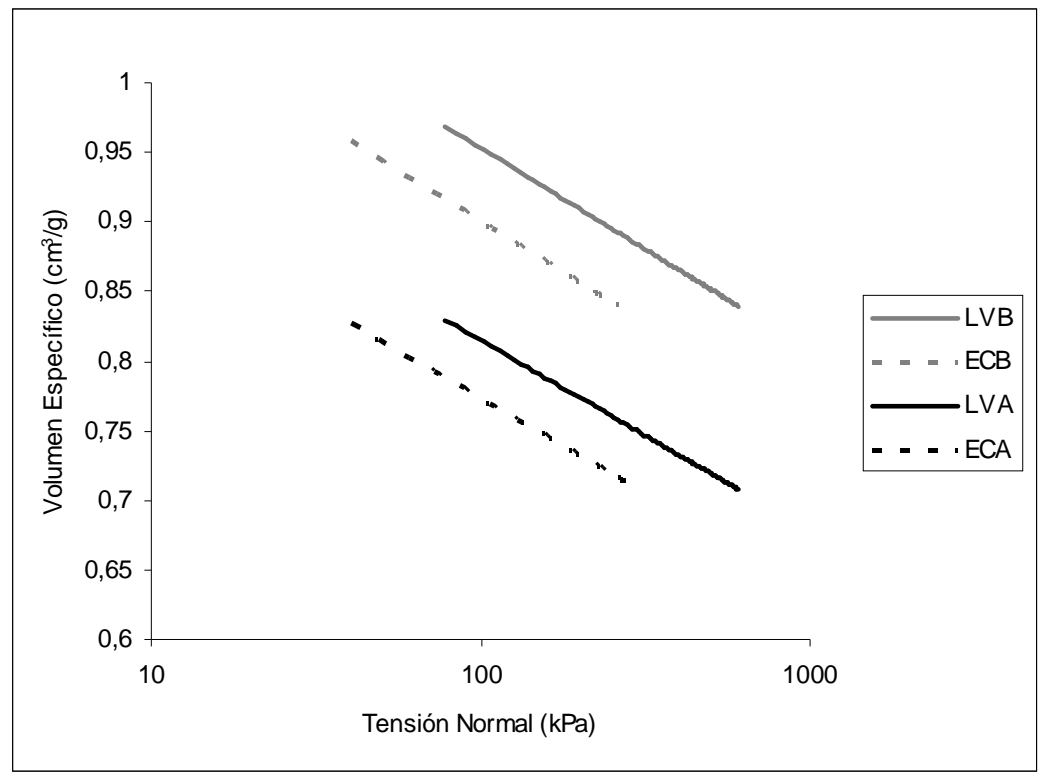

Figura 82: Líneas Virgen (LV) y de Estado Crítico (EC) de CDA vs. CDB al $8 \%$ de humedad.

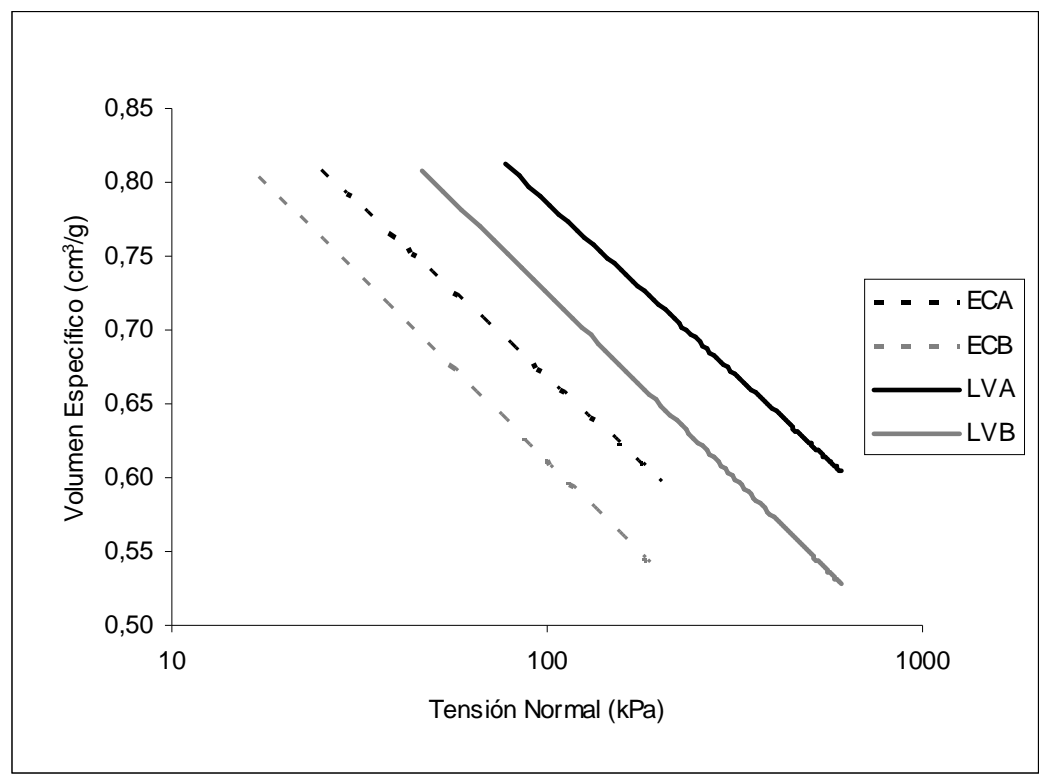

Figura 83: Líneas Virgen (LV) y de Estado Crítico (EC) de CDA vs. CDB al $18 \%$ de humedad. 


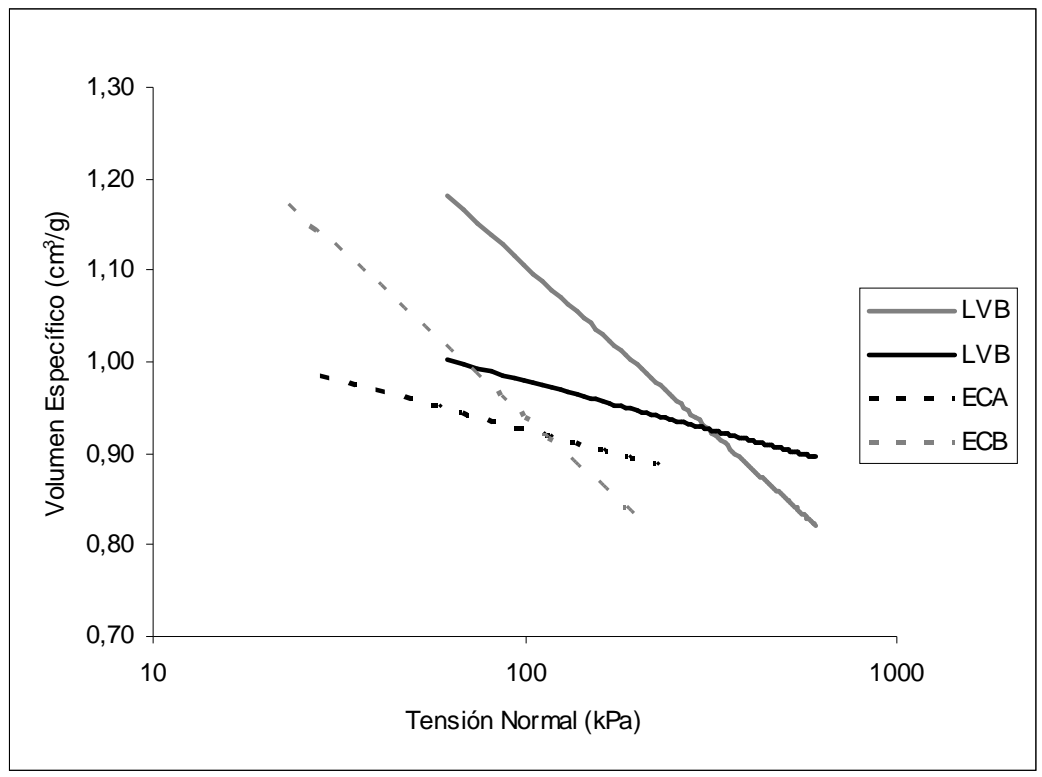

Figura 84: Líneas Virgen (LV) y de Estado Crítico (EC) de OZA vs. OZB Clase I al $5 \%$ de humedad.

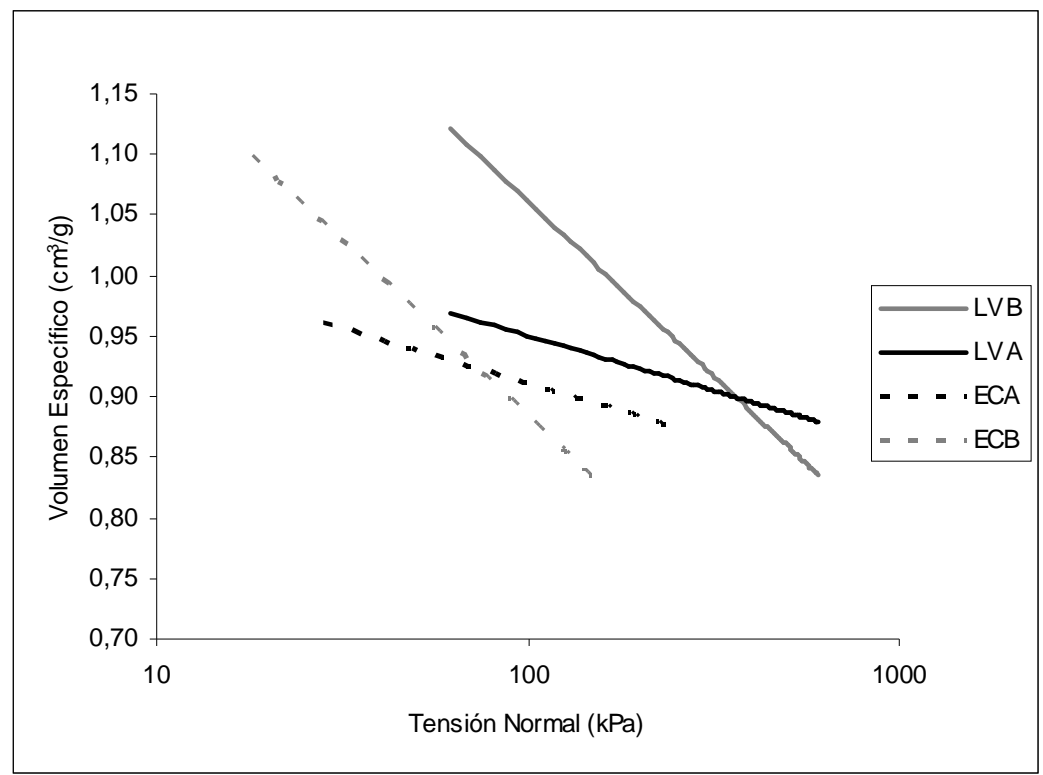

Figura 85: Líneas Virgen (LV) y de Estado Crítico (EC) de OZA vs. OZB Clase II al $5 \%$ de humedad. 


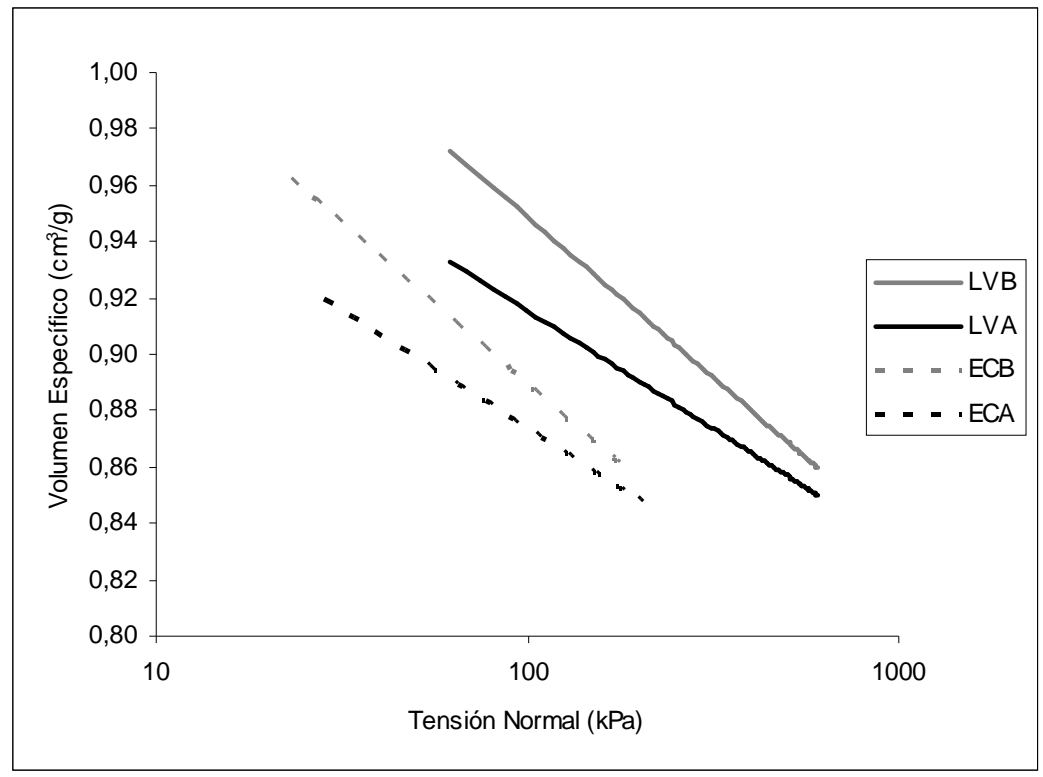

Figura 86: Líneas Virgen (LV) y de Estado Crítico (EC) de OZA vs. OZB Clase III al $5 \%$ de humedad.

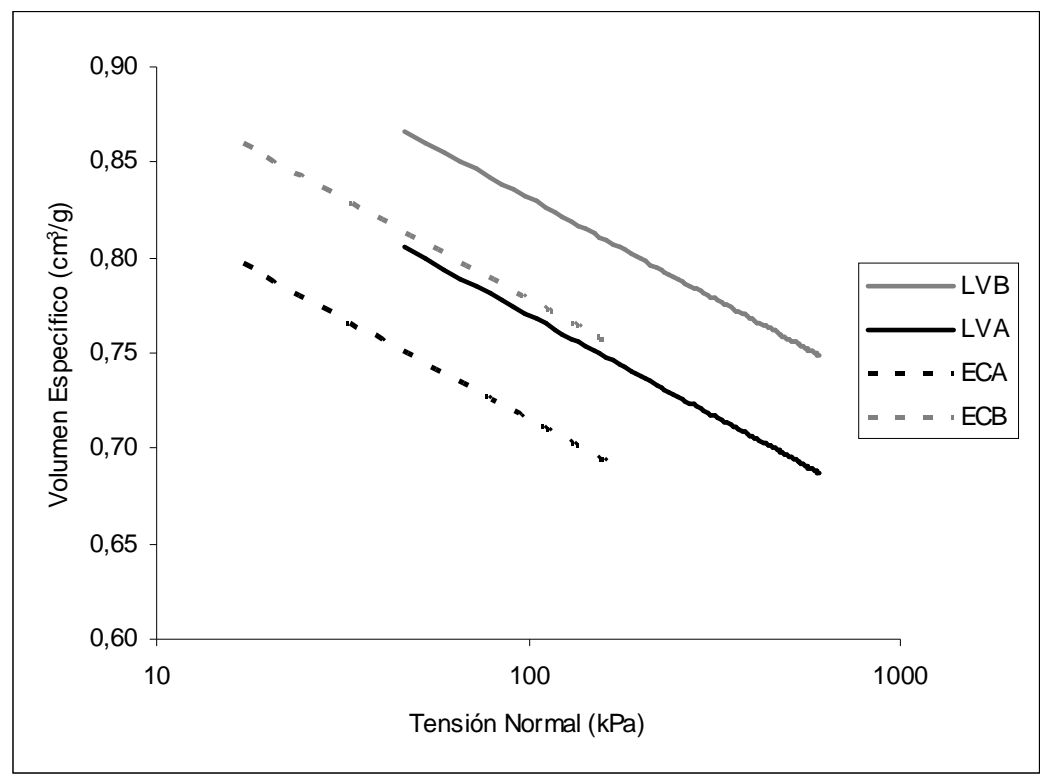

Figura 87: Líneas Virgen (LV) y de Estado Crítico (EC) de OZA vs. OZB Clase IV al $5 \%$ de humedad. 


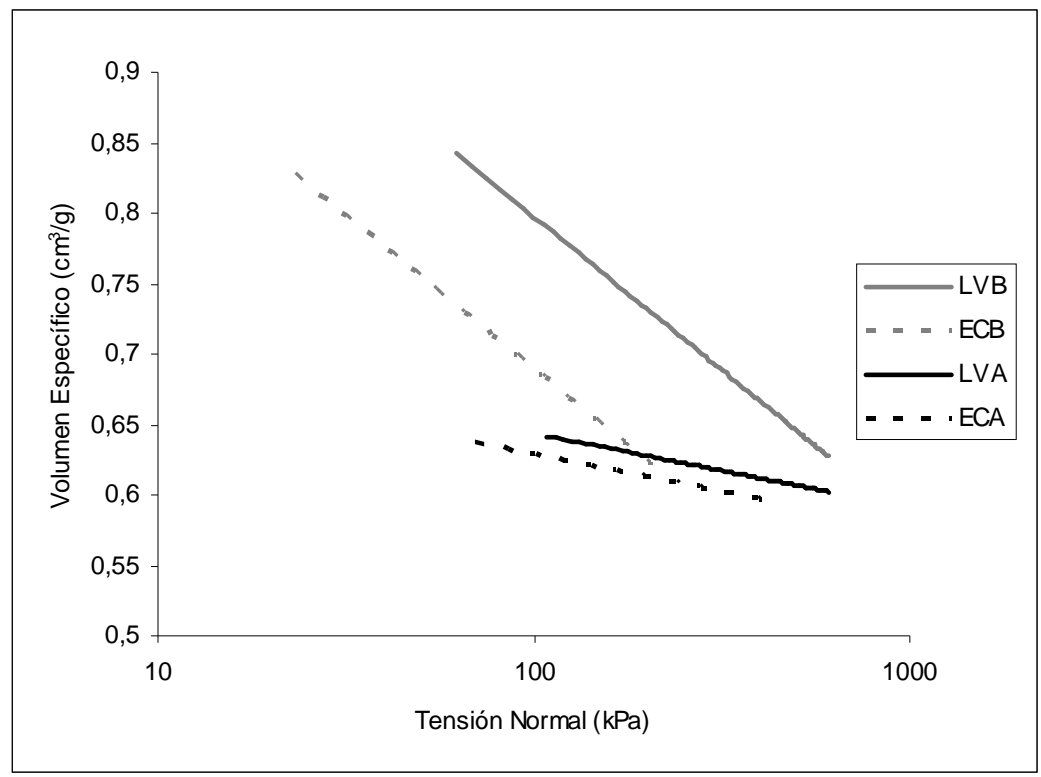

Figura 88: Líneas Virgen (LV) y de Estado Crítico (EC) de OZA vs. OZB Clase II al $15 \%$ de humedad.

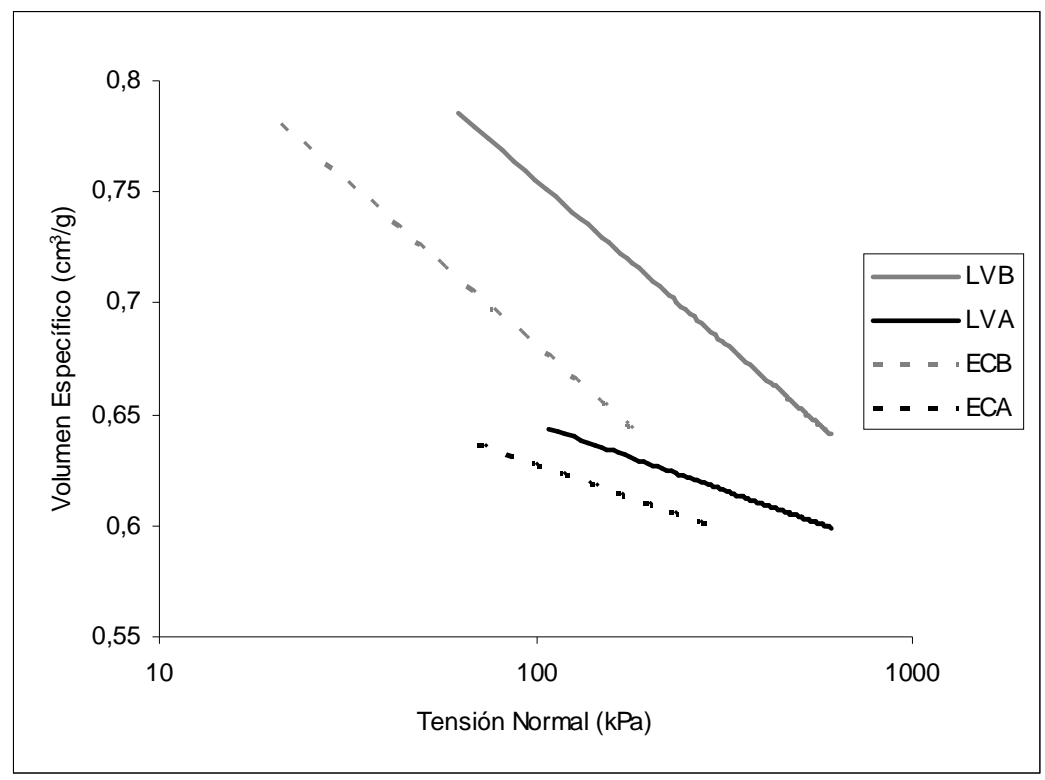

Figura 89: Líneas Virgen (LV) y de Estado Crítico (EC) de OZA vs. OZB Clase III al $15 \%$ de humedad. 
Tabla 33: Términos independientes de la Línea Virgen (N), Línea de Estado Crítico $(\Gamma)$ para todos los tratamientos de ambos suelos (CD y OZ).

\begin{tabular}{|c|c|c|c|}
\hline Suelo & Tratamiento & $\mathbf{N}\left(\mathrm{cm}^{3} / \mathrm{g}\right)$ & $\Gamma\left(\mathrm{cm}^{3} / \mathrm{g}\right)$ \\
\hline \multirow{4}{*}{ Cardone } & $\mathrm{CD} 8 \% \mathrm{H}^{\circ} \mathrm{A}$ & 1,087 & 1,046 \\
\hline & $\mathrm{CD} 8 \% \mathrm{H}^{\circ} \mathrm{B}$ & 1,243 & 1,190 \\
\hline & $\mathrm{CD} 18 \% \mathrm{H}^{\circ} \mathrm{A}$ & 1,252 & 1,133 \\
\hline & $\mathrm{CD} 18 \% \mathrm{H}^{\circ} \mathrm{B}$ & 1,228 & 1,113 \\
\hline \multirow{12}{*}{ Ozzano } & $\mathrm{OZ} \mathrm{5 \% \textrm {H } ^ { \circ } \mathrm { Al }}$ & 1,194 & 1,140 \\
\hline & $\mathrm{OZ} 5 \% \mathrm{H}^{\circ} \mathrm{BI}$ & 1,834 & 1,667 \\
\hline & OZ 5\% $\mathrm{H}^{\circ} \mathrm{A} \| \mathrm{I}$ & 1,133 & 1,093 \\
\hline & $\mathrm{OZ} 5 \% \mathrm{H}^{\circ} \mathrm{B} \|$ & 1,638 & 1,461 \\
\hline & OZ 5\% $\mathrm{H}^{\circ} \mathrm{A}$ III & 1,083 & 1,041 \\
\hline & OZ 5\% $\mathrm{H}^{\circ} \mathrm{B}$ III & 1,177 & 1,117 \\
\hline & OZ 5\% $\mathrm{H}^{\circ}$ A IV & 0,982 & 0,927 \\
\hline & OZ 5\% $\mathrm{H}^{\circ} \mathrm{B}$ IV & 1,043 & 0,990 \\
\hline & OZ 15\% $\mathrm{H}^{\circ} \mathrm{A} \| \mathrm{I}$ & 0,749 & 0,735 \\
\hline & OZ 15\% $\mathrm{H}^{\circ} \mathrm{B} \mathrm{II}$ & 1,231 & 1,123 \\
\hline & OZ 15\% $\mathrm{H}^{\circ} \mathrm{A}$ III & 0,765 & 0,747 \\
\hline & OZ 15\% $\mathrm{H}^{\circ} \mathrm{B}$ III & 1,048 & 0,973 \\
\hline
\end{tabular}


Tabla 34: Diferencia entre términos independientes de LV y LEC $(\mathrm{N}-\Gamma)$ para todos los tratamientos de ambos suelos (CD y OZ).

\begin{tabular}{|c|c|c|c|}
\hline \multirow{2}{*}{ Suelo } & \multirow{2}{*}{ Prueba } & \multicolumn{2}{|c|}{ Tratamiento } \\
\hline & & $(\mathrm{N}-\Gamma) \mathrm{A}$ & $(\mathrm{N}-\Gamma) \mathrm{B}$ \\
\hline \multirow{2}{*}{ Cardone } & $\mathrm{CD} 8 \%$ de $\mathrm{H}^{\circ}$ & 0,041 & 0,053 \\
\hline & CD $18 \%$ de $\mathrm{H}^{\circ}$ & 0,119 & 0,115 \\
\hline \multirow{6}{*}{ Ozzano } & $\mathrm{OZ} \mathrm{I} \mathrm{al} 5 \%$ de $\mathrm{H}^{\circ}$ & 0,054 & 0,167 \\
\hline & OZ II al $5 \%$ de $\mathrm{H}^{\circ}$ & 0,040 & 0,177 \\
\hline & OZ III al $5 \%$ de $H^{\circ}$ & 0,042 & 0,060 \\
\hline & OZ IV al $5 \%$ de $\mathrm{H}^{\circ}$ & 0,055 & 0,053 \\
\hline & OZ II al $15 \%$ de $\mathrm{H}^{\circ}$ & 0,014 & 0,108 \\
\hline & OZ III al $15 \%$ de $\mathrm{H}^{\circ}$ & 0,018 & 0,075 \\
\hline & Media & $0,048 \mathrm{~b}$ & $0,101 \mathrm{a}$ \\
\hline
\end{tabular}

Letras diferentes denotan diferencias estadísticas significativas (LSD p<0,05)

En base a los parámetros obtenidos a través de la Teoría del Estado Crítico puede verse que los tratamientos con mayor contenido de Sodio (A) tendrían una menor distancia entre la Línea Virgen y la Línea de Estado Crítico y por lo tanto la región sub.-crítica sería reducida, característica que les conferiría una mayor capacidad de expansión durante el corte con respecto a los tratamientos menos sodificados (B). Esto significaría también que los tratamientos más sódicos tolerarían Tensiones Normales superiores y aún podrían presentar expansión durante el corte. Este hecho coincide con lo expresado por Hettiaratchi (1987) 
quien explica como con el aumento del parámetro $\lambda$, la línea de Estado Crítico se aproxima a la Línea de Consolidación Virgen produciendo una expansión de la superficie Hvorslev en detrimento de la Roscoe.

Este comportamiento se visualizó en ambos suelos (Ozzano y Cardone) salvo en el tratamiento de Cardone cortado al $18 \%$ de humedad. Posiblemente la correcta ubicación de la Línea de Estado Crítico, y por ende la posibilidad de una mejor observación de diferencias entre los tratamientos A y B, se dé en situaciones de humedad más baja. Palancar (2007) utilizando caja de corte directo, encontró dificultades para el correcto trazado de la Línea de Estado Crítico en algunos suelos cortados al 20\% de humedad. Es posible hipotetizar que la correcta ubicación de la Línea de Estado Crítico sea más simple en condiciones de suelo seco. Hettiaratchi y O'Callaghan (1980) al igual que Leeson y Campbell (1983) explicaron como el contenido de humedad produce una variación en la posición de la Línea de Estado Crítico. Estos autores afirman que cuando en un suelo se produce una disminución del contenido de humedad el volumen específico determinado por la LEC en el plano $p-v$ permanece constante pero su dureza se ve incrementada, debido al aumento de la tensión de agua de sus poros y aumento de su cementación. En estas circunstancias el estrés desviatórico necesario para llevar la muestra al Estado Crítico aumenta provocando el alejamiento de la LEC respecto al origen del plano $p-v$. Sumado a esto, la pendiente de la Línea Virgen $(\lambda)$ disminuye y como se mencionara 
anteriormente esto provoca una aproximación de la LEC (Hettiaratchi, 1987) acentuándose posiblemente las diferencias entre tratamientos. La humedad de $18 \%$ pudo además jugar otro rol en la correcta ubicación de la LEC ya que las arcillas dispersas no tuvieron posibilidad de actuar como ligante debido al aumento de la doble capa difusa a esa humedad respecto a humedades más bajas tal como lo explicara Rengasamy y Olsson (1991).

Retomando el comportamiento general de los suelos estudiados, el aumento del espacio supercrítico, es decir la mayor tendencia expansiva del tratamiento A, podría explicarse recurriendo al modelo de pequeños poros que presentaría este tratamiento, en el cual sería difícil para las partículas mayores encontrar nuevos huecos donde reacomodarse para seguir comprimiéndose.

De acuerdo a Spugnoli et al (2002) el mayor comportamiento expansivo registrado por los suelos altamente saturados con $\mathrm{Na}^{+}$muestra aparentemente un mejoramiento en la respuesta del suelo a las tensiones externas aplicadas. Indirectamente, esto podría sugerir una situación positiva ante las operaciones de labranza, que podría balancear la alta energía requerida para roturar el suelo (alta resistencia al corte). Sin embargo desde un punto de vista más cualitativo, se observó que los tratamientos con menor contenido de sodio (B) pueden arribar en el corte, con Tensiones Normales bajas, a valores más altos de volumen específico y por ende mayor porosidad que los suelos más sodificados. Este hecho puede observarse en las Figura 90 y 
Figura 91 donde se toman como ejemplo OZ Clase II y Clase III, ambas al $5 \%$ de humedad. Sobre ambos gráficos se observa que a Tensiones Normales Bajas, el tratamiento B podría alcanzar al corte valores superiores de Volumen Específico respecto a A.

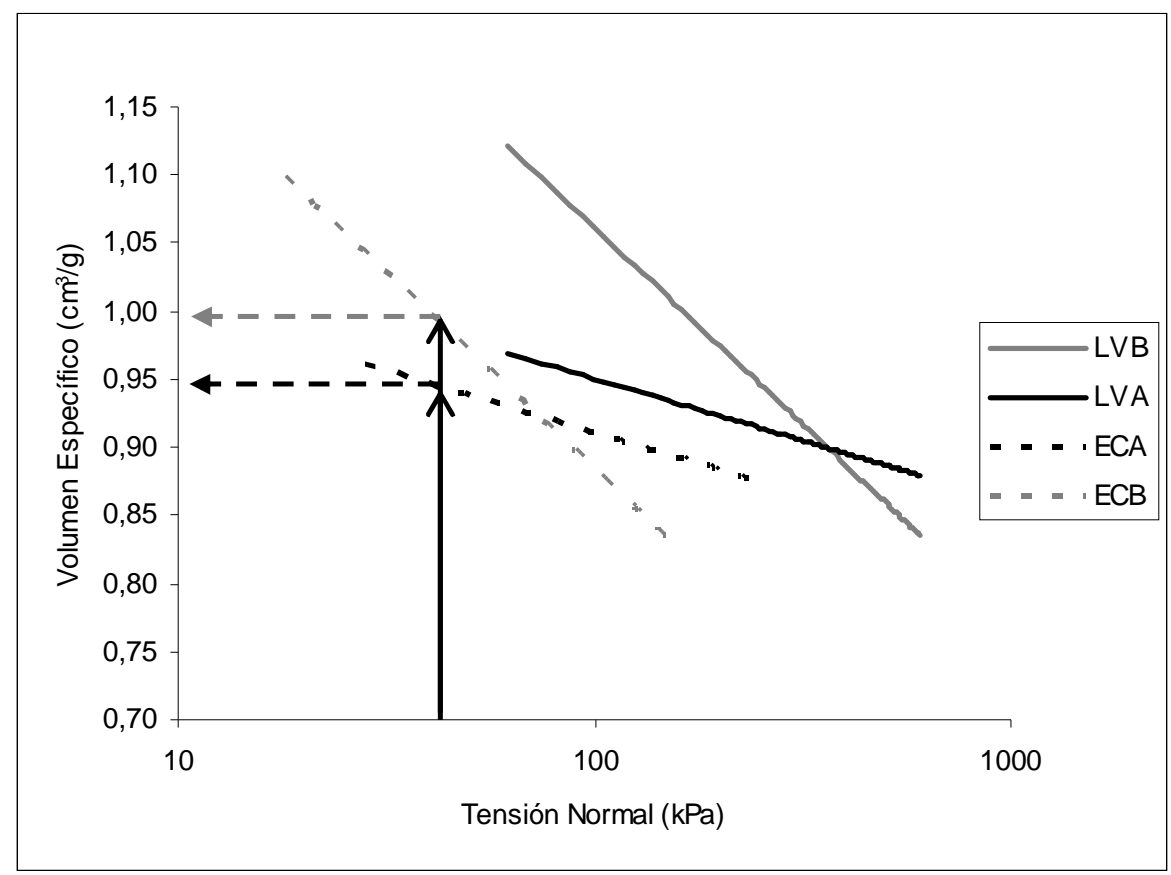

Figura 90: Líneas de LV y EC para OZ Clase II al $5 \%$ de $\mathrm{H}^{\circ}$ (A vs B). A una misma Tensión Normal OZ B tendría la posibilidad de alcanzar Vol.Esp. superiores. 


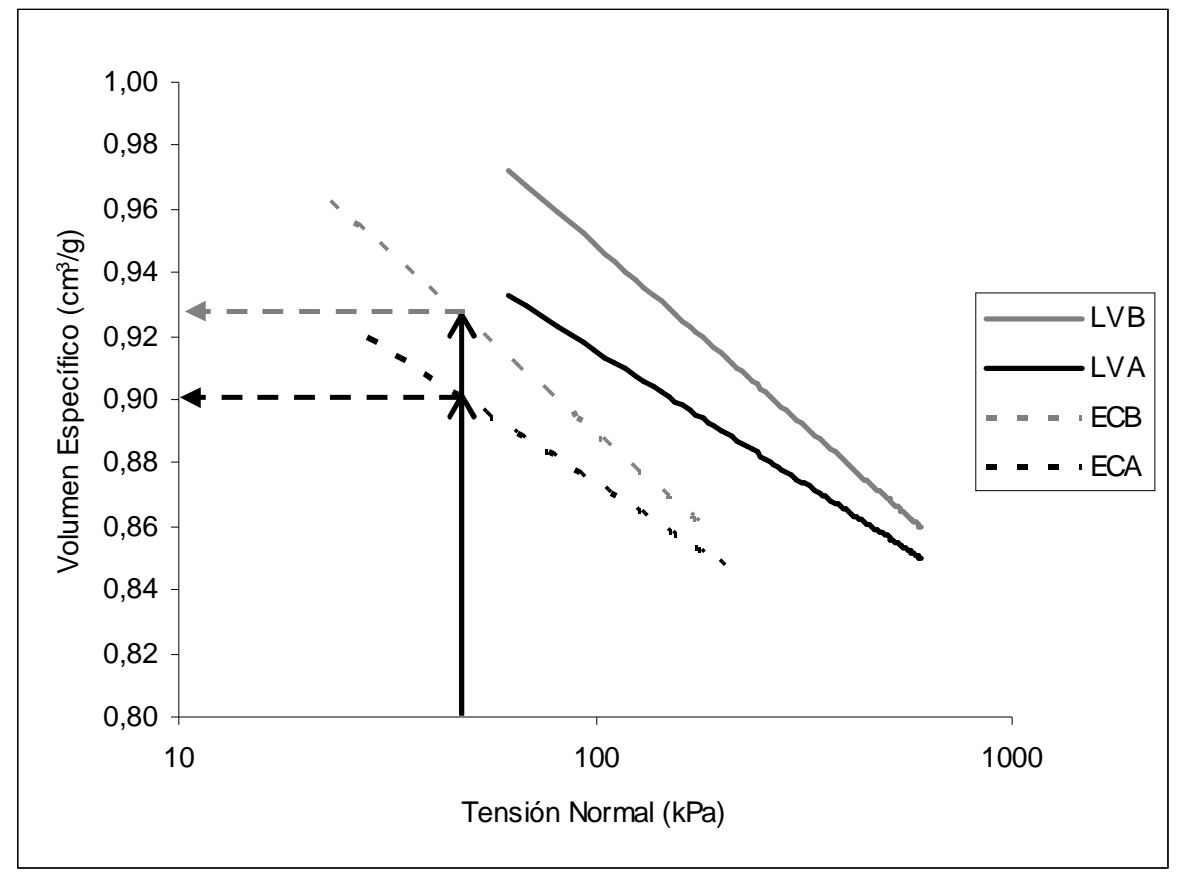

Figura 91: Líneas de LV y EC para OZ Clase III al $5 \%$ de $H^{\circ}$ (A vs B). A una misma Tensión Normal OZ B tendría la posibilidad de alcanzar Vol.Esp. superiores.

Si bien un suelo sodificado (como el A) presentaría mayor tendencia a la expansión, esto sería solo en términos relativos, ya que un suelo con menor contenido de sodio (como el B) posee inicialmente valores de volumen específico mayores a los que puede arribar el suelo más sodificado aún expandiendo proporcionalmente más. Por lo tanto, si bien un suelo más sodificado tendería a una mayor expansión, difícilmente pueda alcanzar valores de porosidad como las de un suelo menos sodificado a paridad de Tensión Normal. Los efectos deletéreos 
del sodio en la porosidad de un suelo serían de una magnitud tal que no podrían ser asimilados por la mayor capacidad expansiva.

Por otra parte, puede decirse que los tratamientos más sodificados $(A)$, requieren una relación Tensión de Corte / Tensión Normal considerablemente superior que los tratamientos B para alcanzar un valor de Volumen Específico determinado. Para ilustrar éste fenómeno puede realizarse un ejercicio similar al anterior, tomando nuevamente como ejemplo OZ Clase II y Clase III, ambas al $5 \%$ de humedad, puede observarse que para alcanzar un Vol. Específico determinado el tratamiento A deberá ser cortado a Tensiones Normales más bajas que B (Figura 92 y Figura 93)

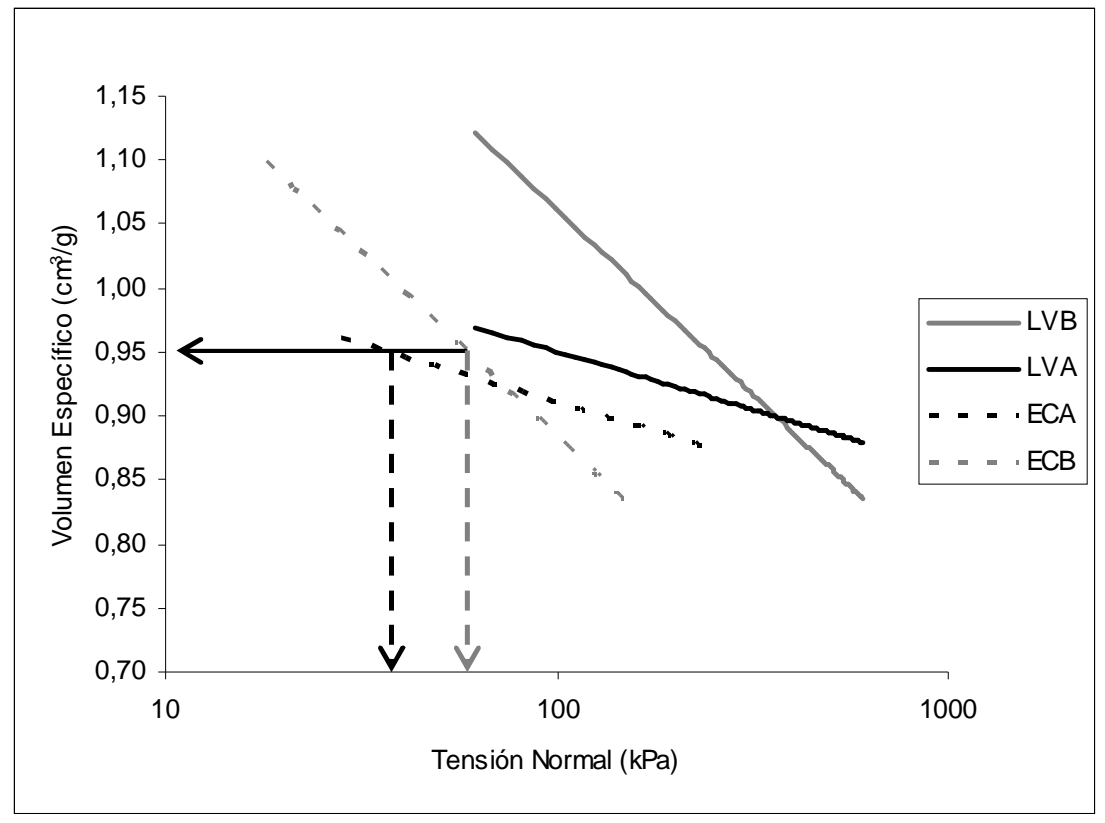

Figura 92: Líneas de LV y EC para OZ Clase II al $5 \%$ de $\mathrm{H}^{\circ}$ (A vs B). Para obtener un mismo valor de Vol. Esp., A soportaría menor Tensión Normal que B. 


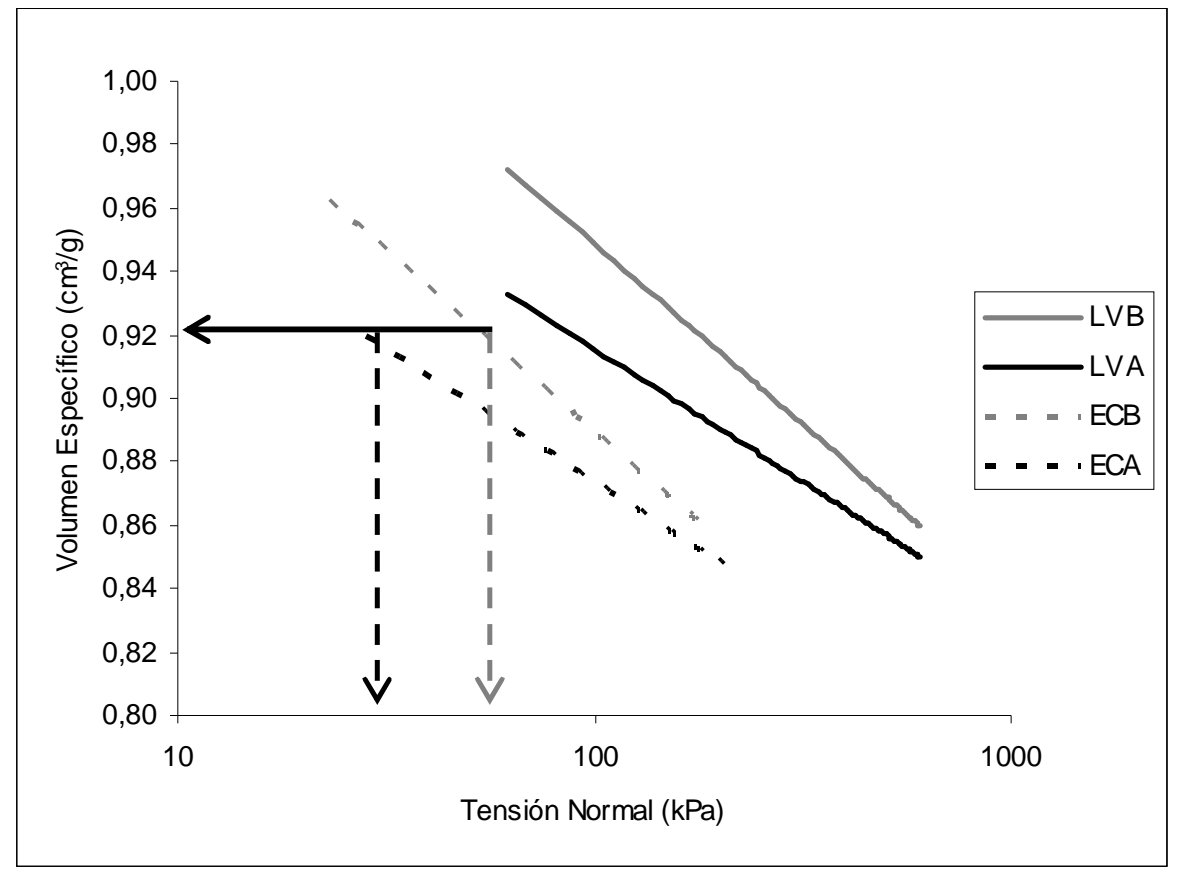

Figura 93: Líneas de LV y EC para OZ Clase III al $5 \%$ de $H^{\circ}$ (A vs B). Para obtener un mismo valor de Vol. Esp., A soportaría menor Tensión Normal que B.

Por su parte, los tratamientos con menor contenido de Sodio (B) requieren un menor esfuerzo desviatórico, soportando Tensiones Normales Superiores y por ende una relación Tensión de Corte / Tensión Normal menor para lograr un incremento similar en su volumen específico. llustrando con otro ejemplo, en una situación hipotética en la que se requiera lograr mediante el corte un incremento de aproximadamente un 10\% del Volumen Específico respecto al que se ha arribado durante la compresión (Figura 94 y Figura 95) se observa que el tratamiento A requeriría ser cortado a Tensiones Normales inferiores para lograr dicho incremento respecto al tratamiento $\mathrm{B}$. 


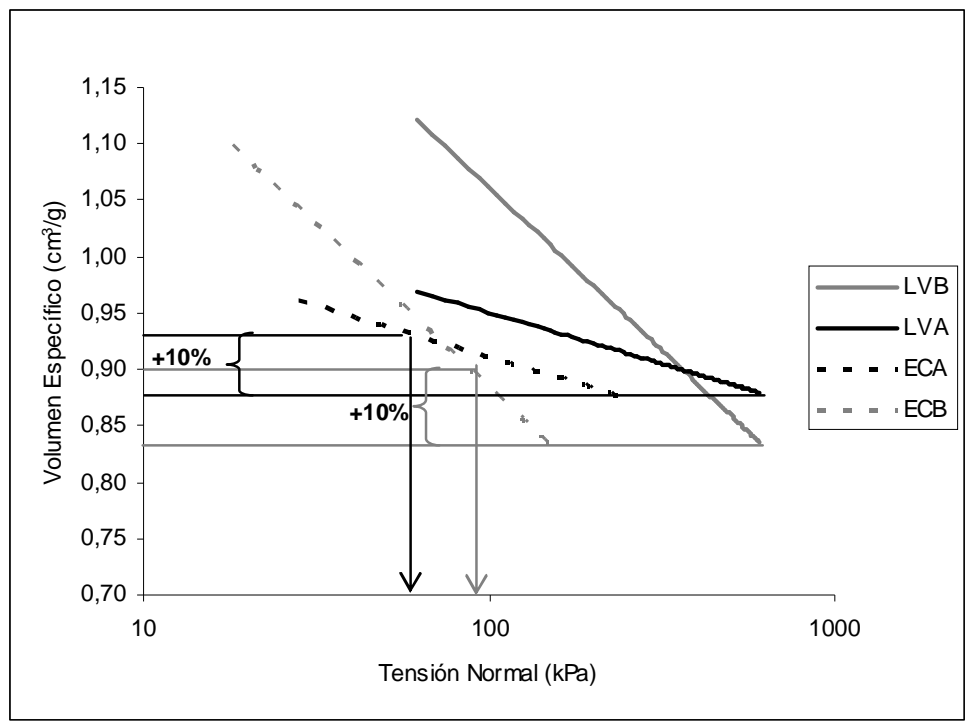

Figura 94: Líneas de LV y EC para OZ Clase II al $5 \%$ de $H^{\circ}$ (A vs B). Tensión Normal al Corte al que se podría esperar un incremento de Vol.Esp. del $10 \%$ aproximadamente.

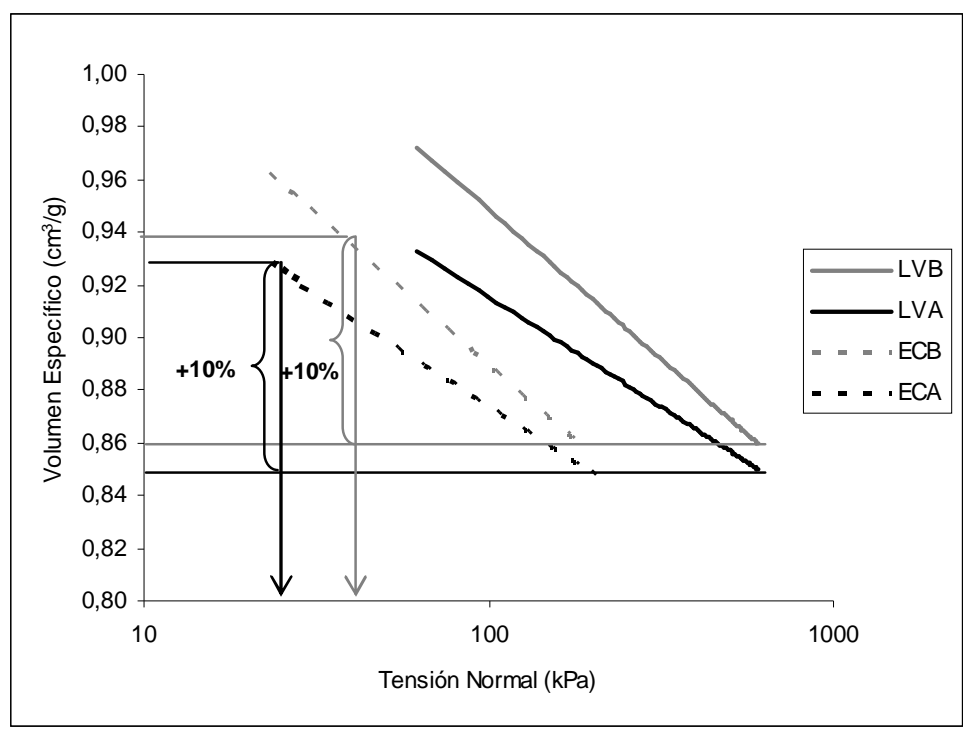

Figura 95: Líneas de LV y EC para OZ Clase III al $5 \%$ de $\mathrm{H}^{\circ}$ (A vs B). Tensión Normal al Corte al que se podría esperar un incremento de Vol.Esp. del $10 \%$ aproximadamente. 


\subsection{Consideraciones Finales.}

A pesar de que los valores de PSI alcanzados por los suelos en los que se simuló la aplicación de láminas de riego con agua enriquecida en sodio, no fueron excesivamente elevados (alrededor de $5 \%$ ), se observaron alteraciones de las propiedades físicas. Este hecho indicaría que la problemática de la presencia de sodio en los suelos genera consecuencias importantes aún a valores de PSI donde la realización de un análisis químico indicaría una leve sodificación.

De los parámetros evaluados, el volumen específico o su inversa la densidad, fue uno de los más alterados por la presencia de sodio en el agua de riego, siendo agronómicamente una de las propiedades físicas de mayor relevancia. En términos de operaciones de campo los resultados obtenidos en esta tesis pueden explicar el aumento del requerimiento energético en las operaciones de labranza sobre suelos con alta RAS. Cuando estos suelos, sin estructura, con poros de pequeñas dimensiones, pretendan ser roturados con porcentajes de humedad cercanos al límite de retracción, estarán muy compactados, sus agregados tendrán una gran resistencia interna, y el trabajo necesario para su rotura será muy elevado. Cuando se pretenda labrarlos con mayores porcentajes de humedad, la dificultad será que muy rápidamente se vuelve significativa la tensión superficial de los meniscos de agua. La cohesión superficial y la adhesión suelometal serán las responsables de la elevada energía demandada. 
Con respecto a la friabilidad de los suelos sódicos, Guarnieri et al. (2005) encontraron que los suelos regados con soluciones con alto PSI disminuyeron su ventana de labor, disminuyendo el \% de humedad del límite líquido y del límite plástico con lo cual más rápidamente se alcanza el comportamiento plástico del suelo. Lo hallado por estos autores permite hipotetizar que en los tratamientos con mayor contenido de sodio estudiados en ésta tesis, sería esperable que se vea reducido el período elástico o friable, en el cual las labranzas son efectivas.

Con respecto a la transitabilidad de los suelos afectados por el sodio, podría hipotetizarse que la misma sería mejor ya que al presentar una menor susceptibilidad a la compresión y un mayor componente cohesivo, el esfuerzo de corte que debería realizar la rueda u oruga para que el suelo llegue a fallar debería ser mayor, con lo que el patinamiento se vería reducido. Asimismo según lo hallado en esta tesis, las características porosas de esta tipología de suelos con predominancia de microporos, los volvería menos compresibles por lo que poseerían una mayor capacidad portante. No obstante, esto que inicialmente aparece como ventajoso, debe analizarse como un conjunto teniendo en cuenta que el suelo agrícola no sólo debe proveer sustento a las máquinas que por el deben transitar, sino que debe reunir las condiciones apropiadas para el buen crecimiento de los cultivos. Paradójicamente, las condiciones óptimas para el tránsito se oponen a las deseables para la producción de los cultivos. Así, 
para el tránsito sería deseable un sustrato duro, poco deformable, poco poroso donde la rueda u oruga encontrase reacción, mientras que para un adecuado establecimiento de los cultivos en cambio, es deseable un suelo con una gran porosidad (para el adecuado intercambio de agua y aire), blando y deformable (para permitir la germinación y poder ser penetrado por las raíces). Aunque exista una adecuada disponibilidad de agua y nutrientes, las plantas crecen más lentamente en un suelo con elevada resistencia mecánica. Es por esta razón que puede asumirse que si un suelo es afectado por el sodio, mejora su transitabilidad y simultáneamente empeora su potencial productivo.

A través de los resultados obtenidos con la utilización de la teoría del Estado Crítico, y desde el punto del laboreo, se observa la relevancia de utilizar implementos de labranza vertical en aquellos suelos que han sido poco o nada alterados químicamente y más aún en aquellos suelos alterados físicamente y químicamente por la presencia de sodio. Los implementos desarrollados para éste tipo de labranza como el cincel, combinan una gran componente de corte con tensiones normales relativamente bajas disminuyendo el riesgo de compactación, y además permitiendo a los suelos sodificados lograr incrementos de Volumen Específico aprovechando su mayor capacidad expansiva relativa. Puede hipotetizarse que ante un eventual laboreo con implementos de labranza vertical, los suelos más sodificados podrían presentar profundidades críticas de laboreo mayores a los suelos menos sodificados ya que serían capaces 
de expandir aún a profundidades donde las tensiones normales son mayores. En situaciones donde el riego es complementario, la mayor capacidad expansiva podría ser favorable ya que la roturación en profundidad asociada a las precipitaciones contribuiría a la lixiviación del exceso de sodio. En estas condiciones, el pasaje de herramientas de labranza vertical combinado con las precipitaciones y el uso de enmiendas cálcicas podrían disminuir la alteración física del suelo debida al sodio contenido en el agua de riego.

Desde un encuadre más amplio de la práctica del riego y la calidad del agua utilizada se desprende la necesidad de la conformación de grupos de trabajo interdisciplinarios con el fin de abordar todos los aspectos ligados a dicha práctica, profundizando las investigaciones en el área orientadas a lograr la sustentabilidad de los sistemas agropecuarios. 


\section{CONCLUSIONES}

- El sodio disminuye la vulnerabilidad a la compresión de los suelos.

- El sodio aumenta la resistencia a la rotura de los agregados independientemente de su tamaño.

- Existe una jerarquía de agregados siendo los agregados de mayores dimensiones menos resistentes a la rotura.

- El incremento de sodio provoca un incremento de cohesión pero no afecta el ángulo de roce de las partículas.

- La sodificación del suelo aproxima la Línea de Estado Crítico a la Línea Virgen aumentando el dominio súpercrítico. 


\section{BIBLIOGRAFÍA}

1. Agassi M.; Shainberg I.; Morin J. (1981). Effect of electrolyte concentration and soil sodicity on infiltration rates of sodic soils: Geoderma. 36, 263-276.

2. Agassi M.; Morin J.; Shainberg I. (1985). Effect of raindrop impact energy and water salinity on infiltration rates of sodic soils. Soil Science Society of America Journal. 49, 186190.

3. Alakukku L. (1996). Persistence of soil compaction due to high axle load traffic. I. Short term effects of the properties of clay and organic soils. Soils \& Tillage Research. 37, 211222.

4. Alexandrou A.; Earl R. (1998). The Relationship among the Pre-compaction Stress, Volumetric Water Content and Initial Dry Bulk Density of Soil. Journal of Agricultural Engineering Research. 80, 71-75.

5. Ali O.M.; Yousaf M.; Rhoades J. D. (1987). Effect of exchangeable cation and electrolyte concentration on mineralogy of clay dispersed from aggregates: Soil Science Society of America Journal. 45, 848-900.

6. Alonso E. E.; Gens A.; Josa A. (1990). A constitutive model for partially saturated soil. Geotechnique. 40(3), 405-430.

7. Aluko O.B.; Koolen A.J. (2001). Dynamics and characteristics of pore space changes during the crumbling 
on dryng of structured agricultural soil. Soil and Tillage Research. 58, 45-54.

8. Amiotti, N.; Bravo, O. (2006). Suelos de las terrazas del río Colorado: Características e impacto del riego por gravedad. XX Congreso Argentino de la Ciencia del Suelo. 19 al 22 de septiembre de 2006. Salta. Argentina

9. Arvidsson J.; Keller T. (2011). Comparing penetrometer and shear vane measurements with measured and predicted mouldboard plough draught in a range of Swedish soils. Soil and Tillage Research. 111, 219-223.

10. Ashburner J.E. y Sims B.J. (1984). Elementos de diseño de diseño del tractor y elementos de labranza. IICA. San José, Costa Rica.

11. Aitchison G.D. (1960). Relationship of misture stress and effective stress functions in unsaturated soils. In Pore Pressure and Suction in Soils Conference, London, Butterworths. 47-52.

12. Baldi F.; Parenti A.; Spugnoli P. (1990). Test di compressione uniassiale per valutare la traficabilitá di un suolo agrícolo. Rivista d'Ingegneria Agraria. 4, 193-198.

13. Barzegar A.R.; Murray G.J.; Churchman G.J.; Rengasamy P. $\left(1994^{\mathrm{a}}\right)$. The strength of remoulded soils as affected by exchangeable cations and dispersible clay. Australian Journal Soil Research. 32, 185-199.

14. Barzegar A.R.; Oades J.M.; Rengasamy P.; Giles L. $\left(1994^{\mathrm{b}}\right)$. Effect of sodicity and salinity on disaggregation 
and tensile strength of an Alfisol under different cropping systems. Soil and Tillage Research. 32, 329-345.

15. Barzegar A.R.; Rengasamy P.; Oades J.M. (1995). Effects of clay type and rate of wetting on the mellowing of compacted soil. Geoderma. 68, 39-45.

16. Barzegar A.R.; Oades J.M.; Rengasamy P. (1996). Soil structure degradation and mellowing of compacted soils by saline-sodic solutions. Soil Science Society of America Journal. 60, 583-588.

17. Barzegar A.R.; Asoodar M. A.; Ansari M. (2000). Effectiveness of sugarcane residue incorporation at different water contents and the Proctor compaction loads in reducing soil compactibility. Soil and Tillage Research. 57(3), 167-172.

18. Barzegar A. R.; Asoodar M. A.; Cádiz A. (2003). Soil physical characteristics and chickpea yield responses to tillage treatments. Soil and Tillage Research. 71, 49-57.

19. Barzegar A. R.; Hashemi A. M.; Herbert S. J. (2004). Interactive effects of tillage system and soil water content on aggregate size distribution for seedbed preparation in Fluvisols in southwest Iran. Soil and Tillage Research.

20. Baumgart T. y Horn R. (1991). Effect of aggregate stability on soil compaction. Soil and Tillage Research. 19, 203-213.

21. Bengough A.G. (1997). Modelling rooting depth and soil strength in a drying soil profile. Journal of theoretical Biology. 186, 327-338. 
22. Ben-Hur M.; Shainberg I.; Bakker D.; Keren R. (1985). Effect of soil texture and $\mathrm{CaCO}_{3}$ content on water infiltration in crusted soil as related to water salinity. Irrigation Science. 6, 281-94.

23. Bishop A. W. (1959). The principle of effective stress. Teknisk Ukeblad. 106(39), 859-863.

24. Blackwell P.S. y Seoane B.D. (1981). A method of predicting bulk density changes in field soils resulting from compaction by agricultural traffic. Journal of Soil Science. 32, 51-65.

25. Blunden B. G.; McLachlan C. B.; Kirby J. M. (1993). A High - Speed Shear Box Machine. Technical Note. Journal of Agricultural Engineering Research. 56, 81-87.

26. Borselli L.; Carnicelli S.; Ferrari G.A. (1996). Effects of gypsum on hydrological, mechanical and porosity properties of a kaolinitic crusting soil. Soil Technology. 9, 39-54.

27. Bronick C.J.; Lal R. (2005). Soil Structure and management: a review. Geoderma.

28. Buckland G.D.; Bennett D.R.; Mikalson D.E.; De Jong E.; Chang C. (2002). Soil salinization and sodication from alternate irrigations with saline-sodic water and simulated rain. Journal of Soil Science. 82, 297- 309.

29. Buringh P. (1977). Food production potential of the world. In Rhade Sinha, ed. The world food problem: Consecuences and conflict. Oxford: Pergamon Press. 477- 485. 
30. Casagrande A. (1936). The determination of the preconsolidation load and its practical significance. In: Int. Conf. on Soil Mech. and Found. Eng. Proc. Of ICSMFE. Cambridge. vol. 3, 60-64.

31. Cavazza L.; Patruno A.; Cirillo E. (2002). Soil traits and structure stability in artficialy sodicated soil. Italian Journal Agronomical. 6(1), 15-25.

32. Chaplain V.; De' fossez P.; Richard G.; Tessier D.; RogerEstrade J. (2011). Contrasted effects of no-till on bulk density of soil and mechanical resistance. Soil and Tillage Research 111, 105-114.

33. Chen Y. y Banin A. (1975). Scaning electron microscope (SEM) observations of soil structure changes induced by sodium - calcicum exchange in relation to hydraulic conductivity. Soil Science. 120, $428-436$.

34. Chen Y.; Tessier S.; Rouffignat J. (1988). Soil Bulk Density Estimation for Tillage System and Soil Texterures. Transaction of the ASAE. 41(6), 1601-1610.

35. Choudhary O.P; Ghumana B.S.; Bijay-Singha; Thuyb N.; Bureshb R.J. (2011). Effects of long-term use of sodic water irrigation, amendments and crop residues on soil properties and crop yields in rice-wheat cropping system in a calcareous soil. Field Crops Research. 121, 363-372.

36. Churchman G.J.; Skjemstad O.; Oades M.J. (1993). Influence of clay minerals and organic matter on effects of 
sodicity on soils. Australian Journal Soil Research. 31, 779 -800 .

37. Costa J.L., Aparicio V., (2000). Efecto del sodio en la degradación de los suelos del sudeste de la Provincia de Buenos Aires, Argentina. 11ava Conferencia de la Organización Internacional de la Conservación del Suelo. 22 al 27 de Octubre de 2000. Buenos Aires. Argentina.

38. Currie D.R.; Grant C.D.; Murria R.S.; McCarthy M. (2006). Does drip irrigation degrade soil structure in vineyards. 18th World Congress of Soil Science. Philadelphia, USA.

39. Czarnes S.; Dexter A. R.; Bartoli F. (1999). A simplified method for analyzing the mechanics of clod: clod interactions in topsoils with a wide range of clay content. Soil and Tillage Research. 52, 59-71.

40. Delage P.; Lefebvre G. (1984). Study of the structure of a sensitive Champlain clay and of its evolution during consolidation. Canadian Geotechnical Journal. 21, 21-35.

41. Derdoura H. y Angersb D.A. (1992). Influence on salinity and other constituents on the mechanical behaviour of clay soil. Soil Technology. 5(1), 39-46.

42. Dexter A.R.; Kroesbergen B. (1985). Methodology for determination of tensile strength of soil aggregates. Journal of Agricultural Engineering Research. 31, 139-147.

43. Dexter A.R. (1988). Advances in characterization of soil structure. Soil and Tillage Research. 11,199 - 238. 
44. Dexter A.R. y Bird N.R.A. (2001). Methods for predicting the optimum and the range of soil water contents for tillage based on the water retention curve. Soil and Tillage Research. 57, 203-212.

45. Dexter A. R. (2004). Soil physical quality Part. I. Theory effects of soil texture, density, and organic matter, and effects on root growth. Geoderma. 120, 201-214.

46. Draghi L.; Jorajuria D.; Palancar T.; Spugnoli P.; Guilino F. (2009) Enriquecimiento en sodio e impedancia mecánica del suelo. Actas del $X$ Congreso Argentino de Ingeniería Rural y II del MERCOSUR. Editores Di Leo N.; Montico S.; Nardón G. Editorial de la Universidad Nacional de Rosario. ISBN 978-950-673-748-1. 347-354.

47. Dubey S.K.; Mondal R.C. (1994). Effect of amendments and saline irrigation water on soil properties and yields of rice and wheat in highly sodic soil. Journal of Agricultural Science Cambridge University Press. 122, 351-357.

48. Durán Garcia H. M. (2002). Effect of the Moisture Content on the Mechanical Resistance of a loam Textured Soil. Terra Latinoamericana. 20(3), 227-234.

49. Earl R. (1997). Assessment of the behaviour of field soils during compression. Journal of Agricultural Engineering Research. 68, 147-157.

50. Emerson W.W.; Bakker A.C. (1973). The comparative effects of exchangeable calcium, magnesium, and sodium on some physical properties of red-brown earth subsoils II. 
The spontaneous dispersion of aggregates in water: Australian Journal of Soil Research. 11, 151-157.

51. Escario V. y Sáez J. (1986). The shear strength of partly saturated soils. Géotechnique. 36(3), 453-456.

52. Falciani Samuele. (2008). Effetti della sodicitá sull'impedanza meccanica di un suolo agrario. Tesis Doctoral.

53.FAO. (2006). Dirección de estadísticas de la FAO. http://www.fao.org/es/ess/es/index es.asp.

54. Forsythe W. (1975). Física de suelos. Manual de Laboratorio. Cap. 5 y 6. Ed. IICA, San José, Costa Rica.

55. Fredlund D.G. (1979). Appropriate Concepts and Technology for Unsaturated Soils. Canadian Geotechnical Journal. 16, 121-139.

56. Gal M.; Stern R.; Levin J.; Ben-Hur M. (1992). Polymer effect on infiltration and erosion of sodic soils. South African Journal of Plant and Soil. 9, 108-112.

57. Ghassemi F.M. ; Jakeman A.J.; Nix H.A. (1995). Salinization of land and water resources: Human causes, extent, management, and case studies. CAB Int., Wallingford, Oxon, UK.

58. Giardini L. (1992). Agronomia Generale. Patrone Editor, Bologna.

59. Grant C.D.; Dexter A.R. (1989). Generation of microcracks in moulded soils by rapid wetting. Australian Journal Soil Research. 27, 169-82. 
60.Griffiths F.J.; Joshi R.C. (1989). Change in pore size distribution due to consolidation of clays. Geotechnique. 39, 159-67.

61. Guarnieri A.; Fabbri A.; Molari G. (2005). Influence of sodicity and salinity on the mechanical properties of two italian soils. Biosystems Engineering. 91 (2), 239-243.

62. Gysi M.; Klubertanz G.; Vulliet L. (2000). Compaction of an Eutric Cambisol under heavy wheel traffic in Switzerlandfield data and modeling. Soil and Tillage Research. 56, 117129.

63. Hadas A.; Larson W.E.; Allmaras R.R. (1988). Advances in Modelling Machina-Soil-Plant Interactions. Soil and Tillage Research. 11, 349-372.

64. Hakanson I.; Lipiec J. (2000). A review of the usefulness of relative bulk density values in studies of soil structure and compaction. Soil and Tillage Research. 53, 71-85.

65. Halliwell D.; Barlow K.; Nash D.M. (2001). A review of the effects of wastewater sodium on soil physical properties and their implications for irrigation systems. Australian Journal Soil Research. 39, 1259-1267.

66. Hettiaratchi D.P.R. y O'Callaghan J.R. (1980). Mechanical behaviour of agricultural soils. Journal of Agricultural Engineering Research. 25, 891-904.

67. Hettiaratchi D.P.R. (1987). A critical state soil mechanics model for agricultural soil. Soil use and management. 3, 94105. 
68. Hettiaratchi D.R.P. (1988). Theoretical Soil Mechanics and Implement Design. Soil and Tillage Research. 11, 325-347. 69. Hillel D. (1998). Environmental soil physics. Academic Press. $p 771$

70. Hutson J.L. (1971). Crust formation on some Natal soils. Master Science Agricultural Thesis. University of Natal, Pietermaritzburg, South Africa.

71. Imhoff S.; Pires Da Silva A.; Fallow D. (2004). Susceptibility to Compaction, Load Support Capacity, and Soil Compressibility of Hapludox. Soil Science Society of America Journal. 68, 17 - 24.

72. Jassogne L.T.P.; Davidson R.; McNeill, A.; Chittleborough D. (2006). How do roots cope with sodic hostile subsoils?. 18th World Congress of Soil Science. Philadelphia, USA.

73. Jalali M.; Ranjbar F. (2009). Effects of sodic water on soil sodicity and nutrient leaching in poultry and sheep manure amended soils. Geoderma 153, 194-204.

74. Jayawardane N.S. y Chan K.Y. (1994). The management of soil physical properties limiting crop production in Australian sodic soils. A review. Australian Journal of Soil Research. 32(1), 13-44.

75. Jorajuría D.; Draghi L.; Aragon A. (1997). The effect of vehicle weight on the distribution of compaction with depth and the yield of Lolium/Trifolium grassland. Soil and Tillage Research. 41, 1-12. 
76. Kaur J.; Choudhary O.P.; Singh B. (2006). Microbial biomass and different extractable organic carbon pools as influenced by sodic water irrigation, gypsum and organic amendemnts under rice-wheat system. 18th World Congress of Soil Science. Philadelphia, USA.

77. Kay B.D. y Dexter A.R. (1992). The influence of dispersible clay and wetting/drying cycles on the tensile strength of a red-brown earth. Australian Journal of Soil Research. 30, 297-310.

78. Kazman Z.; Shainberg I.; Gal M. (1983). Effect of low levels of exchangeable sodium and applied phosphogypsum on the infiltration rate of various soils. Soil Sczence. 135, 18492.

79. Kirby J. M. (1991 a). Strength and deformation of agricultural soil: measurement and practical significance. Soil Use and Management. 7(4), 223-229.

80. Kirby J.M. y Blunden B.G. $\left(1991^{\mathrm{b}}\right)$. Interaction of Soil Deformations, Structure and Permeability. Australian Journal of Soil Research. 29, 891-904.

81. Kirby J.M. $\left(1991^{\circ}\right)$. The influence of soil deformations on the permeability to air. Journal of Soil Science. 42, 227-235. 82. Kirby J.M. (1994). Simulating soil deformation using a critical-state model: I. Laboratory tests. European Journal of Soil Science. 45, 239-248. 
83. Kirby J.M. y O'Sullivan M.F. (1997). Critical state soil mechanics analysis of the constant cell volume triaxial test. European Journal of Soil Science. 48, 71-78.

84. Kirkham D.; De Boodt M. F.; De Leenheer L. (1959). Modulus of rupture determination on undisturbed soil core sample. Soil Science. 87, 14-144.

85. Lal R. (1991). Soil structure and sustainability. Journal of Sustainable Agriculture . 1, 61-92.

86. Larson W.E.; Gupta S.C.; Useche R.A. (1980). Compression of agricultural soils from eight soil orders. Soil Science Society of America Journal. 44, 450-457.

87. Lebert M. y Horn R. (1991). A method to predict the mechanical strength of agricultural soils. Soil and Tillage Research 19, 275-286.

88. Leeson J.J. y Campbell D.J. (1983). The variation of soil critical state parameters with water content and its relevance to the compaction of two agricultural soils. Journal of Soil Science. 34, 33-44.

89. Levy G. J. y Van der Watt H. (1988). Effects of clay mineralogy and soil sodicity on soil infiltration rate. South Afncan Journal of Plant and Soil. 5, 92-96.

90. Levy G. J. y Van der Watt H. (1990). Effect of exchangeable potassium on the hydraulic conductivity and infiltration rate of some South African soils. Soil Sczence. 149, 69-77. 
91. Levy G.H. y Mamedov A.I. (2002). High energy moisture characteristic aggregate stability as a predictor for seal formation. Soil Science Society of America Journal. 66, 1603-1609.

92. Lloret A. y Alonso E.E. (1985). State surfaces for partially saturated soils. Proc. 11th Int. Conf. Soil Mech. Fdn. Engng. San Francisco. 2, 557-562.

93. Macari E.J.; Hoyos L.R.; Arduino P. (2003). Constitutive modeling of unsaturated soil behaviour under axisymmetric stress states using a stress/suction controlled cubical test cell. Int. Journal of Plasticity. 19, 1481-1515.

94. Mamedov I.; Levy G.J.; Shainberg I.; Letey J. (2001). Wetting rate, sodicity, and soil texture effects on infiltration rate and runoff. Australian Journal of Soil Research. 39, 1293-1305.

95. Masle J. y Passioura J. B. (1987). The effect of soil strength on the growth of young wheat plants: Australian Journal of Plant physiology. 14, 643-656.

96. Matyas E.L. y Radhakrishna H.S. (1968). Volume changes characteristics in partially saturated soils. Géotechnique. 18(4), 432-448.

97. Miller W. P. (1987). Infiltration and soil loss of three gypsum-amended Ultisols under simulated rainfall. Sozl Science Society of America Journal. 51, 1314-1320. 
98. Miller W.P. y Scifres J. (1988). Effect of sodium nitrate and gypsum on infiltration and erosion of a highly weathered soil. Sod Sczence of America Journal. 145, 304-309.

99. Miller W.P.; Sumner M. E.; Kim H. (1991). Chemical amelioration of surface crusting to reduce runoff and erosion on highly weathered soils. Sozt Technology. 4, 319327.

100. Mitchell J.K. (1976). Fundamentals of Soil Behaviour. 222-223. Wiley: New York.

101. Mosaddeghi M.R.; Hemmat A.; Hajabbasi M.A.; Alexandrou A. (2003). Pre-compression stress and its relation with the physical and mechanical properties of a structurally unstable soil in central Iran. Soil and Tillage Research. 70, 53-64.

102. Mzezega J.; Gotosab J,; Nyamwanzab B. (2003). Characterisation of a sodic soil catena for reclamation and improvement strategies. Geoderma 113, 161- 175.

103. Mosaddeghi M.R.; A. Hemmat; M.A.; Hajabbasi; and Alexandrou A. (2003). Pre-compression stress and its relationship with physical and mechanical properties of a structurally unstable soil in central Iran. Soil and Tillage Research. 70(1), 53-64.

104. Nannucci Lorenzo. (2009). Resistenza meccanica in suoli a diversa sodicitá. Tesis Doctoral.

105. Okello J. A. (1991). A review of Soil Strength Measurement Techniques for Prediction of Terrain Vehicle 
Performance. Journal of Agricultural Engineering Research. 50, 129-155.

106. Oster J.D. (1994). Irrigation with poor quality water. Agricultural Water Management. 25, 271-297.

107. Oster J.D.; Shainberg I. (2001). Soil responses to sodicity and salinity: challenges and opportunities. Australian Journal of Soil Research. 39, 1219-1224.

108. O'Sullivan M.F.; Campbell D.J.; Hettiaratchi D.R.P. (1994). Critical state parameters derived from constant cell volume triaxial test. European Journal of Soil Science. 45, 249-256.

109. O'Sullivan M.F.; Robertson E.A.G.; Henshall J.K. (1999). Shear effects on gas transport in soil. Soil and Tillage Research. 50, 73-83.

110. Palancar T. (2007). Compresibilidad y resistencia al corte de suelos salinizados y sodificados por irrigación. Tesis doctoral.

111. Parker M. D. (1984). Soil crusting on some selected soils of Georgia. Master Science Thesis. University of Georgia, Athens, GA.

112. Patruno A.; Cavazza L.; Patruno A.; Cirillo E. (2002). Soil Traits and Structure Stability in Artificially Sodicated Soils. Italian Journal of Agronomy. 6(1), 15-25.

113. Pilatti M. A.; Imhoff S.; Ghiberto P.; Marano R. P. 2006. Changes in some physical properties of Mollisols 
induced by supplemental irrigation. Geoderma. 133, 431443.

114. Pizarro F. (1985). Drenaje Agrícola y Recuperación de Suelos Salinos. Ed. Agrícola Española S.A., $2^{\circ}$ Ed., Madrid. Cap. 3 y 4.

115. Pons Y. ; Capillon A. ; Cheverry C. (2000). Water movement and stability of profiles in drained, clayey and swelling soils: at saturation, the structural stability determines the profile porosity. European Journal of Agronomy. 12, 269-279.

116. Quirk J.P. y Murray R.S. (1991). Towards a model for soil structural behaviour. Australian Journal Soil Research. 29, 829-867

117. Rahimi H.; Pazira E.; Taji F. (2000). Effect of soil organic matter, electrical conductivity and sodium adsorption ratio on tensile strength of aggregates. Soil and Tillage Research. 54, 145-133

118. Rajaram G. y Erbach D.C. (1998). Drying stress on mechanical behaviour of a clay-loam soil. Soil and Tillage Research. 49, 147-158.

119. Rajaram G. y Erbach D.C. (1999). Effect of wetting and drying on soil physical properties. Journal of Terramechanics. 36, 39-49.

120. Rao S.M.; Reddy B.V.V.; Muttharam M. (2001). The impact of cyclic wetting and drying on the swelling 
behaviour of stabilized expansive soils. Engineering Geology. 60, 223-233.

121. Rengasamy P. y Olsson K.A. (1991). Sodicity and Soil Structure. Australian Journal of Soil Research. 29, 935952.

122. Rhoades J.D. (1997) Sustainability of irrigation: An overview of salinity problems and control strategies. Annual Conference : Footprints of Humanity. Reflection on fifty years of water resource developments. Lethbridge, Alberta, Canadá, p.1- 42.

123. Richards L. Editor. (1956). Diagnóstico y rehabilitación de suelos salinos y sódicos. Manual de agricultura № 60. Laboratorio de Salinidad de los Estados Unidos de América. Departamento de Agricultura (USDA). Washington. p 172.

124. Richards L.A. Editor. (1980). Diagnóstico y rehabilitación de suelos salinos y sódicos. Laboratorio de Salinidad de los Estados Unidos de América. Ed. Limusa, $6^{\circ}$ Ed. México.

125. Rogowski A.S. (1964). Strength of soil aggregates. Thesis Ph.D. lowa State University of Science and Technology. Ames, lowa.

126. Ruiz-Vera V. M. y Laosheng W. (2006). Influence of sodicity, clay mineralogy, prewetting rate, and their interaction on aggregate stability. Soil Science Society of American Journal. 70, 1825-1833. 
127. Sánchez Girón Renedo V. (1996). Dinámica y Mecánica de Suelos. Ed. Agrotécnicas, S. L. Madrid. p 426. 128. Sánchez-Hermosilla J.; Gil J.; Aguera J. (1999). Evaluación de las propiedades mecánicas del suelo en locomoción extraviaria. Revista Iberoamericana de Ingenieria Mecánica. 3, 67-76.

129. Seta A.K. y Karathanasis A.D. (1996). Water dispersible colloids and factors influencing their dispersibility from soil aggregates. Geoderma. 74, 255266.

130. Shainberg I. y Letey J. (1984). Response of soils to sodic and saline conditions. Hilgardia. 52, 1-57.

131. Shainberg I.; Gal M.; Ferreira A. G.; Goldstein D. (1991). Effect of water quality and amendments on the hydraulic properties and erosion from several Mediterranean soils. Soil Technology. 4 , 135-46.

132. Smith C.W.; Hadas A.; Dan J.; Koyumdjisky H. (1985). Shrinkage and Atterberg limits in relation to other properties of frpincipal soil types in Israel. Geoderma. 35(1), 47-65.

133. Smith H. J. C.; Levy G. J.; Shainberg I. (1990). Water-droplet energy and soil amendments: Effect on infiltration and erosion. Soil Science Society of America Journal. 54, 1084-1087.

134. Soane B.D.; Dickson J.W.; Campbell D.J. (1982). Compaction by agricultural vehicles: a review. III. Incidence 
and control of compaction action in crop production. Soil and Tillage Research. 2, 3-36.

135. Soane B.D. (1990). The role of organic matter in soil compactibility: a review of some practical aspects. Soil and Tillage Research. 16, 179-201.

136. Sokal R. R.; Rohlf F.J. (1995). Biometry: the principles and practice of statistics in biological research. 3rd edition. W. H. Freeman and Co.: New York. 887 pp.

137. Soverini E. (2001). Caratterizzazione Meccanica dei terreni agrari: Applicazion al caso di suoli trattati con acque salmastre. Tesis Doctoral. Dipartamento di ingegneria agraria e forestale. Universitá degli Studi di Firenze (Italia).

138. Spugnoli P.; Soverini E.; Palancar T. (2002). Effects of Irrigation with brackish water on soil trafficability and workability. In Pagliai M., Jones R. Sustainable Land Management - Environmental Protection A Soil Physical Approach. (35, 267-278). ISBN: 3-923381-48-4. Special issue of Advances in GeoEcology. Reiskirchen: Catena Verlag (Germany).

139. Stepniewski W.; Horn R.; Martyniuk S. (2002). Managing soil Biophysical properties for environmental protection. Agriculture, Ecosystem and Environment. 88, 175-181.

140. Suarez D.L. (1981). Relation ship between $\mathrm{pH}$ and SAR and an alternative method of estimating SAR of soil or 
drainage water. Soil Science Society of America Journal. $45,469-475$.

141. Sumner M. E. y Miller W. P. (1992). Soil crusting in relation to global soil degradation. American Journal of Alternative Agriculture. 7, 41-47.

142. Sumner M. (1993). Sodic Soils: New Perspectives.

Australian Journal of Soil Research. 31, 683-750.

143. Taboada M.A y Lavado R.S. (1996). Interactive effects of exchangeable Sodium and water content on soil modulus of ruptura. Soil Technology. 8, 345-349.

144. Thompson L.M. y Troech F.R. (1982). Los suelos y su fertilidad. Ed. Reverté, S.A. 649 pp.

145. Umali D.L. (1993). Irrigation induced salinity. Technical Paper $n^{\circ}$ 215. World Bank. Washington, DC, EEUU, pp. 3-25.

146. U.S. Salinity Laboratory Staff (1954). Diagnosis and Improvement of Saline and Alkali Soils. USDA Agric. Handbook 60, US Government Printing Office, Washington DC.

147. Utomo W.H. y Dexter A.R. (1981). Soil friability. European Journal of Soil Science 32, 203-213.

148. Uttam K. M.; Bhardwaj A.K.; Warrington D.N.; Goldstein D.; Bar T. A.; Levy G.J. (2008). Changes in soil hydraulic conductivity, runoff, and soil loss due to irrigation with different types of saline-sodic water. Geoderma. 144, 509-516. 
149. Varallyay G. (2002). Enviromental stresses induced by salinity/alcalinity in the Carpathian Basin (Central Europe) Symposium № 33 Paper № 1570. 17th World Congress of Soil Sciences. Tailandia. 14-21.

150. Vázquez M. (2003). Evaluación de la alteración de algunas propiedades edáficas bajo riego complementario en suelos de la provincia de Buenos Aires. Tesis Doctoral.

151. Violante P. (2000). Metodi di analisi chimica del suolo. Franco Angeli, Milano.

152. Waldrom L.J.; Constantin C.K. (1968). Bulk volume and hydraulic conductivity changes during sodium saturation test. Soil Science Society of America Journal. 32, 175179.

153. Ward P.A. y Carter B.J. (2004). Dispersion of saline and non-saline nitric mollisols and alfisols. Soil Science. 169(8), 554-566.

154. Watts C. W.; Dexter A. R.; Dumitru E.; Arvidsson J. (1996). An assessment of the vulnerability of soil structure to destabilisation during tillage. Part I. A laboratory test. Soil and Tillage Research. 37, 161-174.

155. Whalley W.R.; Dumitru E.; Dexter A.R. (1995). Biological effects of soil compaction. Soil and Tillage Research. 35, 53-68. 
156. Willat S.T. (1987). Influence of aggregate size and water content on compactability of soil using short-time. Journal of Agricultural Engineering Research. 37, 107-115.

157. Willcocks T.J. (1981). Tillage of clod-forming and loam soils in the semi-arid climates of Botswana: Soil and Tillage Research. 1, 323-350.

158. Wulfsohn D.; Adams B. A.; Fredlund D.G. (1998). Triaxial Testing of Unsaturated Agricultural Soils. Journal of Agricultural Engineering Research. 69, 317-330.

159. Zhang H.; Hartge K.H.; Ringe H. (1997). Effectiveness of organic matter incorporation in reducing soil compactibility. Journal of Agricultural Engineering Research. 61, 239-245.

160. Zhang B.; Zhao Q.G.; Horn R.; Baumgartl T. (2001). Shear strength of surface soil as affected by soil bula density and soil water content. Soil and Tillage Research. 59, 97-106. 